UNIVERSIDADE DE SÃO PAULO

ESCOLA DE ENGENHARIA DE SÃO CARLOS

DEPARTAMENTO DE GEOTECNIA

\title{
AVALIAÇÃO DA INTERAÇAO SOLO-FITAS METÁLICAS E POLIMÉRICAS PARA SOLUÇÃO EM TERRA ARMADA EM SOLOS NÃO CONVENCIONAIS
}

\section{ALBANO SÂLZON MAPARAGEM}

Dissertação apresentada à Escola de Engenharia de São Carlos da Universidade de São Paulo, como parte dos requisitos para a obtenção do Título de Mestre em Ciências, Programa de pós graduação em Geotecnia

PROF. DR. BENEDITO DE SOUZA BUENO

\section{Versão corrigida}

São Carlos-SP

2011 
AUTORIZO A REPRODUÇÃO E DIVULGAÇÃO TOTAL OU PARCIAL DESTE TRABALHO, POR QUALQUER MEIO CONVENCIONAL OU ELETRÔNICO, PARA FINS DE ESTUDO E PESQUISA, DESDE QUE CITADA A FONTE.

Ficha catalográfica preparada pela Seção de Tratamento da Informação do Serviço de Biblioteca - EESC/USP

Maparagem, Albano Sâlzon.
M297a Avaliação da interação solo-fitas metálicas e poliméricas para soluções em terra armada em solos não convencionais / Albano Sâlzon Maparagem ; orientador Benedito de Souza Bueno. -- São Carlos, 2011.

Dissertação (Mestrado-Programa de Pós-Graduação em Geotecnica) -- Escola de Engenharia de São Carlos da Universidade de São Paulo, 2011.

1. Interação solo-reforço. 2. Ensaios de arrancamento. 3. Terra Armada. 4. Resistência de interface. I. Título. 
Candidato: Licenciado ALBANO SÂLZON MAPARAGEM

Título da dissertação: Avaliação da interação solo-fitas metálicas e poliméricas para soluções em terra armada em solos não convencionais.

Data da defesa: 22/08/2011:

Comissão Julgadora:

Prof. Titular Benedito de Souza Bueno (Orientador)

(Escola de Engenharia de São Carlos/EESC)

Prof. Titular Nélio Gaioto

(Escola de Engenharia de São Carlos/EESC)

Prof. Dr. Paulo César Lodi

(Universidade Estadual Paulista "Julio de Mesquita Filho"/UNESP/campus de Bauru)
Resultado:

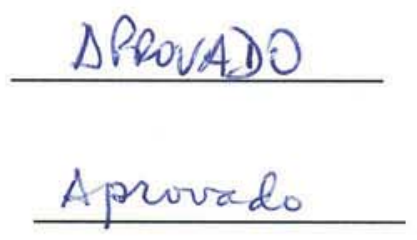

APROVADO

Coordenador do Programa de Pós-Graduação em Geotecnia:

Prof. Titular Osni José Pejon

Presidente da Comissão de Pós-Graduação:

Prof. Associado Paulo Cesar Lima Segantine 

À Deus pela providência da vida, saúde e toda a proteção À minha esposa Natália Aos meus filhos Tabita, Albano Júnior e Gilsa Aos Meus Pais Maparagem e Mari Aos Meus irmãos Samuel, Luisa, Lucas, Alexandre Carvalho, Mateus e Baptista 



\section{AGRADECIMENTOS}

Ao Professor Benedito de Souza Bueno pela sua orientação, paciência e dedicação que fizeram com que este trabalho seja uma realidade.

Ao Professor Lázaro Valentim Zuquette pelo acolhimento e apoio prestados desde os primeiros momentos.

Ao CNPq, Conselho Nacional de desenvolvimento Científico e Tecnológico, pela bolsa de estudo fornecida durante todo o periodo do mestrado.

Ao Professor Orêncio M. Vilar pela paciência na supervisão durante o estágio pedagógico.

Aos amigos e colegas Pablo Noronha, Tiago Souza, Thiago Peixoto, Gian Franco, Luís Miguel, Thiago Santos, Tânia Coacallas Camilo Hernandez, José Brito, Fernando Portelinha, Diovane Dionísio. Daniel Baltromeu, Luís Miguel, Ítalo Patiu, Jorge vieira, Marcus Campos, Francisco Avesani, Fagner França, Sérgio de Miranda. Liliana Mercedes, Geny, Natália Correia, Nostor Barros,Simone Lopes, Alberto Douglas e Paola Arab.pela convivência e apoio que prestaram.

Aos Colegas da turma do mestrado de 2009;pela convivência.

Aos Professores do Departamento que com paciência me ensinaram.

Aos funcionários do Departamento de Geotecnia da EESC/USP especialmente Maristela Álvaro e Neiva, pelo apoio constante que prestaram.

Aos técnicos e estagiários do laboratório de geossintéticos especialmente Clever Valentim, Walter da Costa, Manoel, Rogério de Souza e Daniel Pereira pelo apoio durante a parte experimental da pesquisa.

Aos técnicos do laboratório do Departamento de Geotecnia, especialmente José Luís, Oscar, António, Benedito e Dércio.

Ao Diretor da Beira Empreitadas \& Empreendimentos Ltd, Dr. Alexandre Calves Maparage pelo apoio que deu.

À Diretora do Instituto Industrial e Comercial da Beira, Dr ${ }^{a}$. Maria Roque pela compreesão e apoio

À Diretora da da Glórias Consultorias \& Engenharias, Dr ${ }^{a}$. Natália Joaquim Maparagem por toda a compreensão.

Ao Director da Interbuilding Moçambique Lda, Sr Manuel Américopela ajuda que pestou durante os dois anos do Curso. 
"The fear of the Lord is the beginning of wisdom, and knowledge of the Holy One is understanding." Author: Proverbs of Solomon - Holy Bible. 


\section{RESUMO}

\section{MAPARAGEM, A. S. Avaliação da Interação Solo-Fitas Metálicas e Poliméricas Para}

Soluções em Terra Armada em Solos Não Convencionais. 2011. Dissertação do Mestrado Departamento de Geotecnia Escola de Engenharia de São Carlos, Universidade de São Paulo.

Grande percentagem do território brasileiro é coberta por solos finos (\% passando peneira \# $200>50 \%$ ), geralmente de origem tropical, que poderiam ser classificados como solos de baixa capacidade de drenagem. Estes solos não atendem às recomendações técnicas para solos de aterro de estruturas reforçadas, conforme exigido pela AASHTO e BS 8006. Neste trabalho foi avaliado experimentalmente um dos parâmetros mais importantes de projeto de Terra Armada, que condiciona o mecanismo de transferência de carga, o coeficiente de atrito aparente solo-fita metálica ( $\left.f^{*}\right)$. Foi avaliada a influência das características dos solos para as classes de solos estabelecidas pela NBR 9286/86 para o caso de fitas metálicas, e, dos critérios que sustentam o uso de fitas poliméricas, sob diversas tensões verticais atuantes nas fitas, simulando o efeito da profundidade. As informações foram obtidas através de ensaios de arrancamento de fitas metálicas e poliméricas realizados em laboratório e depois comparadas aos resultados teóricos da norma e àqueles preconizados para o uso de fitas poliméricas. Os ensaios realizados com as fitas em solo não convencional $1 \mathrm{e}$ em areia mal graduada, mostraram que para profundidades equivalentes a tensões verticais até $50 \mathrm{kPa}$, os dois tipos de inclusões possuem valores de coeficiente de interação com o solo maiores que a unidade, isso tornaria razoável o seu uso sob o ponto de vista deste parâmetro e nas condições da realização dos ensaios, quando comparado com a norma, e com os critérios que sustentam o uso das fitas poliméricas em técnica de solo armado. No entanto, para maiores profundidades, a interação apresenta uma tendência de diminuição. $O$ solo não convencional 2 valores da interação muito baixos. Foram instalados strain gages ao longo do comprimento das fitas para monitoramento dos esforços no maciço. Nota-se que esforços elevados ocorreram nas regiões mais próximas do ponto de aplicação da força de arrancamento.

Palavras Chave: Interação Solo-Reforço, Ensaios de Arrancamento, Terra Armada Resistência de Interface. 



\begin{abstract}
MAPARAGEM, A. S. Evaluation of the interaction of soil and metal strips and soil and polymeric strips applied to mechanically stabilized earth with concrete wall facing reinforce with unconventional soil. 2011. Dissertação do Mestrado - Departamento de Geotecnia Escola de Engenharia de São Carlos, Universidade de São Paulo.
\end{abstract}

A large percentage of Brazil's territory is covered with fine tropical soil (50\% passing \#200) which can be classified as soils with low drainage capacity. These soils do not meet the technical recommendations for backfill of reinforced soil structures by AASHTO and BS 8006. This paper presents the result of an experimental evaluation of one of the most important design parameters of mechanically stabilized earth with concrete wall facing. The apparent friction coefficient of soil-steel strips and soil-polymeric strips is the project parameter. Also was evaluated the influence of soil characteristics for soil types listed by the NBR 9286/86 for metal strips and for the criteria that support the use of polymeric strips. The evaluation included the application of different vertical stresses on the strips simulating the effect of depth. The information obtained from pullout tests performed in laboratory was compared to the standard theoretical values and design values for polymeric strips. Tests performed on strips in nonconventional soil (1) and poorly graded sand showed that at depths equivalent to vertical stresses up to $50 \mathrm{kPa}$ the two types of inclusions have coefficients of interaction greater than unity, which appears reasonable. Therefore, such soils can be used as backfill soils in the conditions tested and at equal or lesser stress levels. Nonconventional soil (2) showed low value of the friction coefficient. The strain gages installed along the length of the strips recorded the distribution of tensile stress in pull-out tests. Higher tensile stress was recorded by the gages nearest the point of application of the pull-out force.

Keywords: Soil-Reinforcement Interaction, Pullout Tests, Mechanically Stabilized Earth with Concrete Wall Facing. 



\section{LISTA DE FIGURAS}

Figura 2.1- Distribuição granulométrica dos solos estudados por Kakuda (2005) apud Miranda (2009) ................5

Figura 2.2-Comparação de resultados dos ensaios com valores sugeridos por norma (MIRANDA 2009). ............. 6

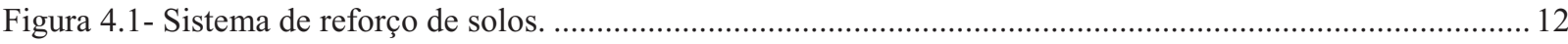

Figura 4.2. Sistema de contenção, terra armada com o uso de fitas metálicas (NHI) ........................................ 13

Figura 4.3. Sistema de contenção, terra armada com o uso de fitas poliméricas (MACCAFERRI 2011) ............... 13

Figura 4.4- Comportamento típico do solo: (a) sem reforço; e (b) com reforço (SIEIRA 2003). .......................... 15

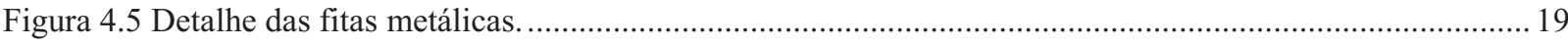

Figura 4.6 - fita polimérica usada em sistemas de contenção.................................................................... 19

Figura 4.7 Detalhes de diferentes tipos de escamas(BUENO) ….........................................................2

Figura 4.8,- Esquema de uma estrutura em terra armada ................................................................. 21

Figura 4.9- Deslocamento horizontal máximo em estruturas de terra armada (SPRINGER, 2001)......................22

Figura 4.10 Efeito da dilatância do material de aterro nas vizinhanças da armadura ..........................................28

Figura 4.11- Possíveis faixas de classificação de grupos de solo para NBR 9286/86, (MIRANDA 2009)............28

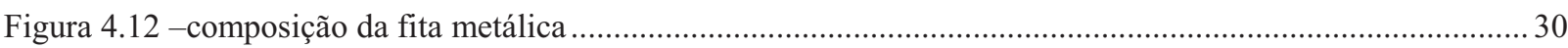

Figura 4.13-Carregamentos e diagramas de esforços( BUENO) ................................................................. 33

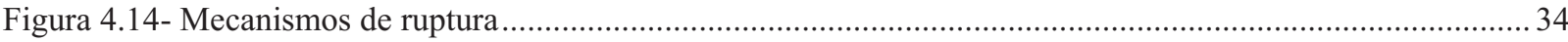

Figura 4.15- Variação do coeficiente de empuxo ativo com a profundidade ................................................... 35

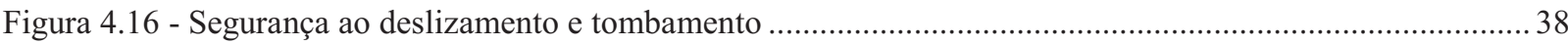

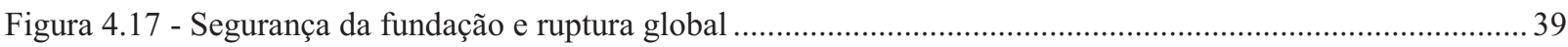

Figura 4.18 - Tração máxima em cada armadura (NBR: 9286/1986) …......................................................42

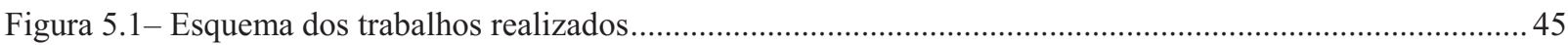

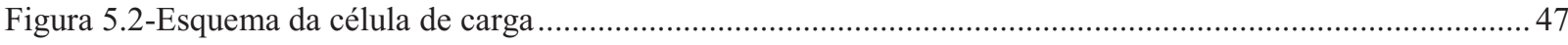

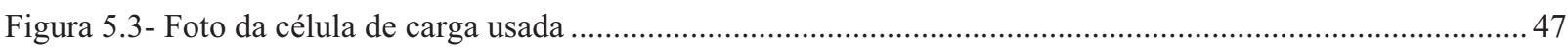

Figura 5.4- Desenho esquemático das células de tensão total (dimensões em mm), (MIRANDA 2009) ...............47

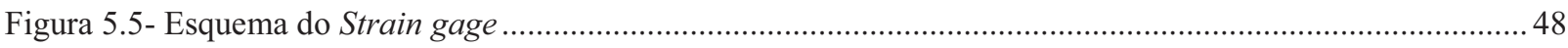

Figura 5.6- caixa de calibração das células de tensão total .......................................................................52

Figura 5.7- Gráfico de Calibração da célula de tensão total ......................................................................... 53

Figura 5.8 - Esquema de calibração das fitas metálicas........................................................................5

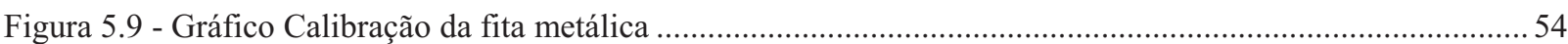


Figura 5.10 (a) - representação do posicionamento da fita metálica com detalhes de instrumentação; (b) - Fita

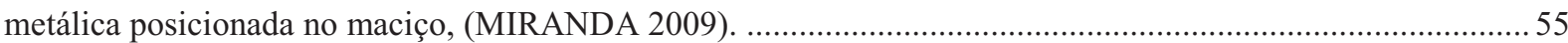

Figura 5.11- Dimensões de corpo de prova reduzido de tração, conforme norma ASTM A_370[64]...................5 59

Figura 5.12- Resultado dos ensaios de tração das fitas metálicas ................................................................6 60

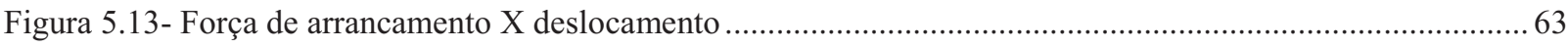

Figura 5.14- Resistência da interface X deslocamento ( forma usual em terra armada) ..................................63

Figura 5.15 - Resistência da interface em função do comprimento arrancado X deslocamento ............................ 64

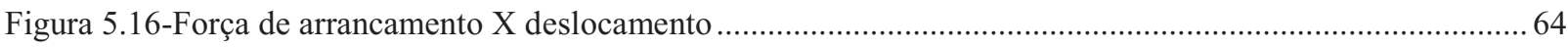

Figura 5.17 - Resistência da interface X deslocamento ( forma usual em terra armada) ......................................65

Figura 5.18- Resistência da interface em função do comprimento arrancado X deslocamento ............................65

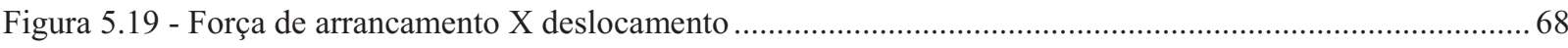

Figura 5.20 - Resistência da interface X deslocamento ( forma usual em terra armada) ....................................69

Figura 5.21 - Resistência da interface em função do comprimento arrancado X deslocamento ............................69

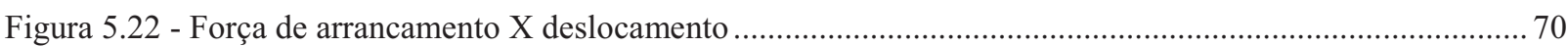

Figura 5.23 - Resistência da interface X deslocamento ( forma usual em terra armada) ................................... 70

Figura 5.24 - Resistência da interface em função do comprimento arrancado X deslocamento ............................. 71

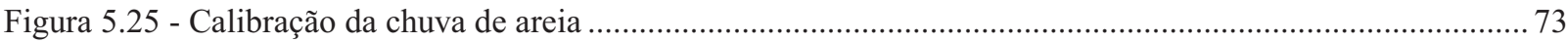

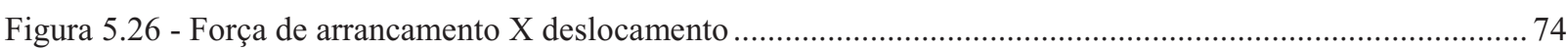

Figura 5.27 - Resistência da interface X deslocamento ( forma usual em terra armada) .................................. 75

Figura 5.28 - Resistência da interface em função do comprimento arrancado X deslocamento .............................75

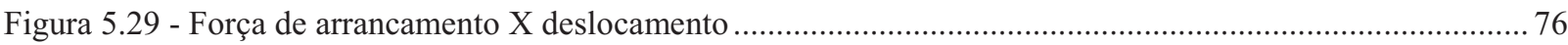

Figura 5.30 - Resistência da interface X deslocamento ( forma usual em terra armada) .................................. 76

Figura 5.31 - Resistência da interface em função do comprimento arrancado X deslocamento ........................... 77

Figura 5.32 - resultado de ensaios de tração para fita polimérica de $50 \mathrm{~mm}$ de largura...................................... 79

Figura 5.33 - Resultados de ensaios de tração de fita polimérica de $47 \mathrm{~mm}$. de largura .................................... 79

Figura 5.34 - inserção da fita polimérica no maciço ................................................................................ 80

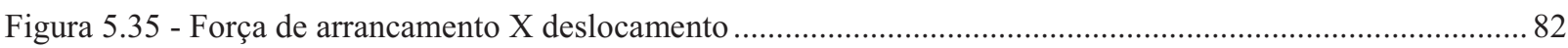

Figura 5.36 - Resistência da interface X deslocamento ( forma usual em terra armada) .................................. 82

Figura 5.37 - Resistência da interface em função do comprimento arrancado X deslocamento ............................83

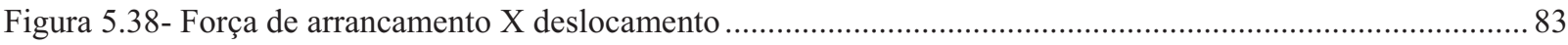

Figura 5.39 - Resistência da interface X deslocamento ( forma usual em terra armada) .................................... 84 
Figura 5.40- Resistência da interface em função do comprimento arrancado X deslocamento

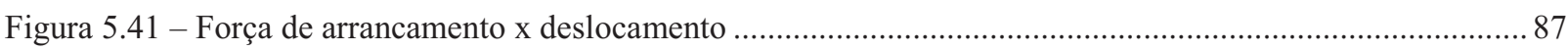

Figura 5.42- Resistência da interface X deslocamento ( forma usual em terra armada) ................................. 87

Figura 5.43 - Resistência da interface em função do comprimento arrancado X deslocamento............................8 88

Figura 5.44 - Envoltória do solo não convencional 1 e fitas metálicas ........................................................... 90

Figura 5.45 - Envoltória do solo não convencional 2 e fitas metálicas ...................................................... 90

Figura 5.46 - Envoltória da Areia e fitas metálicas ................................................................................ 91

Figura 5.47 - Envoltória do solo não convencional 1 e fitas poliméricas ....................................................... 91

Figura 5.48 - Envoltória da Areia e fitas Poliméricas ............................................................................ 92

Figura 5.49- comportamento do andamento das trações ao longo das fitas (Solo granular) ............................... 96

Figura 5.50 - comportamento do andamento das trações ao longo das fitas (Solo Campus II) .............................96

Figura 5.51 - comportamento do andamento das trações ao longo das fitas poliméricas (Solo Campus II) ............97

Figura 5.52 - Distribuição dos resultados de ensaios em relação à curva da norma NBR9286/86 - solo-fita metálica (campus II)

Figura 5.53 - Distribuição dos resultados de ensaios em relação à curva da norma NBR9286/86 - solo-fita metálica (Rodovia SP215) 98

Figura 5.54 - Distribuição dos resultados de ensaios em relação à curva da norma NBR9286/86 - solo-fita metálica (Areia) 



\section{LISTA DE TABELAS}

Tabela 4.1 - Equipamentos para testes de interface; suas vantagens e limitações

Tabela 4.2-Critério mecânico para seleção do material de aterro para fitas metálicas nervuradas (NBR9286/86).26

Tabela 4.3- Critério químico para a seleção de material do aterro.

Tabela 4.4- Critérios mecânicos para a seleção do material de aterro para armaduras lisas.

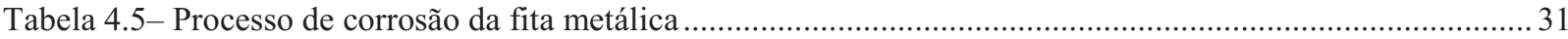

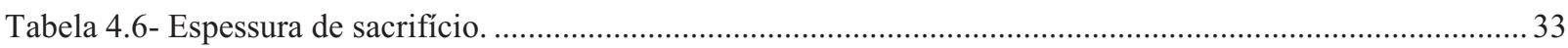

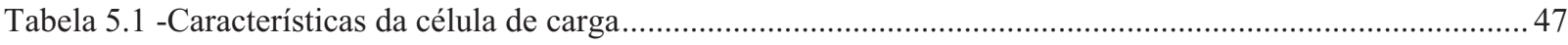

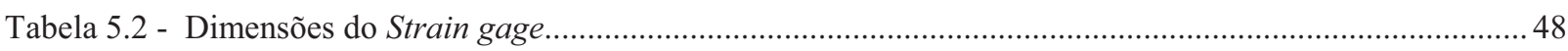

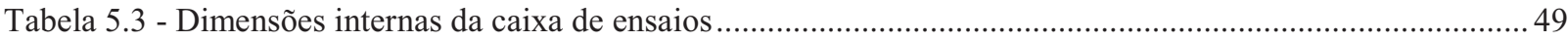

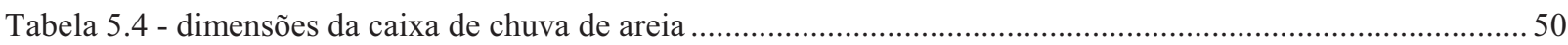

Tabela 5.5 Resumo das características do solo não convencional I - Campus II - São Carlos .............................56

Tabela 5.6-Propriedades do solo da Rodovia 215-São Carlos-SP ..................................................................... 57

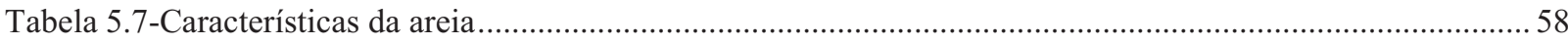

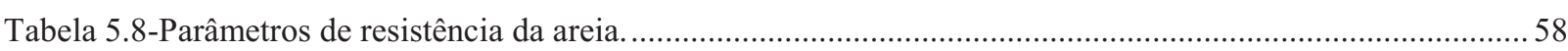

Tabela 5.9- dimensões dos corpos de prova se resultado dos ensaios de permeabilidade....................................58

Tabela 5.10 - Características dos ensaios com o solo não Convencional 1- Campus II ..................................... 61

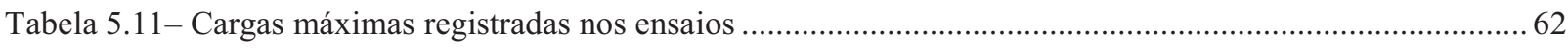

Tabela 5.12- resultados calculados a partir dos resultados dos ensaios sem considerar a coesão .........................66

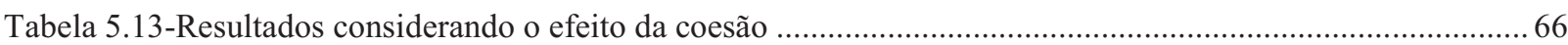

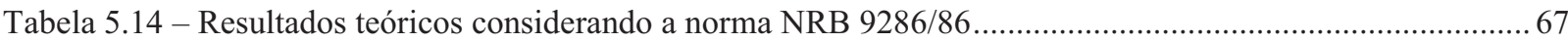

Tabela 5.15- Controle de umidade e grau de compactação. .......................................................................6 68

Tabela 5.16 - forças de arrancamento máximas registadas................................................................... 71

Tabela 5.17 - Resultados de cálculos sem considerar a coesão do solo ........................................................ 72

Tabela 5.18 - resultados calculados pela equação 37 , considerando a coesão …................................................ 72

Tabela 5.19 -Resultados do cálculo considerando a norma NBR 9286/86 ...................................................... 73

Tabela 5.20 - apresenta os valores que caracterizaram os ensaios com areia e fitas metálicas. ........................... 74

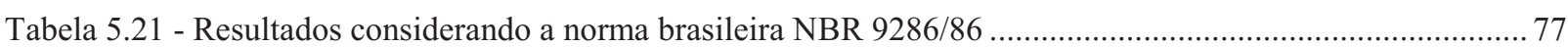

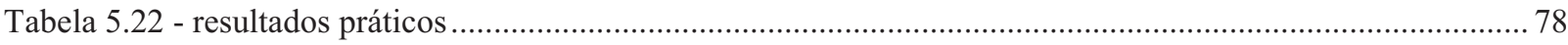

Tabela 5.23- valores das forças de arrancamento e das pré-cargas usadas nos ensaios (solo não convencional 1) .80 
Tabela 5.24 - controle de umidade e grau de compactação.

Tabela 5.25 - resultados práticos sem considerar a coesão do solo ............................................................ 85

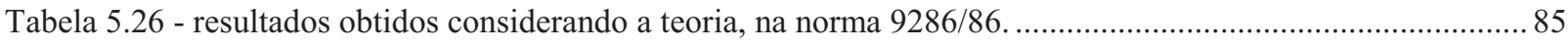

Tabela 5.27 - Resultados do ensaio considerando o efeito da coesão do solo................................................... 85

Tabela 5.28 - Os valores das forças de arrancamento e as pré-cargas registadas em ensaios ................................86

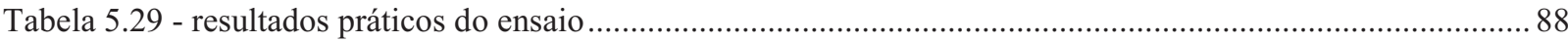

Tabela 5.30 - resultado teórico, considerando a norma NBR 9286/86 ......................................................... 88

Tabela 5.31 - Para resultados teóricos segundo a norma NBR 9286/86........................................................ 92

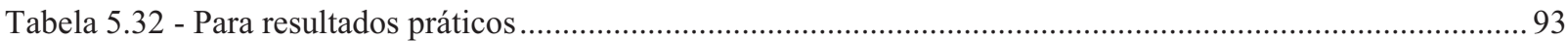




\section{LISTA DE ABREVIATURAS, SIGLAS E SÍMBOLOS}

C $\alpha$ : Adesão/ coesão de interface

ASTM: American Society for Testing and Materials

Au: Área útil da seção transversal da fita

B: Largura da fita

C $\alpha$ : Coesão do solo de aterro

$\mathrm{CP}_{\mathrm{n}}$ : Corpo de prova da ordem $\mathrm{n}$

CR: Compacidade relativa

$\mathrm{Cu}$ : Coeficiente de uniformidade do solo

$D_{n}$ : Diâmetro correspondente a percentagem passante de $n \%$ na curva granulométrica

e: Excentricidade da fita de ordem i

Dr: Densidade

$\mathrm{F}_{\text {arr }}:$ Força de arrancamento

f*: Coeficiente de atrito aparente solo-reforço

$\mathrm{FM}_{\mathrm{n}}$ : Fitas metálicas de largura $\mathrm{n}$

$\mathrm{FPO}_{\mathrm{n}}$ : Fitas poliméricas de largura $\mathrm{n}$

FHWH: Federal Highway Administration

FS: Fator de segurança

GC: Grau de compactação

(GW): Pedregulhos bem graduados

H: Altura da contenção

$\mathrm{H}_{\text {eq }}$ : Altura equivalente do solo correspondente a tensão vertical atuante em função do peso específico 
K: Coeficiente de Empuxo

La: Comprimento de arrancamento

L: Comprimento da fita inserido dentro do maciço

LL: Limite de liquidez

LP: Limite de Plasticidade

NBR: Norma Brasileira

Mc: Massa do cilindro.

MH: Silte elástico

PVC: Policloreto de Vinila

SC: Areia Argilosa

SG: Strain Gage

SUCS: Sistema unificado de classificação dos solos

(SW): Areia apropriada para o concreto

Wi: Peso atuante na fita de ordem i

$\sigma_{\mathrm{ci}}$ :Tensão de tração na conexão da fita de ordem i

$\sigma_{\mathrm{vi}}$ : Tensão vertical na fita de ordem i

$\sigma_{\mathrm{y}}$ : Tensão de escoamento do material

$\delta$ : Ângulo de atrito solo-inclusão

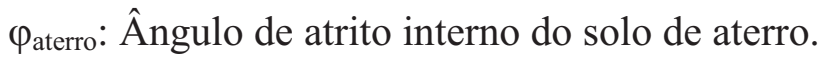

$\varphi$ :Ângulo de atrito interno do solo, determinado por ensaio de cisalhamento rápido, sobre amostra moldada na umidade ótima e compactada até atingir $90 \%$ do grau de compactação (Energia Proctor Normal). 
$\Phi^{\prime}$ : Ângulo de atrito interno do solo, determinado por ensaio de cisalhamento rápido, préadensado sobre amostra saturada após moldagem na umidade ótima e compactada até atingir 90\% do grau de compactação (Energia Proctor Normal).

$\Phi^{\prime \prime}$ : Ângulo de atrito interno do solo, determinado pelo efeito de correlação apenas, por ensaio de cisalhamento rápido, sobre amostra deformada, moldada na umidade correspondente ao limite de liquidez e depois comprimida a $200 \mathrm{KPa}$. 

SUMÁRIO

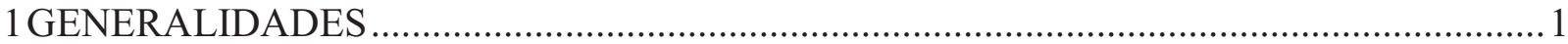

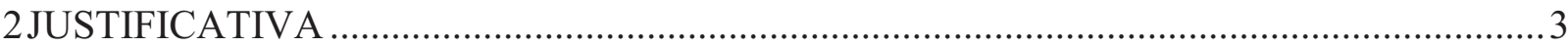

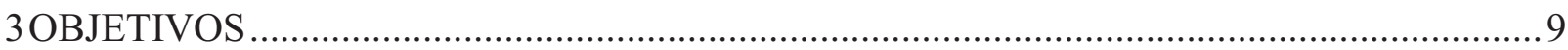

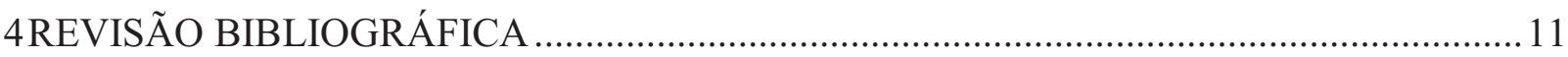

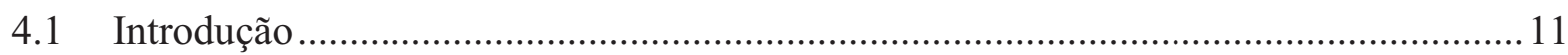

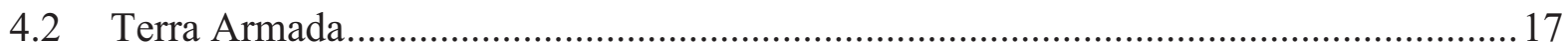

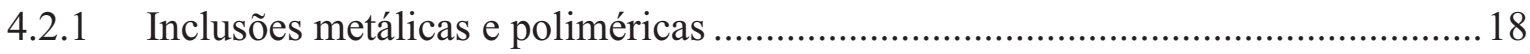

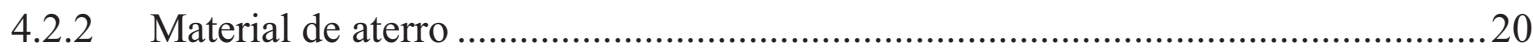

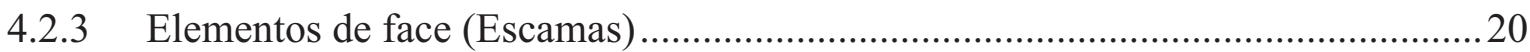

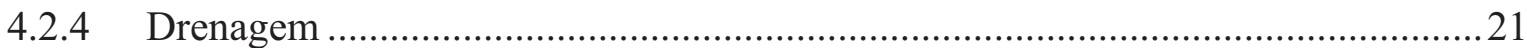

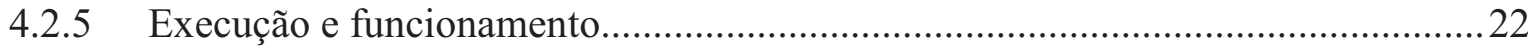

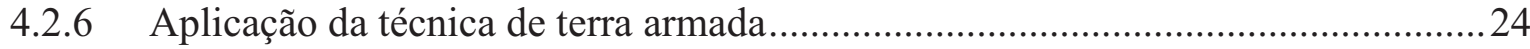

4.2.7 Vantagens da técnica de terra armada sobre outras técnicas...............................24

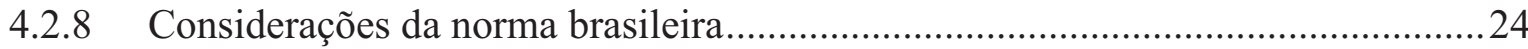

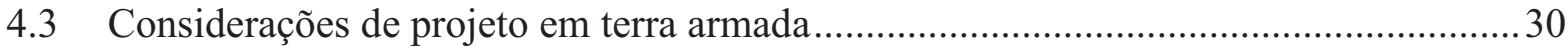

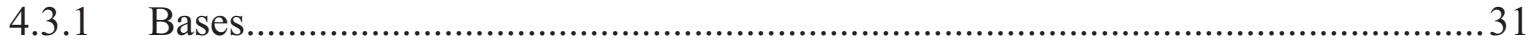

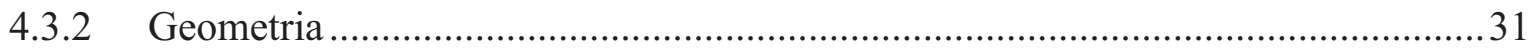

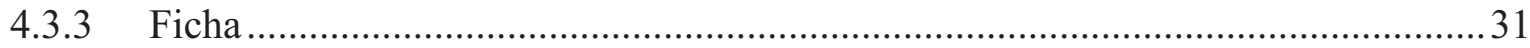

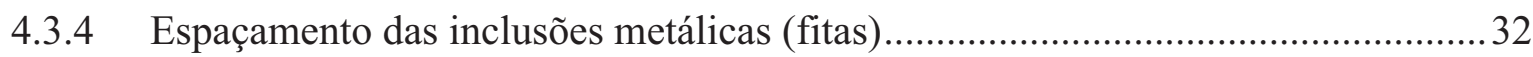

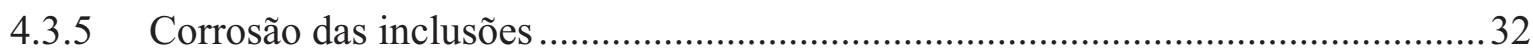

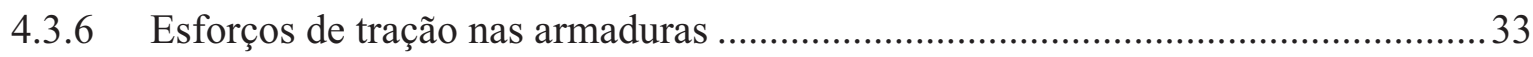

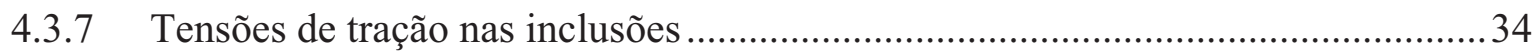

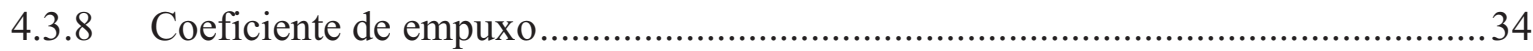

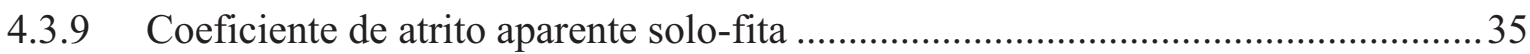

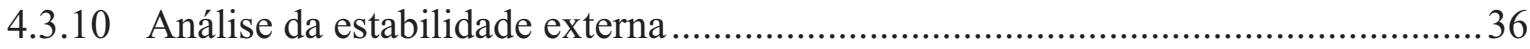

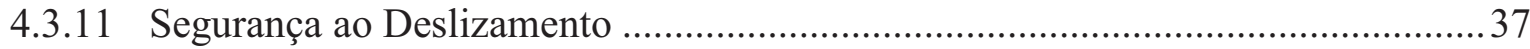




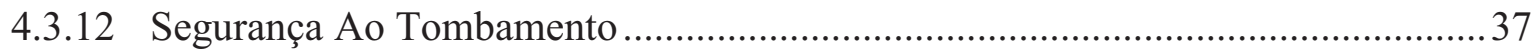

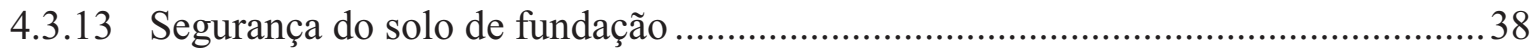

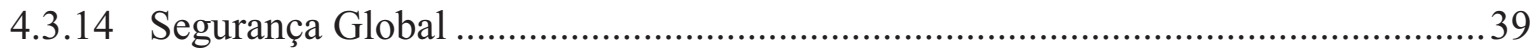

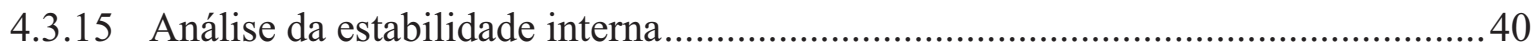

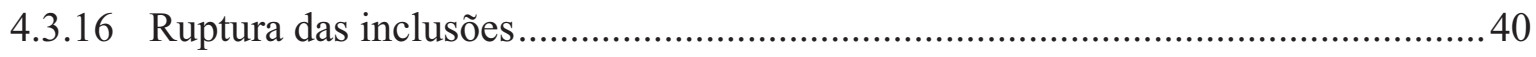

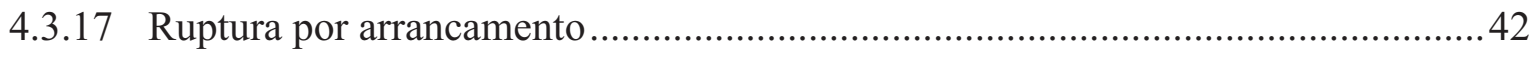

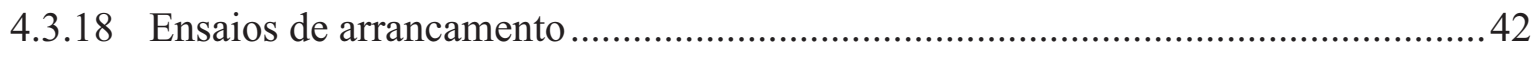

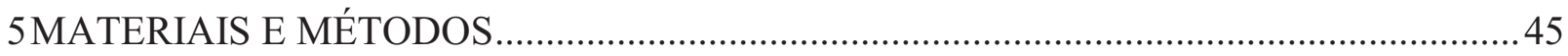

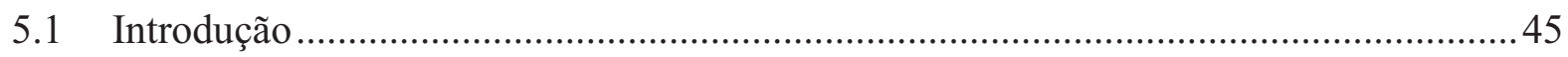

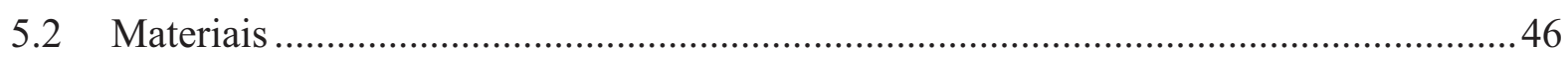

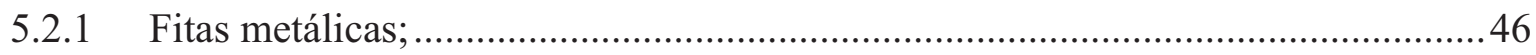

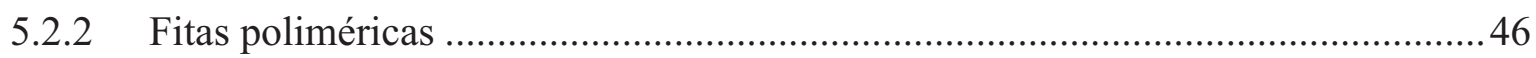

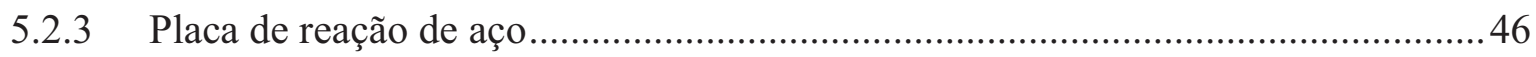

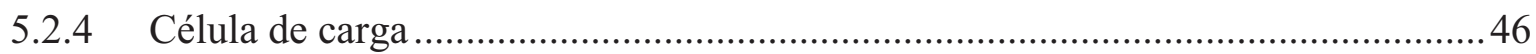

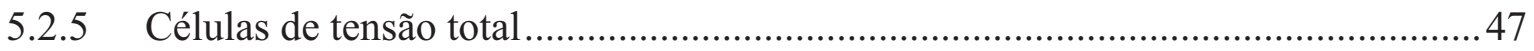

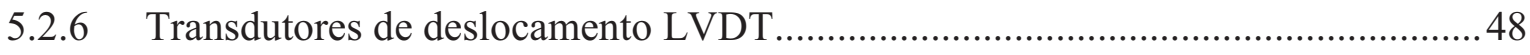

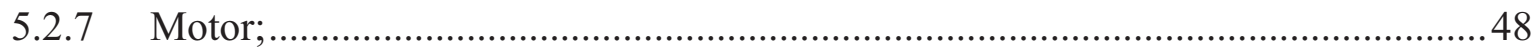

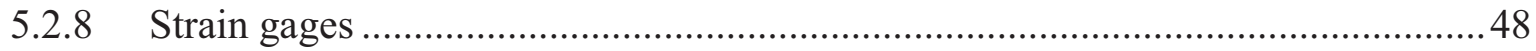

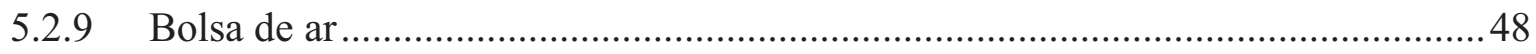

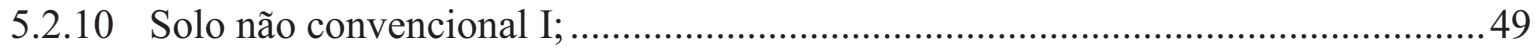

5.2.11 Solo não convencional 2-Rodovia SP 215-São Carlos .......................................49

5.2.12 Solo granular Mineração Jundú-Descalvado-São Carlos-SP ................................49

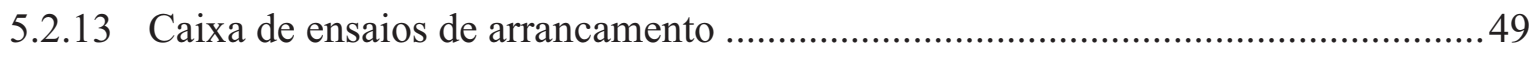

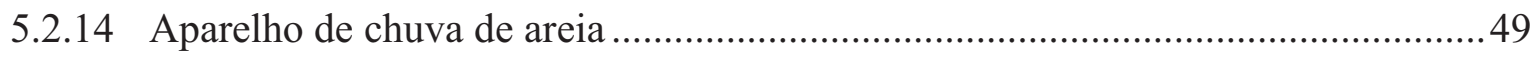

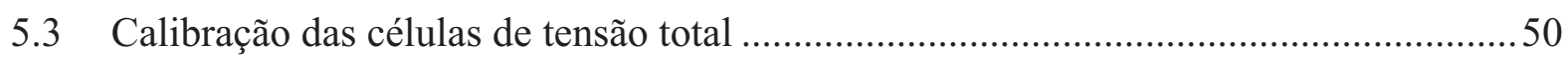

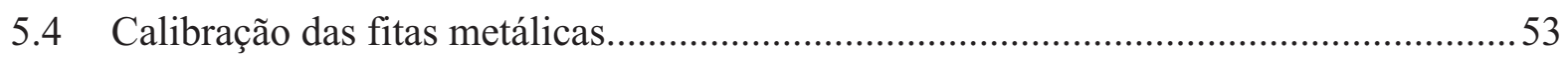

5.5 Preparação para a execução de ensaios de arrancamento .............................................55 


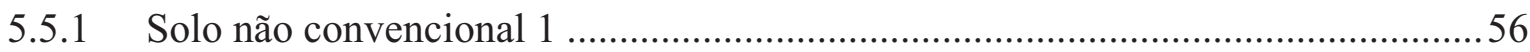

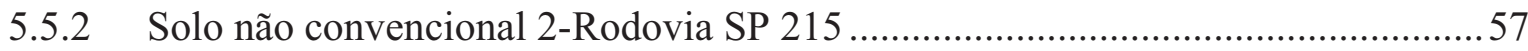

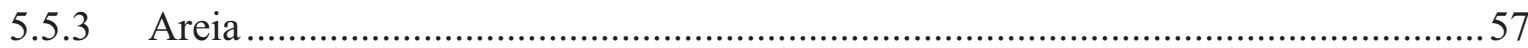

5.6 Ensaios de permeabilidade dos solos não convencionais ............................................58

5.7 Ensaios de arrancamento em solos reforçados por fitas metálicas ..............................59

5.7.1 Solo não Convencional 1 - CAMPUS II - EESC-SÃO CARLOS-SP ...................61

5.7.2 Solo não Convencional 2 - Rodovia 215 -São Carlos-SP ......................................67

5.7.3 Ensaios de arrancamento de fitas metálicas em solo granular da mineradora JunduDescalvado. .73

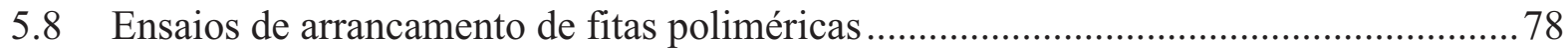

5.8.1 Ensaios com o solo não convencional do campus II............................................ 80

5.8.2 Ensaios de arrancamento de fitas poliméricas em solo granular proveniente da mineradora. 86

5.8.3 Traçado das envoltórias de cada conjunto de materiais. 89

5.8.4 Resumo dos resultados dos ensaios considerando os materiais usados, pelas suas envoltórias.

\subsection{ANÁLISE COMPARATIVA DOS RESULTADOS...............................................93}

5.9.1 Os ensaios realizados com o mesmo material..................................................... 93

5.9.2 Resumo da comparação dos resultados práticos e da norma (NRB 9286/86) .......97 6CONCLUSÕES 101

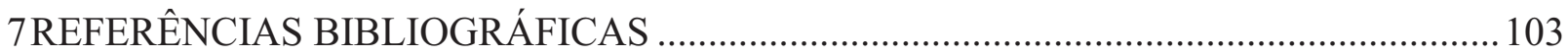

APÊNDICE A - Caracterização do solo não convencional 1 ................................................. 107

APÊNDICE B - Caracterização do Solo não convencional 2 - Rodovia SP 215..................... 108

APÊNDICE C - Caracterização da Areia - Jundu-Descalvado .............................................. 109

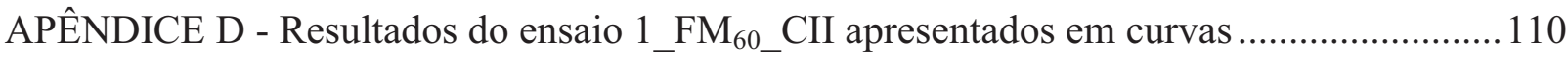

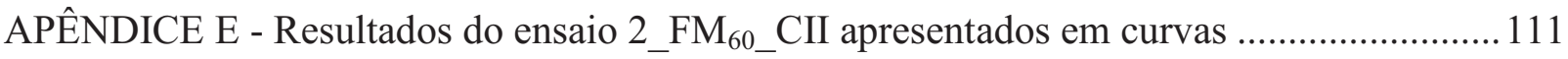

APÊNDICE F - Resultados do ensaio 3_FM60_CII apresentados em curvas........................... 112

APÊNDICE G - Resultados do ensaio 1_FM 40 -CII apresentados em curvas........................... 114 
APÊNDICE H - Resultados do ensaio 2_FM40_CII apresentados em curvas .......................... 115

APÊNDICE I - Resultados do ensaio 3_FM40-CII apresentados em curvas ........................... 116

APÊNDICE J - Resultados do ensaio 1- FM 60 R apresentados em curvas.............................. 117

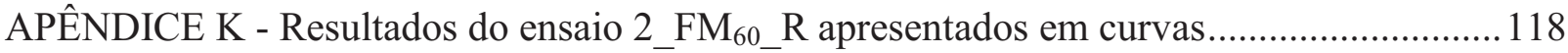

APÊNDICE L - Resultados do ensaio 3_FM60_R apresentados em curvas ............................. 119

APÊNDICE M - Resultados do ensaio 1_FM $\mathrm{FM}_{40} \mathrm{R}$ apresentados em curvas ............................ 120

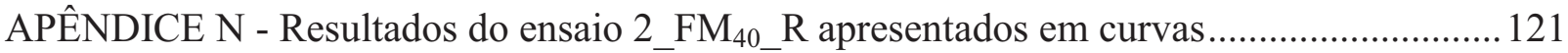

APENNDICE O - Resultados do ensaio 3_FM40_R apresentados em curvas............................. 122

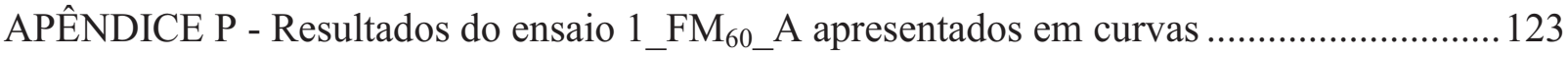

APÊNDICE Q - Resultados do ensaio 2_FM $60 \_$A apresentados em curvas ............................ 124

APÊNDICE R - Resultados do ensaio 3_FM $60 \_$A apresentados em curvas............................. 125

APÊNDICE S - Resultados do ensaio 1_FM40_A apresentados em curvas .............................. 126

APÊNDICE T - Resultados do ensaio 2_FM40_A apresentados em curvas .............................. 127

APÊNDICE U - Resultados do ensaio 3_FM $40 \_$A apresentados em curvas ............................ 128

APÊNDICE V - Resultados do ensaio 1_FPO ${ }_{50}$ CII apresentados em curvas ........................ 129

APÊNDICE W - Resultados do ensaio 2_FPO ${ }_{50}$ CII apresentados em curvas........................ 130

APÊNDICE X - Resultados do ensaio 3_FPO ${ }_{50}$ CII apresentados em curvas ........................ 131

APÊNDICE Y - Resultados do ensaio 1_FPO 47 CII apresentados em curvas ........................ 132

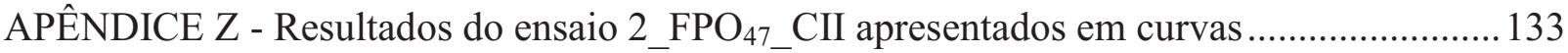

APÊNDICE AA - Resultados do ensaio3_FPO ${ }_{47}$ CII apresentados em curvas....................... 134

APÊNDICE AB - Resultados do ensaio 1_FPO ${ }_{50 \_A}$ apresentados em curvas ......................... 135

APÊNDICE AC - Resultados do ensaio 1_FPO ${ }_{47}$ A apresentados em curvas ......................... 136

APÊNDICE AD - Resultados do ensaio 2_FPO $\mathrm{FP}_{47} \mathrm{~A}$ apresentados em curvas .........................137 


\section{GENERALIDADES}

As obras geotécnicas com elementos de reforços resistentes à tração, que alteram as características internas dos solos nos quais são inseridos, são muito usadas para a contenção ou estabilização de taludes e aterro e são chamadas de estruturas em solos reforçados. As que usam a técnica de terra armada (solo armado) apresentam grandes vantagens no ponto de vista econômico, construtivo e ambiental, principalmente quando se faz o uso dos solos locais como material de aterro. O emprego da técnica de reforço de solos em terra armada encontra-se em expansão em todo o mundo. A introdução de reforços traz ao maciço a ser estabilizado um comportamento mecanicamente mais favorável, pois, quando as inclusões resistentes à tração são convenientemente inseridas promovem uma redistribuição de esforços nas zonas mais susceptíveis a movimentação, tornando o sistema resistente e estável; assim, as estruturas de solo reforçado são mais resistentes e menos deformáveis.

O processo de solo reforçado conhecido popularmente como solo armado foi oficialmente desenvolvido pela primeira vez e patenteado, em 1963, pelo engenheiro e arquiteto francês Henry Vidal.

A técnica de reforço de solo consiste em melhorar o solo conferindo-lhe a capacidade de resistência à tração. Executando o maciço de solo com introdução de inclusões inextensíveis denominadas fitas metálicas. As fitas podem ser nervuradas ou não nervuradas, sendo as nervuradas as melhores por oferecerem maior atrito. As fitas são conectadas a painéis pré-moldados de concreto, cruciformes, que constituem a face do maciço.

A técnica de reforço de solos foi desenvolvendo, permitindo melhorias que culminaram com a escolha de aço galvanizado como elemento de reforço, a substituição do painel metálico em forma de "U" pela face de concreto pré-moldado cruciforme (pele) e o desenvolvimento da armadura nervurada, para aumentar o coeficiente de atrito solo-reforço e, consequentemente, melhorar as transferências dos esforços do maciço para o reforço. Durante algumas décadas houve melhorias, porém, sem avanços científicos relevantes, isso foi por motivos de proteção das patentes que ainda vigoravam. Entretanto, após a queda das patentes, particularmente na década de 90, novas empresas projetistas e construtoras 
surgiram, popularizando o método. Assim, elaborou-se a norma NBR 9286 de Março de 1986. A norma foi elaborada apenas considerando argumentos baseados na experiência obtida com aterros compactados.

O emprego da técnica de terra armada tem se notabilizado, com sucesso em muitas obras de engenharia, entre elas pode-se citar: construção de encontros de pontes e viadutos, ferroviários e rodoviários, retificações de traçado de canais urbanos, estruturas de cais ou rodovias a beira mar e estoque de minérios, muros para nivelamento de terrenos urbanos, contenções de encostas em rodovias e ferrovias.

Atualmente, há inovações no uso das inclusões para os sistemas de reforço, substituindo-se as fitas metálicas por fitas poliméricas, para solos bem selecionados. 


\section{JUSTIFICATIVA}

Uma vez que o funcionamento do maciço em terra armada baseia-se, principalmente, na existência de atrito entre a terra e as armaduras (fitas metálicas), que tecnicamente se justifica a partir da resistência do solo ao cisalhamento, e, considerando as mais diversificadas condições prováveis, de umidade a que a obra possa vir a estar submetida, as especificações de projeto de estruturas de solo reforçado em obras de países da América do Norte, Europa e Japão, em geral, somente fazem referência aos solos granulares, devido à capacidade que esses têm de drenagem e resistência ao cisalhamento. Os solos finos, os siltes e argilas são excluídos pela sua baixa capacidade de drenagem e, consequentemente, pela dificuldade de dissipação do excesso de pressão neutra gerado no interior dos maciços compactados, ocasionando, principalmente, redução da resistência ao cisalhamento do solo, contrariando a justificação técnica do processo de terra armada.

Obras executadas seguindo as recomendações internacionais, instruídas por normas britânicas e norte americanas: BS 8006 (1995 e 2010) e AASHTO (2002) respectivamente; prejudicam o conceito econômico de estruturas de solo armado, pois, recomendam o uso de solos granulares que, muitas vezes devem ser transportados longe do local da obra, este prejuízo, se agrava para o caso do Brasil, cuja grande parte do seu território é coberta por solos finos.

Segundo Mendonça, a experiência internacional com obras em solos reforçados, com enfoque à técnica de Terra Armada, recomenda a necessidade da utilização de solos arenosos para a execução dos aterros (MENDONÇA et al.2000).

Estudos realizados pelo National Highway Institute Office of Bridge Technology (NHI); recomendam que todas as estruturas de terra mecanicamente estabilizadas, requerem um solo de alta qualidade em termos de durabilidade, drenagem, fácil execução e um solo com boa interação com o reforço; o que seria fácil com o uso de material granular e bem graduado, pois o sistema depende da alta fricção do elemento de reforço e do solo de aterro (FHWA-NHI-00-043). 
Abramento et. al. (1998), reiteram esta tendência para casos brasileiros, sugerindo que o solo de aterro geralmente constitui-se em solo arenoso, com menos de $15 \%$ em peso do material passando na peneira \# 200 .

Observando o mapa geomorfológico do Brasil pode-se notar que devido à diversidade climática existente, o país exibe uma grande variedade de solos. De acordo com Bueno (2005) apud Miranda (2008), um típico perfil do solo em áreas tropicais, compõe-se de um horizonte superficial, a camada residual madura, geralmente de natureza laterítica (argila, areia argilosa) ou, por vezes constituídas por siltes micáceos, e areia ou uma camada de solo coluvionar acima do solo residual maduro; ocasionalmente um manto intermediário de argilas duras, mostrando uma estrutura reliquiar ou, por vezes, expansivo, e constituído por uma camada de solo saprolítico constituído de cascalho, areia, solos arenosos e argilosos mostrando estrutura reliquiar da rocha-matriz. Por outro lado, para o uso dos polímeros como inclusões é recomendado para material de dimensões ainda maiores o que tem prejuízos em custos para as obras executadas em regiões sem pedregulhos e areias prescritas.

No Brasil e outros países de clima tropical, materiais granulares não estão facilmente disponíveis na vizinhança dos locais de construção (Bueno et al., 2006). Os solos com granulometria fina, além de serem encontrados em abundância em vastas áreas do território Brasileiro, muitas vezes, apresentam excelentes parâmetros de resistência ao cisalhamento (coesão e ângulo de atrito), característica que permite a execução de estruturas de solo reforçado estáveis, principalmente por torná-las menos deformáveis (Patias, 2005). Embora os solos tropicais lateríticos, geralmente materiais finos e mal graduados, quando classificados de acordo com a análise granulométrica tradicional, são excelentes materiais de construção, comportando-se como se fossem solos grossos (BUENO 2005).

Azumbuja et al. ( 2003 ) afirmam que os solos mais empregados para estruturas de solo reforçado são os predominantemente granulares. Quando se trata de países com solos tropicais, o emprego de solos lateríticos é particularmente vantajoso, recomendando-se assim para a realidade brasileira, solos que possuam índice de plasticidade menor que $15 \%$.

Ehrlich et al. (1994) e Reccius ( 1999) em estudos com solos reforçados, consideraram que a utilização de solos residuais com grandes percentagens de finos 
(tipicamente 50\% passando na peneira de \#200) é indicada para obras de solo reforçado, desde que devidamente compactados. Mendonça et al. (2000) afirmam que, em princípio, não existe uma curva granulométrica, típica ou mínima para a utilização ou não de determinado solo para o aterro em obras de solo reforçado, uma vez que, além da granulometria, a composição mineralógica influi muito no comportamento destes solos quando compactados.

Kakuda (2005) realizou ensaios de arrancamentos em geogrelhas e para tal utilizou seis solos típicos da região do Estado de São Paulo. A distribuição granulométrica destes solos é representada na Figura 2.1, onde se confirma a abundância de solos com granulometria fina e justifica a necessidade de se estudar a utilização desses solos, ditos não convencionais para os casos de obras, na técnica de terra armada.

Um dos parâmetros mais importantes de projeto, que condiciona o mecanismo de transferência de carga, o contato solo-reforço, pode ser quantificado através de ensaios de arrancamento. A fim de avaliar o comportamento destes solos finos, estudos têm sido desenvolvidos no Laboratório de Geossintéticos da EESC-USP.

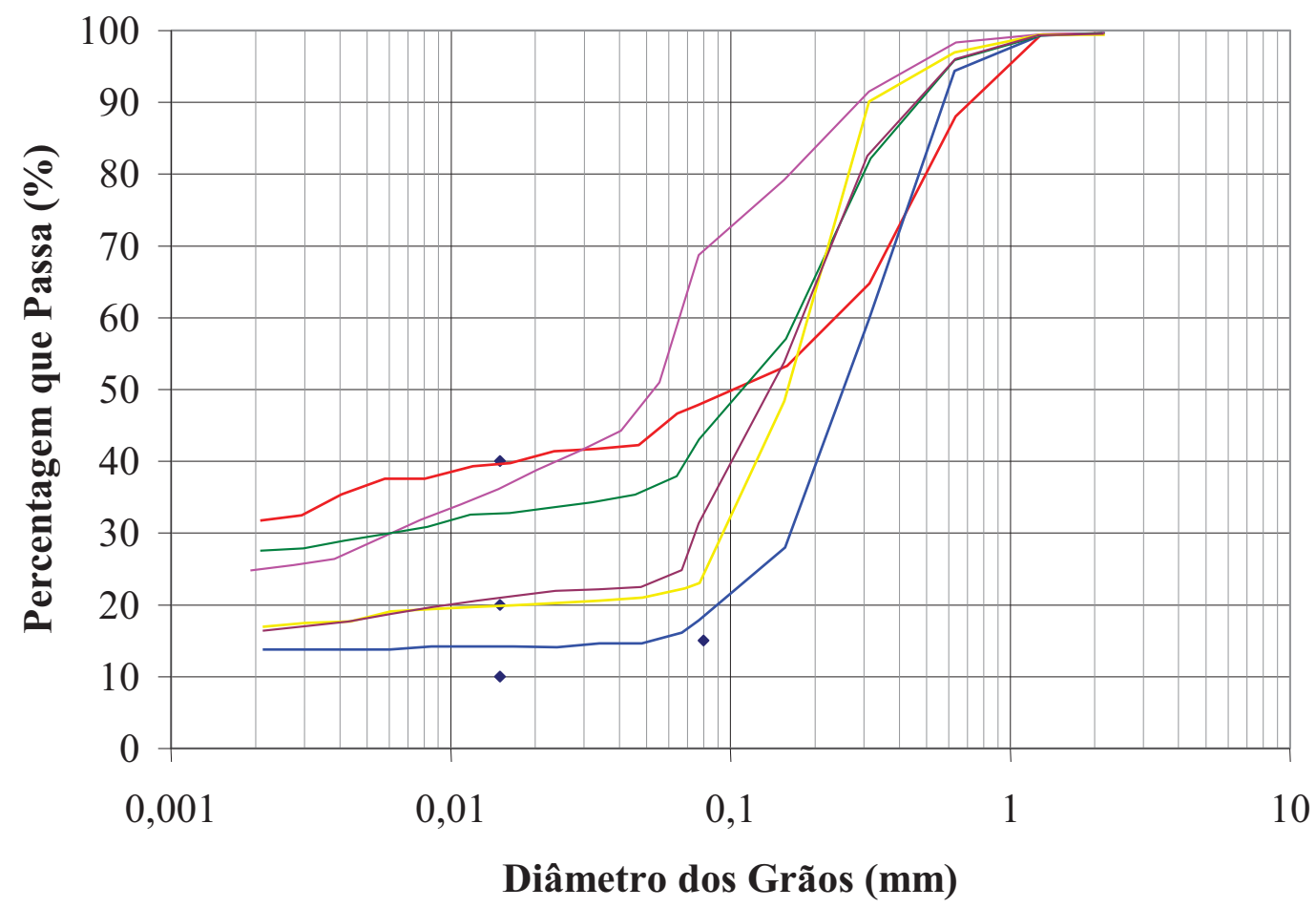

Figura 2.1- Distribuição granulométrica dos solos estudados por Kakuda (2005) apud Miranda (2009) 
Miranda (2008) realizou ensaios de arrancamento de fitas metálicas com solo local da cidade de São Carlos-SP. O resultado experimental apresenta o coeficiente de atrito, $\mathrm{f}^{*}$, divergente ao sugerido na norma, como se observa na figura 2.2. O trabalho de Miranda (2005) tinha como objetivo, apenas uma comparação entre os vários tipos de elementos longitudinais de reforço, com ênfase em elementos para solo grampeado.

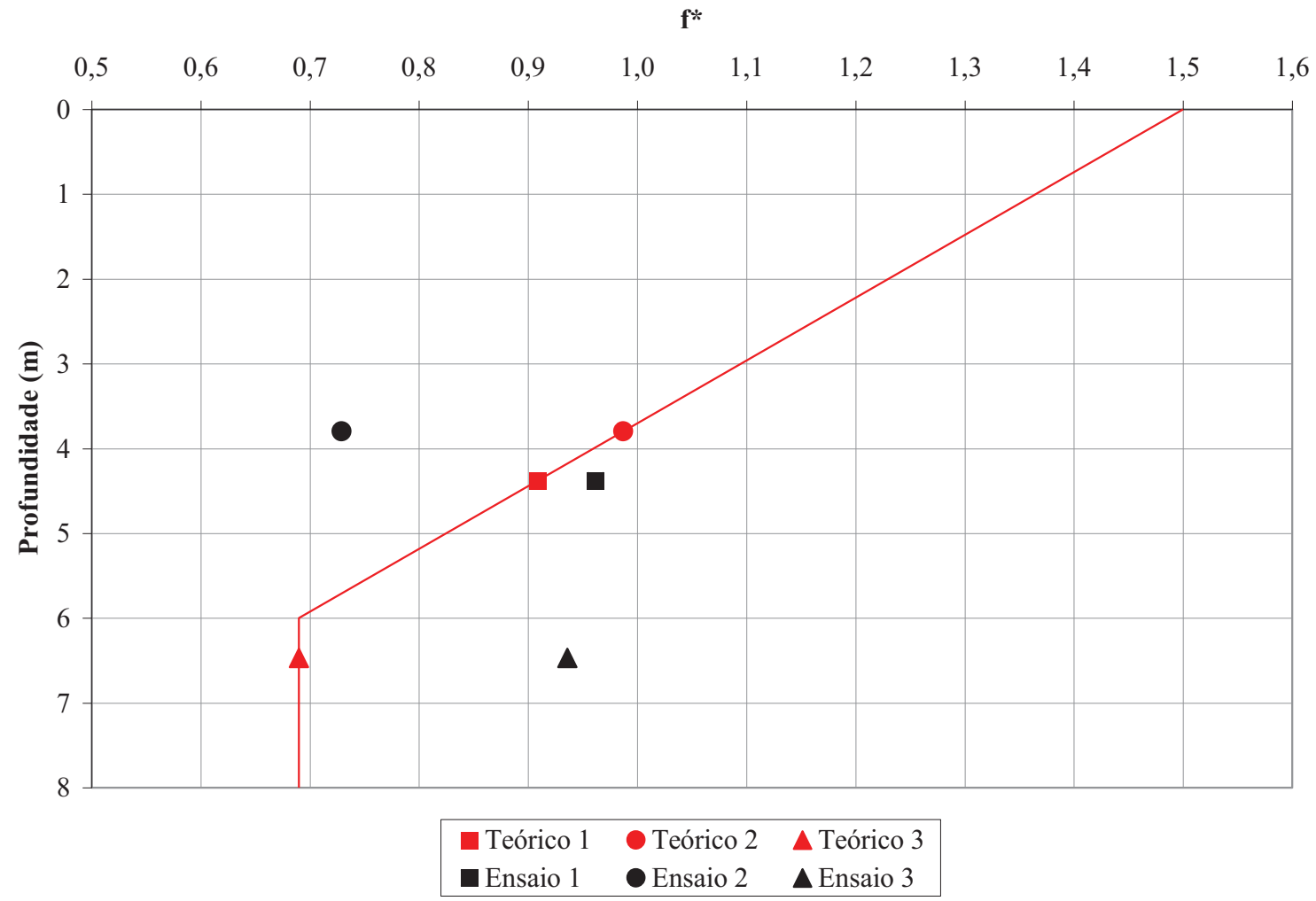

Figura 2.2-Comparação de resultados dos ensaios com valores sugeridos por norma (MIRANDA 2009).

Analisando a Figura 2.2, observa-se que os ensaios 1 e 3 apresentaram coeficientes de atrito acima do previsto, porém quando adotado o fator de segurança de 1,5, sugerido na norma NBR9286/86 estes valores ficam aquém do esperado. Em relação ao ensaio 2, este valor apresenta-se excessivamente abaixo do previsto (MIRANDA, 2009).

Desta forma, é imperioso que se proceda a uma avaliação ampla e profunda do comportamento de fitas convencionais de terra armada implantadas em solos brasileiros, que é uma forma intrínseca de se projetar no Brasil. Este trabalho poderá contribuir de forma positiva para projetos econômicos e seguros.

O uso de solos não convencionais requer um estudo mais detalhado do seu comportamento como material de aterro. Aliado a este fato, há grandes perspectivas de 
redução de custos da técnica quando comparada a outras soluções, visto que no Brasil tem aumentado a experiência e a produção de aço, principal material na confecção das fitas metálicas.

Por estas razões, esta pesquisa pode ser entendida como uma excelente oportunidade para se catalogar a experiência disponível e aumentar o nível de conhecimento sobre a técnica de terra armada, permitindo divulgá-lo de forma mais vigorosa no âmbito da engenharia geotécnica brasileira. Os resultados deste trabalho encontrarão aplicação prática imediata, pois tem relação direta com o desempenho e o custo das obras com o uso da técnica de terra armada. 
Avaliação da Interação Solo-Fitas metálicas e poliméricas para Soluções em Terra Armada em Solos não Convencionais 


\section{OBJETIVOS}

Avaliar a influência dos fatores executivos, particularmente o coeficiente de atrito aparente solo-fitas metálicas e poliméricas (f*), em função das características dos solos para as classes estabelecidas pela NBR 9286/86. 
Avaliação da Interação Solo-Fitas metálicas e poliméricas para Soluções em Terra Armada em Solos não Convencionais 


\section{REVISÃO BIBLIOGRÁFICA}

\subsection{Introdução}

O uso de estruturas em solo reforçado é uma tecnologia de grande importância para projetos de contenção.

Materiais diversos têm sido utilizados para reforço de solo desde a antiguidade. Segundo Seraphin e Mello, 2003, nos primórdios, os Incas utilizavam lã de Lhama misturada com solo para a construção de estradas. Troncos de árvores, arbustos, pele de animais, entre outros materiais, foram utilizados para melhorar as características dos solos naturais.

As soluções mais eficientes são produzidas quando os projetos têm em conta a disponibilidade de materiais com características de resistência normatizadas.

Os sistemas de reforço de solos são essencialmente compostos por três elementos que são: O reforço, o material de preenchimento e os blocos, como mostrado na Figura 4.1. 


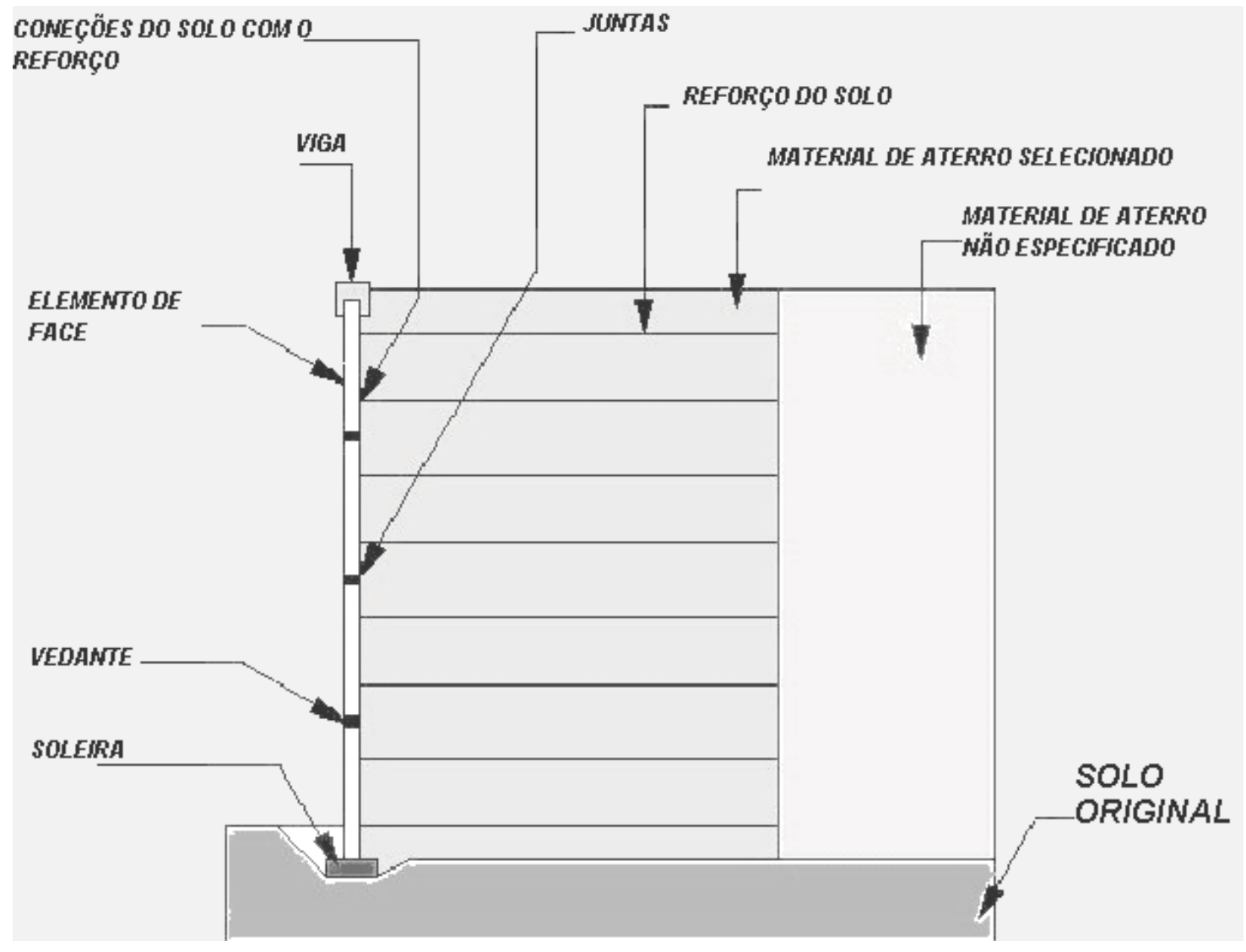

Figura 4.1- Sistema de reforço de solos.

Os elementos de reforço são geralmente classificados como inextensíveis (metálicos) ou extensíveis (polímeros). Esta classificação é baseada na deformação necessária para mobilizar em toda a força no maciço do solo. Os reforços inextensíveis geralmente incluem fitas de aço e grades. Dentre as estruturas construídas com o uso de reforços inextensíveis pode-se citar, por exemplo, estruturas em terra armada, solo grampeado e outras. A figura 4.2, mostra foto de uma estrutura de solo reforçado pela técnica de terra armada e a figura 4.3 mostra o uso de fitas poliméricas. 


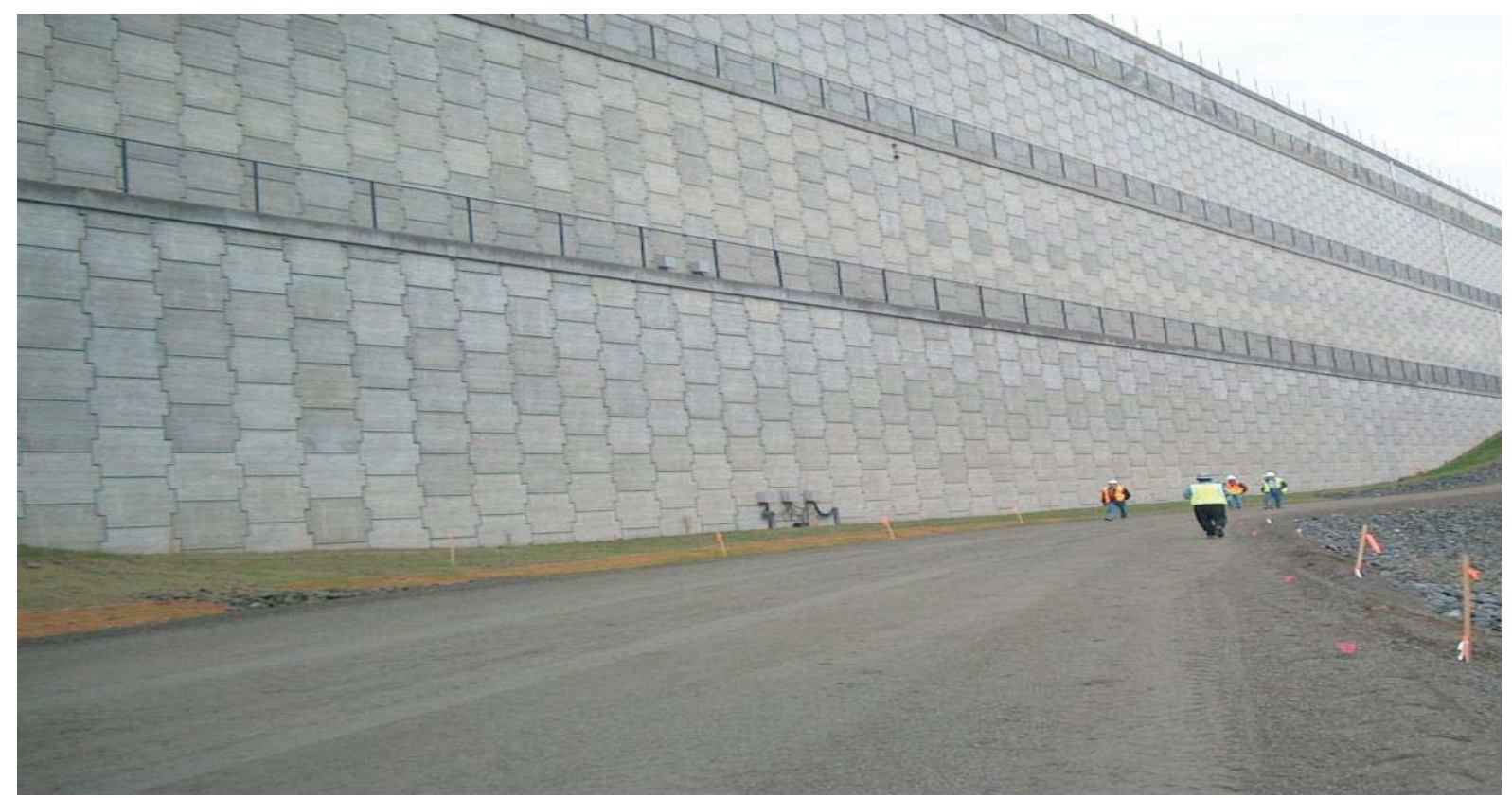

Figura 4.2. Sistema de contenção, terra armada com o uso de fitas metálicas (NHI)

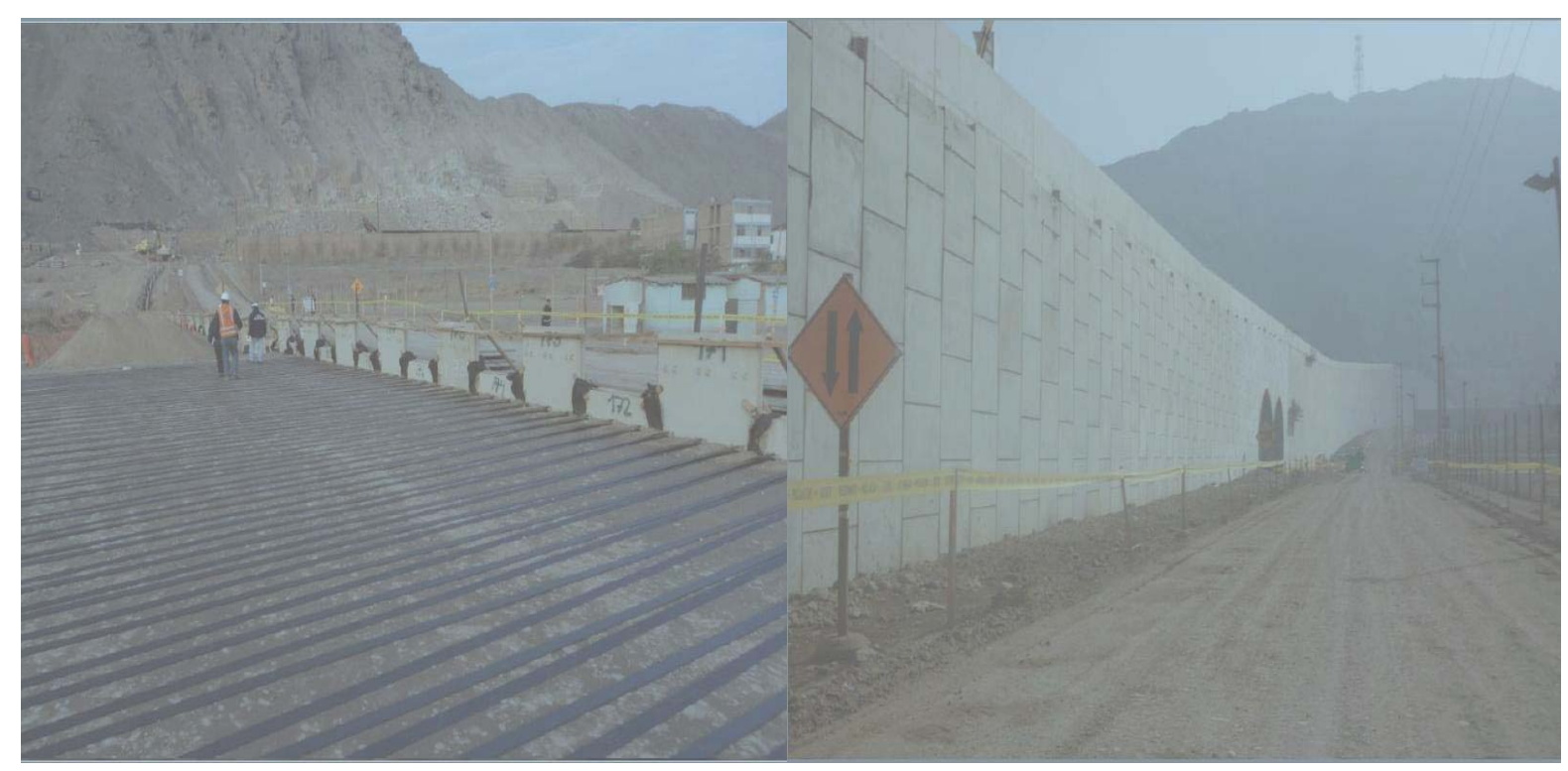

Figura 4.3. Sistema de contenção, terra armada com o uso de fitas poliméricas (MACCAFERRI 2011)

Enquanto os reforços extensíveis incluem polímeros como geogrelhas e geotêxteis.

O material de preenchimento é constituído por solos selecionados

Para manter o sistema estável, com uma boa forma são construídos blocos em elementos pré-fabricados, que geralmente, consistem em painéis de concreto pré-moldado ou unidades de alvenaria modular pré-moldado ou ainda metálicos. Os painéis têm formato 
quadrados, retangulares, cruciformes ou outras formas de polígonos, que se estendem por toda a altura da parede. Os blocos são fabricados com uma ampla variedade de textura, cores e estética.

Para o material de preenchimento, materiais granulares são geralmente mais desejáveis, pelas seguintes razões (JOSEPH E. - FHWA, 2001): boa durabilidade, alta permeabilidade, permite melhor drenagem e menos pressões neutras, maior atrito boa interação solo-reforço e, resistência ao arrancamento relativamente elevada. Por conseguinte, os benefícios econômicos dessas construções são em grande parte limitadas pela indisponibilidade e os custos desse material granular para preenchimento ou aterro.

Quanto ao uso de solos não convencionais, Zornberg e Mitchell (1994). Mostram preocupações em relação a sua baixa permeabilidade que pode permitir o acúmulo de água nos poros, gerando assim, pressões neutras; os ângulos de atrito inferiores relativamente aos materiais granulares; presença de partículas de argila (menores de $2 \mu \mathrm{m}$ ) que aumenta a taxa de corrosão dos reforços metálicos e facilitam deslocamentos pós construção relativamente maiores, entre outras.

Quando uma massa de solo é carregada verticalmente, ocorrem deformações verticais de compressão e deformações laterais de extensão (tração). Contudo, se a massa de solo estiver reforçada, os movimentos laterais são limitados pela reduzida deformabilidade do reforço. Esta restrição de deformações é obtida graças ao desenvolvimento de esforços de tração no elemento de reforço. Neste caso, o solo tende a mover-se em relação ao reforço gerando tensões cisalhantes na interface (WHEELER, 1996). A Figura 4.4, ilustra o princípio básico do comportamento do solo reforçado. 


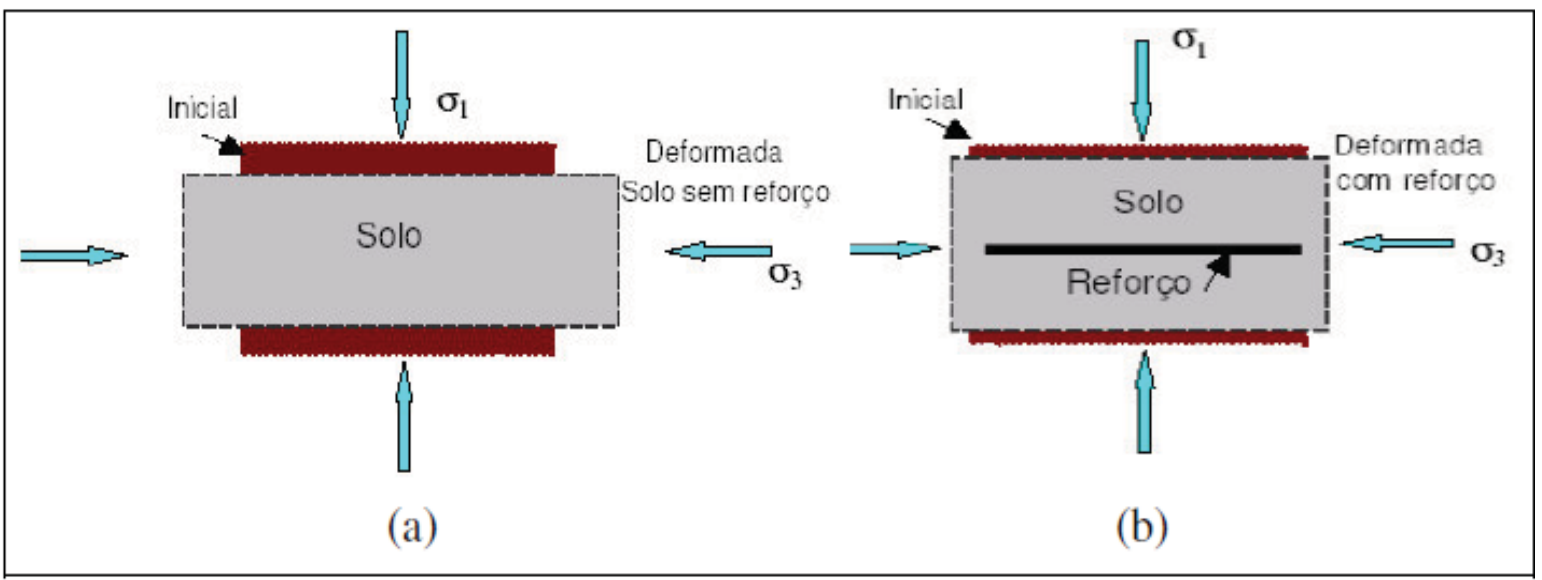

Figura 4.4- Comportamento típico do solo: (a) sem reforço; e (b) com reforço (SIEIRA 2003).

A seleção das técnicas de reforço é feita, dependente de um conjunto de fatores, que analisados, ditarão as vantagens e desvantagens para cada situação e para cada caso de obra.

Em projetos é difícil conhecer com exatidão as tensões normais nas interfaces soloreforço; isso porque, por exemplo, para solos arenosos, o efeito da dilatância dificulta tal exatidão. Neste caso a caracterização da resistência das interfaces é geralmente feita pelos diferentes coeficientes de atrito aparente, dadas pela razão entre as tensões médias de pico ou residual e a tensão normal de referência, considerado como a média das tensões, as tensões normais que, devido ao peso próprio do solo somado a eventuais sobrecargas que atuariam num contorno idêntico à superfície lateral do reforço se esse reforço não existisse. Pode-se ver, então que o conceito do coeficiente de atrito aparente solo-fita metálica f*, é de grande importância no dimensionamento de estruturas em sistemas de reforço de solo.

O dimensionamento é geralmente feito considerando uma tensão normal de referência que, em princípio deve coincidir com a tensão devida ao peso próprio do solo e eventuais sobrecargas localizadas sobre a armadura porque geralmente é difícil, numa obra real ter-se o conhecimento da tensão normal instalada.

Felix (1991), diz que dos ensaios mais comuns utilizados nesse tipo de estudo, ocupam lugar de destaque, ensaios de cisalhamento direto e ensaios de arrancamento, aos quais se devem grande parte dos conhecimentos atuais sobre a interação solo-reforço. No entanto, quando se trata dos ensaios de cisalhamento direto e de arrancamento, as resistências das interfaces são influenciadas por:

- Percentagem das partículas de granulometria fina; 
- Compacidade relativa (em solos granulares);

- Teor de umidade para os solos com grande percentagem de partículas finas;

- O estado de superfície do material estrutural (liso ou rugoso) e

- Nível de tensão normal.

Mesmo assim os ensaios de cisalhamento direto não representam corretamente o que acontece numa obra de reforço, quando se usa armaduras lineares; fato que ocorre porque os ensaios têm um caráter bidimensional enquanto que os fenômenos analisados ao se tracionar uma armadura linear são essencialmente tridimensionais. Ainda, no cisalhamento direto, não é considerada a rigidez das armaduras que afeta o mecanismo da mobilização da resistência. E, na sua maioria esses ensaios, são realizados com tensão normal constante; com a variação de volume; já que quando se trata de solos granulares a restrição da dilatância influencia a resistência da interface. Durante a tração da armadura, dentro do maciço, há transferência de tensões de cisalhamento para o solo e, o solo terá uma tendência de dilatar e como o solo circundante impede essa dilatação; localmente haverá aumento da tensão normal, o que provocará o aumento da força tangencial na interface Felix (1991). A tabela 4.1, apresenta alguns equipamentos para testes de interface; suas vantagens e limitações. 
Tabela 4.1 - Equipamentos para testes de interface; suas vantagens e limitações

\begin{tabular}{|c|c|c|c|}
\hline TIPO & EXEMPLOS & VANTAGENS & LIMITAÇŌES \\
\hline CORTE DIRECTO & $\begin{array}{l}\text { Potyondy (1961); Guilloux et al } \\
\text { (1979); Desai et al (1985) }\end{array}$ & $\begin{array}{l}\text { Sistema simples. } \\
\text { Fácil preparaçáo. } \\
\text { Condução simples do ensaio. }\end{array}$ & $\begin{array}{l}\text { Impossibilidade de distinguir os } \\
\text { deslocamentos devidos a } \\
\text { escorregamentos daqueles } \\
\text { devidos à deformação por corte } \\
\text { do solo. } \\
\text { Redução da área da interface } \\
\text { com o incremento dos } \\
\text { deslocamentos. }\end{array}$ \\
\hline $\begin{aligned} & \text { CORTE ANELAR } \\
\Rightarrow & =\end{aligned}$ & $\begin{array}{l}\text { Brumund e Leonards (1973); } \\
\text { Miyamoto et al (1975) }\end{array}$ & $\begin{array}{l}\text { Simulaçăo geometricamente } \\
\text { correcta do atrito desenvolvido } \\
\text { na face de estacas e reforços } \\
\text { metálicos. }\end{array}$ & $\begin{array}{l}\text { Desconhecimento da tensảo } \\
\text { normal na interface. } \\
\text { Concentração de tensỏes nas } \\
\text { extremidades. }\end{array}$ \\
\hline $\begin{array}{l}\text { CORTE CIRCULAR POR } \\
\text { TORÇẢO }\end{array}$ & Yoshimi e Kishida (1981) & $\begin{array}{l}\text { Năo se verifica concentração de } \\
\text { tensōes nas extremidades. } \\
\text { Área da interface constante. } \\
\text { Contribuiçāo de deslocamentos } \\
\text { observáveis por raio } X \\
\text { (escorregamentos e } \\
\text { deslocamentos devidos à } \\
\text { deformação por corte do solo). }\end{array}$ & $\begin{array}{l}\text { Sistema e condução do ensaio } \\
\text { complexos. } \\
\text { Dificuldades na preparaçáo das } \\
\text { amostras. } \\
\text { Dificuldade na obtenção de } \\
\text { rugosidade uniforme no anel } \\
\text { metálico. }\end{array}$ \\
\hline CORTE SIMPLES & Kishida e Uesugi (1987) & $\begin{array}{l}\text { Área da interface constante. } \\
\text { Fácil preparação. } \\
\text { Condução simples do ensaio. } \\
\text { Mediçáo separada dos } \\
\text { deslocamentos } \\
\text { (escorregamentos e } \\
\text { deslocamentos devidos à } \\
\text { deformaçáo por corte do solo). }\end{array}$ & $\begin{array}{l}\text { Concentração de tensóes nas } \\
\text { extremidades. }\end{array}$ \\
\hline
\end{tabular}

\subsection{Terra Armada}

A técnica de terra armada é uma das técnicas de reforço de solos que se apresenta como uma alternativa técnico-econômica viável e em expansão em todo o mundo. A introdução de inclusões inextensíveis traz ao maciço a ser estabilizado um comportamento mecanicamente mais favorável. Uma vez que as inclusões resistentes a tração são inseridas convenientemente no seu corpo com o objetivo de promover uma redistribuição de esforços nas zonas mais susceptíveis a movimentação; essas zonas transformam-se em 
resistentes e estáveis. Essas estruturas de contenção flexíveis, do tipo gravidade, que associam: aterro selecionado e compactado; elementos lineares de reforço que serão submetidos à tração; e elementos modulares pré-fabricados de revestimento, têm alta capacidade de suportar carregamentos e são ideais para muros de grande altura, ou que estejam sujeitos às sobrecargas excepcionais.

O princípio da tecnologia da terra armada é a interação entre o aterro selecionado e os reforços - armaduras de alta aderência que, corretamente dimensionados, produzem um maciço integrado no qual as armaduras resistem aos esforços internos de tração desenvolvidos no seu interior passando a se comportar como um corpo "coeso" monolítico, suportando, além de seu peso próprio, as cargas externas para as quais foram projetados.

As inclusões geralmente usadas na técnica de terra armada são denominadas inextensíveis (metálicas) chamadas fitas metálicas; podendo ser nervuradas ou não nervuradas. As fitas metálicas nervuradas são as que oferecem maior atrito. Essas armaduras segundo Martins (2005), podem ter larguras que variam de 40 até $120 \mathrm{~mm}$ e o seu comprimento que é obtido por cálculos deve ser superior a $0,7 \mathrm{H}$; em que $\mathrm{H}$ é a altura total do muro. As armaduras são conectadas a painéis pré-moldados de concreto, cruciformes, que constituem a face do maciço.

\subsubsection{Inclusões metálicas e poliméricas}

\subsubsection{Inclusões metálicas}

As inclusões metálicas mais eficientes para o uso em projetos de terra armada são as fitas metálicas nervuradas. Se tratando de obras em terra armada no Brasil, estas fitas devem atender aos critérios para aço CA50 da NBR 7480 - Aço destinado à construção civil e da NBR 6152 no que se refere às especificações de tração.

Os parafusos e as armaduras devem passar por tratamento anticorrosivo (zincagem), atendendo à NBR 6323. 
Os parafusos devem atender às determinações do método de ensaio descrito pela DIN 934. Afigura 4.5, mostra o detalhe das fitas metálicas.

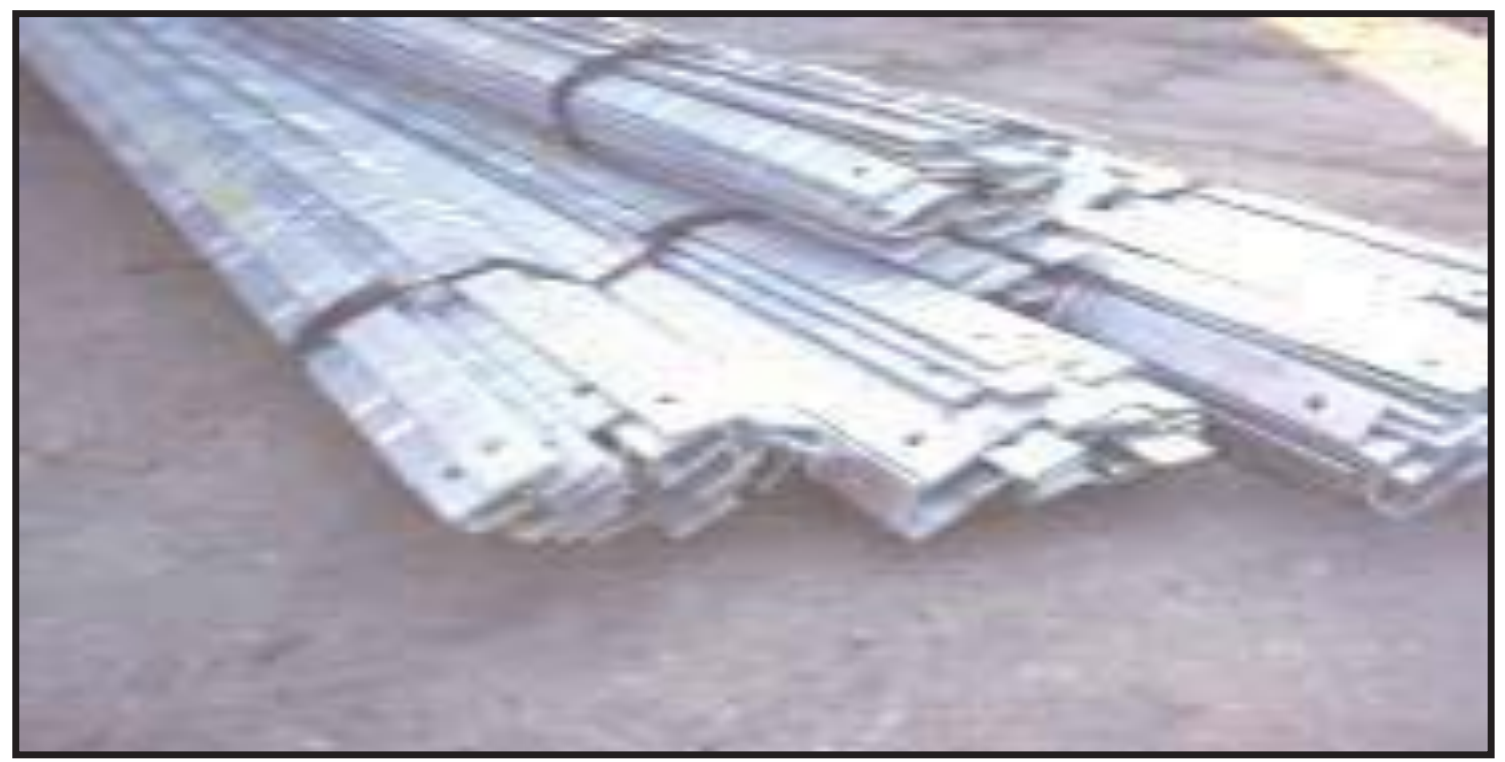

Figura 4.5 Detalhe das fitas metálicas.

\subsubsection{Inclusões poliméricas}

As inclusões poliméricas, são fitas com uma estrutura planar com superfícies rugosas, constituídas por fibras de poliéster de alta tenacidade, considerados apropriadas para usar em terra armada com face de concreto. Sugere-se que para este material é necessário para o seu aterro um material grosso. As inclusões poliméricas têm sido usadas atualmente com sucessos. A figura. 4.6, mostra pormenores de fitas poliméricas.

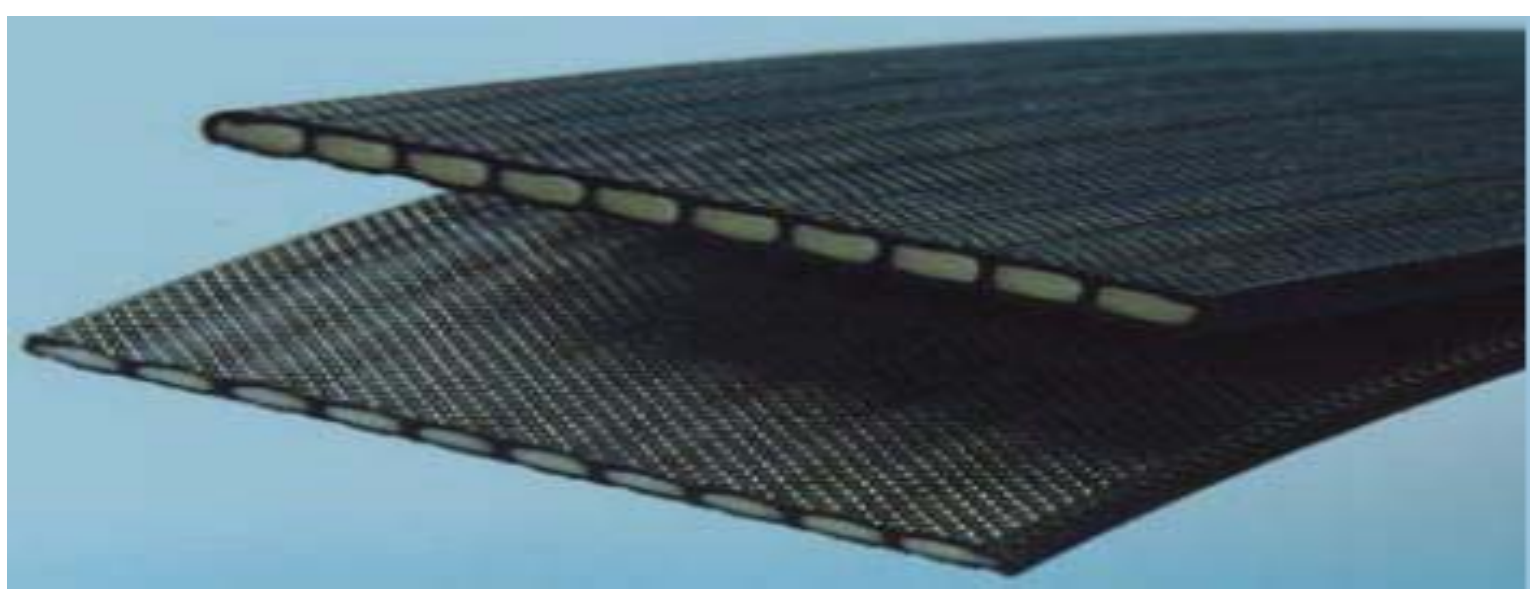

Figura 4.6 - Fita polimérica usada em sistemas de contenção. 


\subsubsection{Material de aterro}

Recomenda-se o uso de material granular que obedeça aos critérios da norma NBR 9286/86; também é recomendação que o grau de compactação para a execução do aterro seja no mínimo de $95 \%$ da densidade aparente seca máxima, obtido no ensaio de compactação com energia Proctor Normal. Essas recomendações são dadas para as inclusões metálicas

O material de aterro depois de consolidado deverá ter no mínimo um ângulo de atrito interno de $25^{\circ}$, medido em corte rápido e a dimensão dos seus elementos não poderá ser superior a $250 \mathrm{~mm}$, mas pelo menos $80 \%$ destes serão de dimensão superior a $0,015 \mathrm{~mm}$ Aguiar (2005).

Para contenções em que as inclusões são as fitas poliméricas são recomendados três tipos de solos que são

- SOLO I - Pedregulhos bem graduados (GW), com dimensões máximas dos grãos de $75,0 \mathrm{~mm}, \mathrm{D}_{(50)}$ aproximadamente de $12,5 \mathrm{~mm}$ e menos de $2 \%$ passando de P\#200; tendo o coeficiente interação fita-solo de 0,90 .

- SOLO II - Areia apropriada para o concreto ou simplesmente areia bem graduada (SW), bem graduada com diâmetro máximo das partículas igual a $25,0 \mathrm{~mm}, \mathrm{D}_{(50)}$ aproximadamente $0,850 \mathrm{~mm}$ e menos de $3,8 \%$ das partículas passando por P\#200 e o coeficiente de interação de 0,80 .

SOLO III - Areia siltosa (MS), com diâmetro máximo das partículas igual a 25,0 mm, $\mathrm{D}_{(50)}$ aproximadamente $0,150 \mathrm{~mm}, 2,9 \%$ de pedregulho, $61 \%$ de areia e $36,1 \%$ passando pela malha P\#200; com o coeficiente de interação de 0,70. (TECHNICAL DATA SHEET Ver .00.Date.30.01.2007)-Maccaferri.

\subsubsection{Elementos de face (Escamas)}

As escamas constituem ao acabamento externo do maciço, desempenhando uma função secundária no funcionamento do sistema estrutural. São responsáveis pelo equilíbrio das tensões da periferia próxima ao paramento externo. São geralmente placas pré-moldadas de concreto que pode ser armado ou não podendo ser metálicas, mas para o casos de uso de fitas poliméricas recomenda-se somente as de concreto; devem conservar juntas abertas entre si para efeito de drenagem e de articulação das peças.

As escamas também têm a função estética. A figura 4.7 mostra os detalhes dos 
diferentes tipos de escamas.

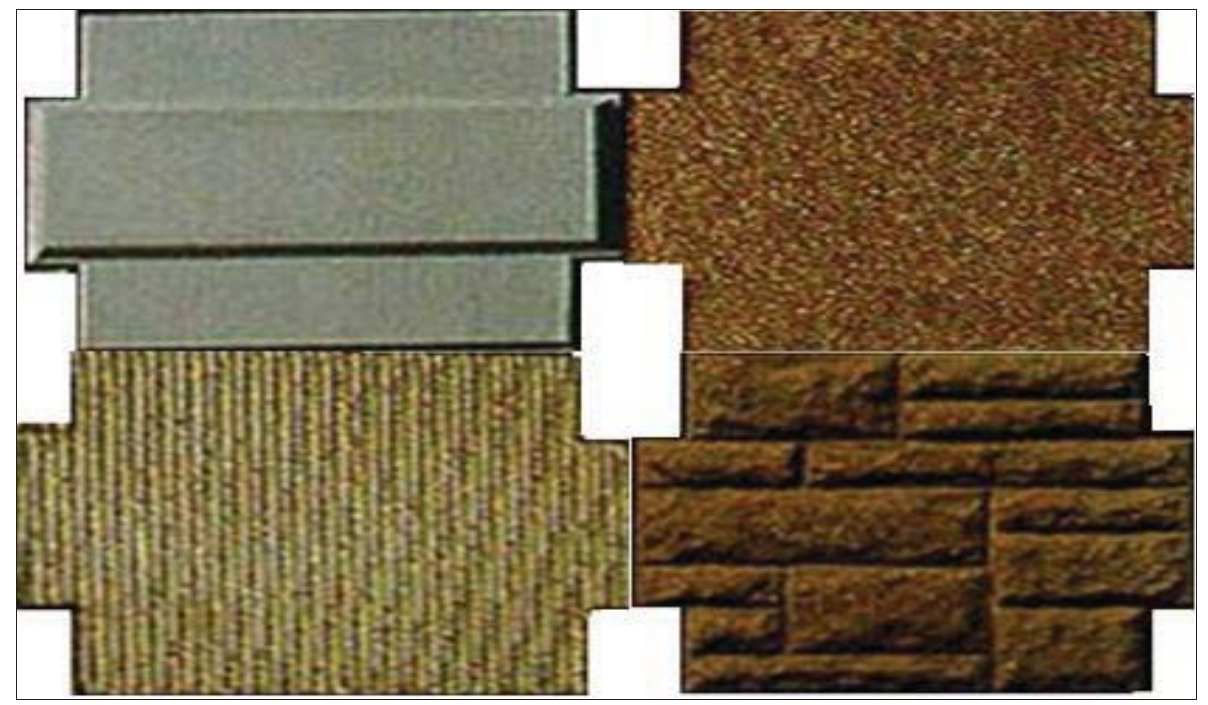

Figura 4.7 - Detalhes de diferentes tipos de escamas(BUENO)

\subsubsection{Drenagem}

É sempre necessário um projeto de drenagem específico para manter a estabilidade da estrutura quando em presença de água; principalmente quando o material de aterro for constituído por finos.

Devem ser previstos dispositivos que permitem aumentar a eficiência da drenagem, escoando a água sem carreamento de finos, e evitando comprometer a estabilidade da obra. Este objetivo pode ser alcançado por soluções com uso de filtros (colchões e valas drenantes) com material granular adequado e/ou geotêxteis. A figura 4.8, representa esquematicamente uma estrutura em terra armada.

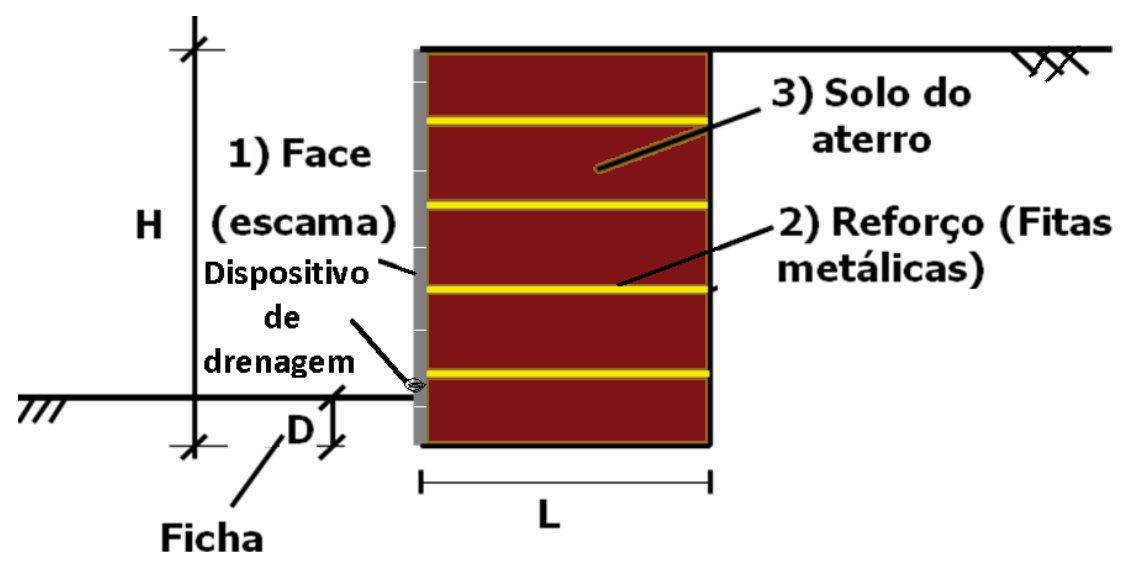

Figura 4.8,- Esquema de uma estrutura em terra armada com drenagem 


\subsubsection{Execução e funcionamento}

Terra armada é uma técnica de reforço de reaterros, onde a estrutura reforçada é construída por preenchimento, em sucessivas fases de baixo para cima. Em paredes de terra armada, os deslocamentos laterais no pé da parede aumentam durante as sucessivas fases de reaterro devido à descompressão das camadas inferiores causada pelo peso do solo. $\mathrm{O}$ resultado é que, durante a construção, pequenas deformações ocorrem na base da estrutura onde os deslocamentos horizontais serão máximos. A Figura 4.9, ilustra o posicionamento das deformações máximas nas estruturas de terra armada.

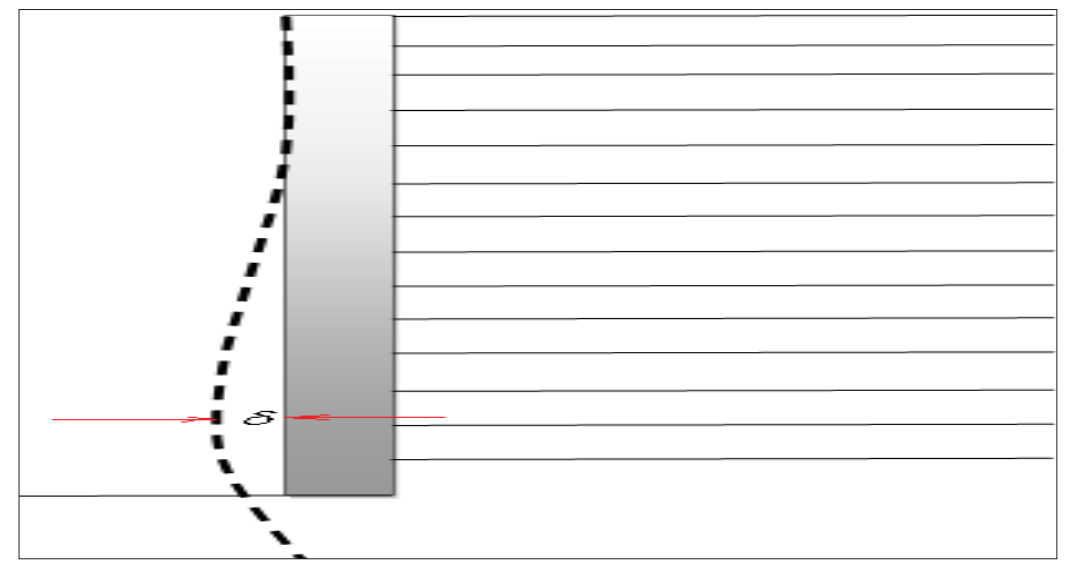

Figura 4.9- Deslocamento horizontal máximo em estruturas de terra armada (SPRINGER, 2001).

As tiras de reforço são completamente flexíveis e opõe-se apenas a esforços de tração (SCHLOSSER, 1982; BASTICK, 1990).

Em solos finos (argilas e siltes) o teor de umidade é um parâmetro importante de projeto. Quando o solo está saturado, o atrito solo-fita metálica é devido, exclusivamente, a resistência não drenada a qual é geralmente insuficiente para combater os esforços de tração do reforço e consequentemente, solos argilosos e siltes são, em geral, inadequados para a elaboração do projeto de terra armada. Este comportamento foi também estudado por e Schlosser em 1982, para soluções em solo grampeado.

Choukeir et al., (1997); e Jones,(1998). Referem que:

- $\quad \mathbf{O}$ elemento de reforço é introduzido no solo sem pré-tensão; as forças desenvolvidas nos reforços surgem quando da ocorrência de deformações no solo; 
- $\quad$ As forças desenvolvidas nos reforços são sustentadas pelo atrito entre o solo e o elemento de reforço;

- $\quad$ Estruturas em terra armada são sistemas que são consistentes e flexíveis. Por esta razão, eles oferecem vantagens em oposição a grandes deformações e em observações de campo após terremotos sobre estruturas de solo grampeado e em terra armada.

Neste tipo de estruturas, verifica-se uma alta resistência das mesmas em relação a esforços dinâmicos (efeitos sísmicos), mesmo considerando que as faces das estruturas, elementos pré-fabricados, não apresentam função estrutural de muita importância.

Muitas especificações indicam para o uso de solos convencionais granulares com alta resistência ao cisalhamento e capacidade de livre drenagem, material que dissipe rapidamente as pressões de água que são desenvolvidas durante a construção e àquelas que serão desenvolvidas durante a vida útil da obra, o que de certa maneira retira a vantagem de redução de custos, para o caso do Brasil, país onde muitas vezes os solos preconizados não estão próximos do local da execução da obra.

No Brasil, os solos finos são encontrados em grandes áreas e, principalmente, quando apresentam comportamento laterítico, seus parâmetros de resistência ao cisalhamento (coesão e atrito), podem ser elevados. Outro fator importante, relacionado aos solos brasileiros, refere-se a sua condição não saturada que pode perdurar em muitas obras. Nesta condição as pressões neutras são negativas, e contribuem para o aumento do parâmetro de coesão do solo (coesão aparente, tornando as obras mais estáveis).

Para o caso do Brasil e outros países tropicais com abundância de solos não convencionais a rápida aceitação dos sistemas de solos reforçados, é devido ao seu custo relativamente baixo, estética, o bom desempenho e fiabilidade, construção relativamente simples, e capacidade suporte de grandes solicitações; esta aceitação, somente terá um valor acrescentado, se forem usados para os aterros, solos locais (o material escavado na área a ser reforçada ou nas suas proximidades).

Tatsuoka e Yamauchi(1985) apud Patias et al. (2005), descrevem que a elaboração de projetos de solo reforçado, utilizando solos não convencionais, deve seguir 
recomendações rígidas que conduzam a um dimensionamento que leve em consideração as análises de estabilidade de curto e longo prazo

\subsubsection{Aplicação da técnica de terra armada}

A técnica de terra amada é aplicada na construção de encontro de pontes e viadutos, muros de arrimo, aterros e em todas as obras onde se faz necessário estabilizar material inconsolidado empilhado, como solo, minério, rejeito de mineração, etc.

\subsubsection{Vantagens da técnica de terra armada sobre outras técnicas}

A técnica permite resolver os problemas decorrentes de situações complexas e proporciona a melhor solução diante de configurações delicadas, tais como espaços exíguos, terrenos instáveis ou com fortes inclinações. A variedade de soluções permite satisfazer as exigências arquitetônicas. Assim, as obras são mais tolerantes a recalques diferenciais; mais tolerantes a abalos, como os sísmicos; permitem o uso de mão de obra local e não especializada; são fáceis de integrar-se nas exigências ambientais e ainda são de baixo custo comparado às outras técnicas.

Os muros de terra armada superam alturas maiores do que os muros convencionais e se valem da colocação gradual de terra para estruturar o terreno; são tecnicamente viáveis para alturas superiores a $25 \mathrm{~m}$.

Devido à elevada flexibilidade dos paramentos os maciços adaptam-se a fundações compressíveis, permitindo bem assentamentos diferenciais não admissíveis para as soluções rígidas clássicas de concreto armado e outras.

\subsubsection{Considerações da norma brasileira}

A norma brasileira NBR-9286/86 estabelece certos critérios para a seleção de materiais aplicados na execução de um sistema de terra armada (material de aterro, inclusões, escamas e acessórios complementares), não fazendo menção de fitas poliméricas.

Solo de aterro: normalmente constituído por solo arenoso. A seleção do material de aterro deve atender a critérios geotécnicos, químicos e eletroquímicos; Elementos de reforço (fitas metálicas): As fitas metálicas, comumente fabricadas em aço zincado com ou 
sem nervuras (Figura 4.4), são os elementos de reforço que transmitem as cargas da zona ativa para zona passiva, pelo atrito com o solo de aterro. Elas devem apresentar elevado coeficiente de atrito com o material de aterro, pequena deformabilidade sob carga de serviço (baixa fluência), elevada resistência a tração, com ruptura do tipo não frágil e grande alongamento na ruptura, flexibilidade suficiente de maneiras a não limitar a deformabilidade vertical do maciço, além de permitir facilidades construtivas e boa durabilidade.

Em Inclusões metálicas, deve ser observado o efeito da corrosão, neste caso sobre as fitas metálicas; as espessuras de sacrifício devem ser consideradas no dimensionamento dos muros em Terra Armada. As espessuras levam em consideração as condições ambientais em que as fitas trabalharão, sendo classificadas segundo a NBR-9286/86, em obras não inundáveis, obras inundáveis por água doce, obras inundáveis por água salgada e obras especiais, submetidas a condições de agressividade especiais (líquidos agressivos).

Dois critérios devem ser considerados na escolha do material de aterro: o atrito mecânico, relacionado com o atrito solo - fita metálica e o critério químico, relacionado com a durabilidade.

Em relação ao critério mecânico, a NBR 9286/86 estabelece duas principais características a serem observadas que são: o peso específico e o atrito de interface ( $f^{*}$ coeficiente de atrito aparente solo - fita metálica).

O coeficiente de atrito aparente solo - fita metálica (f*), é definido pela equação 1 , e é dependente da tensão tangencial máxima mobilizada no contato solo - fita metálica $\left(\tau_{\max }\right)$ e da tensão vertical efetiva média do nível considerado $\left(\sigma_{\mathrm{v}}\right)$. É ainda suposto que o coeficiente $\mathrm{f}^{*}$ não varia ao longo do comprimento do elemento.

$$
f^{*}=\frac{\tau_{\max }}{\sigma_{v}}
$$

Com a definição acima, são apresentados os critérios estabelecidos pela NBR 9286/86 para armaduras nervuradas (Tabela 4.2). 
Tabela 4.2-Critério mecânico para seleção do material de aterro para fitas metálicas nervuradas (NBR9286/86)

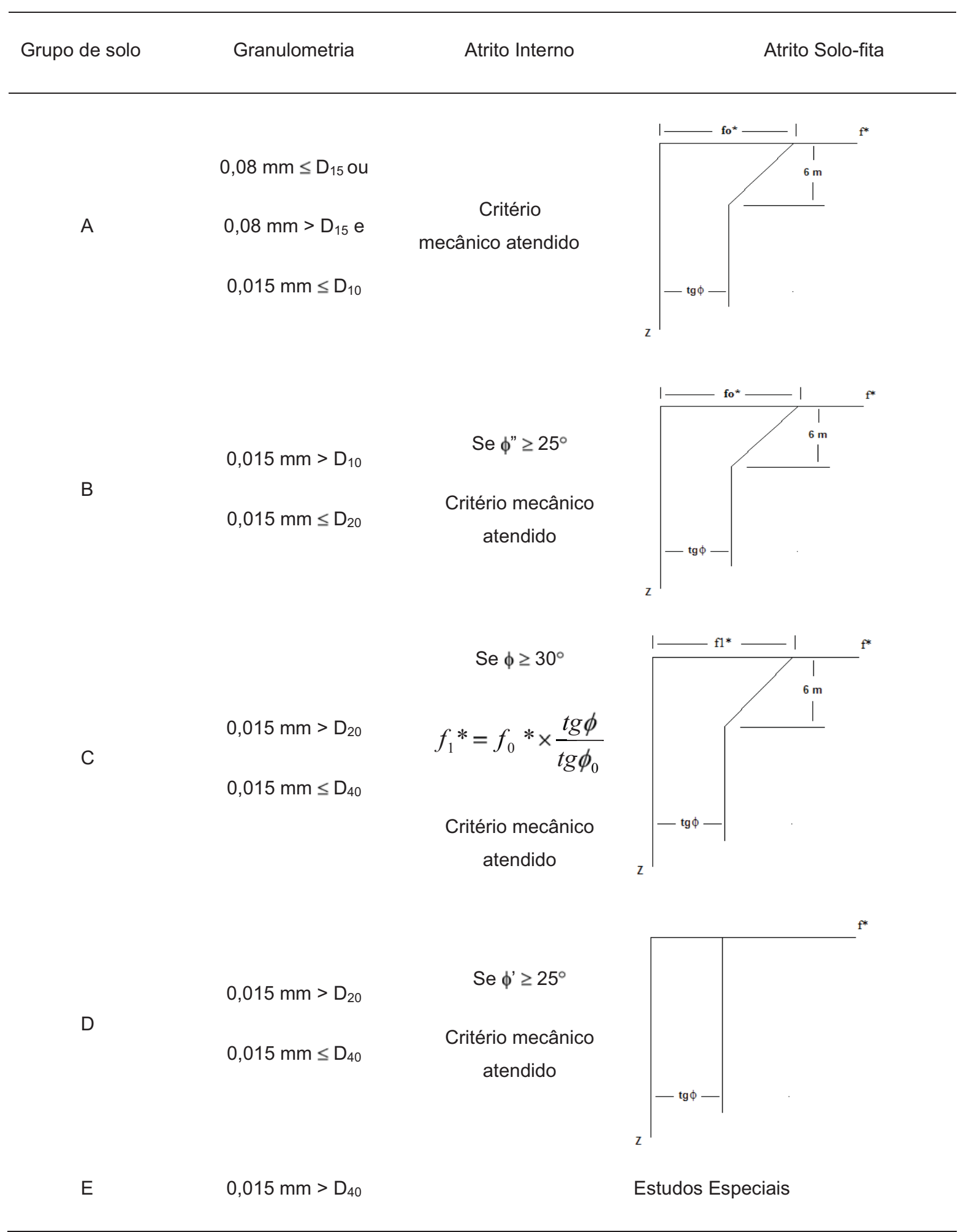


Em que,

1. $\phi=$ ângulo de atrito interno do solo, determinado por ensaio de cisalhamento rápido, sobre amostra moldada na umidade ótima e compactada até atingir 90\% do grau de compactação (Energia Proctor Normal).

2. $\phi^{\prime}=$ ângulo de atrito interno do solo, determinado por ensaio de cisalhamento rápido, pré-adensado sobre amostra saturada após moldagem na umidade ótima e compactada até atingir 90\% do grau de compactação (Energia Proctor Normal).

3. $\quad \phi^{\prime \prime}=$ ângulo de atrito interno do solo, determinado pelo efeito de correlação apenas, po ensaio de cisalhamento rápido, sobre amostra deformada, moldada na umidade correspondente ao limite de liquidez e depois comprimida a $200 \mathrm{KPa}$.

4. $\quad \mathrm{D}_{\mathrm{n}}=$ diâmetro correspondente a porcentagem passante de $\mathrm{n} \%$ na curva granulométrica.

Em aterros compactados, em que a granulometria atende aos critérios estabelecidos para os solos de tipo A e B da tabela 4.2, o valor de $\mathrm{f}^{*}$ varia em função da profundidade que se mede a partir do nível de altura mecânica. A variação de $\mathrm{f}^{*}$ segue a seguinte lei:

$$
\begin{aligned}
& f^{*}=f *_{0}\left(1-\frac{z}{z_{0}}\right)+\operatorname{tg} \phi_{0}\left(\frac{z}{z_{0}}\right), z<z_{0} \\
& f^{*}=\operatorname{tg} \phi, \text { para } z \geq z_{0}
\end{aligned}
$$

Considera-se $\mathrm{z}_{0}=6 \mathrm{~m}$; este valor de $\mathrm{z}_{0}$ foi considerado de acordo com uma série de ensaios em modelos reduzidos e medições em obras reais (NBR 9286/86).

O coeficiente $\mathrm{f}_{0}$ é avaliado pela expressão 4 .

$$
f *_{0}=1,5 \text { ou } f{ }^{*}=1,2 \log C u
$$

$\mathrm{Na}$ figura 4.10, no troço inclinado, da curva profundidade $v s$ coeficiente de atrito aparente solo- fita metálica (f*), que está em função de profundidade sofre a influência da dilatância do material de aterro nas vizinhanças da armadura, a influência da dilatância reduz com a profundidade e alcança valores desprezíveis quando a profundidade for igual a $\mathrm{Z}=6 \mathrm{~m}$. 


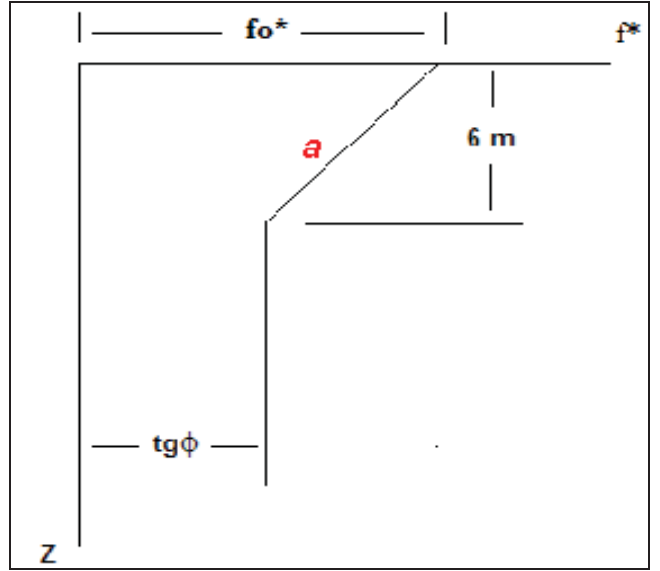

Figura 4.10 Efeito da dilatância do material de aterro nas vizinhanças da armadura

Interpretando melhor o critério mecânico de seleção para fitas metálicas nervuradas pode-se considerar possíveis faixas onde se enquadra a cada um dos grupos de solo, mostradas na figura 4.11 .

Deste ponto de vista, é importante ressaltar que, segundo o critério de norma o que comanda a classificação é a fração fina do solo.

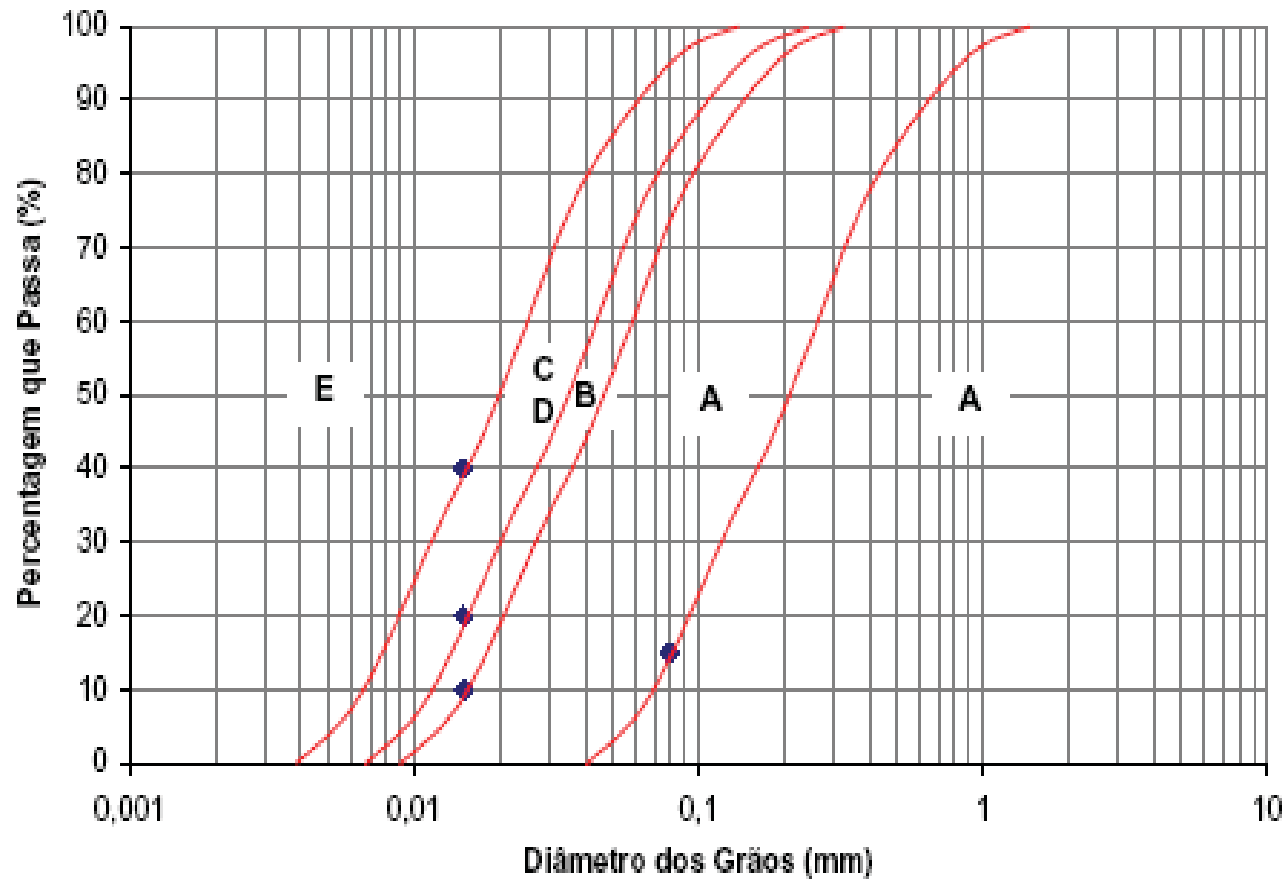

Figura 4.11- Possíveis faixas de classificação de grupos de solo para NBR 9286/86, (MIRANDA 2009).

Segundo o critério Químico, a tabela 4.3, apresenta características para o solo a ser empregado no aterro reforçado. 
Tabela 4.3- Critério químico para a seleção de material do aterro(NBR 9286/86).

\begin{tabular}{lll}
\hline Parâmetro Eletroquímico & Obras não Inundáveis & Obras Inundáveis \\
\hline Cloreto $\left(\mathrm{Cl}^{-}\right)$ & $<200 \mathrm{ppm}$ & $<100 \mathrm{ppm}$ \\
Sulfato $\left(\mathrm{SO}_{4}{ }^{-2}\right)$ & $<1000 \mathrm{ppm}$ & $<500 \mathrm{ppm}$ \\
Resistividade & $>1000 \mathrm{Ohm}-\mathrm{cm}$ & $>3000$ Ohm-cm \\
PH & $5-10$ & \\
& & \\
Matéria Orgânica & $<100 \mathrm{ppm}$ & \\
\end{tabular}

Quando se trata da utilização de material de aterro com uso de armaduras lisas; os critérios mecânicos estão definidos na tabela 4.4.

Tabela 4.4- Critérios mecânicos para a seleção do material de aterro para armaduras lisas.

\begin{tabular}{|c|c|c|c|}
\hline \multicolumn{2}{|l|}{$0,08 m m \leq D_{15}$} & \multicolumn{2}{|c|}{ Critério mecânico satisfeito } \\
\hline & $0,015 \mathrm{~mm} \leq \mathrm{D}_{10}$ & \multicolumn{2}{|c|}{ Critério mecânico satisfeito } \\
\hline \multirow{3}{*}{$0,08 m m>D_{15}$} & & $\delta \geq 22^{\circ}$ & Critério mecânico satisfeito \\
\hline & $\mathrm{D}_{20} \geq 0,015 \mathrm{~mm}>\mathrm{D}_{10}$ & $\delta<22^{\circ}$ & Utilização depende de estudos especiais \\
\hline & $0,015 \mathrm{~mm}>\mathrm{D}_{20}$ & \multicolumn{2}{|c|}{ Utilização depende de estudos especiais } \\
\hline
\end{tabular}

Queiroz (1996) buscou analisar critérios químicos e comparou solos de origem residual com a presença de finos. Estes solos foram submetidos a monitoramento do potencial do elétrodo e polarização eletroquímica em meio aquoso. Como resultados mostraram que os solos finos, ditos alternativos, apresentavam comportamento equivalente do ponto de vista de resistência a corrosão aos solos convencionais arenosos.

A NBR 9286/86 estabelece que possam ser utilizados solos naturais ou materiais de origem industrial, porém não devem conter terra vegetal, não tão poucos detritos domésticos e que possuam dimensão máxima dos grãos de $258 \mathrm{~mm}$. O grau de compactação mínimo exigido é $95 \%$. 


\subsection{Considerações de projeto em terra armada}

Em muitos casos o dimensionamento de estruturas de terra armada se assenta fundamentalmente em observações empíricas obtidas através da instrumentação de obras e a partir de ensaios em modelos reduzidos. A quantidade de fatores que influenciam o comportamento dos muros de terra armada é extensa, sendo por isso conveniente o desenvolvimento de modelos numéricos que facilitem e permitam aprofundar o seu estudo. Naturalmente que esses modelos numéricos deverão ser validados comparando os resultados por eles obtidos com os experimentais, (CLITO 1992).

Para o dimensionamento do maciço de Terra Armada é geralmente dividido em duas partes: a verificação da estabilidade externa e a verificação da estabilidade interna.

$\mathrm{Na}$ verificação da estabilidade externa, devem ser avaliados os mecanismos clássicos de instabilidade de estrutura de contenção: Deslizamento da base da estrutura, tombamento da estrutura e capacidade de carga do solo de fundação, bem como o mecanismo de ruptura global.

A estabilidade interna é verificada pelo chamado método de equilíbrio local, em que cada camada de reforço é analisada de forma independente. No cálculo da estabilidade interna, três condições devem ser verificadas; verificar se ocorrerá corrosão do aço e consequentemente diminuição da área da seção da fita segundo a tabela 4.5, ruptura e arrancamento do reforço. Estas duas condições fornecerão como resultados, respectivamente, a concentração do reforço (espaçamento horizontal e o comprimento das camadas do reforço). O espaçamento vertical geralmente é fixado em $0,75 \mathrm{~m}$ devido às características geométricas das placas.

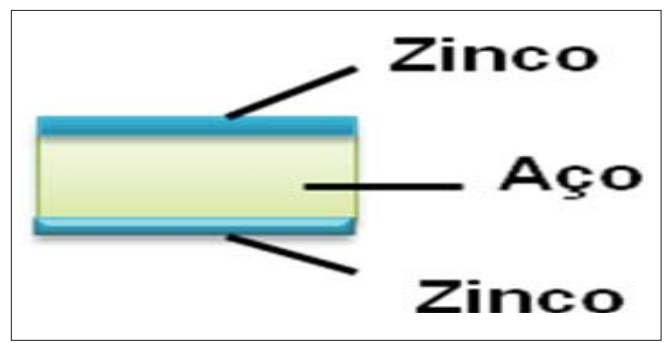

Figura 4.12 -Composição da fita metálica 
Tabela 4.5- Processo de corrosão da fita metálica

\begin{tabular}{lcc}
\hline Corrosão & Primeiros 2 anos $(\mu \mathrm{m} / \mathrm{ano})$ & Anos posteriores $(\mu \mathrm{m} / \mathrm{ano})$ \\
\hline Zinco & 6 & 2 \\
Aço carbônico & 45 & 9 \\
\hline
\end{tabular}

\subsubsection{Bases}

Ressalta-se que todos os conceitos abordados devem seguir, no mínimo, as prescrições da NBR9286/1986.

O funcionamento do sistema Terra Armada se baseia na existência de atrito entre o solo de aterro e as armaduras (fitas). A justificativa se dá a partir da resistência ao cisalhamento dos solos, considerada nas mais adversas umidades que a obra possa vir a ser submetida.

Inicialmente é feito um pré-dimensionamento e após, verifica-se as estabilidades externa e interna do sistema. Se necessário, o processo seguirá por iterações sucessivas, fixando novos pré-dimensionamentos.

\subsubsection{Geometria}

De acordo com a experiência disponível e de resultados experimentais sobre muros em escalas reais; as dimensões $\mathrm{L}$ e $\mathrm{H}$ devem obedecer às relações seguintes:

1. $\mathrm{L} / \mathrm{H}>0,5$ para obras convencionais $\mathrm{e}$

2. $\mathrm{L} / \mathrm{H}>07$ para obras especiais (Encontros portantes, Barragens e outras).

\subsubsection{Ficha}

$\mathrm{O}$ risco de ruptura do solo de fundação junto ao paramento, a possibilidade de descalçamento da obra, fuga de materiais finos, entre outros, impõem a adoção de um embutimento da parede de paramento no solo e que se denomina ficha.

Segundo a NBR9286/1996, em condições normais, não havendo evidência de outros riscos à estabilidade do solo de fundação, adota-se o seguinte critério de ficha (D):

1. $\mathrm{D}_{\min }=0,40 \mathrm{~m}$ ou 
2. $\mathrm{D}=0,1 \mathrm{H}$ quando o terreno a jusante do maciço for horizontal e

3. $\mathrm{D}=0,1$ a $0,2 \mathrm{H}$ quando o terreno a jusante do maciço for inclinado.

\subsubsection{Espaçamento das inclusões metálicas (fitas)}

Para o pré-dimensionamento, devemos estimar um espaçamento vertical $\left(\mathrm{S}_{\mathrm{v}}\right)$ entre as inclusões para mais adiante verificar-se a segurança interna.

\subsubsection{Corrosão das inclusões}

Para a verificação da segurança interna contra o arrancamento e ruptura das inclusões, deve-se considerar uma espessura de sacrifício em função da vida útil da obra, que reduzirá a seção transversal e a largura da fita. Para o cálculo da corrosão é sugerida na tabela 6 .

A NBR 9286/1986, sugere uma espessura de sacrifício “e " conforme a vida útil da obra, tipo de obra, tipo de inclusão (com ou sem revestimento zincado) e da agressividade do meio. O cálculo de "e "s" é feito segundo as recomendações da Tabela 4.6, encontrados na NBR 9286/1996, que fixa valores para obras com vida útil máxima de 70 anos, a obtenção de "e $\mathrm{s}_{\mathrm{s}}$ " é muitas das vezes feita por extrapolação dos critérios da norma. Assim, o cálculo de "es" é feito por duas formas, e adotado o maior valor da corrosão.

A espessura do sacrifício $\mathrm{e}_{\mathrm{s}}$ : (suscetível à corrosão) é dada por

$$
e_{c}=e_{n}-e_{s}
$$

Onde: $e_{c}$ é a espessura de cálculo e e $\mathrm{n}_{\mathrm{n}}$ : espessura nominal. 
Tabela 4.6- Espessura de sacrifício.

\begin{tabular}{|c|c|c|c|c|c|c|}
\hline \multirow[b]{3}{*}{ Vida útil mínima da obra (anos) } & \multicolumn{6}{|c|}{ Espessura do sacrifício (mm) } \\
\hline & \multicolumn{3}{|c|}{ Aço galvanizado } & \multicolumn{3}{|c|}{ Aço sem revestimento } \\
\hline & 5 & 30 & 70 & 5 & 30 & 70 \\
\hline Obras não inundáveis & 0 & 0,5 & 1,0 & 0,5 & 1,5 & 3,0 \\
\hline Obras inundáveis por água doce & 0 & 1,0 & 1,5 & 0,5 & 2,0 & 4,0 \\
\hline Obras inundáveis por água salgada & 0 & $\left({ }^{*}\right)$ & $(*)$ & 1,0 & 3,0 & 5,0 \\
\hline Obras Especiais & \multicolumn{6}{|c|}{ pecial } \\
\hline
\end{tabular}

\subsubsection{Esforços de tração nas armaduras}

Numerosos ensaios e experimentos têm evidenciado que a distribuição de tensões de tração nos diversos níveis de profundidade não ocorre no ponto de fixação da armadura, no paramento, e sim no interior do maciço. A figura 4.13 mostra as diferentes situaçõess de carregamentos em terra armada.

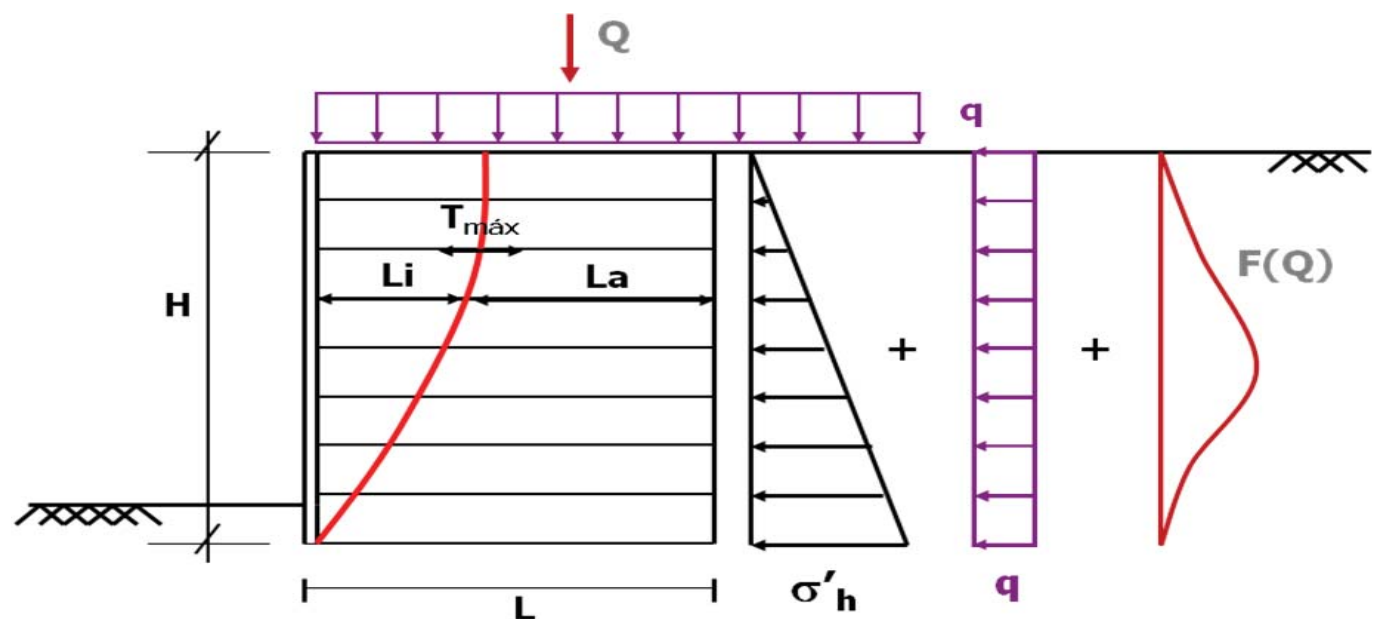

Figura 4.13-Carregamentos e diagramas de esforços( BUENO)

Onde,

$\tau_{\text {max }}=$ Tensão máxima de tração 
$\mathrm{L}_{\mathrm{a}}=$ comprimento de arrancamento

\subsubsection{Tensões de tração nas inclusões}

Para a determinação do lugar geométrico dos pontos de tração máxima, têm-se duas metodologias propostas: Terra Armada e NBR 9286/1986. As duas metodologias são apresentadas na figura 4.14 .

A metodologia da Terra Armada sugere um modelo de ruptura triângulo-retângulo, com valores em função da profundidade de cada inclusão. A proposta da norma brasileira adota um modelo de ruptura triangular - trapezoidal com valores do comprimento de arrancamento também em função da altura.

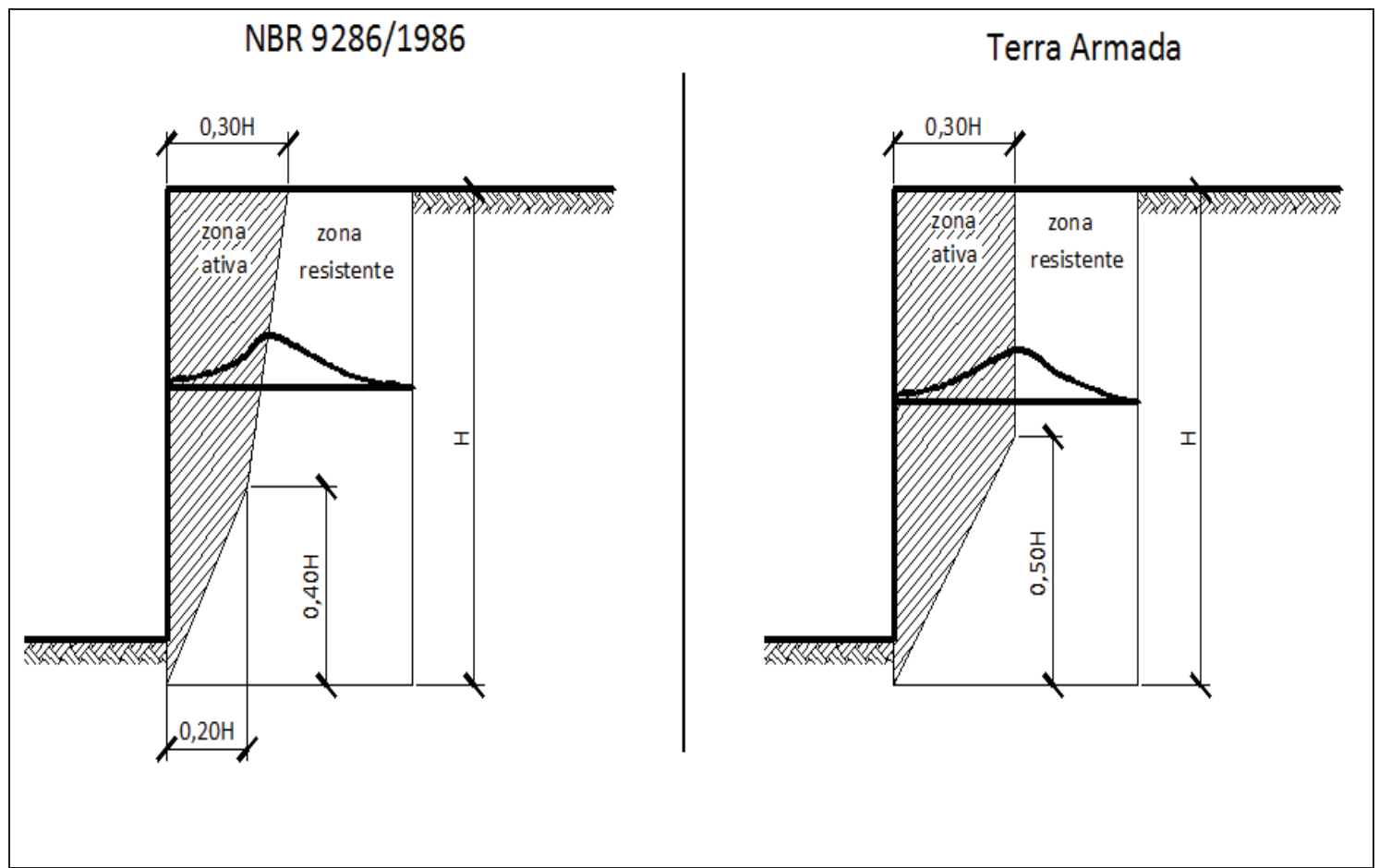

Figura 4.14- Mecanismos de ruptura

\subsubsection{Coeficiente de empuxo}

Para a determinação da força horizontal atuante em cada fita, é necessário calcular o coeficiente de empuxo $(\mathrm{K})$ ao longo da profundidade. 
Constatou-se que $K$ varia do valor de repouso até o valor de empuxo ativo de 0 a $6 \mathrm{~m}$ de profundidade, ou seja, quanto mais próximo à superfície, a tensão horizontal $\left(\sigma_{h}\right)$ tenderá a $K_{0} \cdot \sigma_{v}$, e após $6 \mathrm{~m}$ tenderá a $K_{a} \cdot \sigma_{h}$. A figura 4.15 mostra o esquema da variação do coeficiente de empuxo com a profundidade.

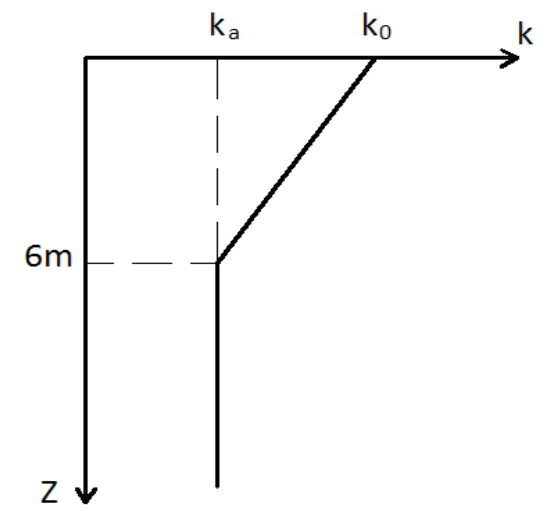

Figura 4.15- Variação do coeficiente de empuxo ativo com a profundidade

Para $6 \mathrm{~m}>\mathrm{z}: \quad K=K_{a}+\left(\frac{6-z}{6}\right) \cdot\left(K_{0}-K_{a}\right)$

Para z $>6 \mathrm{~m}: K=K_{a}$

$K_{0}=1-\sin \phi_{\text {aterro }}$

$K_{a}=\tan ^{2}\left(45^{\circ}-\phi_{\text {aterro }} / 2\right)$

\subsubsection{Coeficiente de atrito aparente solo-fita}

O coeficiente de atrito aparente solo-fita ( $\left.\mathrm{f}^{*}\right)$, utilizado na determinação da resistência ao arrancamento das inclusões, deve ser suposto constante ao longo de uma determinada armadura. Para os aterros compactados cuja granulometria atenda aos critérios definidos para solos tipo A e B da (Tabela 2) da NBR 9286/1986, o valor de $f^{*}$ varia em função da profundidade conforme e equações 3 e 4; considerando as condições da figura 4.15 em que $Z_{0}=6,00 \mathrm{~m}$. Na falta de dados mais específicos adota-se o valor de $f^{*}=1,5$.

Autores como Schlosser e Elias (1978) apud Felix (1991), Alimi et al (1977) e Bacot et al (1978), depois de realizarem ensaios de arrancamento para estudarem a resistência da interface solo-inclusão; verificaram que: 
- O coeficiente de atrito aparente solo-inclusão aumenta com o aumento do comprimento da inclusão tendo indicado dois motivos relacionados com esse aumento:

a) $\mathrm{O}$ aumento de $\mathrm{f}^{*}$ é devido à tensão normal próximo a face de um aterro ser menor do que no interior do maciço

b) Para as inclusões nervuradas, esse aumento de $\mathrm{f}^{*}$ é também devido ao aumento das ondulações médias das armaduras na medida em que aumenta o seu comprimento.

- O coeficiente de atrito aparente solo-inclusão diminui com o aumento da largura das inclusões, para solos granulares; concluindo-se que em média, o crescimento das tensões normais induzido pela dilatância é menor para as armaduras largas do que em armaduras estreitas.

\subsubsection{Análise da estabilidade externa}

Os maciços de Terra Armada se assemelham às obras de contenção por gravidade, exceto ao que se refere à capacidade de tolerar deformações, sensivelmente maiores do que aquelas suportadas pelas estruturas convencionais. Devem ser feitas análises de fator de segurança mínimos em relação a eventos de deslizamento, tombamento, capacidade de carga da fundação e estabilidade global que será analisada após a verificação interna.

Para efetuarem-se as análises, primeiramente é necessário determinar os esforços atuantes devido ao empuxo (E) provocado pelo maciço de solo natural e sobrecarga. Para a determinação do empuxo, porém, antes precisa-se calcular o coeficiente de empuxo $(\mathrm{K})$, que no caso será o coeficiente de empuxo ativo $\left(\mathrm{K}_{\mathrm{a}}\right)$.

$$
\begin{aligned}
& \mathrm{K}_{0}=1-\sin \varphi_{\text {solo.natural }} \\
& K_{a}=\tan ^{2} 45-\varphi_{\text {solo.natural }} / 2 \\
& E=\frac{K_{a} \cdot \gamma_{\text {solonatural }} \cdot H^{2}}{2}+K_{a} \cdot q
\end{aligned}
$$

Um tópico a ser dada importância é a consideração ou não da contribuição da ficha à resistência do sistema. É prática comum não se considerar a ficha na verificação externa, 
por questão de segurança, devido à possibilidade de erosão da mesma fícha ao longo do tempo, problemas na compactação e outros.

\subsubsection{Segurança ao Deslizamento}

Quanto ao deslizamento, deve-se verificar a capacidade resistente ao deslizamento do maciço devida ao atrito, sob um fator de segurança mínimo de 1,50.

$$
F S_{S}=\frac{\sum F_{H R}}{\sum \text { Empuxos }}=\frac{c+(W+q) \cdot \tan \varphi_{\text {menor }}}{E}=\frac{c+(\gamma \cdot H \cdot L+q) \tan \varphi_{\text {menor }}}{E} \geq 1,50 \text { (Eq. 13) }
$$

O equacionamento adota o menor valor entre os dois ângulos de atrito, pois a resistência ao deslizamento é desenvolvida na interface solo natural-aterro, desta forma é sugerido adotar-se o menor valor dentre os dois solos.

\subsubsection{Segurança Ao Tombamento}

A verificação ao tombamento deve ser feita com a relação entre a resistência devida ao momento das forças verticais (em relação ao ponto de interseção da base e a face exterior do aterro) e sentido para baixo, com os momentos atuantes provenientes do carregamento externo e forças verticais contrárias à estabilidade. O fator de segurança deve ser maior ou igual a 2,00. A figura 4.16 mostra o esquema para análise de segurança.

$$
F S=\frac{\sum M_{F_{V}}}{\sum M_{\text {empuxos }}}=\frac{\sum(W+q) \cdot b_{F_{V}}}{\sum\left(E . b_{E}\right)} \geq 2,00
$$




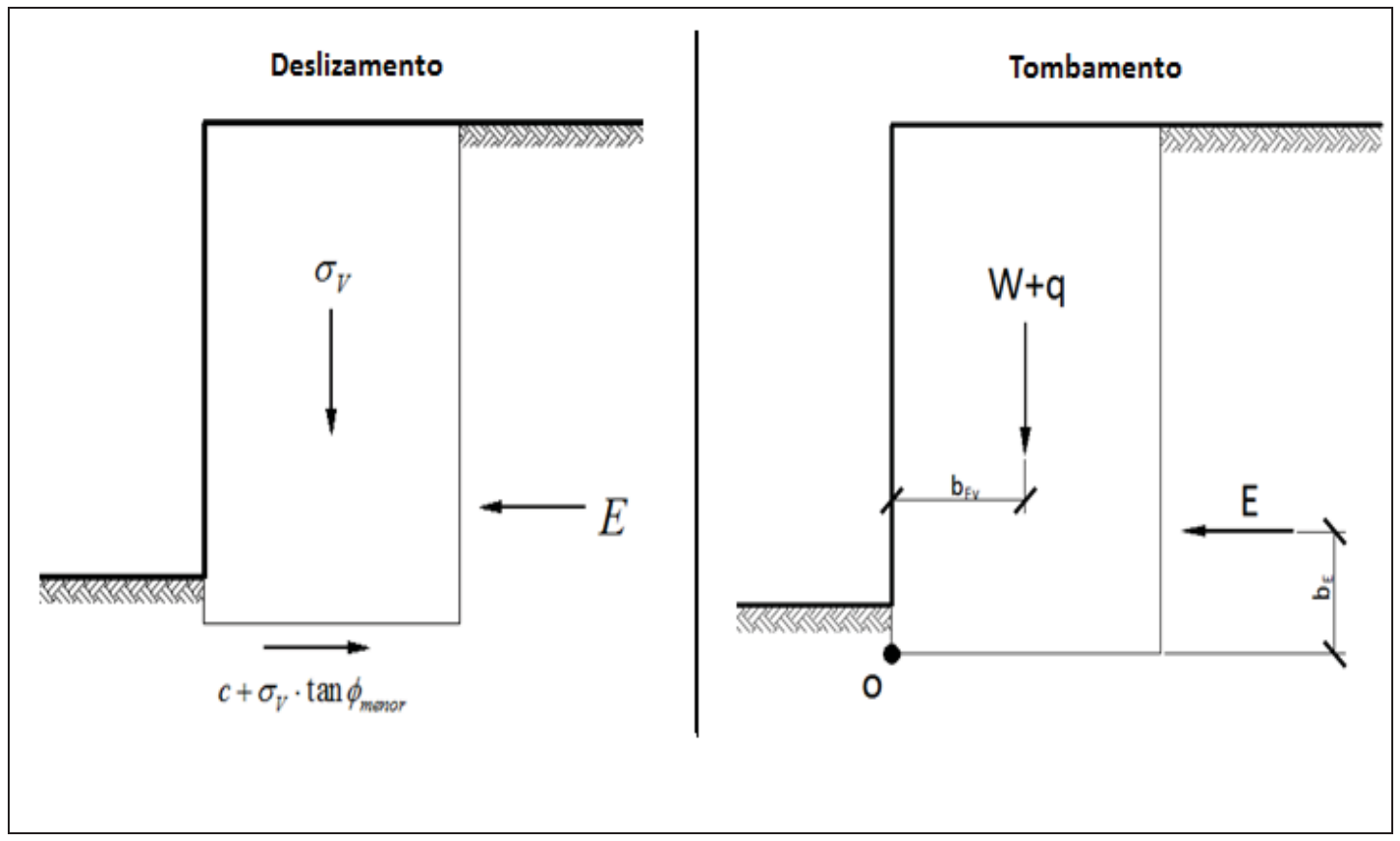

Figura 4.16 - Segurança ao deslizamento e tombamento

\subsubsection{Segurança do solo de fundação}

Para a verificação da segurança à ruptura do solo de fundação, deve-se assegurar que a pressão vertical aplicada seja inferior à pressão admissível, obtida da pressão de ruptura do solo. Ou seja, a razão da resistência de ruptura do solo de fundação com o carregamento aplicado à fundação deve ser maior que o fator de segurança mínimo de 2,00. É recomendável considerar uma redução na área da base de fundação (aumenta-se assim a tensão aplicada ao solo) devido ao efeito de excentricidade, que pode ser feita através da solução de Meyerhof (Meyerhof apud Cintra et. al., 2003), como mostra a figura 4.17.

$e=\frac{E \cdot b_{E}}{\gamma \cdot H L+q \cdot L} \rightarrow L$

A resistência à ruptura do solo pode ser determinada através de ensaios in situ, laboratório ou formulações como $F S_{B C}=\frac{\sigma_{r}}{\sigma_{a}}=\frac{\sigma_{r}}{\gamma \cdot H \cdot L+q \cdot L /[L-2 e . b]} \geq 2,00$ (Eq. 16) de Terzaghi modificada por Meyerhof apud Cintra 2003. 


$$
\begin{aligned}
& \sum M=0 \rightarrow R_{V} \cdot e=E \cdot b_{E} \rightarrow e=\frac{E \cdot b_{E}}{\gamma \cdot H \cdot L+q \cdot L} \rightarrow L \\
& e_{\text {máx }}=L / 6=e \\
& \sigma_{r}=C \cdot N_{c} \cdot S_{c}+q \cdot N_{q} \cdot S_{q}+0,5 \cdot \gamma \cdot N_{\gamma} \cdot(L-2 \cdot e) \cdot S_{\gamma} \\
& F S_{B C}=\frac{\sigma_{r}}{\sigma_{a}}=\frac{\sigma_{r}}{\gamma \cdot H \cdot L+q \cdot L /[L-2 e \cdot b]} \geq 2,00
\end{aligned}
$$

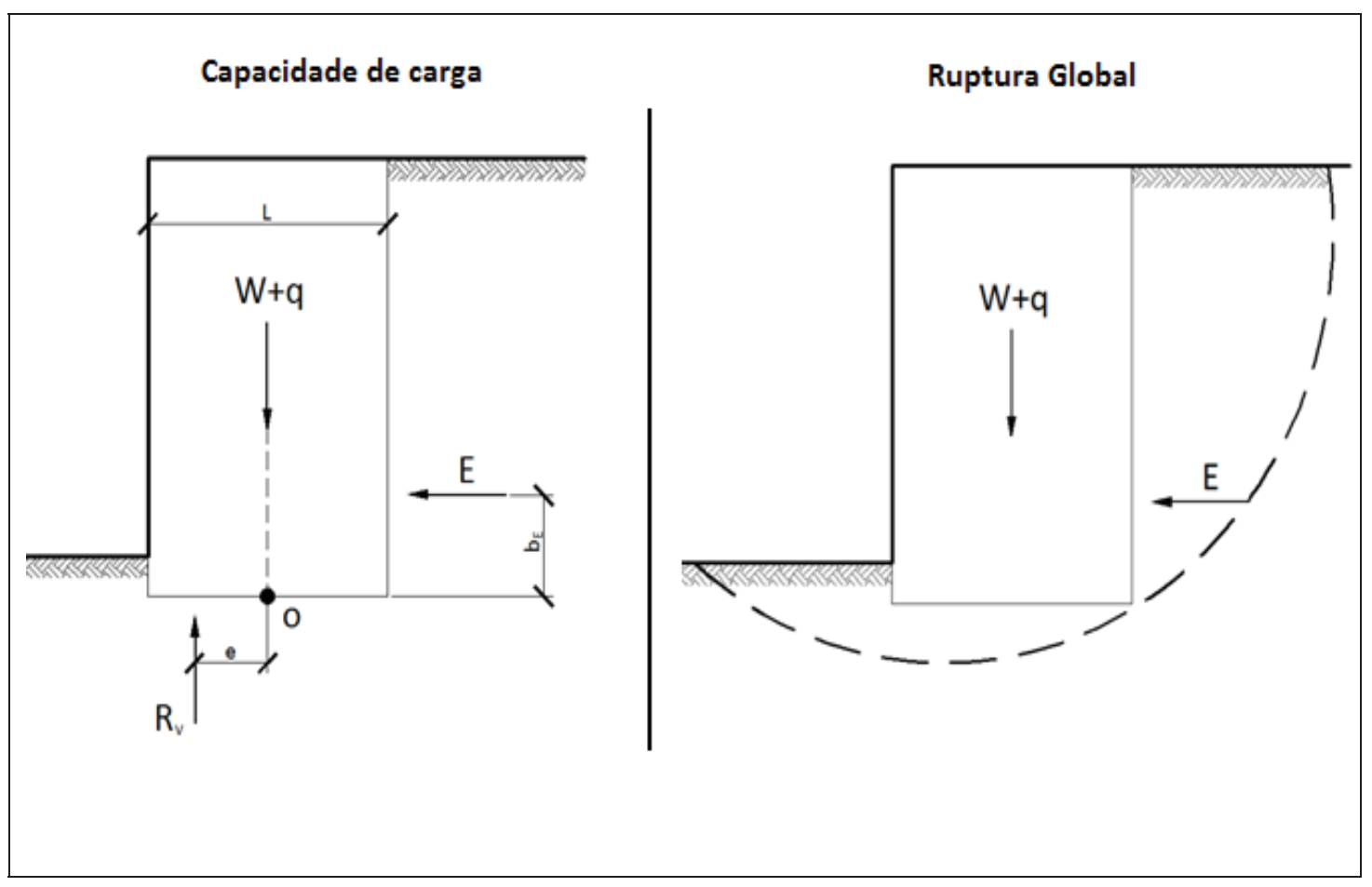

Figura 4.17 - Segurança da fundação e ruptura global

\subsubsection{Segurança Global}

Da mesma forma que se analisa qualquer obra de contenção, deve-se verificar a segurança contra a ruptura ao longo de grandes superfícies que envolvem o sistema, principalmente em encostas e locais de subsolo fraco. O cálculo normalmente é feito considerando superfícies circulares. Na ocorrência de grande variabilidade de camadas e resistências, deve-se proceder a verificação com modelos de superfícies não-circulares. $\mathrm{O}$ fator de segurança mínimo normalizado é de 1,50. 


\subsubsection{Análise da estabilidade interna}

Devido ao atrito que se desenvolve entre o solo e as armaduras, as armaduras são solicitadas à tração, conferindo ao sistema, uma coesão aparente na direção das armaduras e proporcional à sua densidade e resistência

Basicamente deve-se verificar a segurança do sistema em relação à ruptura das inclusões e ao arrancamento das mesmas.

\subsubsection{Ruptura das inclusões}

É necessário calcular a força de tração máxima nas armaduras $\left(\mathbf{F}_{\mathbf{h}}\right)$ originada pelas tensões atuantes dentro do maciço. No ponto de tração máxima na fita, a tensão tangencial entre o solo e a fita (cisalhante) é nula, então as tensões, horizontal e vertical são principais. Desta forma, a tensão horizontal $\left(\sigma_{3}\right)$, (figura) 4.18 , é equilibrada pela armadura ao longo da linha de trações máximas. A força máxima de tração atuante na fita será definida então por:

$$
F_{h}=A_{\text {influencia }} \cdot K \cdot \sigma_{v}^{\prime}=\Delta H \cdot K \cdot \sigma_{v}
$$

A área de influência não será a mesma para cada inclusão como exemplifica a figura 4.18. O cálculo da área de influência é feito por:

$$
A_{\text {influencia }}=\Delta H \cdot 1
$$

A determinação da tensão vertical em cada inclusão pode ser feita através da solução proposta por Meyerhof apud. Cintra considera-se efeito da excentricidade:

$$
\begin{aligned}
& \sigma_{v b}^{\prime}=\frac{W_{z}+q \cdot L \cdot z}{L-2 e} \\
& e_{z}=\frac{E_{z} \cdot b_{z}}{W_{z}+q} \\
& E_{z}=\frac{K_{z} \cdot \gamma \cdot z^{2}}{2}
\end{aligned}
$$


A carga de escoamento da armadura é considerada a mesma do aço de construção civil CA50 (500 MPa), então a máxima resistência $(\tau)$ à uma força de tração na fita é dada para duas expressões, uma para o lugar geométrico das trações máximas:

$$
\begin{aligned}
& \tau=A_{\text {fita }} \cdot \sigma_{T i} \\
& \sigma_{T i} \leq \sigma_{y} / \gamma_{r} \rightarrow \sigma_{T i}=500 / 1,5 \\
& A_{f i t a}=\text { Largura da fita x Espessura da fita }
\end{aligned}
$$

E outra para a seção de ligação com o paramento: a tensão atuante na zona da conexão é menor que a tração máxima, portanto utiliza-se uma redução pelo fator $\alpha$ (item 5.1.3.3.3 NBR 9286/1986). A resistência na seção da conexão $\left(\sigma_{\text {ci }}\right)$ deve ser minorada. Para este caso, o valor de $\alpha$ será anulado com 0,85 , no entanto, a NBR sugere valores diferenciados para cada caso sugerido em seu texto.

$$
\begin{aligned}
& \sigma_{h_{\text {conexao }}}=\frac{\alpha \cdot F_{h}}{A_{\text {ligação }}}=\frac{\alpha \cdot F_{h}}{\left(\operatorname{Larg}_{\text {fita }}-\phi_{\text {parafuso }}\right) \cdot e s p_{\text {fita }}} \\
& \sigma_{c i}=\sigma_{T i} \cdot 0,85
\end{aligned}
$$

A verificação do fator de segurança $(\mathrm{FS} \geq 1,5)$ à ruptura das inclusões então é dada por:

$$
\begin{aligned}
& F S_{R}=\frac{T}{F_{h}} \geq 1,50 \\
& F S_{R_{\text {conexao }}}=\frac{\sigma_{c i}}{\sigma_{\text {conexao }}} \geq 1,50
\end{aligned}
$$

A figura 4.18 mostra o esquema do andamento das trações ao longo de cada fita, numa obra de terra armada. 


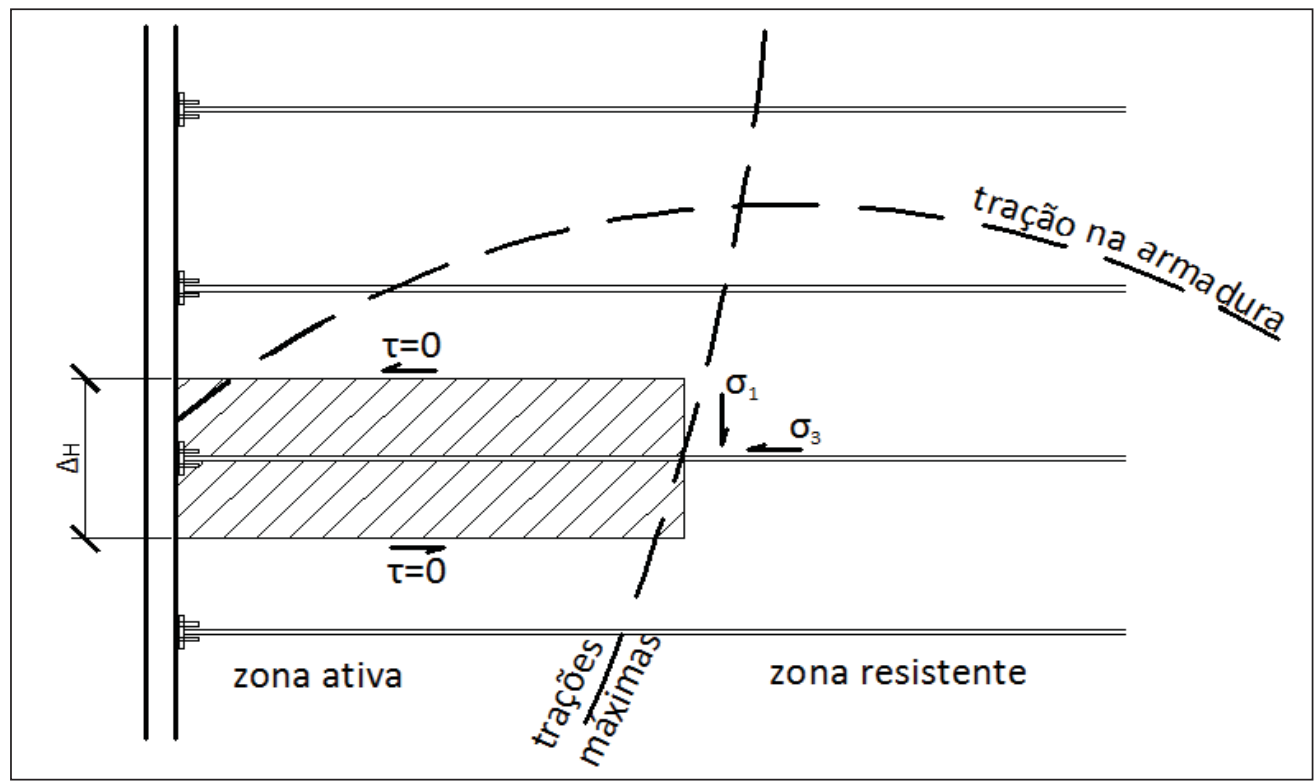

Figura 4.18 - Tração máxima em cada armadura (NBR: 9286/1986)

\subsubsection{Ruptura por arrancamento}

A verificação da ruptura por arrancamento visa assegurar que as armaduras não deslizem quando submetidas ao esforço de tração. Para isso a força de tração $\mathrm{F}_{\mathrm{h}}$ deve então ser igual a uma força limite que é definida por:

$$
\begin{aligned}
& F_{A R R}=2 \cdot L \arg _{\text {fita }} \cdot L_{a n c} \cdot\left(c_{a}+\sigma_{v}^{\prime} \cdot f\right) \\
& L_{a n c}=\text { comprimento na zona resistente: } L_{\text {anc }}=\mid \begin{array}{l}
N B R \\
T \cdot \text { Armada }
\end{array} \\
& F S_{A R R}=\frac{F_{A R R}}{F_{h}} \geq 1,5
\end{aligned}
$$

\subsubsection{Ensaios de arrancamento}

Segundo Felix (1992), a distribuição das trações feitas nas armaduras sujeitas a ensaios de arrancamento apresenta algumas diferenças importantes em relação a que se observa nas obras reais de reforços de solos; porque para os muros de terra armada é possível identificar no maciço reforçado duas zonas bem distintas: zona ativa, na qual as tensões tangenciais são transferidas do solo para as armaduras e a zona resistente em que, as trações nas inclusões vão diminuindo até as suas extremidades posteriores, devido as tensões tangenciais reativas mobilizadas nas interfaces. $\mathrm{O}$ autor ainda realça o fato de os 
campos de deslocamentos nas obras de reforço serem completamente distintos aos dos ensaios de arrancamento; posto que, quando se trata de ensaios de arrancamento, os únicos movimentos do maciço, são os induzidos pelas forças transmitidas ao solo pelas armaduras tracionadas enquanto que nas obras reais, há coexistência deste tipo com os deslocamentos globais causadas pela construção, o que significa que nas obras geralmente as tensões tangenciais mais elevadas começam a ser mobilizadas nas extremidades posteriores, acontecendo o contrário nos ensaios de arrancamento.

Segundo Palmeira e Milligan (1989), o ensaio de arrancamento é o que melhor representa as situações reais de campo, quando são utilizadas geogrelhas como elementos de reforço.

Para que os ensaios de arrancamento em laboratórios sejam representativos é necessário reproduzir adequadamente as características do solo e as de instalação dos reforços que sejam semelhantes às duma obra real, pois isso é determinante para a interação solo-reforço. Os ensaios de arrancamento permitem a obtenção de informações sobre os valores médios das características mecânicas representadas em curvas de variação das forças de arrancamento com os deslocamentos.

A geometria de um projeto em terra armada é determinante no desempenho da obra. A distribuição das fitas metálicas ao longo da face do talude, a determinação dos espaçamentos horizontal e vertical, o comprimento e rugosidade (superfície lisa ou nervurada) das fitas influenciam bastante ao comportamento do maciço. Esses parâmetros dependem diretamente da previsão das cargas máximas de trabalho das fitas que, por sua vez, são função do atrito na interface solo fita (f*). A fim de se determinar estes parâmetros, alguns ensaios e correlações empíricas são propostos.

Para a obtenção de um bom resultado em ensaios de arrancamento é preciso garantir a existência de equipamentos de boa qualidade precisão e eficiência na medição. Os equipamentos devem ser usados de forma a otimizar a sua aplicação; para isso devem ser distribuídos e instalados de uma forma objetiva e cuidadosa.

Leite (2007). Apud Miranda (2010); em estudos de arrancamentos para solos grampeados, refere que é de extremo interesse o conhecimento da distribuição das tensões desenvolvidas ao longo do grampo, a fim de que se possa prever o comportamento da estrutura no processo da estabilização do terreno. Parque quando bem determinadas, esta 
distribuição, é possível identificar o comprimento real do reforço que estará sendo solicitado à tração a medida em que o solo circundante tende a se deslocar.

O uso da instrumentação consiste no monitoramento das deformações, com destaque para o uso de strain gages, pela sua versatilidade de aplicação, precisão das medidas e facilidade de manipulação. Além disso, são capazes de monitorar as deformações até as cargas últimas em ensaios destrutivos (MIRANDA 2009).

Nas fitas metálicas usadas como reforço em terra armada, é muito importante o uso dos strain gages para a percepção do andamento das tensões de tração ao longo da fita durante o processo de arranque; para além dos strain gages, torna-se necessário o uso de células de tensão total para a simulação das profundidades onde as inclusões estão inseridas. A colocação e manuseamento desses sensores durante os ensaios quando não feitos com muito cuidado podem comprometer as leituras e consequentemente conduzir a resultados deturpados ou fora da realidade do que seria de esperar. Muitas vezes é preciso ter algumas aulas de eletrônica para entender como trabalhar com todos os materiais auxiliares dos sensores, de modo a garantir um bom controlo de procedimentos de conexões. Necessário é também o cuidado com procedimentos relacionados com as calibrações, principalmente dos strain gages, que são feitos relacionados três gráficos diferentes para o apuramento das tensões e deformações correspondentes na curva tensão vs deformação.

Com os ensaios de arrancamento bem instrumentados é possível avaliar os efeitos das tensões de tração resultantes dos arrancamentos sobre as fitas e saber-se sobre as limitações a impor no que concerne aos carregamentos, isso é possível usando sensores como strain gages, células de tensão e células de cargas apropriadas e em pontos bem localizados. 


\section{MATERIAIS E MÉTODOS}

\subsection{Introdução}

Este capítulo trata dos materiais e métodos usados para a execução da parte experimental da pesquisa, Foram realizados ensaios de laboratório para a caracterização dos solos e posteriormente os ensaios de cisalhamento direto e os ensaios tri-axiais; seguidos de ensaios de arrancamento; estes últimos com o objetivo de avaliar a interação solo - fita metálica e solo - fita polimérica. A figura 5.1 mostra o esquema dos trabalhos realizados.

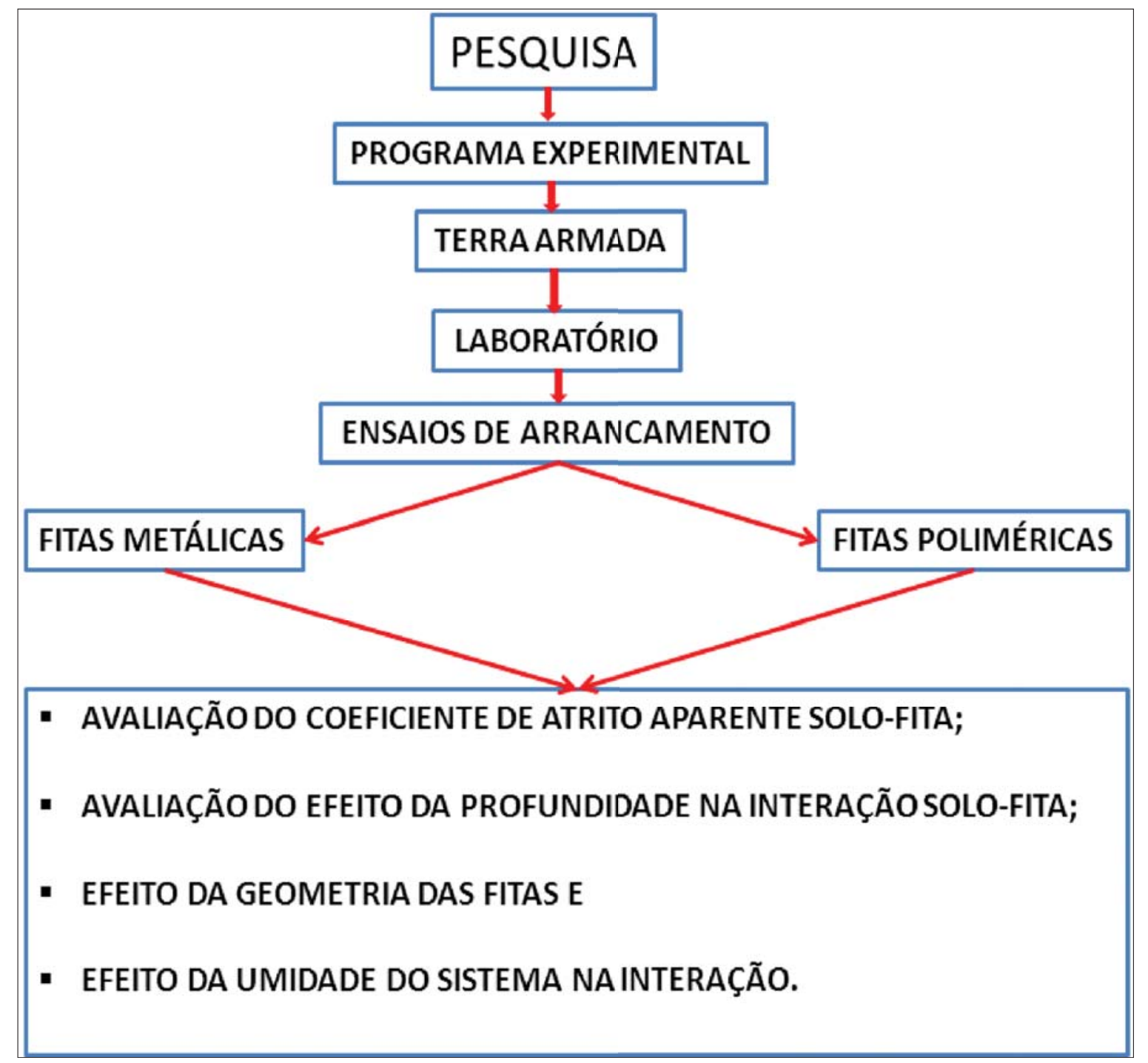

Figura 5.1- Esquema dos trabalhos realizados 


\subsection{Materiais}

Para a realização dos ensaios de arrancamento, em laboratório foi necessário, para além da caixa de ensaios de arrancamento, os materiais e equipamentos abaixo mencionados e descritos:

\subsubsection{Fitas metálicas;}

As fitas metálicas usadas foram fornecidas pela empresa Contern Construções e Comércios 1tda; são fitas nervuradas de aço com o comprimento de $1.480 \mathrm{~mm}$, larguras de $40 \mathrm{~mm}$ e $60 \mathrm{~mm}$, tendo espessura de $40 \mathrm{~mm}$.

\subsubsection{Fitas poliméricas}

As fitas poliméricas foram fornecidas pela Maccaferri; com dimensões usados foram de $1.400 \mathrm{~mm}$ de comprimento dentro do maciço mais $350 \mathrm{~mm}$ para a conecção com a garra de arrancamento; larguras de 47 e $50 \mathrm{~mm}$; tendo uma superfície rugosa.

\subsubsection{Placa de reação de aço}

A placa de aço foi concebida junto com a caixa, para reagir à pressão exercida pela bolsa de ar; é fixada na caixa através de parafusos; serve de tampa para a caixa.

\subsubsection{Célula de carga}

Foi usada uma célula de carga de aço, modelo KS 5.000; concebida para a medição de pesos e forças nos sentidos de tração e compressão, para aplicação em laboratórios e indústrias; a mesma usada durante atração das fitas metálicas e poliméricas no processo de calibração. A Tabela 5.1 e a Figura 5.2 mostram as características da célula de carga e o seu desenho esquemático, respectivamente. 

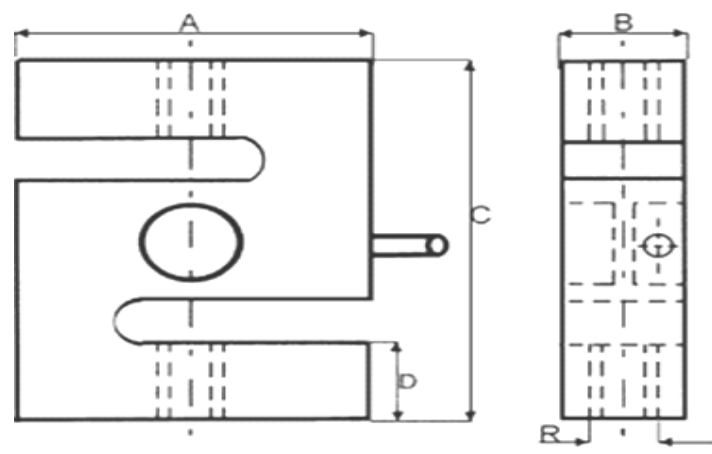

Tabela 5.1 -Características da célula de carga

\begin{tabular}{cc}
\hline Dimensões $(\mathrm{mm})$ & Modelo KS-5.000 \\
\hline A & 110 \\
B & 60 \\
C & 140 \\
D & 30,5 \\
R & M20 $\times 2,5$ \\
\hline
\end{tabular}

Figura 5.2-Esquema da célula de carga

A figura 5.3 mostra uma fotografia de uma célula de carga

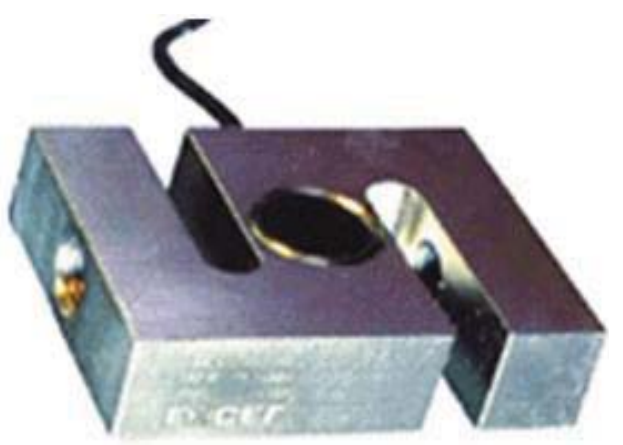

Figura 5.3- Foto da célula de carga usada

\subsubsection{Células de tensão total}

Foram usadas as células de tensões totais modelo BE-2KD (interface) e modelo BE2KC (inclusão) fabricadas pela Kyowa Electronic Instruments Company Limited. A figura 5.4 mostra o desenho esquemático da célula de tensão total.

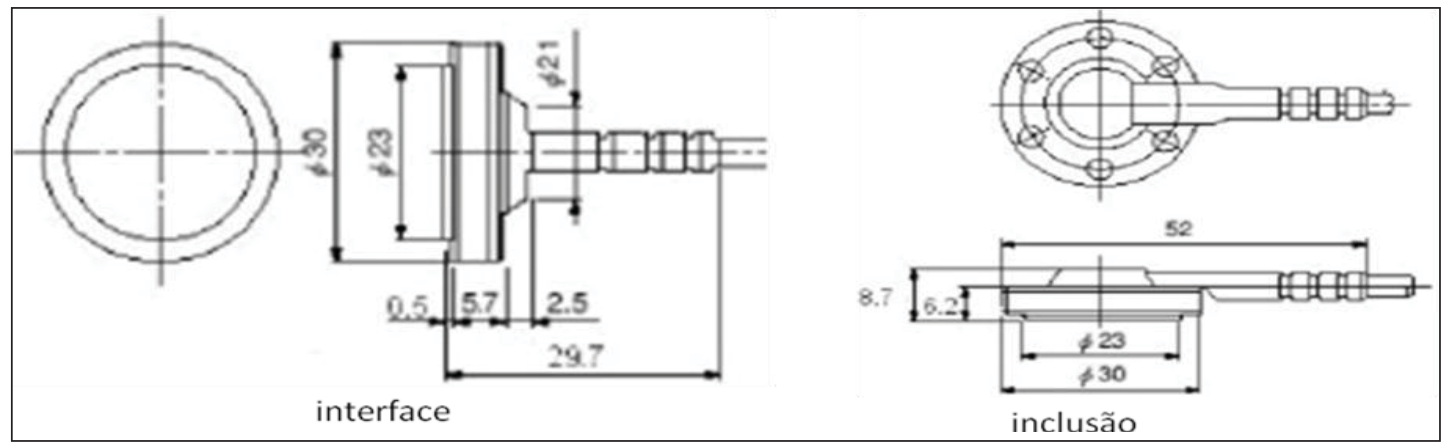

Figura 5.4- Desenho esquemático das células de tensão total (dimensões em mm), (MIRANDA 2009) 


\subsubsection{Transdutores de deslocamento LVDT}

Foram usados transdutores LVDT com uma precisão de $0,001 \mathrm{~mm}$; fabricada pela Vishay Precision Group.

\subsubsection{Motor;}

O motor foi preparado de maneira a realizar o arrancamento com uma velocidade constante; foi ainda montado um LVDT, com precisão até $0,001 \mathrm{~mm}$ para em paralelo monitorar os deslocamentos.

\subsubsection{Strain gages}

Os strain gages usados, foram fornecidos pela Excel sensores e apresentam as características apresentadas na Tabela 5.2 - Dimensões do Strain gage. e o seu desenho esquemático é apresentado na Figura 5.5.

Tabela 5.2 - Dimensões do Strain gage

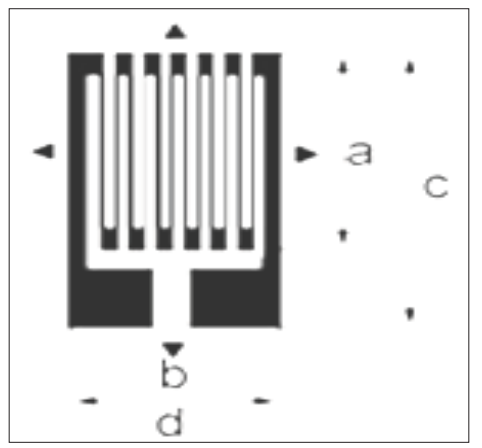

\begin{tabular}{lc}
\hline Dimensões do Strain. Gege & $(\mathrm{mm})$ \\
\hline A & 3.18 \\
B & 3,18 \\
C & 6,35 \\
D & 3,18 \\
\hline
\end{tabular}

Figura 5.5- Esquema do Strain gage

\subsubsection{Bolsa de ar}

A bolsa de ar foi o meio pelo qual os acréscimos da tensão vertical foi aplicada durante a realização de ensaios de arrancamentos; a bolsa é de PVC que foi fabricada pela Formatto; com o comprimento de $1.400 \mathrm{~mm}$, largura de $560 \mathrm{~mm}$ e uma espessura de 20 $\mathrm{mm}$, podendo suportar até $300 \mathrm{kPa}$. 


\subsubsection{Solo não convencional I;}

O solo não convencional 1 é proveniente do Campus II da Escola de Engenharia de São Carlos - USP, já estudado por vários autores.

\subsubsection{Solo não convencional 2-Rodovia SP 215-São Carlos}

O solo não convencional 2, foi extraído nas margens da rodovia SP 215, sendo que no local da sua extração é pouco abundante na superfície, ocorre em grandes quantidades a uma profundidades de 3 a $4 \mathrm{~m}$ da superfície do talude aí existente, foi escolhido por apresentar muitas partículas finas.

\subsubsection{Solo granular Mineração Jundú-Descalvado-São Carlos-SP}

O solo granular é provindo da mineradora de Jundu, São Carlos SP. O solo já foi estudado por alguns autores; este solo caracteriza-se por ter uma granulometria que dificilmente permite o preenchimento dos seus vazios, por isso muito mal graduado.

\subsubsection{Caixa de ensaios de arrancamento}

A caixa de ensaios usada para os ensaios de arrancamentos foi construída por Costa em 2005, a caixa tem um formato prismático com as dimensões apresentadas na Tabela 5.3

Tabela 5.3 - Dimensões internas da caixa de ensaios

\begin{tabular}{lr}
\hline \multicolumn{2}{c}{ Dimensões da caixa de ensaio de arrancamento $(\mathrm{mm})$} \\
\hline Comprimento interna & 1400 \\
Largura interna & 560 \\
Altura interna & 560 \\
\hline
\end{tabular}

\subsubsection{Aparelho de chuva de areia}

O aparelho de chuva de areia é constituído por uma caixa, onde a areia é introduzida. A caixa possui uma tampa na base que é aberta para iniciar a chuva, deixando cair a areia por gravidade diretamente para uma peneira que de seguida a distribui na caixa de ensaio segundo um movimento de vaivém que o conjunto realiza sobre trilhos; o movimento é feito a velocidade constante e a caixa possui mecanismos para regular as alturas desejadas 
segundo a compacidade relativa requerida no ensaio. Para além desses elementos existe uma base separada que permite aumentar a altura de trabalho em caso do sistema ajustável da caixa não permitir maiores alturas que dependem do número e espessuras das camadas necessárias.

Durante a construção do maciço a areia é distribuída de forma uniforme através do sistema que está acoplado a um motor elétrico.

A caixa de chuva de areia possui as dimensões apresentadas na Tabela 5.4

Tabela 5.4 - Dimensões da caixa de chuva de areia

\begin{tabular}{lc}
\hline Dimensões da caixa de chuva de areia $(\mathrm{mm})$ \\
\hline Comprimento interna & 560 \\
Largura interna & 205 \\
Altura interna & 405 \\
\hline
\end{tabular}

\subsection{Calibração das células de tensão total}

As células de tensão total usadas são de modelo.BE-2KC(inclusão) e BE2KD(interface), que depois de conectadas aos cabos e, os cabos aos conectores de saída, eram colocadas e calibradas uma a uma usando para tal uma caixa projetada para ensaios de arrancamento de geogrelhas, segundo pode ser visto na figura 5.6. A caixa metálica com as dimensões seguintes: comprimento $300 \mathrm{~mm}$, largura interna $250 \mathrm{~mm}$ e altura interna de 185mm, com uma tampa também metálica acoplada a uma bolsa de ar em PVC, com uma capacidade de reação de $300 \mathrm{kPa}$; porém, durante a calibração foi usada uma carga de $250 \mathrm{kPa}$.

Colocou-se a célula de tensão total na base da caixa e posteriormente encheu-se a caixa com areia seca, em seguida tampou-se a caixa e começou-se a encher a bolsa. Os carregamentos foram feitos de forma progressiva com um aumento de $10 \mathrm{kPa}$ até atingir $250 \mathrm{kPa}$; depois de atingir $250 \mathrm{kPa}$, eram feitos os descarregamentos, seguindo a ordem decrescente do carregamento até $0,0 \mathrm{kPa}$; o procedimento é repetido várias vezes para a estabilização das leituras garantido assim, a dissipação da histerese, vale salientar que esse 
Avaliação da Interação Solo-Fitas metálicas e poliméricas para Soluções em Terra Armada em Solos não Convencionais

procedimento é realizado para cada uma das células a usar. A Figura 5.6 mostra as imagens no processo da calibração da célula de carga. 


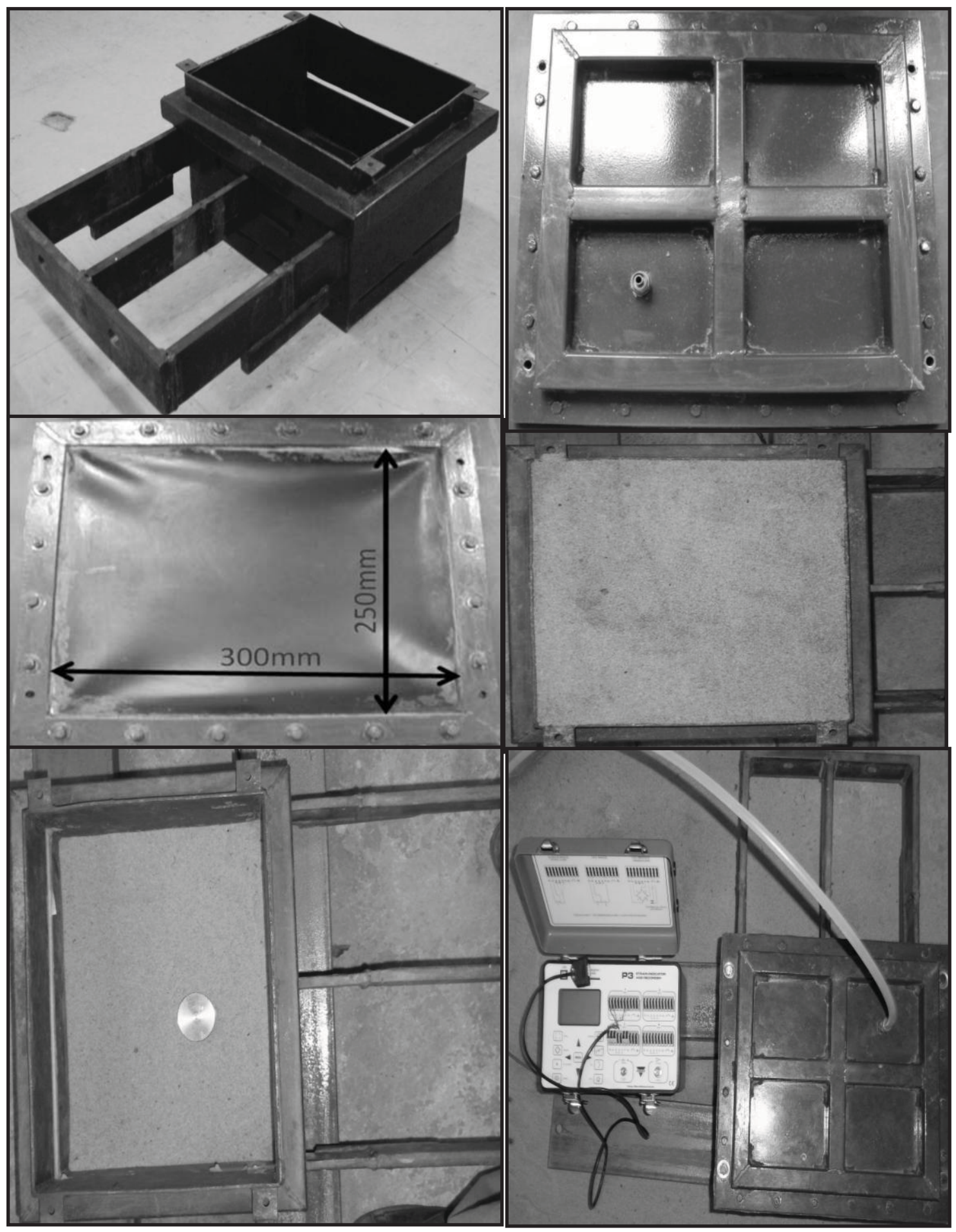

Figura 5.6- Caixa de calibração das células de tensão total

O gráfico de calibração de uma das células de carga total está apresentado na Figura 5.7 


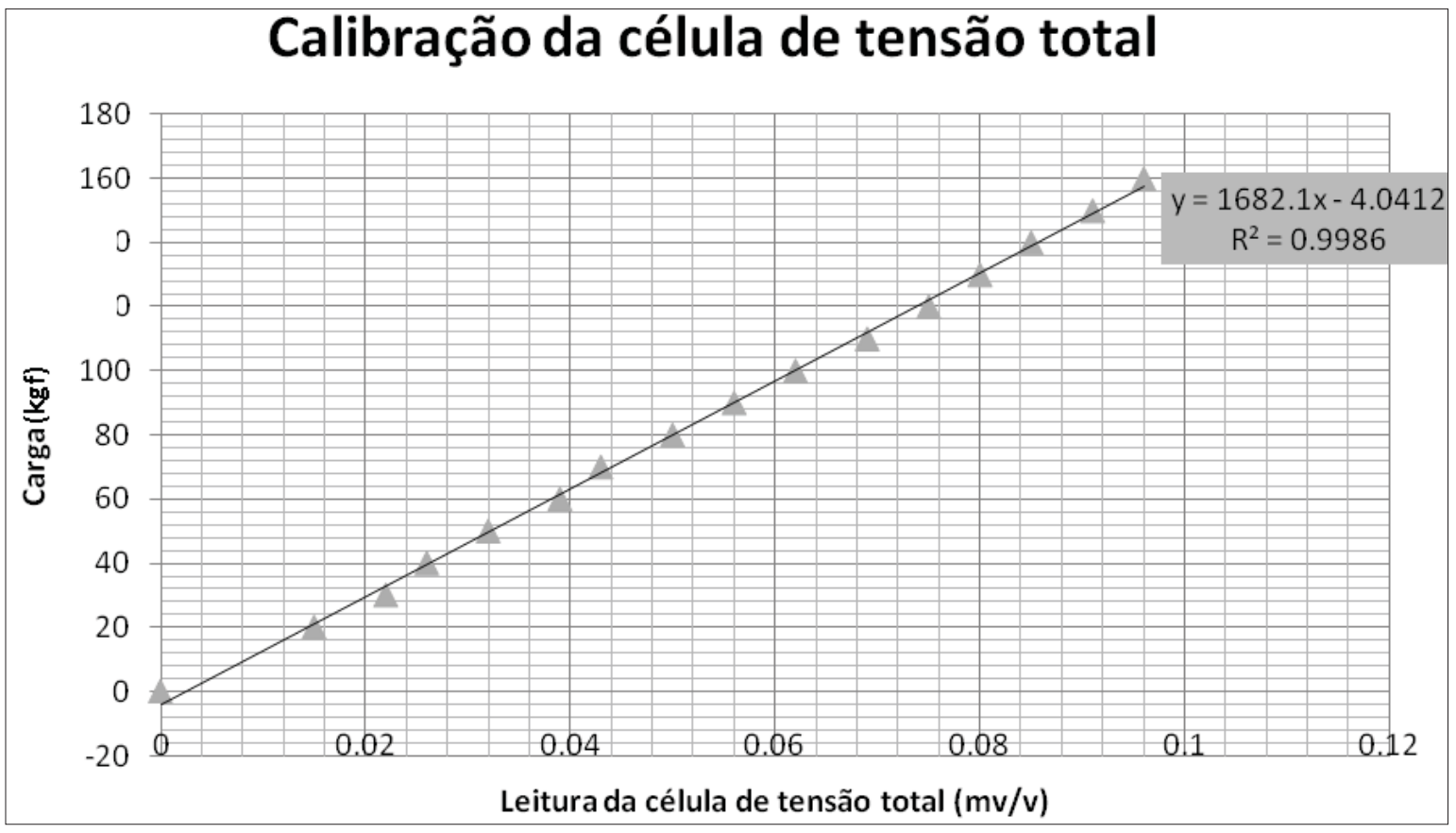

Figura 5.7- Gráfico de Calibração da célula de tensão total

\subsection{Calibração das fitas metálicas}

Para a calibração das fitas metálicas, foram preparados dois suportes que serviram de pilares e fixados num sistema pré - organizado no laboratório de geossintéticos, montou-se um sistema de tração constituído por um guincho fixo num dos pilares onde era encaixada a argola da fita metálica e noutra extremidade da fita metálica a fita foi perfurada e foi concebido um mecanismo de fixação; no sistema da aplicação de cargas de tração foi montada uma manivela; ao sistema foi acoplada uma célula de carga com capacidade de $5000 \mathrm{kgf}$. Com as fitas metálicas, com os strain gages colados sobre si, e com os strain gages conectados aos cabos de transmissão, e, por sua vez os cabos com as outras extremidades soldadas aos conectores padronizados para as entradas do sistema de aquisição de dados. No processo de calibração foram realizados carregamentos (tração) e descarregamentos, para garantir uma boa qualidade de informações na aquisição de resultados durante a execução de ensaios. O esquema da Figura 5.8 mostra o processo de calibração das fitas metálicas. 


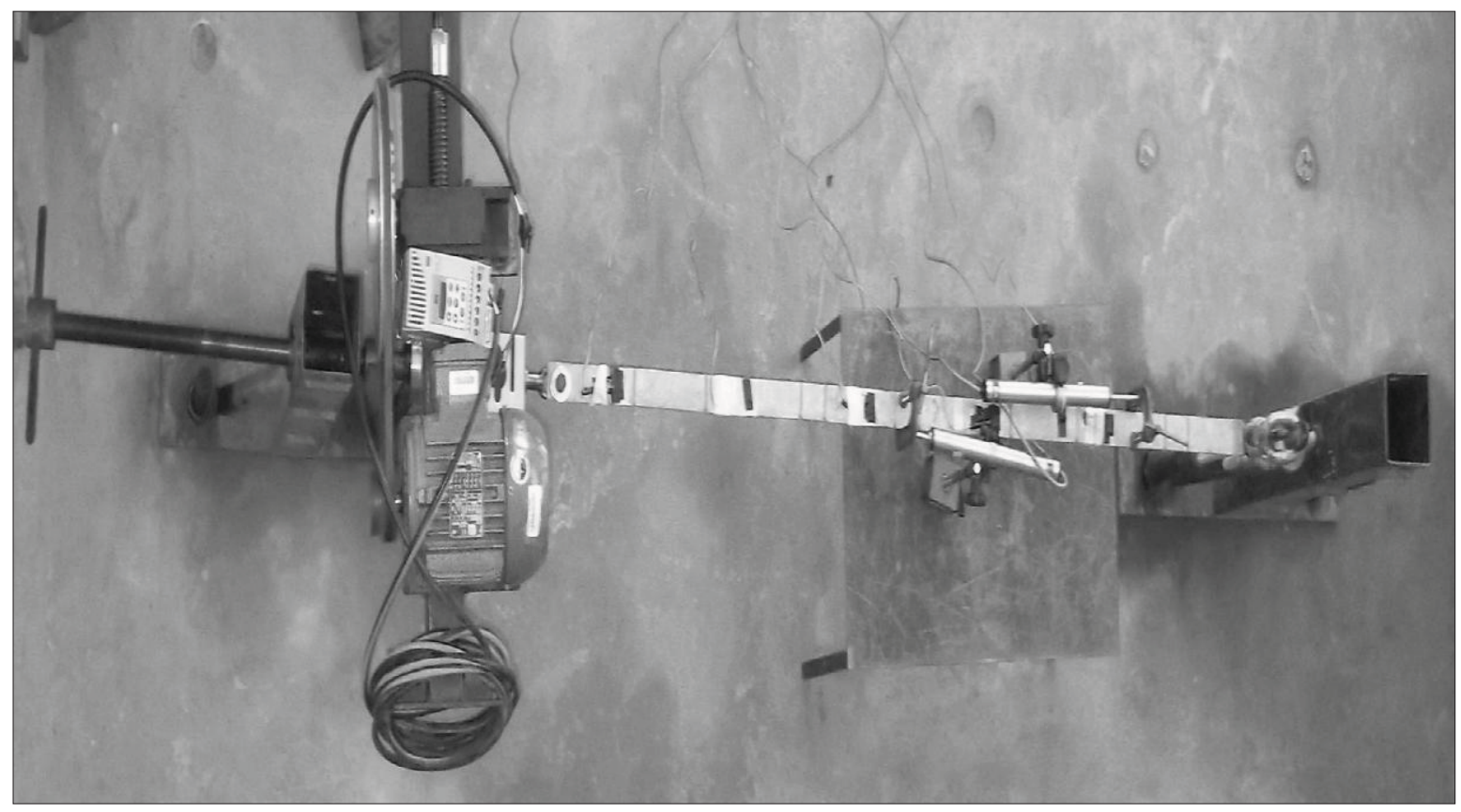

Figura 5.8- Esquema de calibração das fitas metálicas.

A seguir é apresentado o gráfico obtido no processo de calibração das fitas metálicas (Figura 5.9), usando os carregamentos e descarregamentos acima explicados

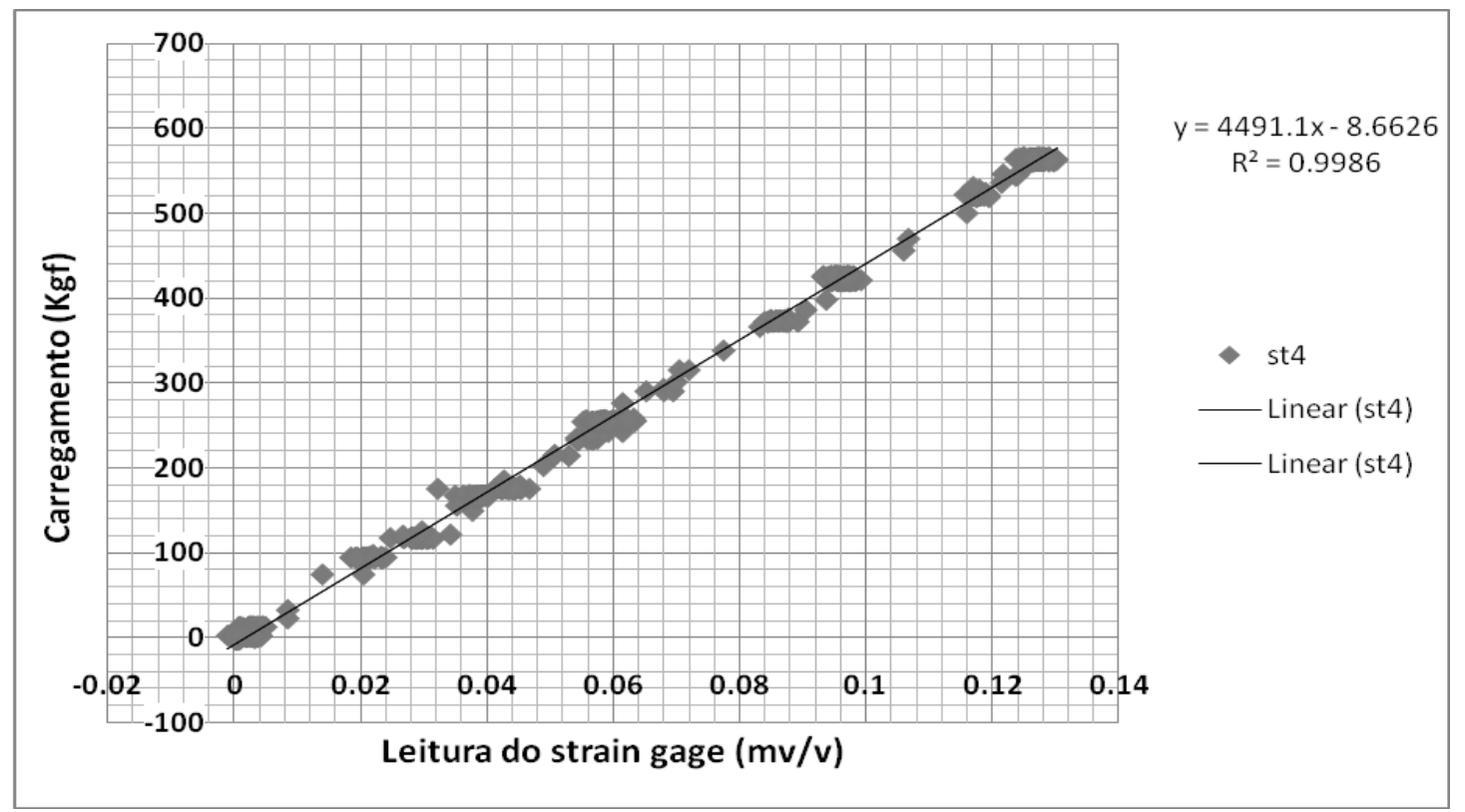

Figura 5.9 - Gráfico Calibração da fita metálica

Semelhantemente foram calibradas as fitas poliméricas que também foram usadas nos ensaios de arrancamento. 


\subsection{Preparação para a execução de ensaios de arrancamento}

Depois de estarem preparados todos os materiais necessários para uma boa realização dos ensaios de arrancamentos, compreendendo os processos da caracterização, os solos passaram da peneira \#40, em seguida foi feito o controlo e correção da umidade, para a umidade desejada para os ensaios; A caixa foi dividida em dez camadas de $50 \mathrm{~mm}$ e uma última camada de $40 \mathrm{~mm}$ para permitir uma boa compactação do solo; os $20 \mathrm{~mm}$ restantes ficara reservados para alojar a bolsa de ar com que se faz a aplicação das tensões verticais. Foram montadas as células de tensão total na base de caixa e realizou-se a compactação do solo nas camadas inferiores a fita-metálica e, ou polimérica, controlando o grau de compactação que deveria ser no mínimo de 95\%, na umidade ótima do solo; depois faziase a montagem da fita já instrumentada com os strain gages, e, ao mesmo nível da fita metálica colocavam-se células de tensão total, para monitorarem as tensões verticais que chegavam às fitas, dado que essas tensões serviriam para a simulação das profundidades ou alturas equivalentes, uma das mais importantes medidas nos ensaios. Seguia-se a compactação das camadas superiores ao nível das fitas e finalmente colocava-se a bolsa de ar e a tampa ou placa de reação. As fitas foram introduzidas na caixa de ensaios segundo o esquema apresentado nas Figura 5.10, usado por (MIRANDA 2009).

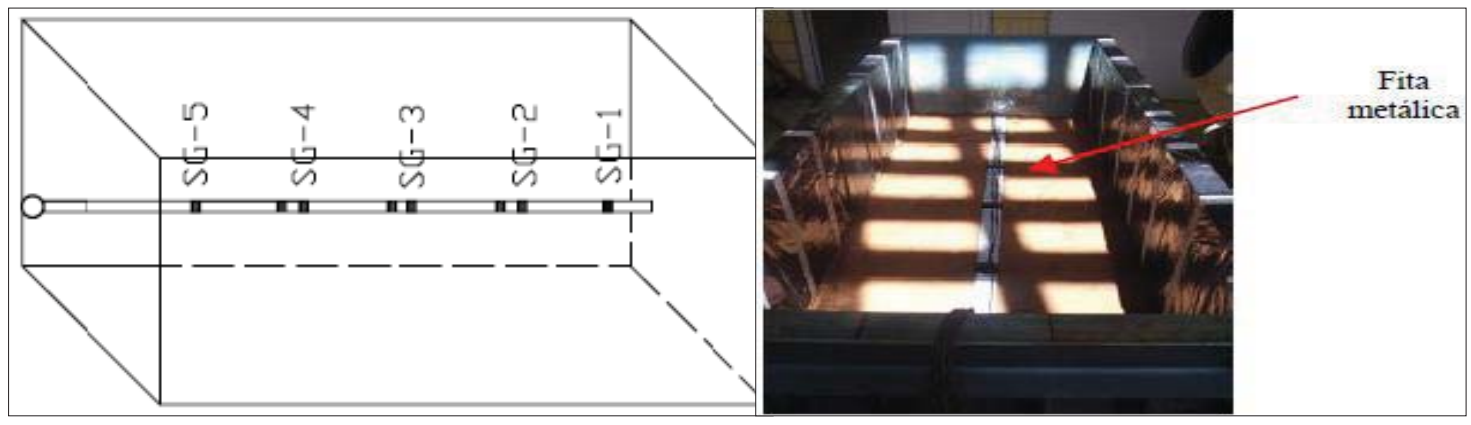

a)

b)

Figura 5.10 (a) - Representação do posicionamento da fita metálica com detalhes de instrumentação; (b)

- Fita metálica posicionada no maciço, (MIRANDA 2009).

Em cada ensaio fez-se o controlo de umidade e grau de compactação em pelo menos 3 pontos; para o controlo de grau de compactação, usou-se o método de cravação do cilindro. 
As fitas metálicas ficavam encaixadas ao sistema de aplicação e de controle e registo da força de arrancamento através de um guincho e as poliméricas a uma garra com o mesmo objetivo ao do guincho; neste caso, as fitas eram apertadas em uma garra que permitia uma boa segurança durante o arrancamento, fazendo com que a fita não escorregasse ao ser arrancada e nem se danificasse.

Os ensaios iniciavam com a aplicação de pressão na bolsa seguida da aplicação da força de arrancamento, a uma velocidade constante.

$\mathrm{Na}$ prossecução das atividades de pesquisa foram realizados ensaios de caracterização para cada solo, para permitir a obtenção de parâmetros de projeto. A seguir são apresentados os resultados dos ensaios de caracterização de cada solo.

\subsubsection{Solo não convencional 1}

O solo não convencional 1, provindo do Campus II da USP-São Carlos apresentou a curva granulométrica em que a percentagem de areia é de cerca de $62 \%$, percentagem de argila $32 \%$ e a percentagem de silte de 6\%; tendo sido classificado como Areia argilosa (SUCS). O ensaio de compactação, forneceu os resultados apresentados nos gráficos do apêndice $\mathrm{A}$, tendo sido $\rho_{\mathrm{d} \text { máx }}$ de $1,86 \mathrm{~g} / \mathrm{cm}^{3}$ e a umidade óptima de $14,7 \%$. Os ensaios de compressão triaxial de tipo consolidados e drenados, forneceram resultados de $28 \mathrm{kPa}$ de coesão e ângulo de atrito interno de $31,7^{\circ}$.

O resumo das características do solo não convencional 1 é apresentado na Figura 5.5.

Tabela 5.5 Resumo das características do solo não convencional I - Campus II - São Carlos

\begin{tabular}{l|l|c}
\hline ENSAIOS & \multicolumn{1}{|c|}{ PROPRIEDADES E CARACTERÍSTICAS } & VALORES \\
\hline GRAVIDADE ESPECÍFICA & Gravidade Específica, $\mathrm{G}_{\mathrm{S}}$ & 2,73 \\
\hline \multirow{2}{*}{ ANÁLISE DAS PARTÍCULAS } & Limite De Liquidez, LL $(\%)$ & 32 \\
\cline { 2 - 3 } & Limite De Plasticidade, LP $(\%)$ & 20 \\
\cline { 2 - 3 } & Índice De Plasticidade, IP $(\%)$ & 12 \\
\hline \multirow{2}{*}{ COMPACTAÇÃO PROCTOR NORMAL } & Teor Ótimo De Umidade $\mathrm{W}_{\text {ót }}(\%)$ & 14.7 \\
\cline { 2 - 3 } & Massa Específica Seca Máx, ${ }_{d}\left(\mathrm{KN} / \mathrm{m}^{3}\right)$ & 18.6 \\
\hline \multirow{2}{*}{ GRANULOMETRIA CONJUNTA } & Percentual De Areia(\%) & 62.0 \\
\cline { 2 - 3 } & Percentual De Silte $(\%)$ & 6.0 \\
\cline { 2 - 3 } & Percentual De Argila(\%) & 32 \\
\hline TRIAXIAL & Ângulo de atrito $\left({ }^{\circ}\right)$ & 31.70 \\
\cline { 2 - 3 } & Coesão (kPa) & 28.00 \\
\hline CLASSIFICAÇÃO DO SOLO & CLASSIFICAÇÃO SUCS & SC \\
\hline AREIA ARGILOSA DE BAIXA PLASTICIDADE CAMPUS II EESC-USP-SÃO CARLOS
\end{tabular}




\subsubsection{Solo não convencional 2-Rodovia SP 215}

Para o solo não convencional 2, é um solo com grande percentagem de finos; como pode ser visto na sua curva granulométrica. O solo é constituído por $15 \%$ de areia, $51 \%$ de silte e $35 \%$ de argila.

O ensaio de compactação forneceu os resultados apresentados nos gráficos do apêndice $\mathrm{B}$, tendo sido $\rho_{\mathrm{d} \text { máx }}$ de $1,49 \mathrm{~g} / \mathrm{cm}^{3}$ e a umidade óptima de $28,9 \%$.

Os ensaios de compressão triaxial de tipo consolidados e drenados, forneceram resultados de $44.6 \mathrm{kPa}$ de coesão e ângulo de atrito interno de 29,11

O resumo das características do solo não convencional 2 é apresentado na .

Tabela 5.6-Propriedades do solo da Rodovia 215-São Carlos-SP

\begin{tabular}{l|l|c}
\hline ENSAIOS & \multicolumn{1}{|c}{ PROPRIEDADES E CARACTERÍSTICAS } & VALORES \\
\hline GRAVIDADE ESPECÍFICA & Gravidade Específica, $\mathrm{G}_{\mathrm{S}}$ & 2,9 \\
\hline \multirow{2}{*}{ ANÁLISE DAS PARTíCULAS } & Limite De Liquidez, LL $(\%)$ & 63 \\
\cline { 2 - 3 } & Limite De Plasticidade, LP $(\%)$ & 40 \\
\cline { 2 - 3 } & Índice De Plasticidade, IP (\%) & 23 \\
\hline \multirow{2}{*}{ COMPACTAÇÃO PROCTOR NORMAL } & Teor Ótimo De Umidade $\mathrm{W}_{\text {ott }}(\%)$ & 28.9 \\
\cline { 2 - 3 } & Massa Específica Seca Máx, $\mathrm{P}_{\mathrm{d}}\left(\mathrm{KN} / \mathrm{m}^{3}\right)$ & 14.9 \\
\hline \multirow{2}{*}{ GRANULOMETRIA CONJUNTA } & Percentual De Areia(\%) & 14 \\
\cline { 2 - 3 } & Percentual De Silte $(\%)$ & 31 \\
\cline { 2 - 3 } & Percentual De Argila(\%) & 29.11 \\
\hline \multirow{2}{*}{ TRIAXIAL } & Ângulo de atrito $\left.{ }^{\circ}\right)$ & 44.60 \\
\cline { 2 - 3 } & Coesão $(\mathrm{kPa})$ & $\mathrm{MH}$ \\
\hline CLASSIFICAÇÃO DO SOLO & Classificação SUCS & \\
\hline
\end{tabular}

\subsubsection{Areia}

Foi igualmente usado como material de aterro a areia extraída na mineradora de Jundu; que já havia sido estudado e caracterizado; tendo uma faixa granulométrica muito restrita, com $100 \%$ de areia como pode se ver na sua curva granulométrica. Os resultados gráficos podem ser consultados no apêndice C.

O resumo das características da areia é apresentado na Tabela 5.7 e os seus parâmetros são apresentados na Tabela 5.8. 
Tabela 5.7-Características da areia

\begin{tabular}{c|c|c|c|c}
\hline \multicolumn{1}{c}{ Massa específica dos sólidos $(\rho \mathrm{s})-20{ }^{\circ} \mathrm{C}=2.624 \mathrm{~g} / \mathrm{cm}^{3}$} \\
\hline $\mathrm{D}_{(10)}=\underline{0.35}$ & $\mathrm{D}_{(30)}=\underline{0.42}$ & $\mathrm{D}_{(60)}=\underline{0.60}$ & $\mathrm{Cu}=\underline{1.71}$ & \multicolumn{2}{c}{$\mathrm{Cc}=\underline{0.84}$} \\
\hline Classificação: & Areia Mal Graduada - Muito Uniforme & SUCS: $\underline{\text { SP }}$ & AASHTO: $\underline{\mathrm{A}-3}$ \\
\hline & &
\end{tabular}

Tabela 5.8-Parâmetros de resistência da areia.

\begin{tabular}{ccccc}
\hline$\sigma / \mathrm{Dr}$ & $20 \%$ & $45 \%$ & $70 \%$ & $90 \%$ \\
\hline 25 & 17.5 & 19.1 & 20.3 & 22.2 \\
50 & 33.2 & 34.1 & 35.3 & 40.0 \\
100 & 64.6 & 68.2 & 72.8 & 75.2 \\
$\varphi=$ & 33.1 & 34.4 & 36.1 & 37.5 \\
\hline
\end{tabular}

\subsection{Ensaios de permeabilidade dos solos não convencionais}

Foram realizados ensaios permeabilidade com carga variável, com a intenção de avaliar aquilo que seria a drenagem dos dois solos não convencionais em relação a areia; tomando em conta que a permeabilidade típica de areias é de k igual a $10^{-3}$ a $10^{-5} \mathrm{~m} / \mathrm{s}$.

Foram moldados corpos nas umidades ótimas dos solos; os corpos de prova tinham as dimensões resumidas na Tabela 5.9 que também apresenta os resultados dos ensaios.

Tabela 5.9- Dimensões dos corpos de prova se resultado dos ensaios de permeabilidade

\begin{tabular}{cccc}
\hline CP do Solo não convencional 1 & & CP do Solo não convencional 2 & \\
\hline Altura $(\mathrm{cm})$ & 5,0 & Altura $(\mathrm{cm})$ & 5 \\
Diâmetro $(\mathrm{cm})$ & 5,0 & Diâmetro $(\mathrm{cm})$ & 1964 \\
Área $\left(\mathrm{cm}^{2}\right)$ & 1964 & Área $\left(\mathrm{cm}^{2}\right)$ & 188.57 \\
Massa $(\mathrm{g})$ & 209.45 & Massa $(\mathrm{g})$ & 2.45 \\
$\rho_{\mathrm{s}}\left(\mathrm{g} / \mathrm{cm}^{3}\right)$ & 2.13 & $\rho_{\mathrm{s}}\left(\mathrm{g} / \mathrm{cm}^{3}\right)$ & 1.49 \\
$\rho_{\mathrm{d}}\left(\mathrm{g} / \mathrm{cm}^{3}\right)$ & 1.86 & $\rho_{\mathrm{d}}\left(\mathrm{g} / \mathrm{cm}^{3}\right)$ & 0.71 \\
Índice de vazios & 0.47 & Índice de vazios &
\end{tabular}


$\mathrm{O}$ solo não convencional 1 teve um valor médio de $3.44 \times 10^{-7} \mathrm{~cm} / \mathrm{s}$ enquanto que o solo não convencional 2 , apresentou uma média de $2.62 \times 10^{-7} \mathrm{~cm} / \mathrm{s}$; isto é, $31 \%$ menos permeável que o primeiro.

\subsection{Ensaios de arrancamento em solos reforçados por fitas metálicas}

Este capítulo faz referência aos resultados obtidos nos ensaios de arrancamento das fitas metálicas, são consideradas as cargas verticais, a força de arrancamento, os graus de compactação, a umidade, as forças de tração ao longo do comprimento da fita (registradas por strain gages). As fitas metálicas possuíam larguras de 40 e $60 \mathrm{~mm}$, respectivamente.

Para efeito de comparação dos efeitos que as forças de arrancamento provocariam na deformação das fitas metálicas foram realizados ensaios de tração das fitas metálicas para avaliar as resistências reais do material. Para tal, foi extraída uma amostra e dela usinados quatro corpos de prova com as dimensões normatizadas na ASTM A_370[64], segundo a Figura 5.11.

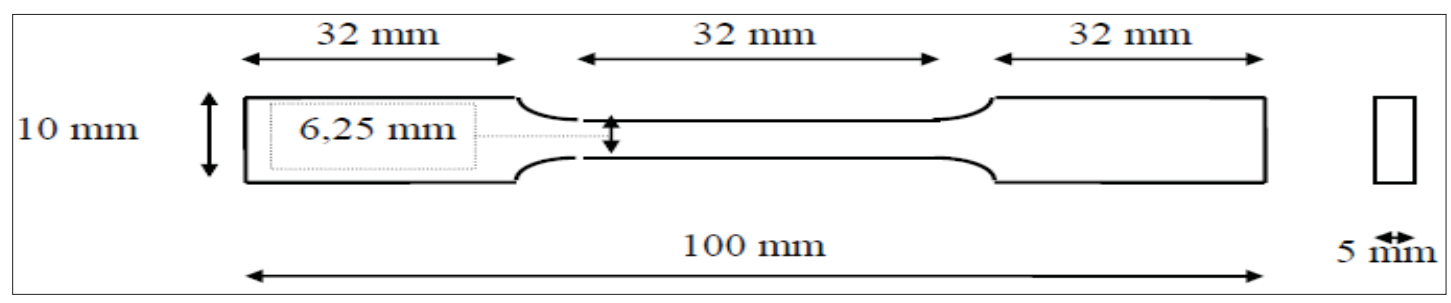

Figura 5.11- Dimensões de corpo de prova reduzido de tração, conforme norma ASTM A_370[64]

Os resultados dos ensaios de tração das fitas, estrão apresentados na figura Figura 5.12. Vale salientar que os resultados são referidos aos ensaios numa seção de $6.25 \mathrm{~mm}$ x 5 $\mathrm{mm}$. 


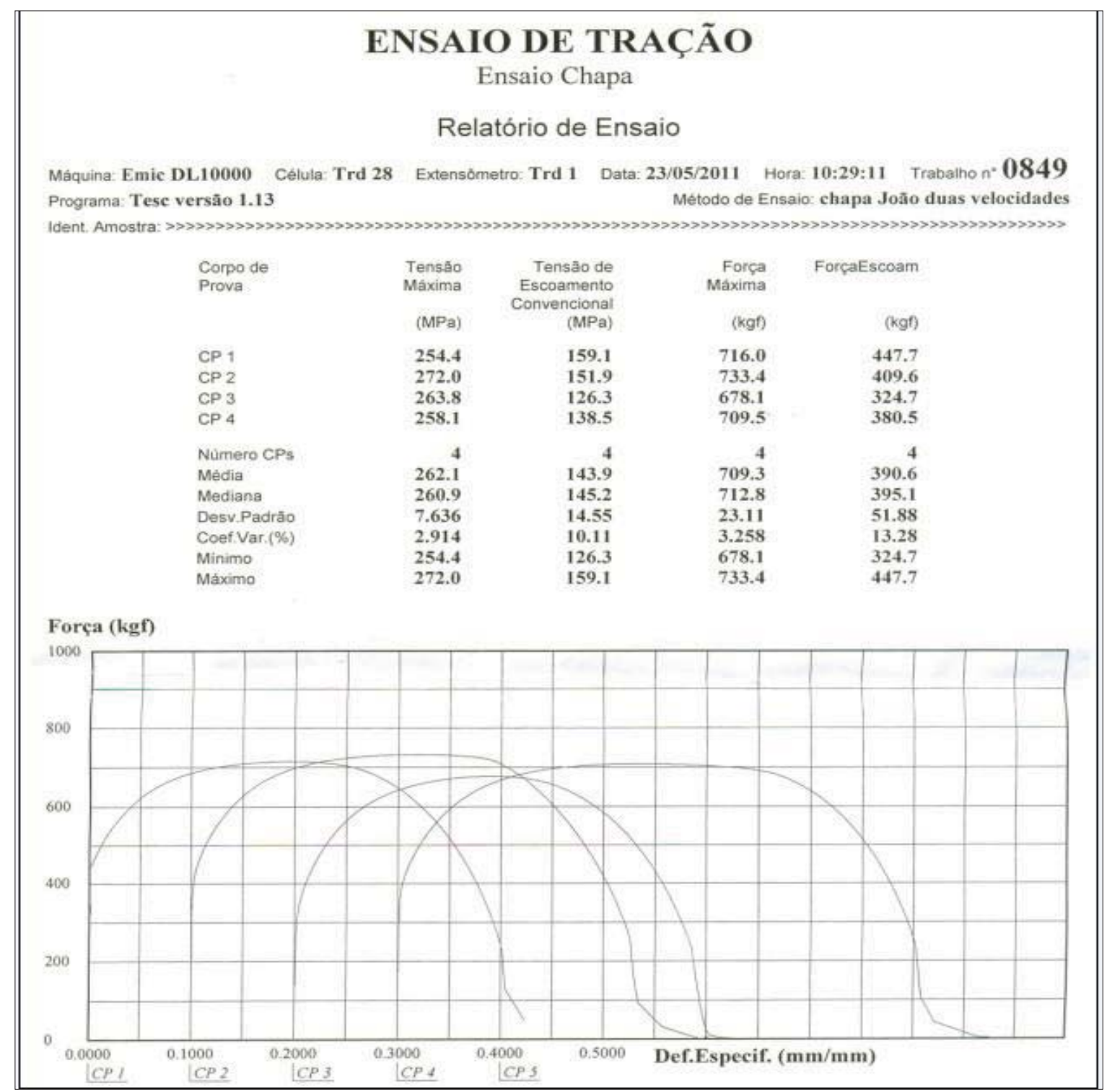

Figura 5.12- Resultado dos ensaios de tração das fitas metálicas

Os ensaios são designados pelo número de sequência de execução e por um índice que indica a largura da barra ensaiada, dado que as mesmas barras possuem comprimentos e espessuras iguais em fitas metálicas (FM). Para as fitas poliméricas (FPO), embora com espessuras diferentes, as designações seguiram o mesmo critério e no final, foram usadas as designações (CII) significando campus II; (A) significando areia e (R), significando Rodovia.

As fitas metálicas possuíam geometrias diferentes e todas eram nervuradas ou de alta aderência. 
Durante os ensaios foram considerados os valores de tensão vertical que atuaram em fitas tomando em conta aos acréscimos de tensão aplicados através da bolsa de ar. Isso proporcionou a simulação da variação da profundidade.

As umidades e os graus de compactação que são apresentados em tabelas são as médias dos valores de controle durante a execução dos maciços na preparação dos ensaios.

Foram calculadas as alturas equivalentes do solo, que são as alturas do solo, correspondentes às tensões verticais atuantes na fita, em função do peso específico do solo.

\subsubsection{Solo não Convencional 1 - CAMPUS II - EESC-SÃO CARLOS-SP}

Os ensaios de arrancamento com as fitas metálicas de largura $60 \mathrm{~mm}$, foram designadas por $\left(\mathrm{FM}_{60}\right)$ e as de largura de $40 \mathrm{~mm}$ por $\left(\mathrm{FM}_{40}\right)$; esta nomenclatura foi usada somente para este solo em relação aos ensaios realizados com as fitas metálicas.

Para a determinação das tensões de tração máximas foram usadas duas fórmulas, a primeira que considera o comprimento inicial da fita inserida no maciço e a segunda que considera a redução do comprimento durante o processo de arrancamento.

A Tabela 5.10 apresenta os valores médios que caracterizaram os ensaios de controle da umidade e grau de compactação; o controle foi realizado em pelo menos três camadas para cada ensaio.

Tabela 5.10 - Características dos ensaios com o solo não Convencional 1- Campus II

\begin{tabular}{lcccccccc}
\hline Ensaio & $\mathrm{w}$ & $\mathrm{m}_{\text {cilindro }}$ & $\mathrm{m}_{\mathrm{s}+\text { cilindro }}$ & $\mathrm{m}_{\text {solo }}$ & $\mathrm{V}_{\text {cilindro }}$ & $\rho_{\mathrm{n}}$ & $\rho_{\mathrm{d}}$ & $\mathrm{GC}$ \\
\hline & $(\%)$ & $(\mathrm{g})$ & $(\mathrm{g})$ & $(\mathrm{g})$ & $(\mathrm{cm})$ & $(\mathrm{g} / \mathrm{cm} 3)$ & $(\mathrm{g} / \mathrm{cm} 3)$ & $(\%)$ \\
1-FM60_CII & 14.65 & 1220.60 & 3281.97 & 2061.37 & 1006.838 & 2.04737 & 1.786 & $97.1 \%$ \\
2-FM60_CII & 14.70 & 1220.60 & 3260.11 & 2039.51 & 1006.838 & 2.025659 & 1.766 & $96.0 \%$ \\
3-FM60_CII & 14.75 & 1220.60 & 3105.00 & 1884.40 & 1006.838 & 1.871602 & 1.631 & $88.6 \%$ \\
1-FM40_CII & 14.68 & 1220.60 & 3260.09 & 2039.49 & 1006.838 & 2.025639 & 1.766 & $96.0 \%$ \\
2-FM40_CII & 14.65 & 1220.60 & 3117.03 & 1896.43 & 1006.838 & 1.88355 & 1.643 & $89.3 \%$ \\
3-FM40_CII & 14.61 & 1220.60 & 3201.01 & 1980.41 & 1006.838 & 1.96696 & 1.716 & $93.3 \%$ \\
4-FM40_CII & 14.41 & 1220.60 & 3235.11 & 2014.51 & 1006.838 & 2.000828 & 1.749 & $95.0 \%$ \\
\hline
\end{tabular}

Onde,

- n_FM $\mathrm{FM}_{60}$ CII é o ensaio de arrancamento número $\mathrm{n}$ da fita metálica de largura 60 $\mathrm{mm}$ com o solo do Campus II. 
- n_FM $\mathrm{FM}_{40}$ CII é o ensaio de arrancamento número $\mathrm{n}$ da fita metálica de largura 40 mm com o solo do Campus II.

Durante a execução dos ensaios foram traçadas curvas força de arrancamento vs deslocamento, os valores das forças de arrancamento máximas são apresentadas na tabela Tabela 5.11 .

Tabela 5.11- Cargas máximas registradas nos ensaios

\begin{tabular}{|c|c|}
\hline ENSAIO & FORÇA DE ARRANCAMENTO (KN) \\
\hline 1-FM $\mathrm{FO}_{-} \mathrm{Cll}$ & 11,84 \\
\hline 2-FM ${ }_{60} \mathrm{Cll}$ & 16,43 \\
\hline 3-FM $\mathrm{FO}_{60} \mathrm{Cll}$ & 5,20 \\
\hline 4-FM40_Cll & 9,76 \\
\hline 5-FM40_Cll & 5,55 \\
\hline 6-FM40_Cll & 7,60 \\
\hline 7-FM 40 & 12,30 \\
\hline
\end{tabular}

Devido à quantidade de resultados obtidos, serão apresentados apenas alguns gráficos sendo que os demais poderão ser consultados nos apêndices. A seguir são apresentados alguns gráficos típicos para cada grupo de ensaios realizados. Vale salientar que nos gráficos traçados, força de arrancamento $v s$ deslocamento e Resistência de interface( $\tau$ vs deslocamento), foram colocados para cada curva, valores da tensão vertical máxima aplicada e que tiveram como consequências os resultados plotados em gráficos.

\subsubsection{1 nsaios realizados com as Fitas metálicas de largura $60 \mathrm{~mm}$.}

Os gráficos dos ensaios realizados com fitas metálicas de largura de $60 \mathrm{~mm}$ e solo não convencional 1, são apresentados nas Figura 5.13,Figura 5.14 e Figura 5.15. Ainda deve-se compreender que as sequências da colocação deste tipo de gráficos, no texto, é da força de arrancamento $v s$ deslocamento seguido da resistências real da interface solo-fita (calculada com a fórmula usual) vs deslocamento e, finalmente os gráficos resistências em da interface solo-fita em função do comprimento remanescente da fita na caixa durante o processo de arrancamento vs deslocamento, como vem identificado nas legendas das figuras a seguir apresentadas. 


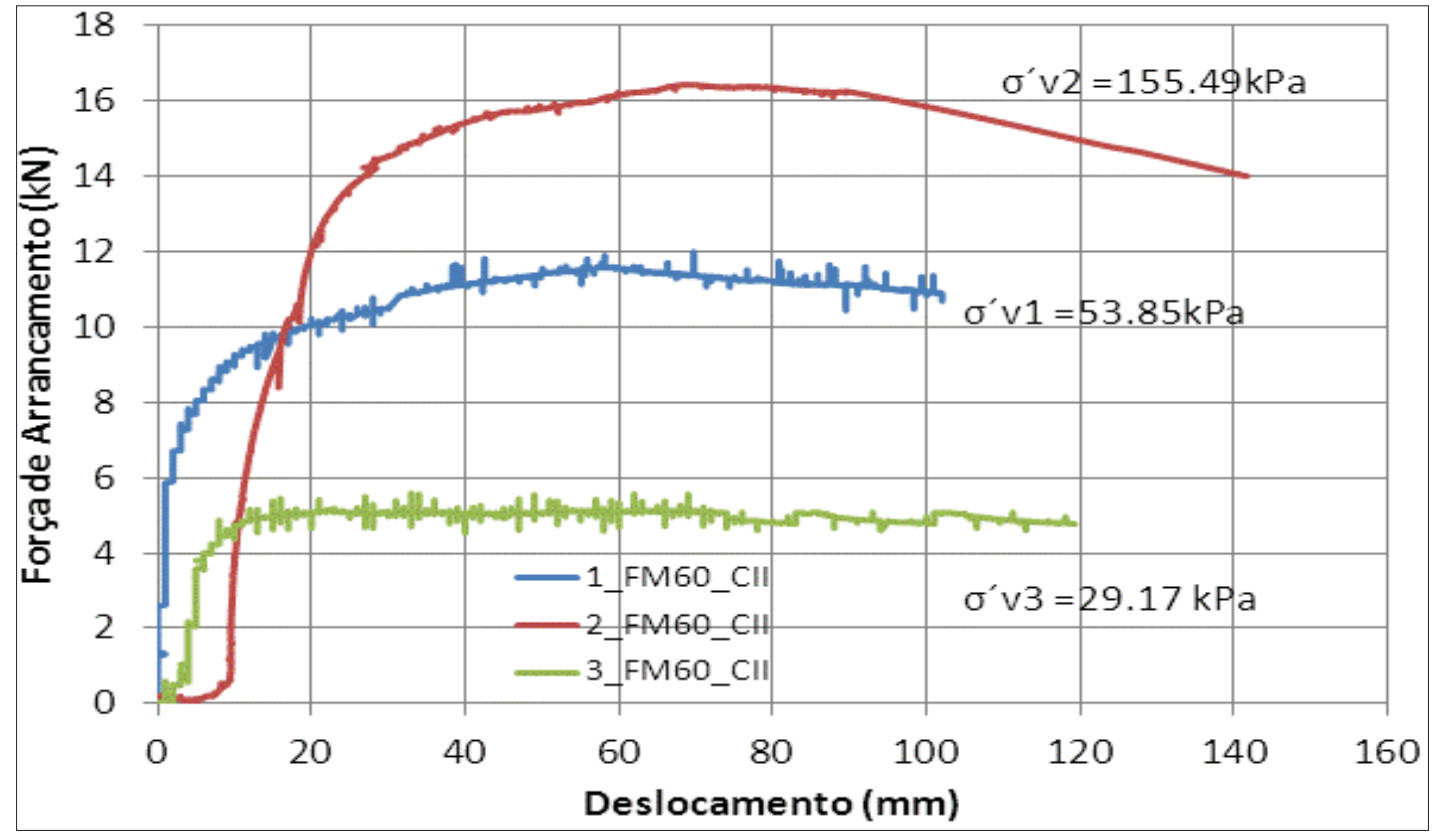

Figura 5.13- Força de arrancamento X deslocamento

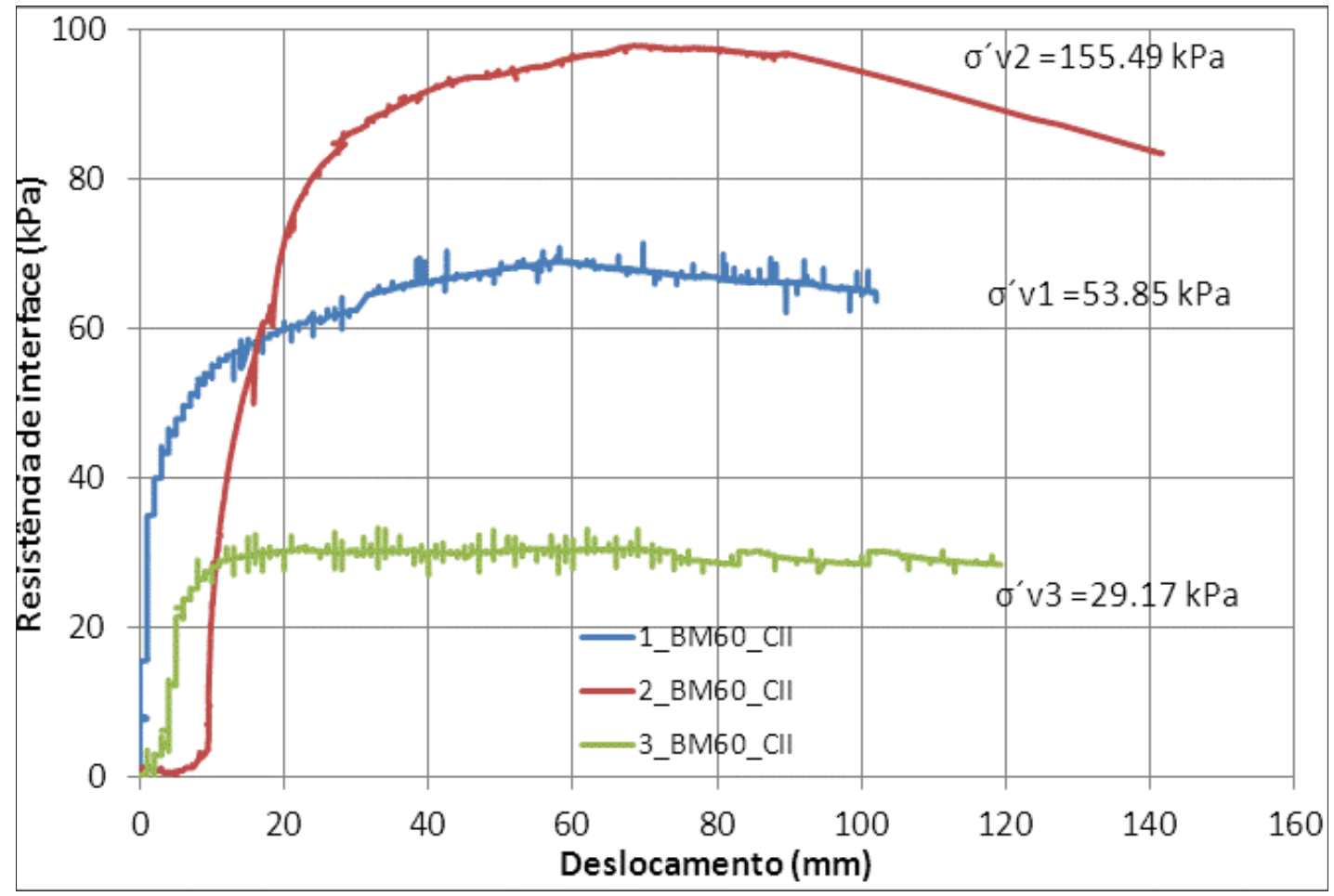

Figura 5.14- Resistência da interface X deslocamento ( forma usual em terra armada) 


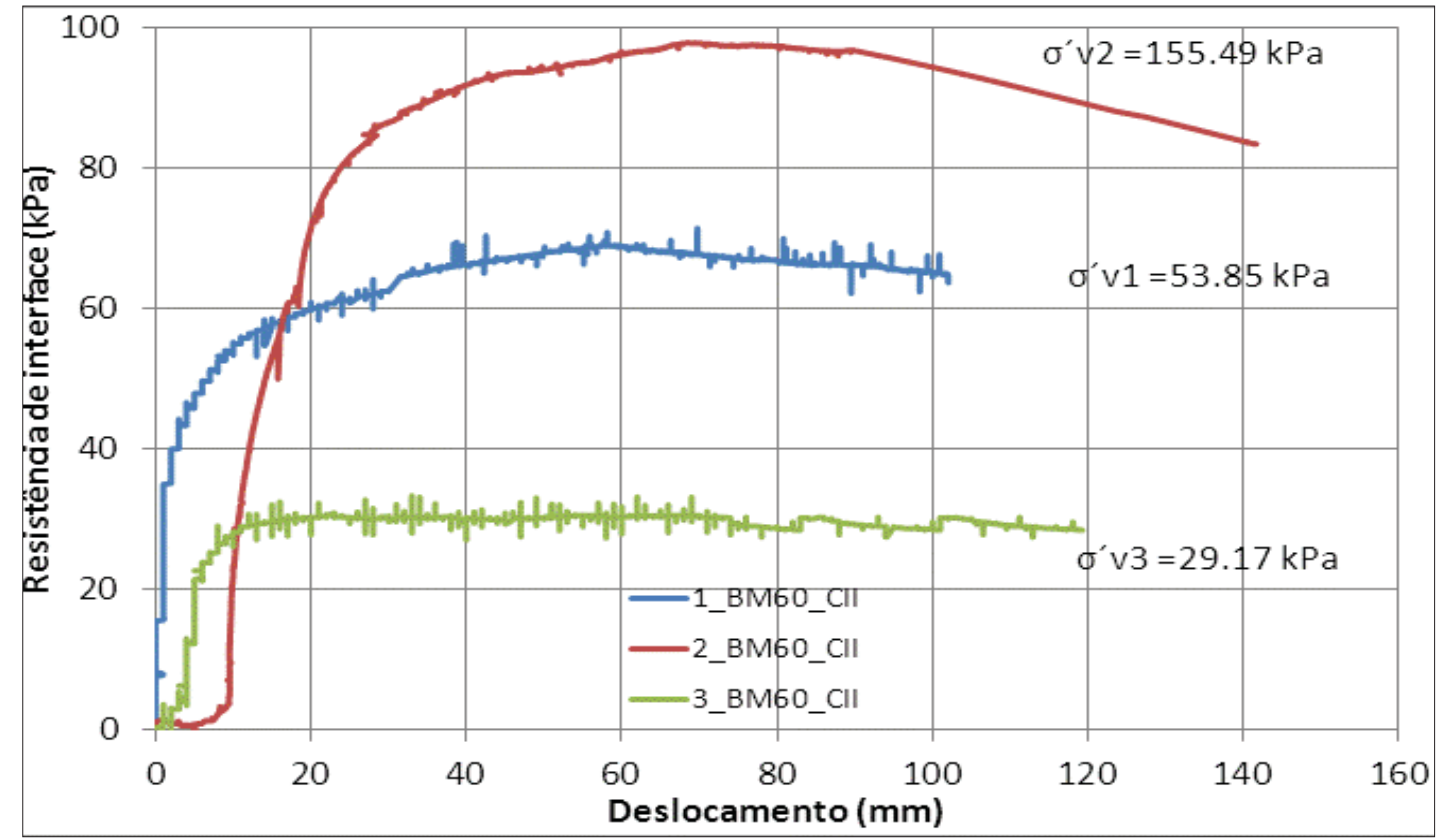

Figura 5.15 - Resistência da interface em função do comprimento arrancado X deslocamento

\subsubsection{Ensaios realizados com as fitas metálicas de largura $40 \mathrm{~mm}$.}

Gráficos dos ensaios de arrancamento realizados com fitas metálicas de largura de 40 mm e solo não convencional 1, são apresentados nas Figura 5.16, Figura 5.17 Figura 5.18.

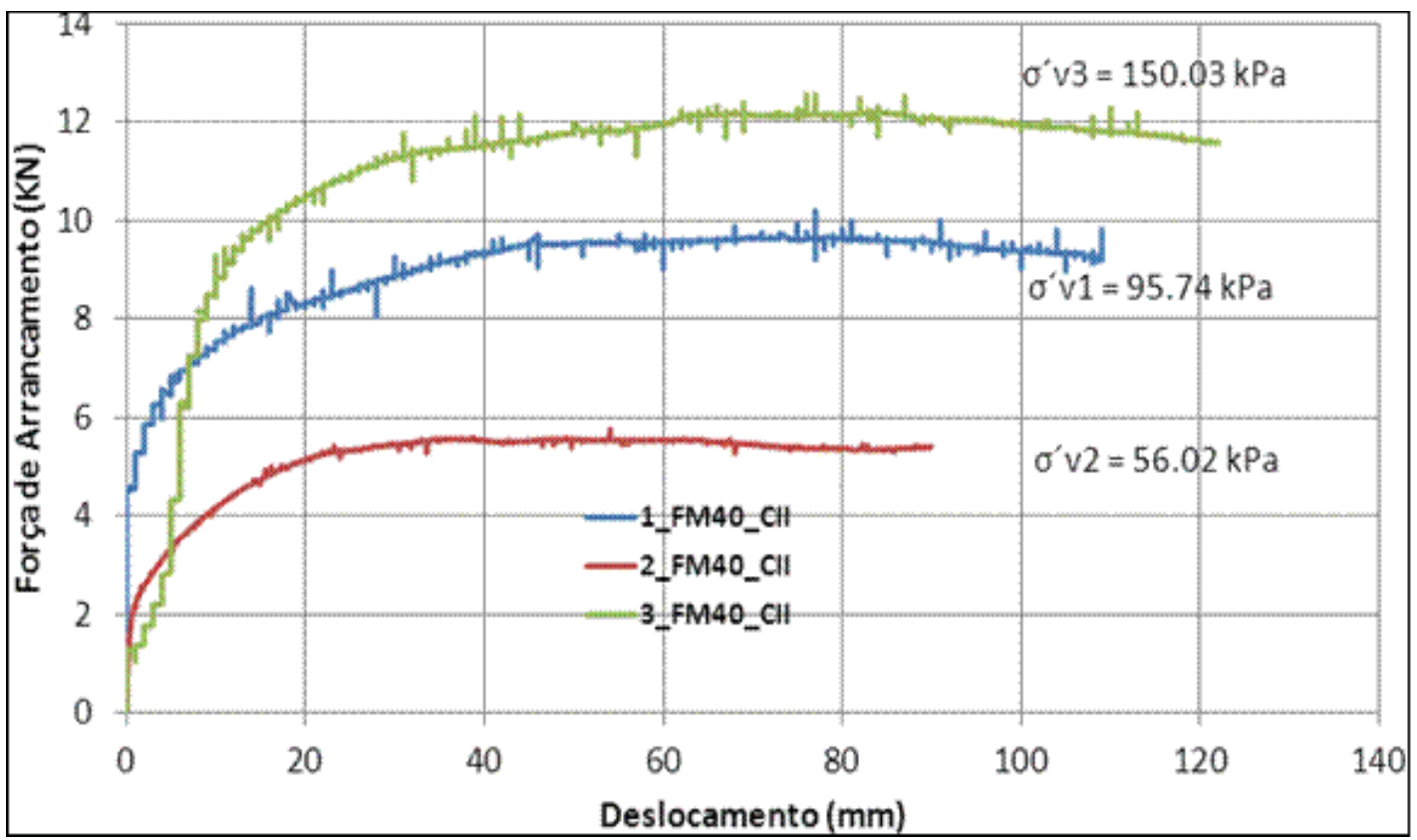

Figura 5.16-Força de arrancamento X deslocamento 


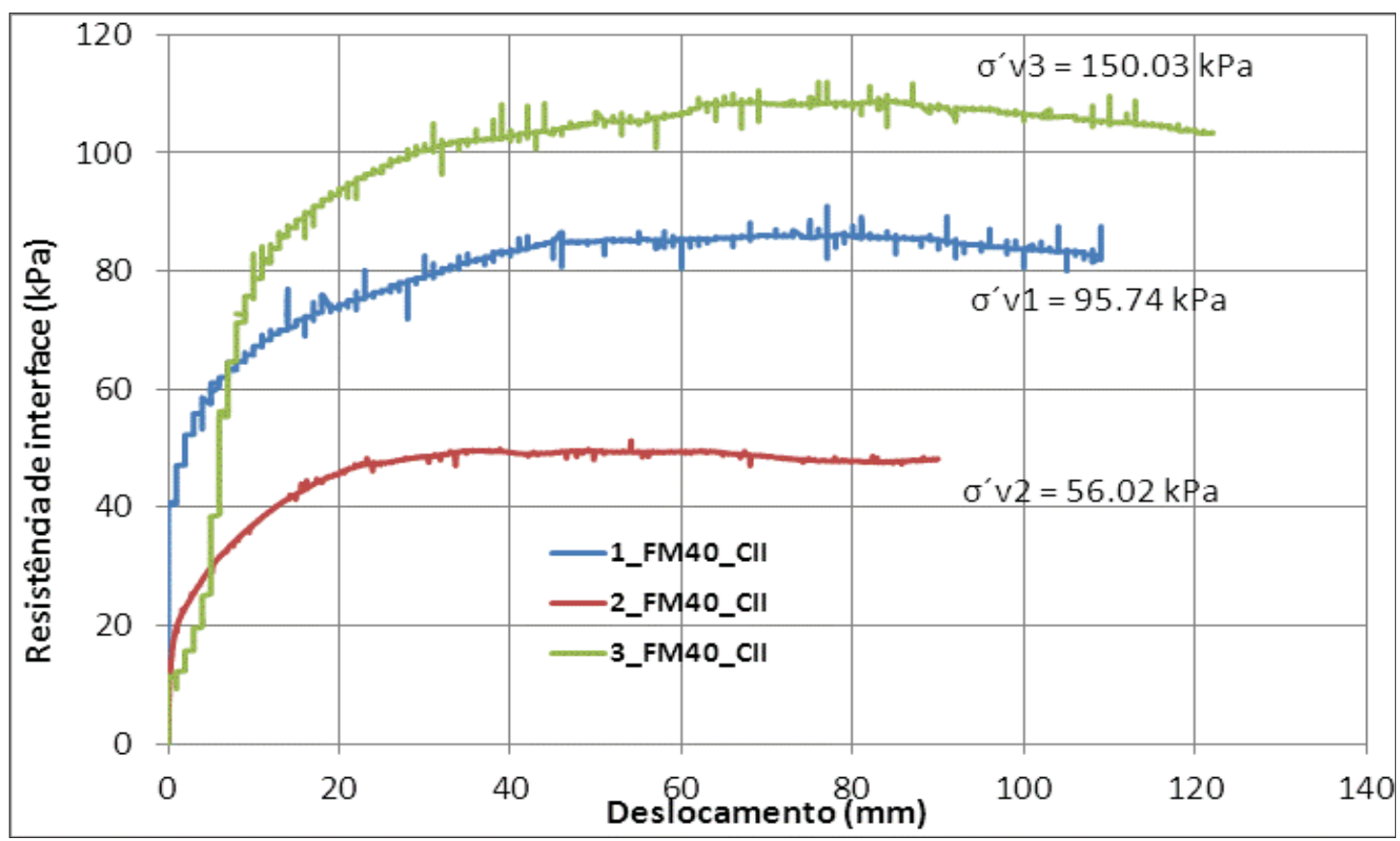

Figura 5.17 - Resistência da interface X deslocamento ( forma usual em terra armada)

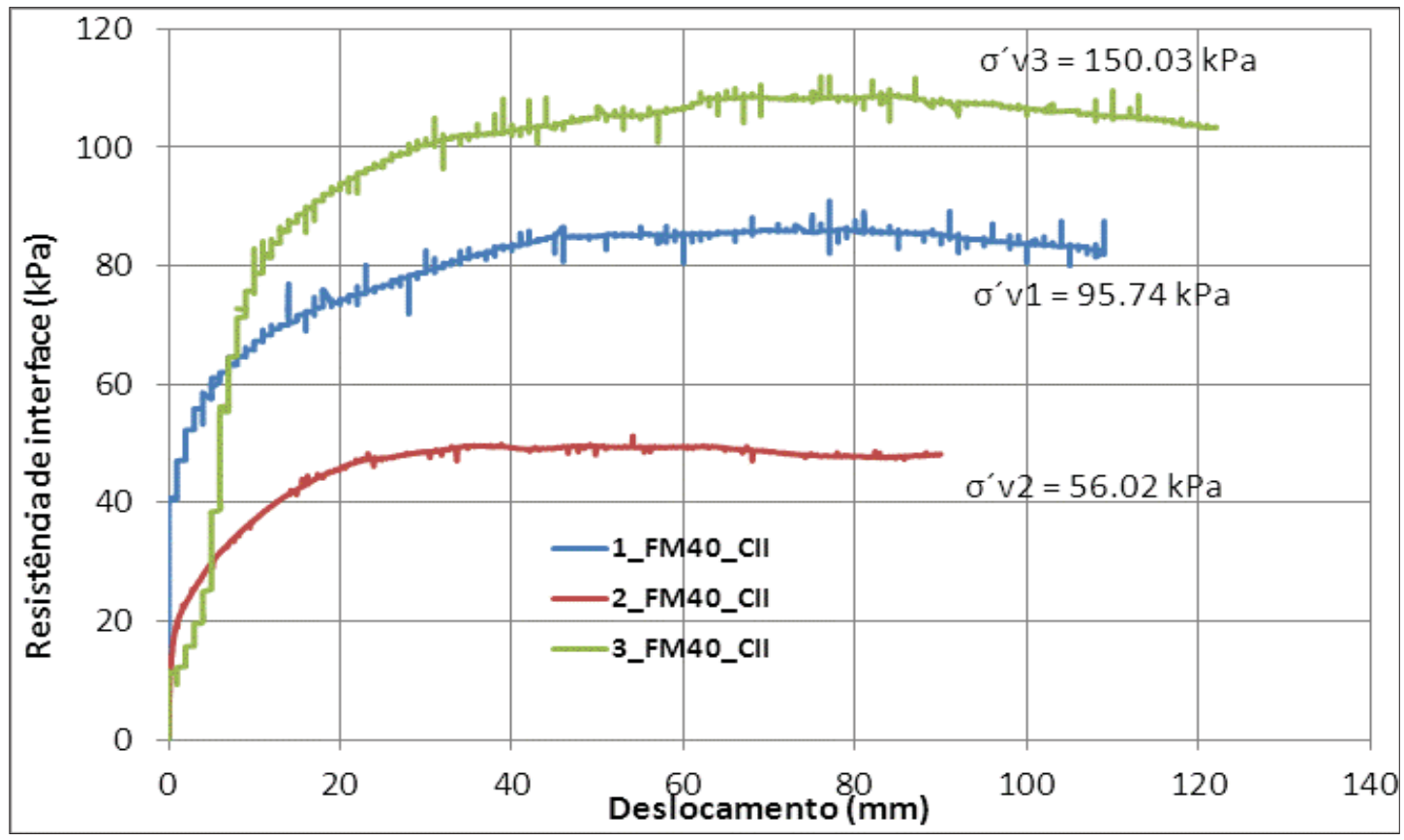

Figura 5.18- Resistência da interface em função do comprimento arrancado X deslocamento

\subsubsection{Determinação do coeficiente de atrito aparente solo - fita metálica}

A determinação do coeficiente de atrito aparente solo - fita metálica (f* ) foi possível utilizando os dados apresentados nas tabelas 5.10 e 5.11; tendo se calculado a tensão tangencial máxima $\left(\tau_{\max }\right)$, tomando em consideração a carga máxima e a área da fita que fica em contato com o solo, durante o arrancamento. Para o cálculo do $\mathrm{f}^{*}$ e $\tau_{\max }$ foram 
usadas as expressões 1 e 36 respectivamente. Os resultados obtidos estão apresentados na Tabela 5.12.

$$
f^{*}=\frac{\tau_{\max }}{\sigma_{v}^{\prime}} \quad ; \quad \tau_{\max }=\frac{F_{a r r}}{2 * B^{*} L}
$$

Tabela 5.12- resultados calculados a partir dos resultados dos ensaios sem considerar a coesão

\begin{tabular}{|c|c|c|c|c|c|c|c|c|}
\hline Ensaio & $\tau_{\max }$ & $\mathrm{F}_{\text {arr. }}(\mathrm{KN})$ & $\Delta \sigma_{v}{ }^{\prime}(k P a)$ & $\sigma_{v^{\prime} \text { tatal }}(\mathrm{KPa})$ & $L(m)$ & $B(m)$ & $\mathrm{H}_{\mathrm{eq}}(\mathrm{m})$ & $f^{*}$ ad \\
\hline 1 - $\mathrm{FM}_{60}$ _Cll & 70.48 & 11.84 & 48.83 & 53.85 & 1.400 & 0.060 & 2.90 & 1.309 \\
\hline $2-\mathrm{FM}_{60}{ }_{60} \mathrm{Cll}$ & 97.80 & 16.43 & 150.47 & 155.49 & 1.400 & 0.060 & 8.36 & 0.629 \\
\hline $3-\mathrm{FM}_{60 \_\mathrm{CII}}$ & 30.95 & 5.20 & 24.15 & 29.17 & 1.400 & 0.060 & 1.57 & 1.061 \\
\hline 1-FM40_Cll & 87.14 & 9.76 & 90.72 & 95.74 & 1.400 & 0.040 & 5.15 & 0.910 \\
\hline 2-FM ${ }_{40}$ CII & 49.55 & 5.55 & 51.00 & 56.02 & 1.400 & 0.040 & 3.01 & 0.885 \\
\hline 3-FM $\mathrm{FM}_{40} \mathrm{Cll}$ & 67.86 & 7.6 & 27.94 & 32.96 & 1.400 & 0.040 & 1.77 & 2.059 \\
\hline 4-FM $\mathrm{FM}_{40} \mathrm{Cll}$ & 109.82 & 12.30 & 145.00 & 150.02 & 1.400 & 0.040 & 8.07 & 0.732 \\
\hline
\end{tabular}

\subsubsection{Uso da relação que considera o efeito da coesão}

Como o solo convencional1 - do campus II é coesivo, para considerar a coesão usouse a equação 33 para formular a equação que determina o coeficiente de atrito aparente solo-fita $\mathrm{f}^{*}$, que foi designada por equação 37.

$F_{a r r}=2$. Area. $C_{\alpha}+\sigma_{v}^{\prime} \cdot f^{*} \Rightarrow f^{*}=\frac{\left(\frac{F_{a r r}}{2 * B^{*} L}\right)-C \alpha}{\sigma_{v}^{\prime}}$

Tabela 5.13-Resultados considerando o efeito da coesão

\begin{tabular}{ccccccccc}
\hline Ensaio & $\sigma^{\prime}{ }_{\text {tatal }}(\mathrm{KPa})$ & $\mathrm{F}_{\text {arr }(\mathrm{KN})}$ & $\mathrm{H}_{\text {eq }}(\mathrm{m})$ & $\mathrm{Ca}(\mathrm{kPa})$ & $\mathrm{T}_{\max }(\mathrm{kPa})$ & $f^{\prime}$ & $\mathrm{L}(\mathrm{m})$ & $\mathrm{B}(\mathrm{m})$ \\
\hline 1-FM60_CII & 53.850 & 11.84 & 2.90 & 40.6 & 70.48 & 0.555 & 1.400 & 0.060 \\
2-FM60_CII & 155.490 & 16.43 & 8.36 & 40.6 & 97.80 & 0.368 & 1.400 & 0.060 \\
3-FM60_CII & 29.174 & 5.20 & 1.57 & 40.6 & 30.95 & -0.331 & 1.400 & 0.060 \\
1-FM40_CII & 95.742 & 9.76 & 5.15 & 40.6 & 87.14 & 0.486 & 1.400 & 0.040 \\
2-FM40_CII & 56.022 & 5.55 & 3.01 & 40.6 & 49.55 & 0.160 & 1.400 & 0.040 \\
3-FM40_CII & 32.962 & 7.61 & 1.77 & 40.6 & 67.95 & 0.830 & 1.400 & 0.040 \\
4-FM40_CII & 150.022 & 12.30 & 8.07 & 40.6 & 109.82 & 0.461 & 1.400 & 0.040 \\
\hline
\end{tabular}


Quando o coeficiente de atrito aparente e calculado pela norma brasileira NRB 9286 de 1986, através das equações 2 e 3, conduzem à resultados diferentes dos resultados pela prática dos ensaios, a Tabela 5.14 mostra os resultados segundo a norma.

Tabela 5.14 - Resultados teóricos considerando a norma NRB 9286/86

\begin{tabular}{|c|c|c|c|c|c|c|c|c|}
\hline Ensaio & $\sigma^{\prime}{ }_{v}(\mathrm{kPa})$ & $f^{*}$ & $\mathrm{H}_{\mathrm{eq}}(\mathrm{m})$ & $F_{\text {arr. }}(\mathrm{KN})$ & $\Phi\left(^{\circ}\right)$ & $Z_{0}(m)$ & $\tau_{\max }(\mathrm{kPa})$ & $f^{*}{ }_{0}$ \\
\hline 1 - $\mathrm{FM}_{60} \_\mathrm{Cll}$ & 53.85 & 1.074 & 2.90 & 11.84 & 31.7 & 6 & 57.85 & 1.500 \\
\hline 2-FM $\mathrm{FO}_{60} \mathrm{Cll}$ & 155.49 & 0.618 & 8.36 & 16.43 & 31.7 & 6 & 96.09 & 1.500 \\
\hline 3-FM ${ }_{60 \_C l l}$ & 29.17 & 1.269 & 1.57 & 5.20 & 31.7 & 6 & 37.03 & 1.500 \\
\hline 1-FM40_Cll & 95.74 & 0.743 & 5.15 & 9.76 & 31.7 & 6 & 71.13 & 1.500 \\
\hline 2-FM40_CII & 56.02 & 1.057 & 3.01 & 5.55 & 31.7 & 6 & 59.22 & 1.500 \\
\hline 3-FM40_CII & 32.96 & 1.239 & 1.77 & 7.6 & 31.7 & 6 & 40.85 & 1.500 \\
\hline 4-FM40_CII & 150.02 & 0.618 & 8.07 & 12.30 & 31.7 & 6 & 92.71 & 1.500 \\
\hline
\end{tabular}

\subsubsection{Solo não Convencional 2 - Rodovia 215 -São Carlos-SP}

O solo não convencional 2 - Rodovia 215, é classificado como sendo silte elástico MH. Este solo, segundo a norma brasileira de terra armada NBR9286 de 1986, faz parte de solos do grupo E; com uma granulometria $\left(0,015 \mathrm{~mm}>\mathrm{D}_{20}\right)$, segundo a mesma norma, a utilização de solos deste grupo depende de estudos especiais.

Para este solo, foram realizados ensaios de arrancamento e de permeabilidade, com a intenção de avaliar a sua interação com as inclusões durante o ensaio de arrancamento comparando os resultados com os teóricos e ainda comparar a sua condutividade hidráulica a de areia, com o propósito de entender como seria a drenagem neste tipo de solo. Os resultados dos ensaios são apresentados a seguir em formas de tabelas e gráficos.

Ensaios com as fita metálica com larguras de $60 \mathrm{~mm}$ para este solo foram designadas por " $\mathrm{FM}_{60}-\mathrm{R}$ ", as de largura de $40 \mathrm{~mm}$, por " $\mathrm{FM}_{40}-\mathrm{R}$ ". O R serviu como diminuitivo da palavra rodovia.

A Tabela 5.15 apresenta os valores médios que caracterizaram os ensaios de arrancamento de fitas metálicas em solo não convencional 2. 
Tabela 5.15- Controle de umidade e grau de compactação.

\begin{tabular}{ccccccccc}
\hline Ensaio & $\begin{array}{c}\mathrm{w} \\
(\%)\end{array}$ & $\begin{array}{c}\mathrm{m}_{\text {cilindro }} \\
(\mathrm{g})\end{array}$ & $\begin{array}{c}\mathrm{m}_{\mathrm{s}+\text { cilindro }}(\mathrm{g}) \\
\text { 1-FM60_R }\end{array}$ & $\begin{array}{c}\mathrm{m}_{\text {solo }} \\
(\mathrm{g})\end{array}$ & $\begin{array}{c}\mathrm{V}_{\text {cilindro }} \\
(\mathrm{cm} 3)\end{array}$ & $\begin{array}{c}\rho_{\mathrm{n}} \\
(\mathrm{g} / \mathrm{cm} 3)\end{array}$ & $\begin{array}{c}\rho_{\mathrm{d}} \\
(\mathrm{g} / \mathrm{cm} 3)\end{array}$ & $\begin{array}{c}\mathrm{GC} \\
(\%)\end{array}$ \\
\hline 2-FM & 29.50 & 1220.60 & 3101.97 & 1881.37 & 1006.838 & 1.868593 & 1.443 & $97.5 \%$ \\
3-FM & 29.10 & 1220.60 & 3103.11 & 1882.51 & 1006.838 & 1.869725 & 1.448 & $97.9 \%$ \\
1-FM40_R & 29.70 & 1220.60 & 3099.80 & 1879.20 & 1006.838 & 1.866437 & 1.439 & $97.2 \%$ \\
2-FM40_R & 29.80 & 1220.60 & 3058.03 & 1837.43 & 1006.838 & 1.824951 & 1.406 & $95.0 \%$ \\
3-FM40 R & 29.30 & 1220.60 & 3101.01 & 1880.41 & 1006.838 & 1.867639 & 1.444 & $97.6 \%$ \\
\hline
\end{tabular}

Como se pode observar, na Tabela 5.15, a umidade ficou ligeiramente acima da umidade ótima, mas sem passar de 1\% para todos os ensaios; quanto ao grau de compactação registrou-se uma variação entre os seis ensaios de $3.10 \%$, isso se deve ao fato de nalgumas vezes tentar-se reduzir a energia de modo a evitar a danificação dos sensores inseridos no maciço, nomeadamente células de tensão total e os strain gages.

\subsubsection{Gráficos obtidos usando fitas de $60 \mathrm{~mm}$ de largura.}

Os gráficos que representam os resultados dos ensaios de arrancamento de fitas metálicas com o solo da rodovia (solo não convencional 2), são apresentados nas Figura 5.19 aFigura 5.24.

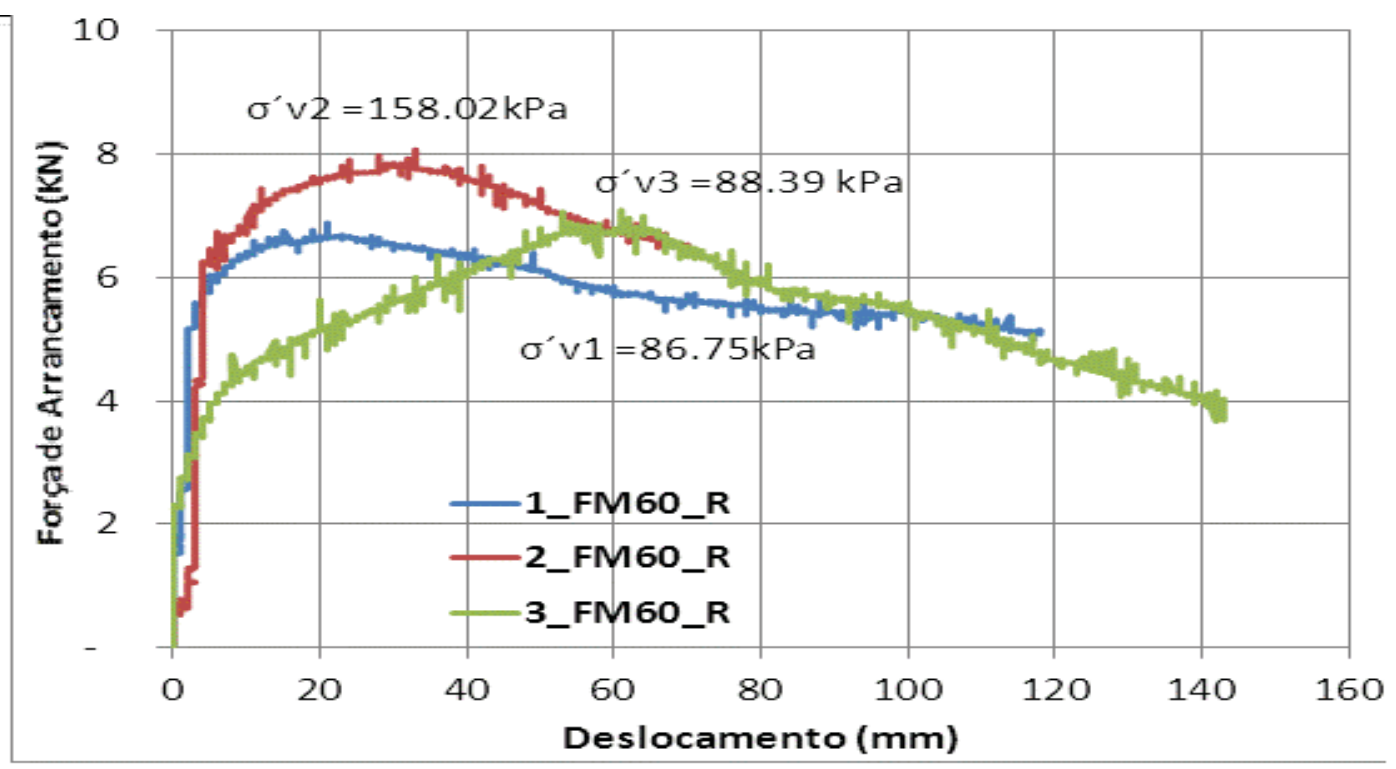

Figura 5.19 - Força de arrancamento X deslocamento 


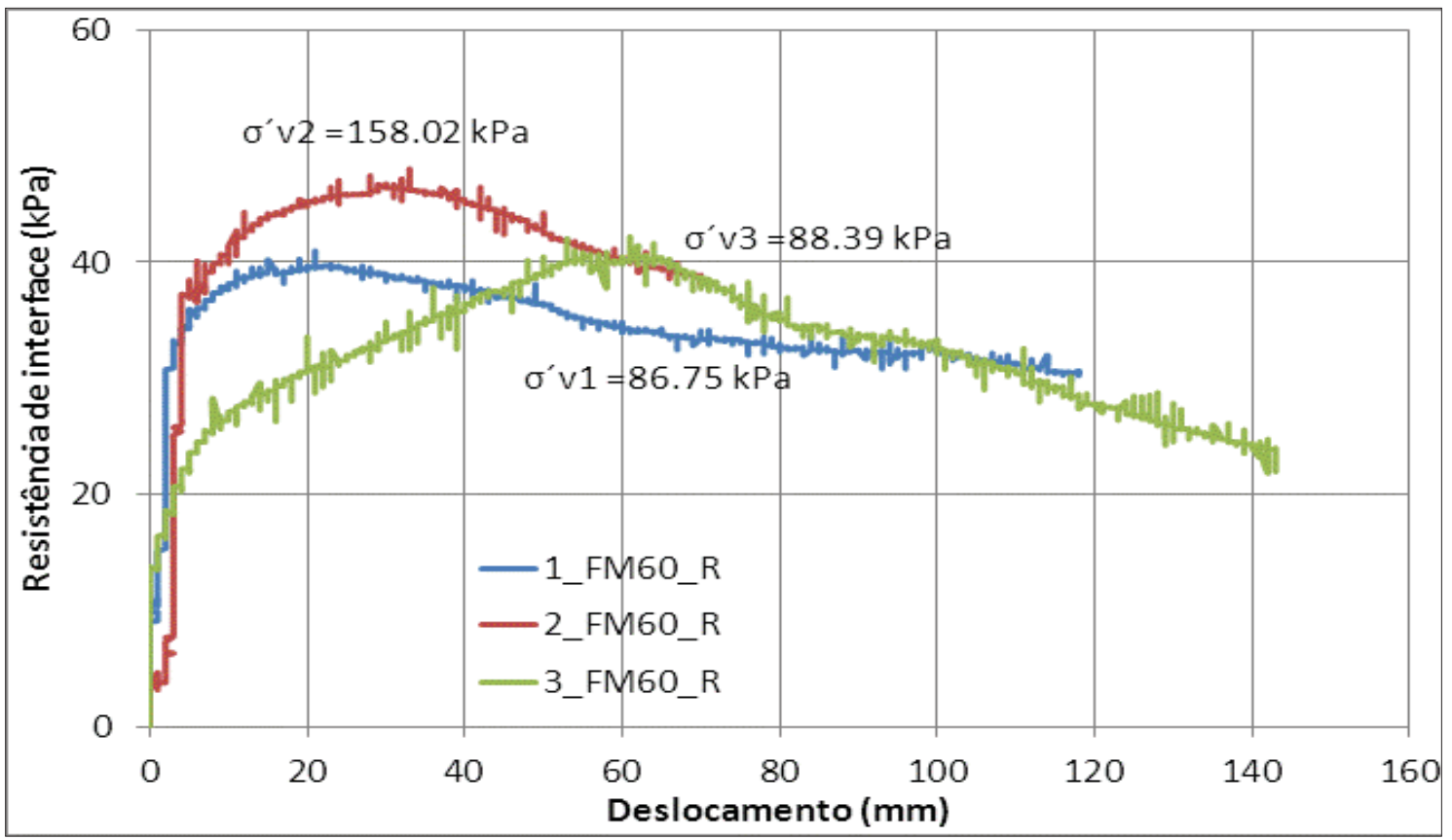

Figura 5.20 - Resistência da interface X deslocamento ( forma usual em terra armada)

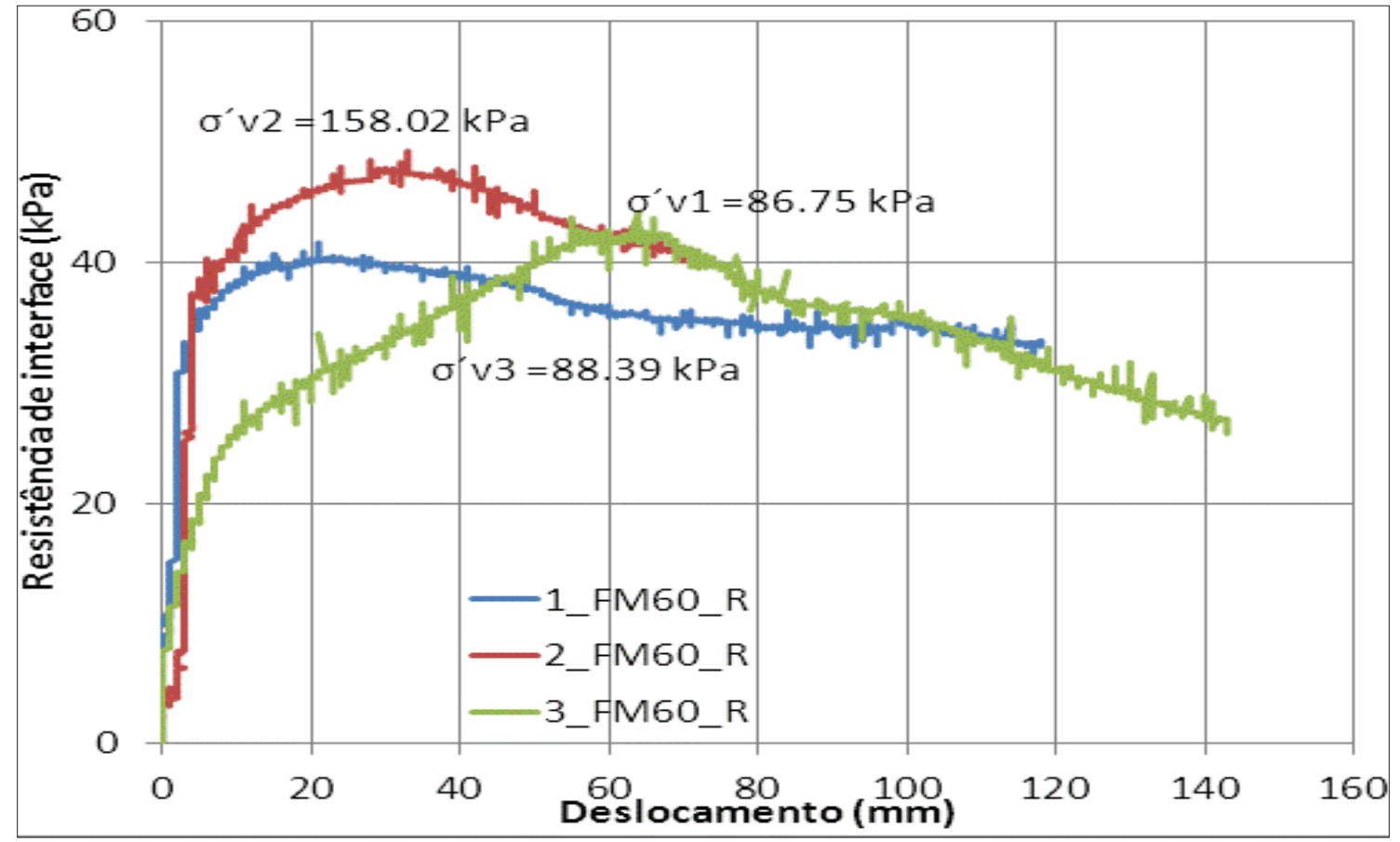

Figura 5.21 - Resistência da interface em função do comprimento arrancado X deslocamento 


\subsubsection{Gráficos para fitas de largura $40 \mathrm{~mm}$}

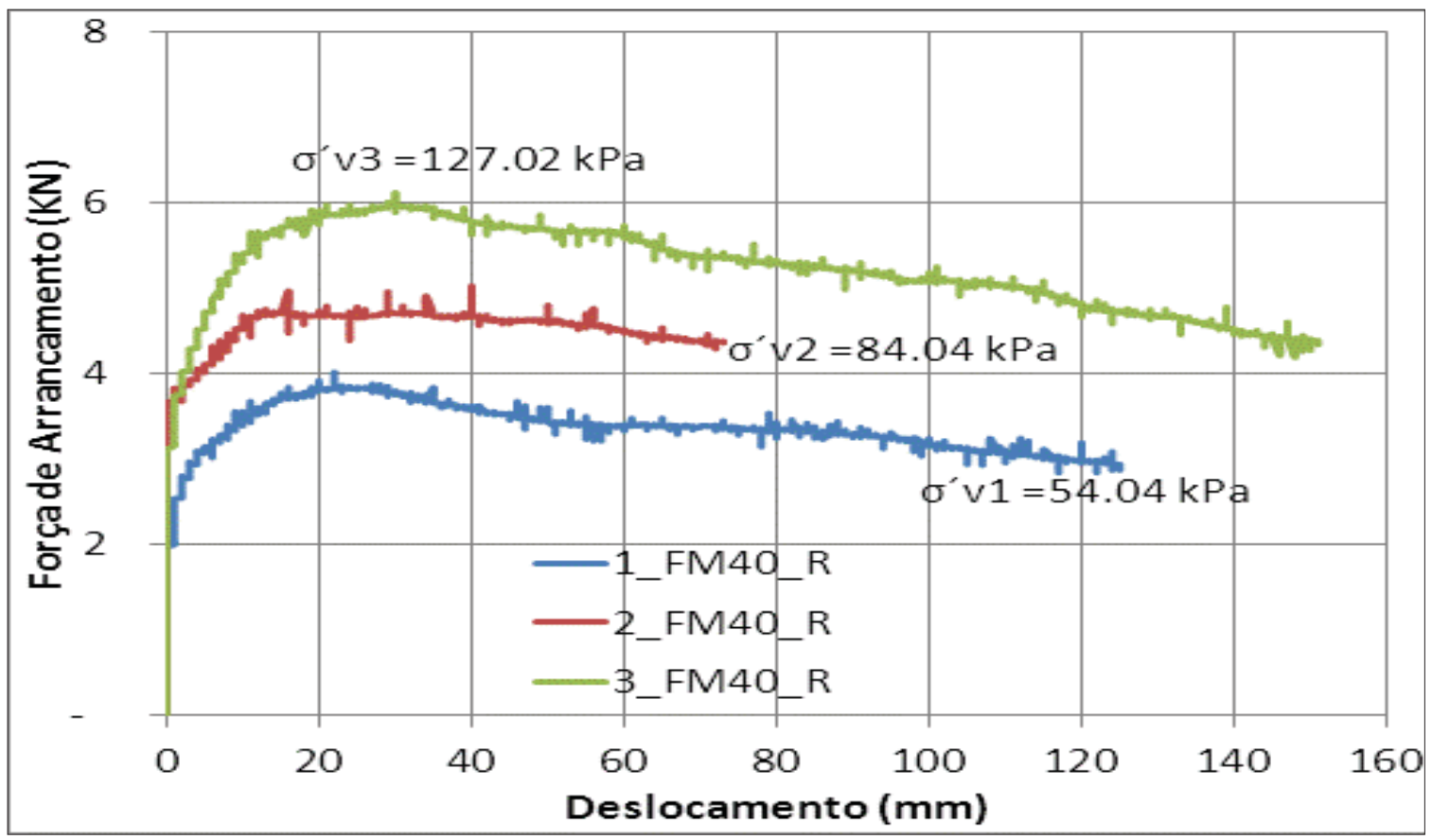

Figura 5.22 - Força de arrancamento X deslocamento

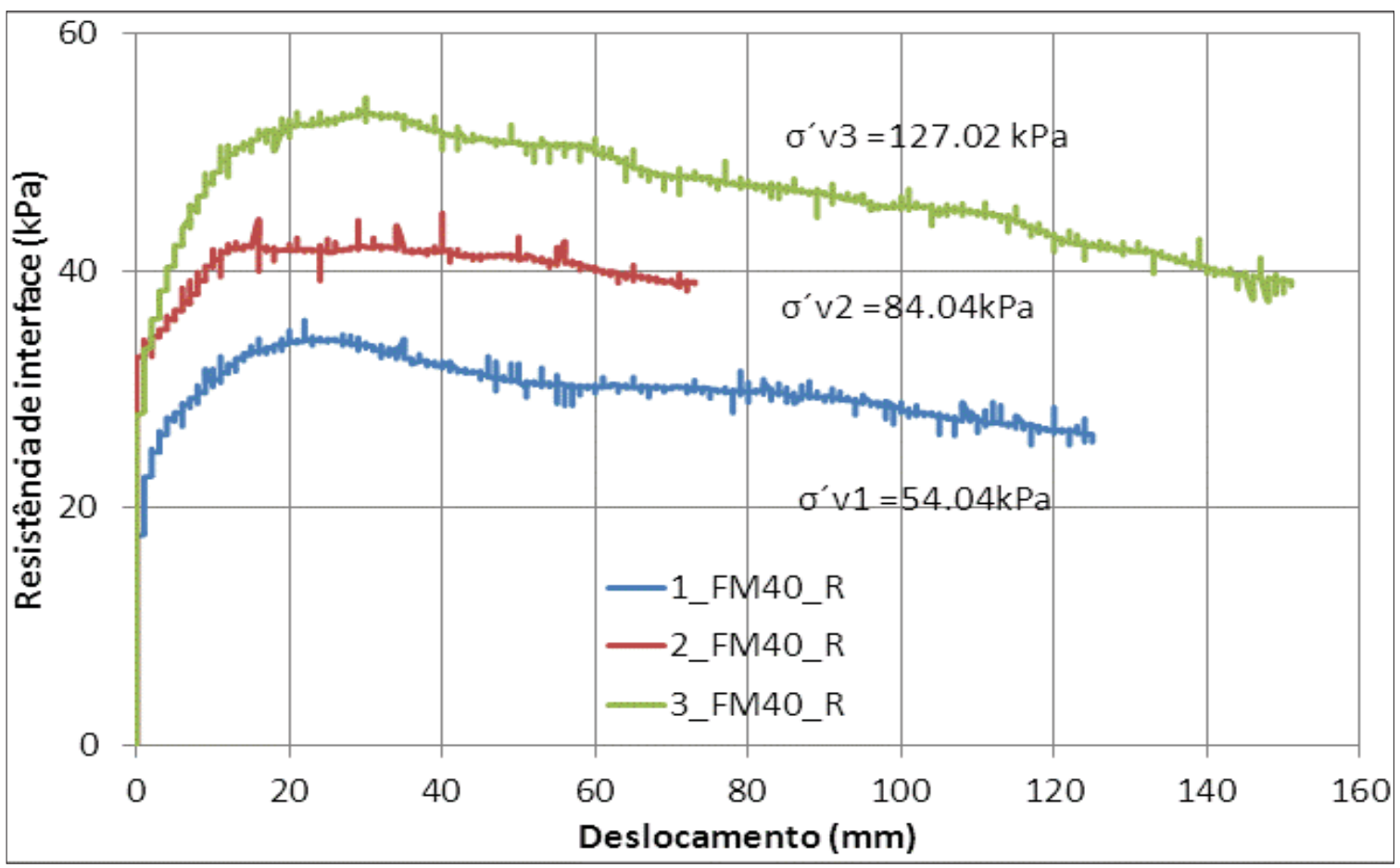

Figura 5.23 - Resistência da interface X deslocamento ( forma usual em terra armada) 


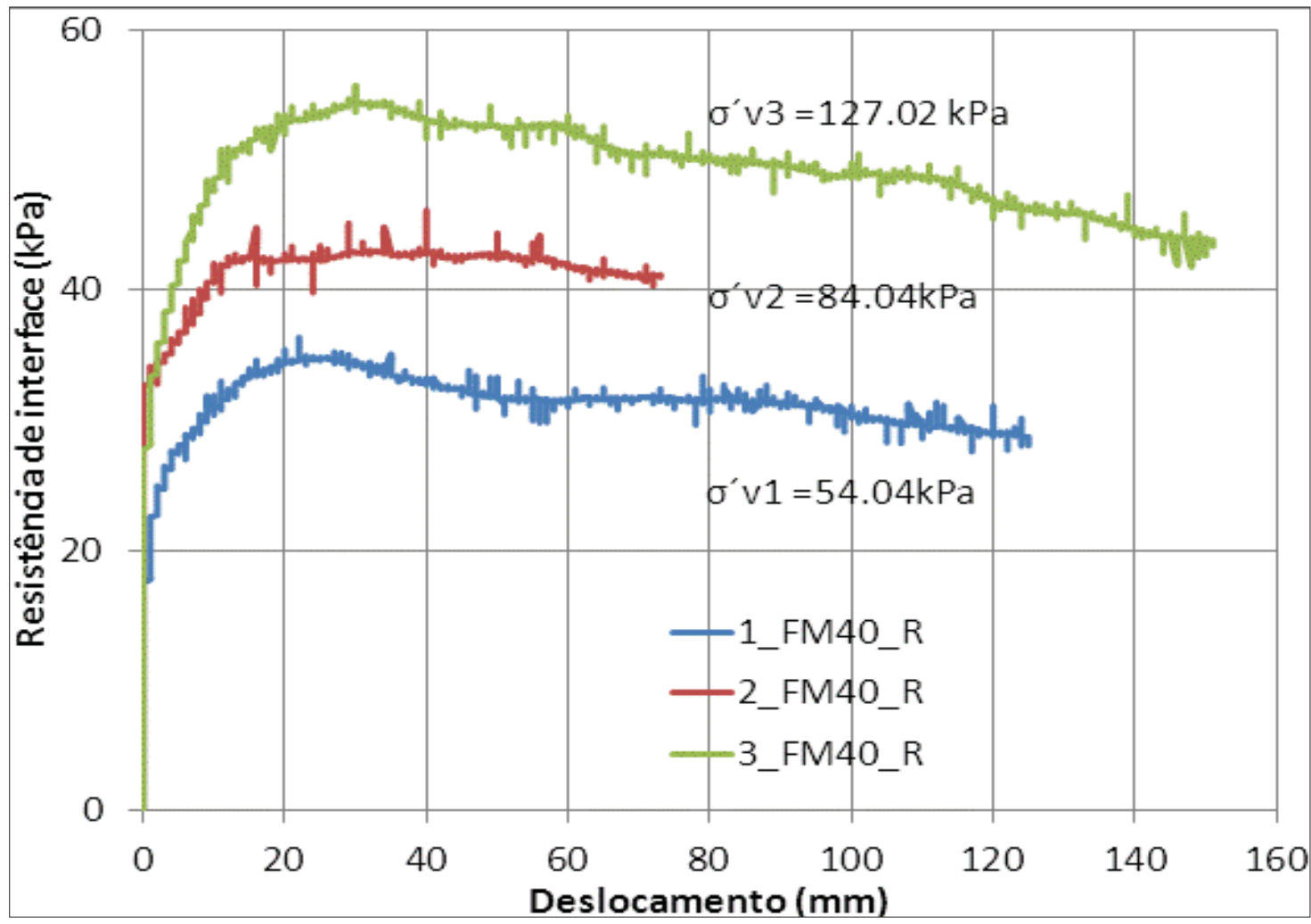

Figura 5.24 - Resistência da interface em função do comprimento arrancado X deslocamento

Os valores das forças de arrancamento máximas obtidas durante o arrancamento das fitas são apresentados na Tabela 5.16.

Tabela 5.16 - Forças de arrancamento máximas registadas.

\begin{tabular}{lrcc}
\hline Ensaio & $\Delta \sigma_{\mathrm{v}}{ }^{\prime}(\mathrm{kPa})$ & $\sigma_{\mathrm{v}}{ }^{\prime}$ tatal $(\mathrm{KPa})$ & $\mathrm{F}_{\text {arr }}(\mathrm{KN})$ \\
\hline 1 - FM60_R & 82.731 & 86.754 & 6.760 \\
2 - FM60_R & 154.000 & 137.523 & 7.850 \\
3 - $\mathrm{FM}_{60 \_R}$ & 84.369 & 51.392 & 6.900 \\
1-FM40_R & 50.021 & 54.044 & 3.900 \\
2-FM40_R & 80.017 & 84.040 & 4.890 \\
3-FM40_R & 123.000 & 127.023 & 6.000 \\
\hline
\end{tabular}

Usando a equação 36, que não considera o efeito da coesão têm-se os resultados apresentados a seguir, na Tabela 5.17. 
Tabela 5.17 - Resultados de cálculos sem considerar a coesão do solo

\begin{tabular}{|c|c|c|c|c|c|c|c|c|}
\hline Ensaio & $\tau_{\max }(\mathrm{kPa})$ & $\mathrm{F}_{\text {arr }}(\mathrm{KN})$ & $\Delta \sigma_{\mathrm{v}}{ }^{\prime}(\mathrm{kPa})$ & $\sigma_{v^{\prime} \text { tatal }}(\mathrm{KPa})$ & $\mathrm{L}(\mathrm{m})$ & $B(m)$ & $\mathrm{H}_{\mathrm{eq}}(\mathrm{m})$ & $f^{*}$ ad \\
\hline 1 - FM $\mathrm{FM}_{60 \mathrm{R}}$ & 40.24 & 6.760 & 82.731 & 86.754 & 1.400 & 0.060 & 5.82 & 0.464 \\
\hline 2 - FM $60 \_R$ & 46.73 & 7.850 & 154.000 & 158.023 & 1.400 & 0.060 & 10.61 & 0.296 \\
\hline 3 - FM $60 \_R$ & 41.07 & 6.900 & 84.369 & 88.392 & 1.400 & 0.060 & 5.93 & 0.465 \\
\hline 1-FM40_R & 34.82 & 3.900 & 50.021 & 54.044 & 1.400 & 0.040 & 3.63 & 0.644 \\
\hline 2-FM $40 \_R$ & 43.66 & 4.890 & 80.017 & 84.040 & 1.400 & 0.040 & 5.64 & 0.520 \\
\hline 3-FM $\mathrm{FM}_{40 \mathrm{R}}$ & 53.57 & 6.000 & 123.000 & 127.023 & 1.400 & 0.040 & 8.53 & 0.422 \\
\hline
\end{tabular}

Usando a equação 37, que considera a coesão têm-se os valores apresentados na Tabela 5.18.

Tabela 5.18 - Resultados calculados pela equação 37, considerando a coesão

\begin{tabular}{|c|c|c|c|c|c|c|c|c|}
\hline Ensaio & $\sigma \mathrm{V}^{\prime}$ tatal $(\mathrm{KPa})$ & $\mathrm{F}_{\text {arr (KN) }}$ & $\mathrm{H}_{\mathrm{eq}}(\mathrm{m})$ & $\mathrm{Ca}(\mathrm{kPa})$ & $T_{\max }(\mathrm{kPa})$ & 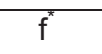 & $\mathrm{L}(\mathrm{m})$ & $B(m)$ \\
\hline 1-FM $60-R$ & 86.754 & 6.760 & 5.82 & 29.98 & 40.24 & 0.118 & 1.400 & 0.060 \\
\hline 2-FM $60-R$ & 158.023 & 7.850 & 10.61 & 29.98 & 46.73 & 0.106 & 1.400 & 0.060 \\
\hline 3-FM $60-R$ & 88.392 & 6.900 & 5.93 & 29.98 & 41.07 & 0.125 & 1.400 & 0.060 \\
\hline 1-FM $\mathrm{FM}_{40} \mathrm{R}$ & 54.044 & 3.900 & 3.63 & 29.98 & 34.82 & 0.090 & 1.400 & 0.040 \\
\hline 2-FM $\mathrm{FM}_{40} \mathrm{R}$ & 84.040 & 4.890 & 5.64 & 29.98 & 43.66 & 0.163 & 1.400 & 0.040 \\
\hline $3-\mathrm{FM}_{40}-\mathrm{R}$ & 127.023 & 6.000 & 8.53 & 29.98 & 53.57 & 0.186 & 1.400 & 0.040 \\
\hline
\end{tabular}

Quando o coeficiente de atrito aparente é calculado pela norma brasileira NRB 9286 de 1986, através das equações 2 e 3, obtêm-se os resultados apresentados na Tabela 5.19.

$$
\begin{aligned}
& f^{*}=f_{0}^{*}\left(1-\frac{z}{z_{0}}\right)+\operatorname{tg} \phi_{0}\left(\frac{z}{z_{0}}\right), z<z_{0} \\
& f^{*}=\operatorname{tg} \phi, \text { para } z \geq z_{0}
\end{aligned}
$$


Tabela 5.19 -Resultados do cálculo considerando a norma NBR 9286/86

\begin{tabular}{rccccccr}
\hline Ensaio & $\sigma_{\mathrm{v}}{ }^{\prime}(\mathrm{kPa})$ & $\mathrm{f}^{*}$ & $\mathrm{H}_{\mathrm{eq}}(\mathrm{m})$ & $\Phi\left(^{\circ}\right)$ & $\mathrm{Z}_{0}(\mathrm{~m})$ & $\tau_{\text {máx }}(\mathrm{kPa})$ & $f^{*}{ }_{0}$ \\
\hline 1-FM60_R & 86.75 & 0.644 & 5.82 & 29.11 & 6 & 55.84 & 1.500 \\
2-FM $\mathrm{FM}_{60} \mathrm{R}$ & 158.02 & 0.557 & 10.61 & 29.11 & 6 & 88.02 & 1.500 \\
3-FM60_R & 88.39 & 0.628 & 5.93 & 29.11 & 6 & 55.47 & 1.500 \\
1-FM40_R & 54.04 & 0.967 & 3.63 & 29.11 & 6 & 52.24 & 1.500 \\
2-FM40_R & 84.04 & 0.671 & 5.64 & 29.11 & 6 & 56.35 & 1.500 \\
3-FM40_R & 127.02 & 0.557 & 8.53 & 29.11 & 6 & 70.75 & 1.500 \\
\hline
\end{tabular}

\subsubsection{Ensaios de arrancamento de fitas metálicas em solo granular da mineradora Jundu-Descalvado.}

Para os ensaios com o solo granular para além dos equipamentos já descritos nas páginas anteriores foi adicionalmente usada a caixa de chuva de areia. Com ajuda da caixa de chuva de areia, foi calibrada a altura da qual a queda corresponde às diferentes compacidades relativas. A caixa, durante a preparação do maciço faz a distribuição do solo na caixa de ensaio, pois, é composta por um sistema que permite circular de uma ponta a outra, permitindo controlar a compacidade do solo. A Figura 5.25, mostra o gráfico de calibração da chuva de areia.

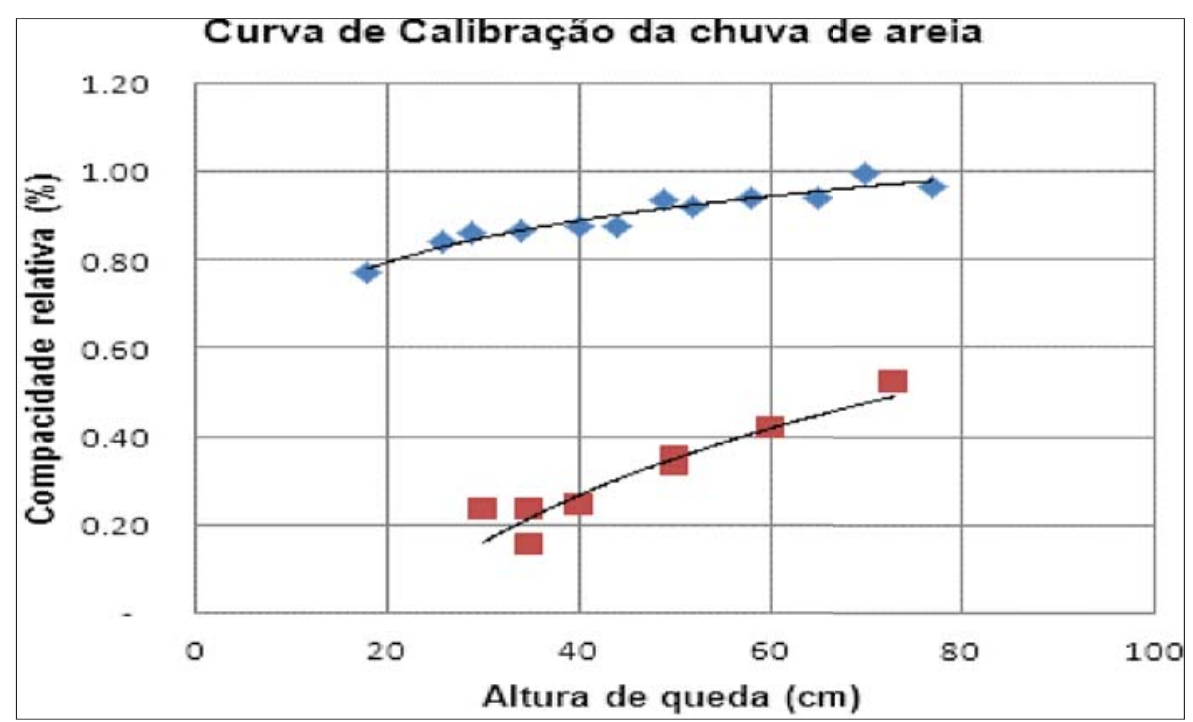

Figura 5.25 - Calibração da chuva de areia 
A Tabela 5.20 apresenta as forças de arrancamento máximas obtidas durante os ensaios arrancamento das fitas metálicas em areia.

Tabela 5.20 - Os valores que caracterizaram os ensaios com areia e fitas metálicas.

\begin{tabular}{ccccc}
\hline Ensaio & $\Delta \sigma_{v}{ }^{\prime}(\mathrm{kPa})$ & $\sigma_{\mathrm{v}}{ }^{\prime}$ tatal $(\mathrm{KPa})$ & $\mathrm{F}_{\text {arr. }}(\mathrm{KN})$ & $\mathrm{CR}(\%)_{\text {médio }}$ \\
\hline 1_FM40_A & 51.400 & 55.99 & 2.720 & 99 \\
2_FM40_A & 93.710 & 98.30 & 6.480 & 99 \\
3_FM40_A & 140.224 & 144.81 & 8.980 & 99 \\
4_FM60_A & 60.416 & 65.01 & 6.100 & 99 \\
5_FM60_A & 95.117 & 99.71 & 6.800 & 99 \\
6_FM60_A & 157.142 & 161.73 & 13.100 & 99 \\
\hline
\end{tabular}

Nos gráficos que são apresentados a seguir, são apresentados os resultados dos ensaios de arrancamento com areia provinda da mineradora de Jundú, São Carlos-SP. Vale lembrar que essa areia era mal graduada. As Figura 5.26 a Figura 5.31 apresentam os gráficos dos resultados desses ensaios.

\subsubsection{Ensaios de arrancamento com fitas metálicas de largura $60 \mathrm{~mm}$}

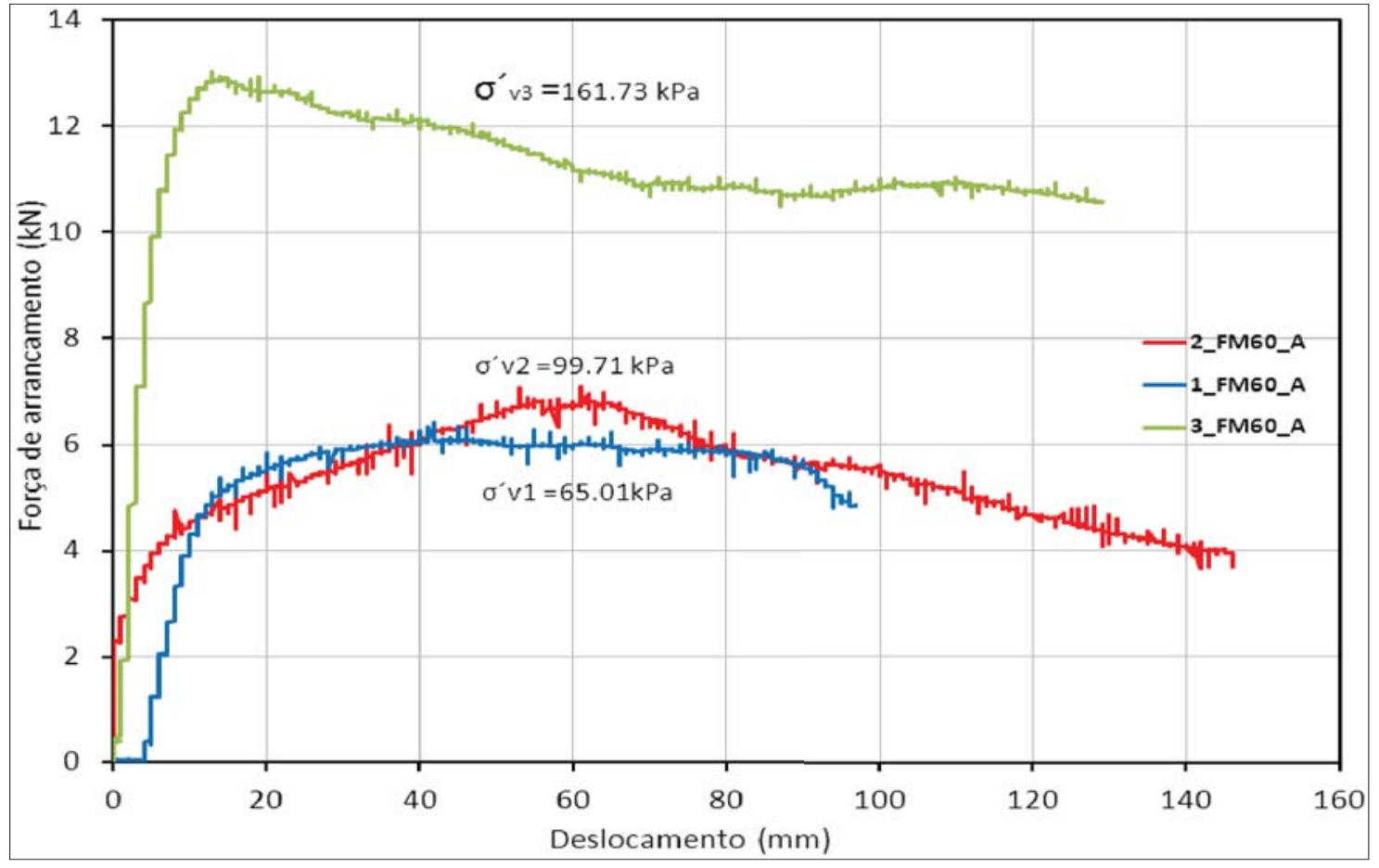

Figura 5.26 - Força de arrancamento X deslocamento 


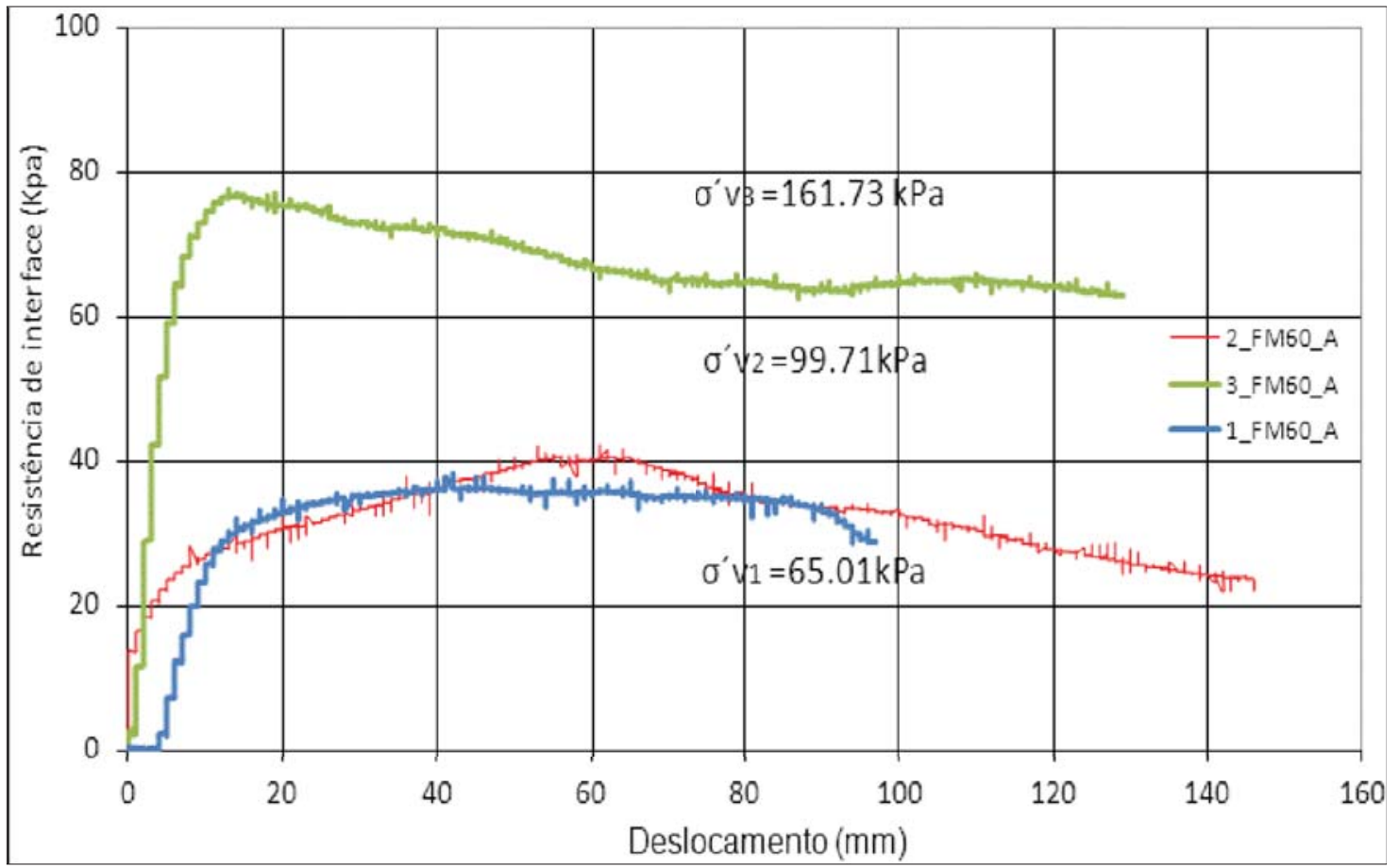

Figura 5.27 - Resistência da interface X deslocamento ( forma usual em terra armada)

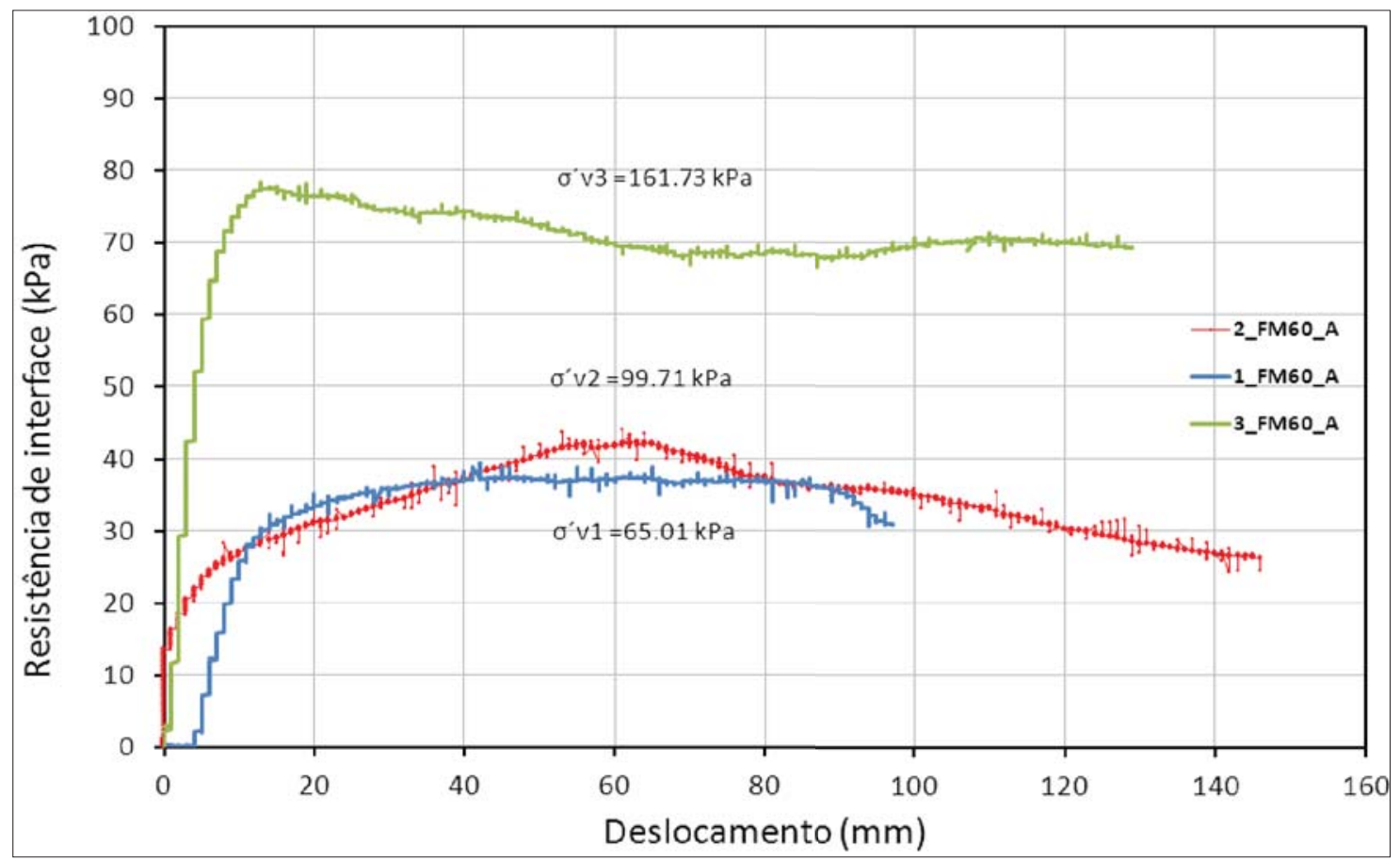

Figura 5.28 - Resistência da interface em função do comprimento arrancado X deslocamento 


\subsubsection{Ensaios de arrancamento com fitas metálicas de largura $40 \mathrm{~mm}$}

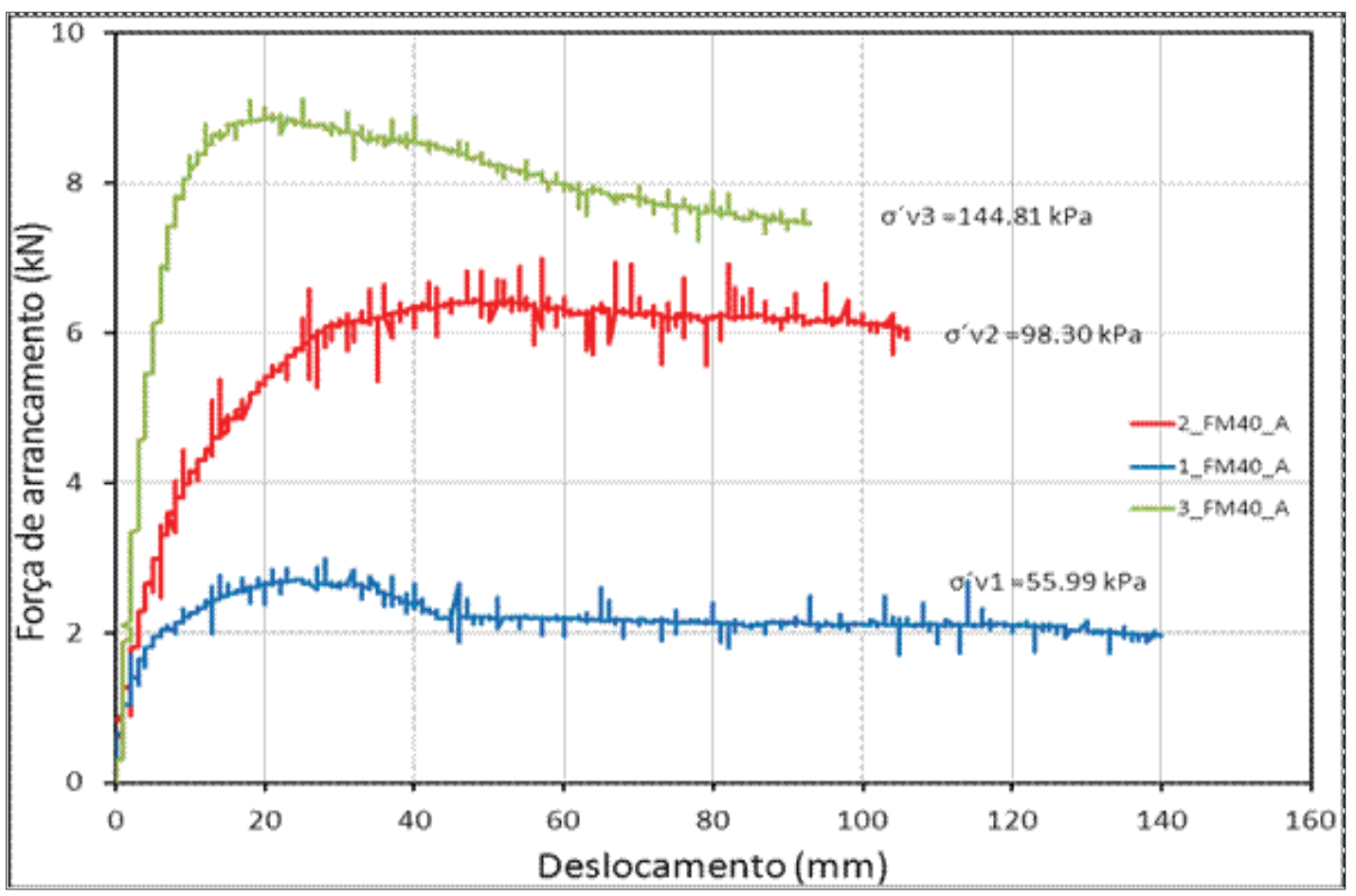

Figura 5.29 - Força de arrancamento X deslocamento

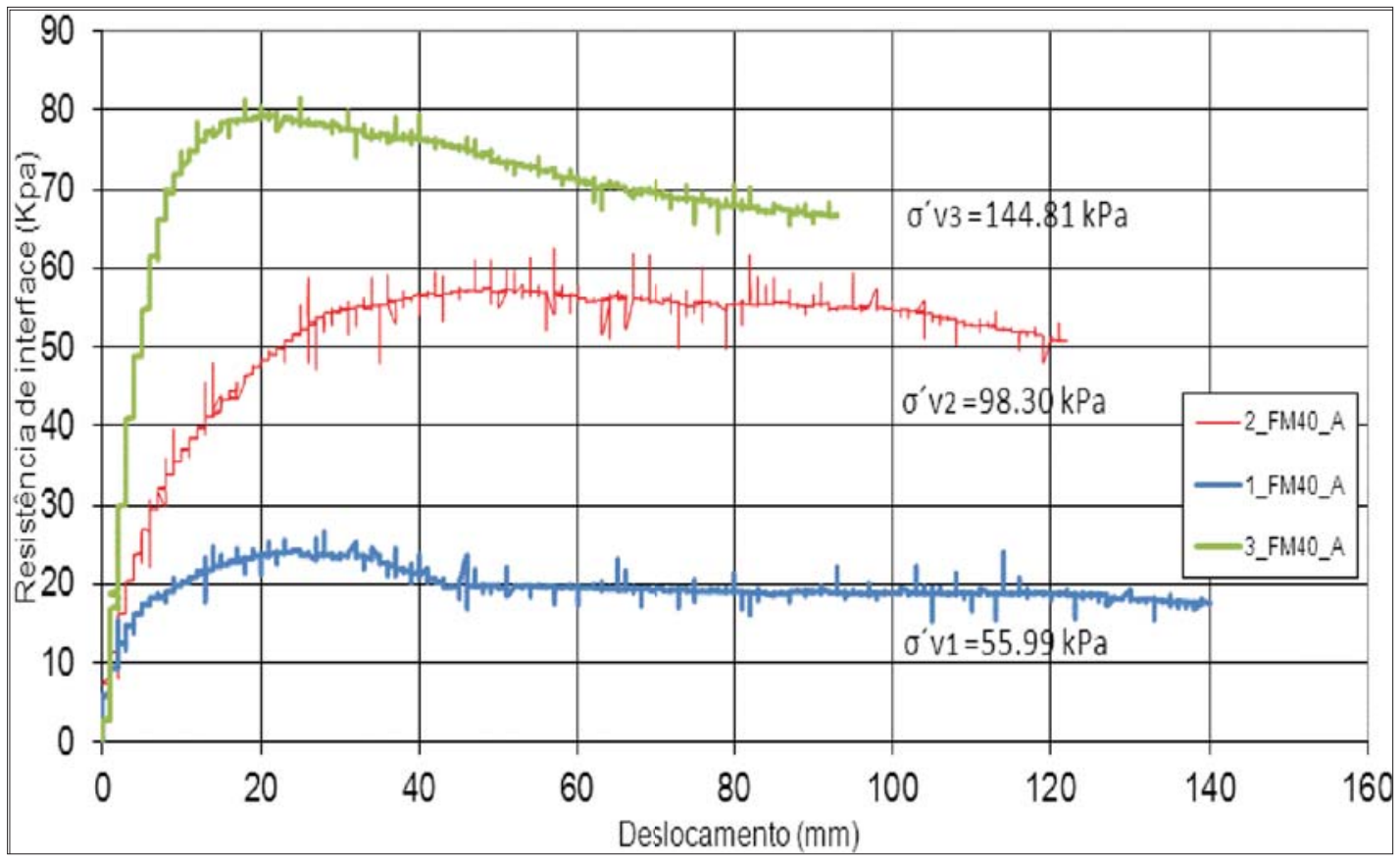

Figura 5.30 - Resistência da interface X deslocamento ( forma usual em terra armada) 


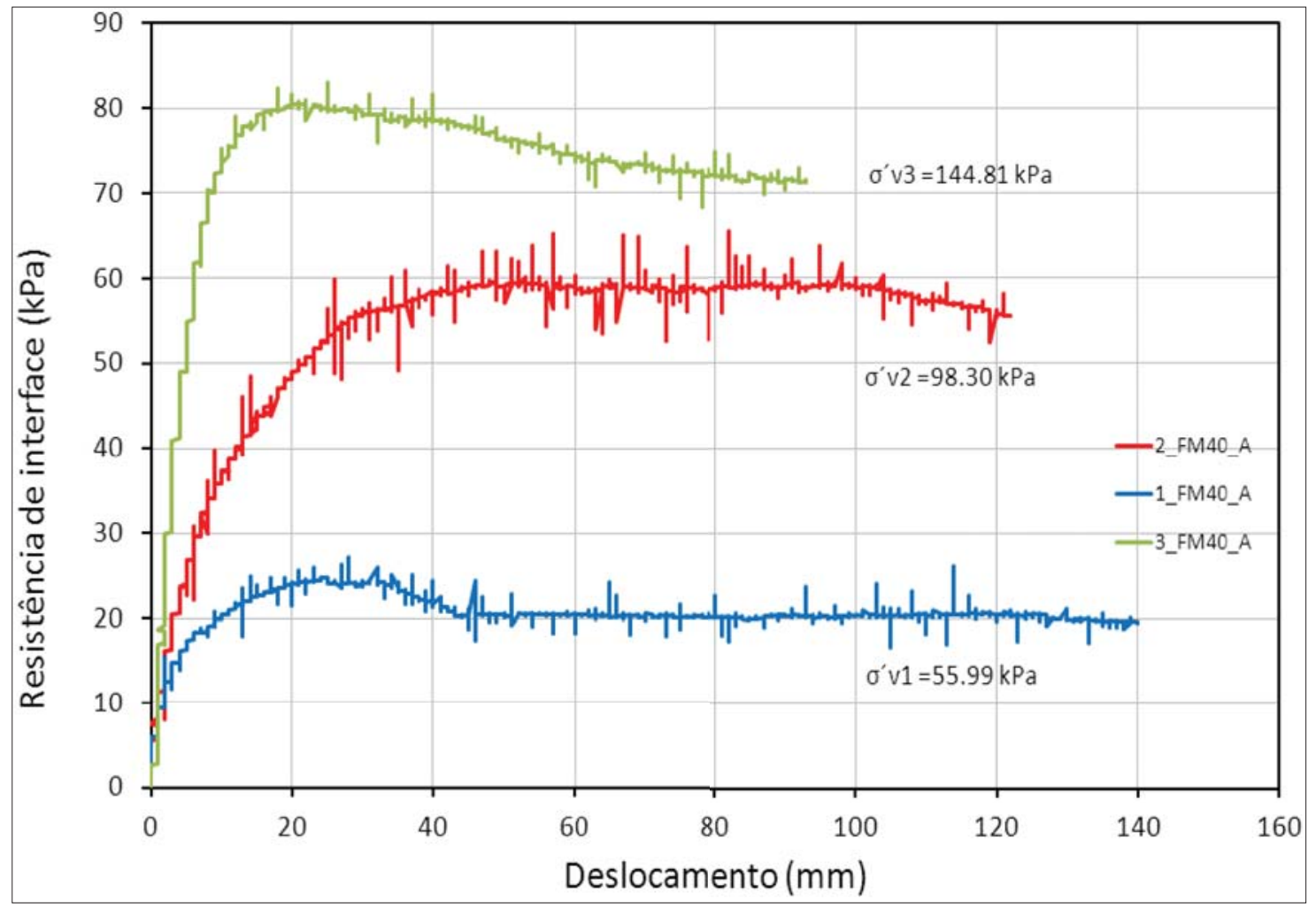

Figura 5.31 - Resistência da interface em função do comprimento arrancado X deslocamento

$\mathrm{Na}$ Tabela 5.21, a seguir, são apresentados os resultados práticos e teóricos que correspondem aos resultados obtidos segundo a norma NBR 9286/86, considerando a tensão vertical aplicada.

Os cálculos foram feitos considerando as mesmas condições dos solos anteriores exceto a coesão, por se tratar de um solo granular. Assim, têm-se na Tabela 5.21, resultados considerando a norma.

Tabela 5.21 - Resultados considerando a norma brasileira NBR 9286/86

\begin{tabular}{lcccccccccc}
\hline Ensaio & $\sigma_{\mathrm{v}}{ }^{\prime}(\mathrm{kPa})$ & $\mathrm{f}^{*}$ & $\mathrm{H}_{\text {eq }}(\mathrm{m})$ & $\Phi\left(^{\circ}\right)$ & $\mathrm{Cu}$ & $\mathrm{D}_{60}(\mathrm{~mm})$ & $\mathrm{D}_{10}(\mathrm{~mm})$ & $\mathrm{Z}_{0}(\mathrm{~m})$ & $\tau_{\operatorname{máx}}(\mathrm{kPa})$ & $\mathrm{f}^{*}$ \\
\hline 1_FM40_A & 55.99 & 1.004 & 3.29 & 37.5 & 1.71 & 0.68 & 0.35 & 6 & 56.23 & 1.433 \\
2_FM40_A & 98.30 & 0.680 & 5.78 & 37.5 & 1.71 & 0.68 & 0.35 & 6 & 66.87 & 1.433 \\
3_FM40_A & 144.81 & 0.767 & 8.52 & 37.5 & 1.71 & 0.68 & 0.35 & 6 & 111.12 & 1.433 \\
4_FM60_A & 65.01 & 0.935 & 3.82 & 37.5 & 1.71 & 0.68 & 0.35 & 6 & 60.79 & 1.433 \\
5_FM60_A & 99.71 & 0.767 & 5.87 & 37.5 & 1.71 & 0.68 & 0.35 & 6 & 76.51 & 1.433 \\
6_FM60_A & 161.73 & 0.767 & 9.51 & 37.5 & 1.71 & 0.68 & 0.35 & 6 & 124.10 & 1.433 \\
\hline
\end{tabular}

Os resultados práticos são apresentados na Tabela 5.22. 
Tabela 5.22 - Resultados práticos

\begin{tabular}{ccccccccc}
\hline Ensaio & $\tau_{\text {máx }}(\mathrm{kPa})$ & $\mathrm{F}_{\text {ar }}(\mathrm{kN})$ & $\Delta \sigma_{\mathrm{v}}{ }^{\prime}(\mathrm{kPa})$ & $\sigma_{\mathrm{v}}{ }^{\prime}$ tatal \\
\hline 1_FPa $(\mathrm{KP})$ & $\mathrm{L}(\mathrm{m})$ & $\mathrm{B}(\mathrm{m})$ & $\mathrm{H}_{\text {eq }}(\mathrm{m})$ & $\mathrm{f}^{*} \mathrm{ad}$ \\
\hline 2_FM40_A & 24.29 & 2.720 & 51.400 & 55.99 & 1.400 & 0.040 & 3.29 & 0.434 \\
3_FM40_A & 80.86 & 6.480 & 93.710 & 98.30 & 1.400 & 0.040 & 5.78 & 0.589 \\
1_FM60_A & 36.31 & 6.980 & 140.224 & 144.81 & 1.400 & 0.040 & 8.52 & 0.554 \\
2_FM60_A & 40.48 & 6.800 & 60.416 & 65.01 & 1.400 & 0.060 & 3.82 & 0.559 \\
3_FM60_A & 77.98 & 13.100 & 157.142 & 161.73 & 1.400 & 0.060 & 9.51 & 0.480 \\
\hline
\end{tabular}

\subsection{Ensaios de arrancamento de fitas poliméricas}

Com a intenção de avaliar a interação solo-fita polimérica foram realizados ensaios sendo seis ensaios de arrancamento de fitas poliméricas com areia argilosa do Campus II e outros três ensaios com o solo granular provindo da mineradora de Jandú.

As fitas poliméricas foram submetidas a ensaios de tração (Figura 5.32 e 5.33); o objetivo dos ensaios de tração foi de avaliar se as forças de arrancamentos obtidas durante a execução de ensaios poderia provocar deformações excessivas ou não nas fitas poliméricas. Os ensaios foram executados em amostras não reduzidas, facilitando assim à comparação das resistências a tração durante os ensaios de tração e de arrancamento respectivamente. Os ensaios de tração foram realizados no Laboratório de Geossintéticos do Departamento de Geotecnia da EESC-USP, no mesmo laboratório onde os ensaios de arrancamento foram executados. 


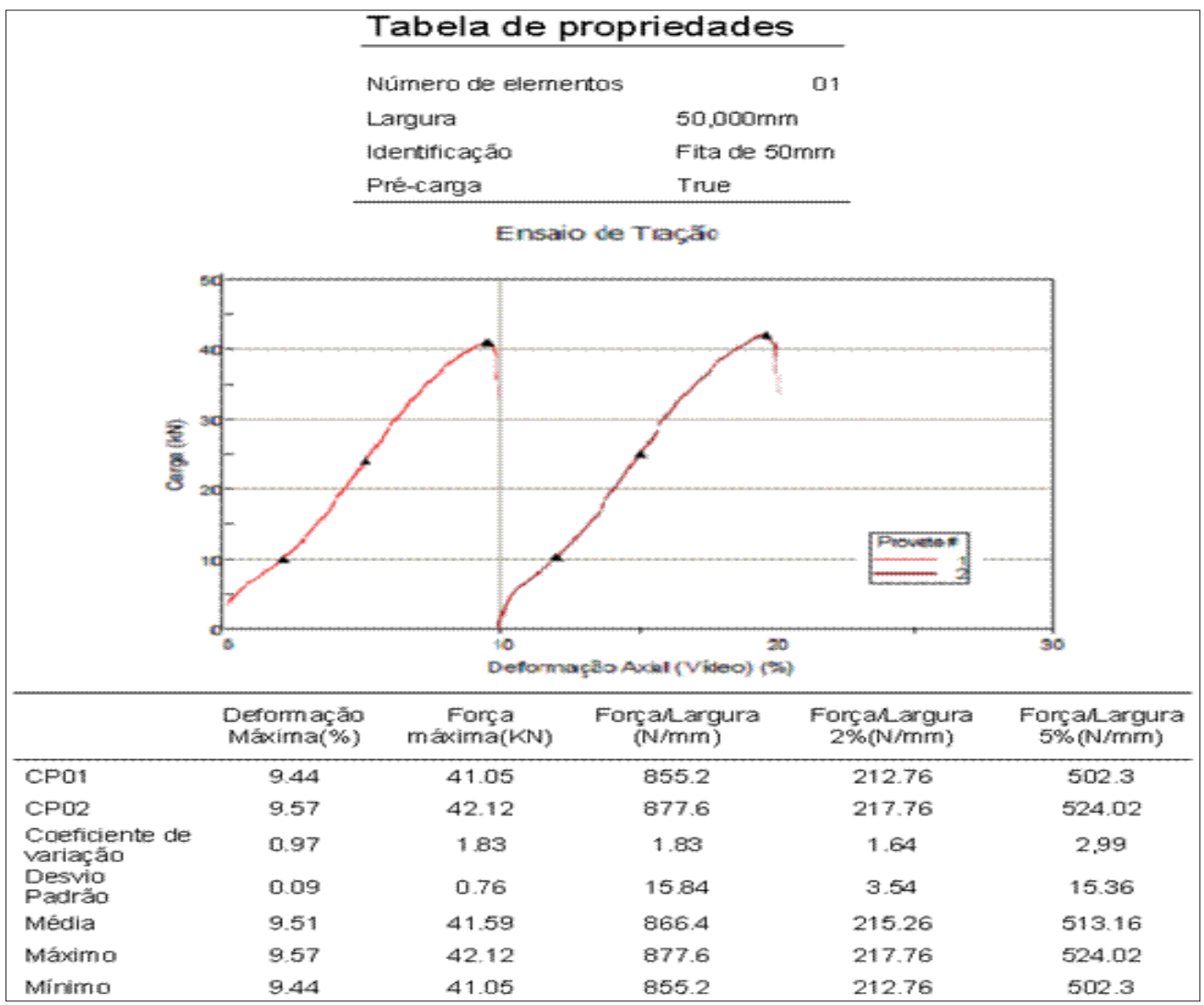

Figura 5.32 - Resultado de ensaios de tração para fita polimérica de $50 \mathrm{~mm}$ de largura

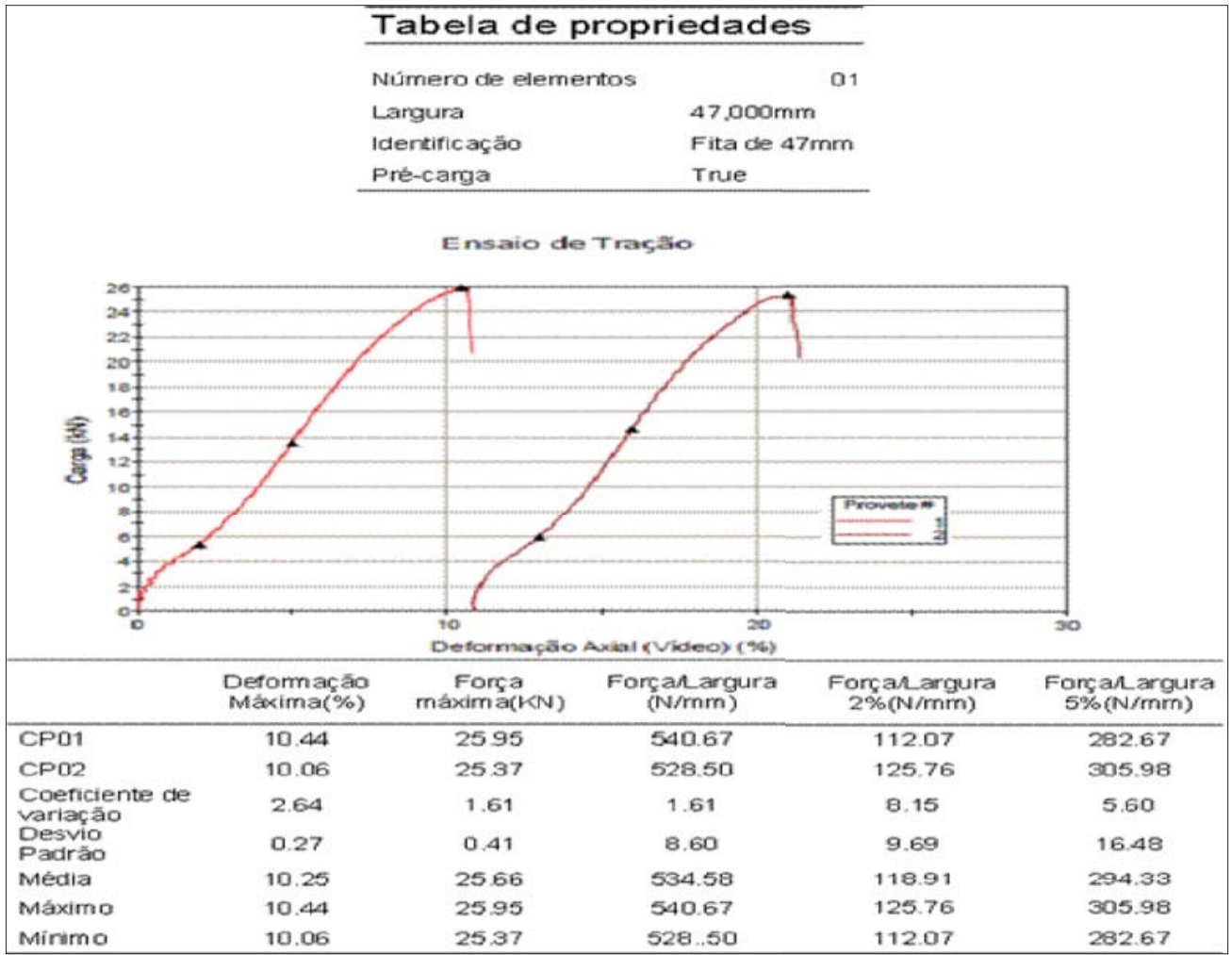

Figura 5.33 - Resultados de ensaios de tração de fita polimérica de $47 \mathrm{~mm}$. de largura 
Foi necessário aplicar uma pré-carga para cada ensaio de modo a garantir que os deslocamentos devido ao ajuste na garra de arrancamento, não interferissem no percurso do LVDT. As pré-cargas foram consideradas e adicionadas às forças de arrancamento finais.

A Figura 5.34, abaixo mostra a inserção das fitas poliméricas no maciço, durante o processo de preparação do ensaio.

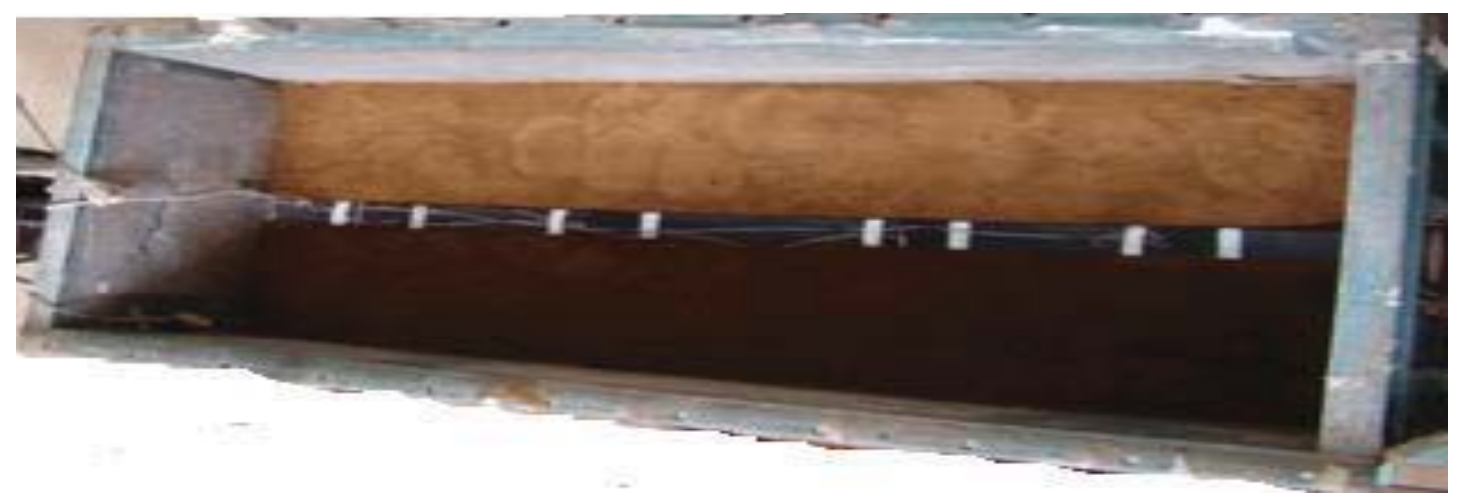

Figura 5.34 - inserção da fita polimérica no maciço

Os ensaios apresentaram resultados abaixo demonstrados através de gráficos e tabelas.

\subsubsection{Ensaios com o solo não convencional do campus II}

A Tabela 5.23 Mostra os valores das forças de arrancamento e as pré-cargas aplicadas durante a execução dos ensaios de arrancamento de fitas poliméricas em solo não convencional 1.

Tabela 5.23-Valores das forças de arrancamento e das pré-cargas usadas nos ensaios (solo não convencional

1)

\begin{tabular}{|c|c|c|c|c|c|}
\hline Ensaio & $\mathrm{F}_{\mathrm{ar}}(\mathrm{KN})$ & $\Delta \sigma_{\mathrm{v}}{ }^{\prime}(\mathrm{kPa})$ & $\sigma_{v_{v}^{\prime} \text { tatal }}(\mathrm{KPa})$ & Pé-carga $(\mathrm{KN})$ & $F_{\text {arr.total }(K N)}$ \\
\hline 1_FPO 47 CII & 5.400 & 41.470 & 46.492 & 0.392 & 5.792 \\
\hline 2_FPO ${ }_{47}$ Cll & 7.200 & 105.000 & 110.022 & 0.4214 & 7.621 \\
\hline 3_FPO ${ }_{47} \_\mathrm{Cll}$ & 8.100 & 156.660 & 161.682 & 0.3234 & 8.423 \\
\hline 1_FPO50_Cll & 8.950 & 61.536 & 66.558 & 0.3822 & 9.332 \\
\hline 2_FPO ${ }_{50 \_} \mathrm{Cll}$ & 9.000 & 124.201 & 129.223 & 0.3626 & 9.363 \\
\hline 3_ $\mathrm{FPO}_{50} \mathrm{Cll}$ & 9.500 & 160.003 & 165.025 & 0.392 & 9.892 \\
\hline
\end{tabular}


A Tabela 5.24 Mostra os valores que caracterizaram os ensaios.de arrancamento das fitas poliméricas em solo não convencional 1 .

Tabela 5.24 - Controle de umidade e grau de compactação.

\begin{tabular}{|c|c|c|c|c|c|c|c|c|}
\hline Ensaio & w & $\mathrm{m}_{\text {cilindro }}$ & $\mathrm{m}_{\mathrm{s}+\mathrm{cilin} d r o}$ & $m_{\text {solo }}$ & $\mathrm{V}_{\text {cilindro }}$ & $\rho_{n}$ & $\rho_{d}$ & GC \\
\hline & $(\%)$ & (g) & (g) & (g) & (cm3) & $(\mathrm{g} / \mathrm{cm} 3)$ & $(\mathrm{g} / \mathrm{cm} 3)$ & $(\%)$ \\
\hline 1_FPO47_Cll & 14.50 & 1220.60 & 3199.27 & 1978.67 & 1006.838 & 1.96523 & 1.716 & $93.8 \%$ \\
\hline 2_FPO47_Cll & 14.30 & 1220.60 & 2821.99 & 1601.39 & 1006.838 & 1.59051 & 1.392 & $94.6 \%$ \\
\hline 3_FPO $\mathrm{FP}_{47} \mathrm{Cll}$ & 14.65 & 1220.60 & 2837.00 & 1616.40 & 1006.838 & 1.60542 & 1.400 & $95.2 \%$ \\
\hline 1_FPO ${ }_{50 \_C l l}$ & 14.61 & 1220.60 & 2841.12 & 1620.52 & 1006.838 & 1.60951 & 1.404 & $95.4 \%$ \\
\hline 2_FPO50_CII & 14.65 & 1220.60 & 2827.01 & 1606.41 & 1006.838 & 1.5955 & 1.392 & $94.6 \%$ \\
\hline 3_FPO $\mathrm{FPO}_{50} \mathrm{Cll}$ & 14.61 & 1220.60 & 2804.90 & 1584.30 & 1006.838 & 1.57354 & 1.373 & $93.3 \%$ \\
\hline
\end{tabular}

Os cálculos foram efetuados considerando as relações usadas em páginas anteriores com inclusões metálicas. Em seguida, são apresentados os resultados em forma de gráficos, resultados das forças. e posteriormente as tabelas que contêm os valores calculados dos coeficientes de atrito aparente solo-fitas poliméricas. Os resultados em gráficos são apresentados nas Figuras 35 a 40, segundo a sequência usada nos ensaios anteriores. 


\subsubsection{Gráficos obtidos usando fitas de $50 \mathrm{~mm}$ de largura.}

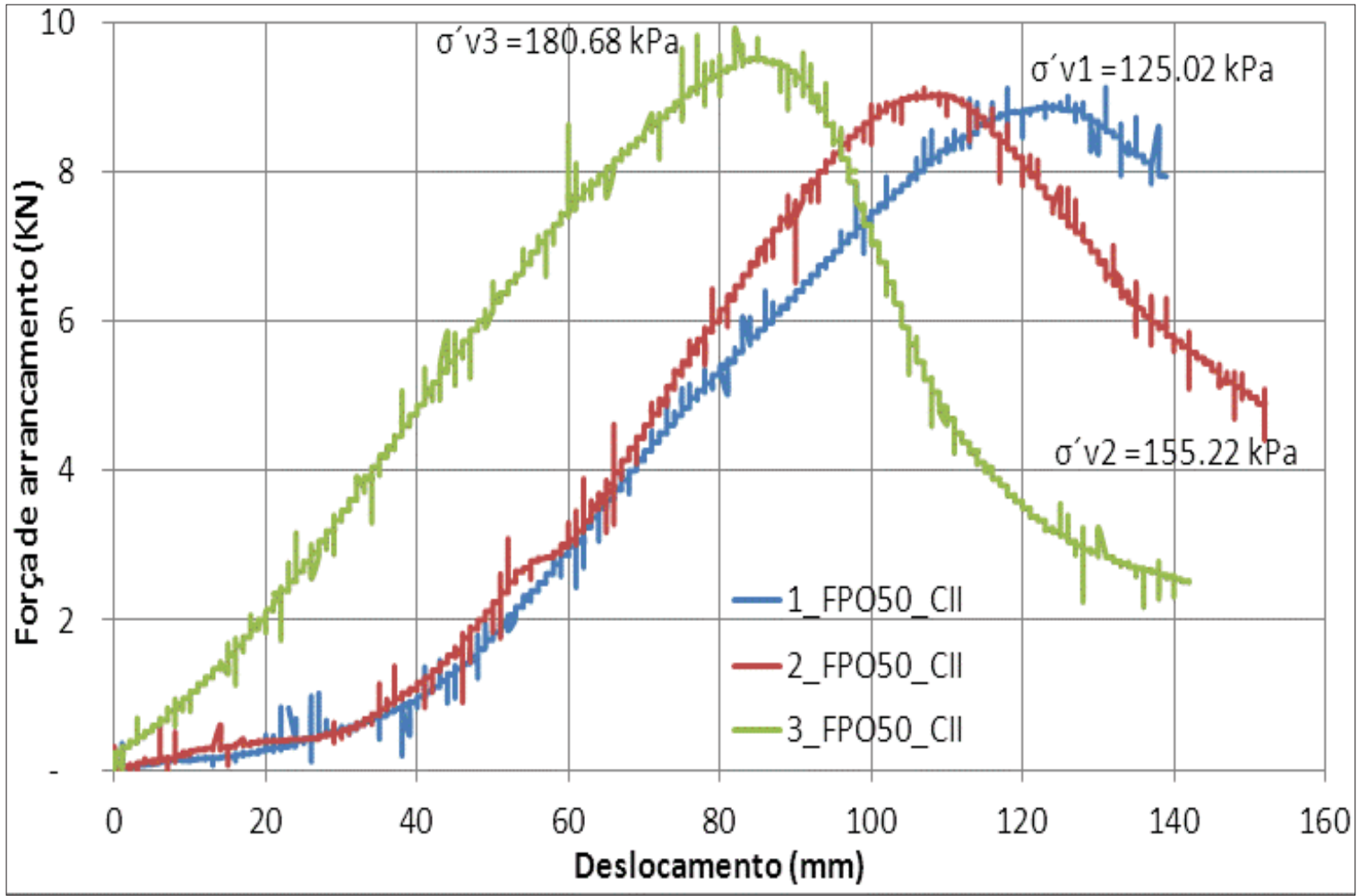

Figura 5.35 - Força de arrancamento X deslocamento

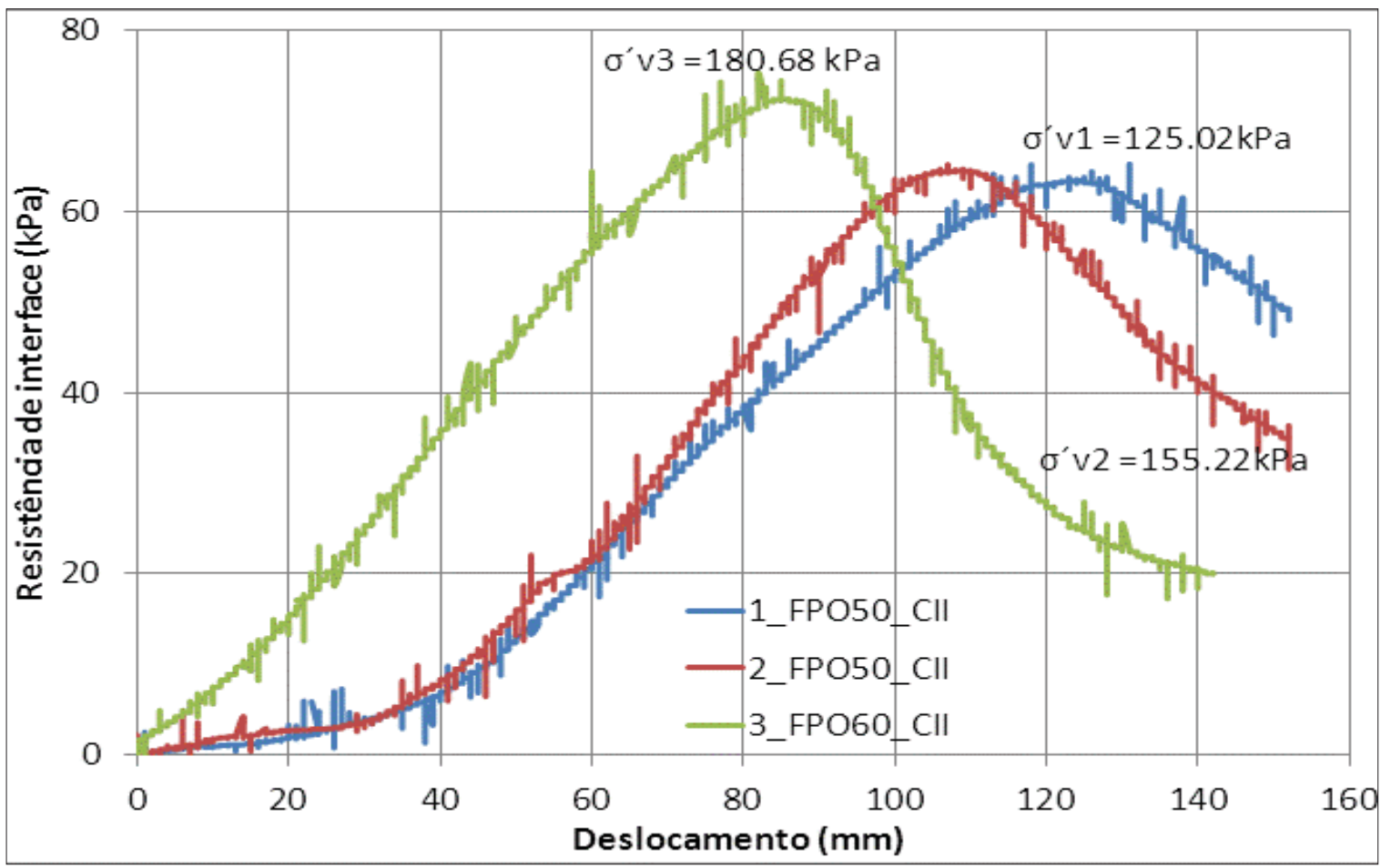

Figura 5.36 - Resistência da interface X deslocamento ( forma usual em terra armada) 


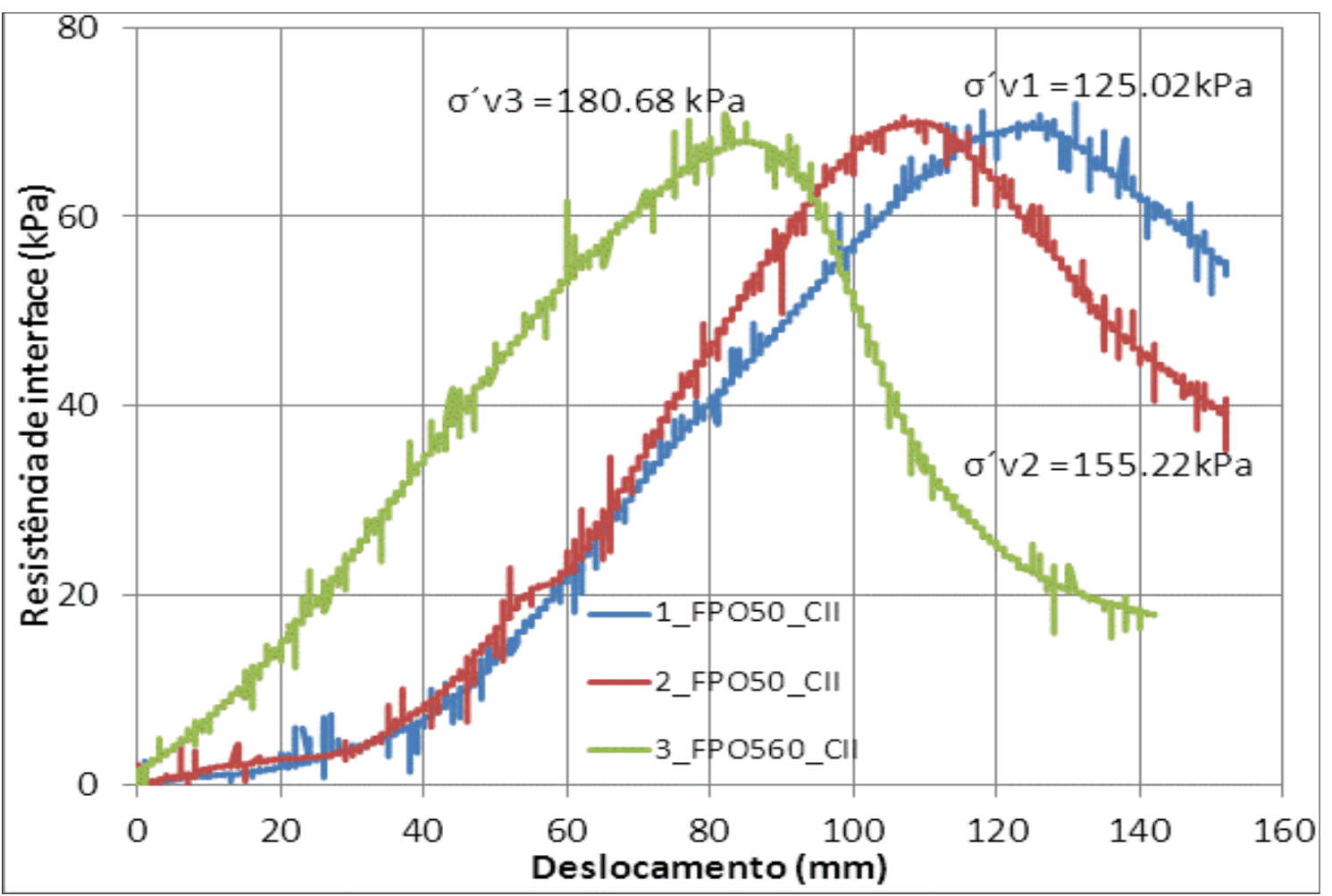

Figura 5.37 - Resistência da interface em função do comprimento arrancado X deslocamento

5.8.1.2 Gráficos obtidos usando fitas de $47 \mathrm{~mm}$ de largura e o solo não convencional 1

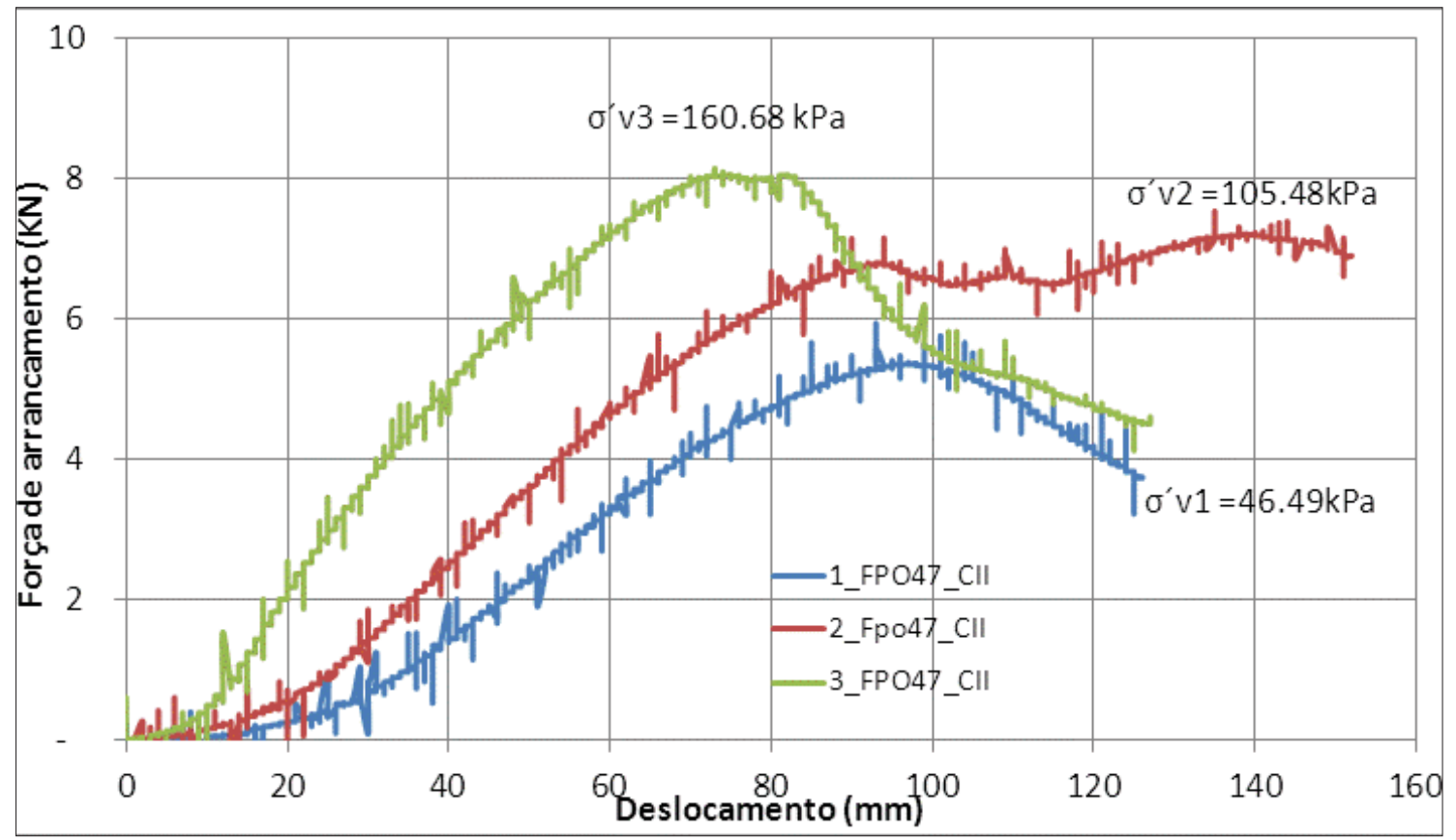

Figura 5.38- Força de arrancamento $\mathrm{X}$ deslocamento 


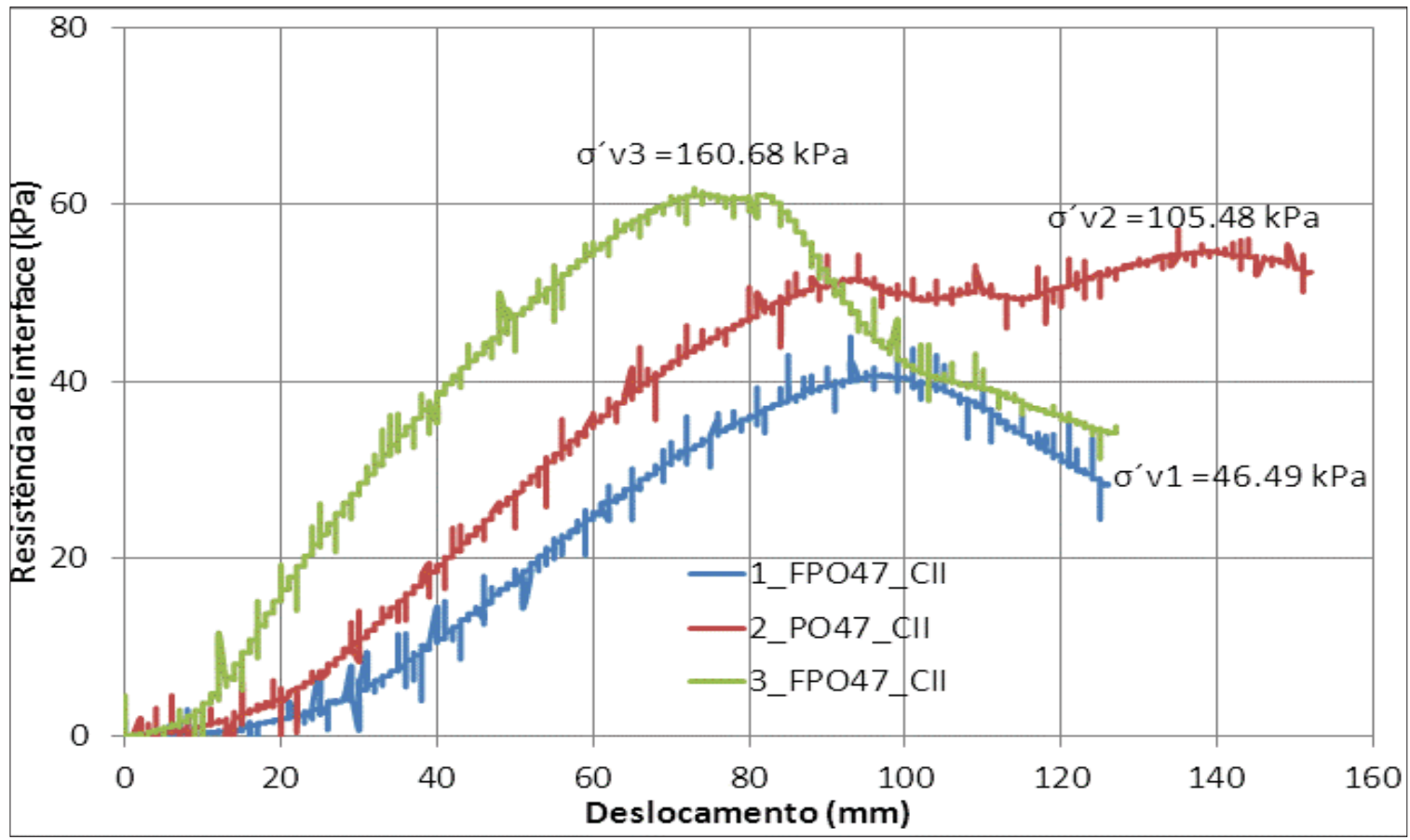

Figura 5.39 - Resistência da interface X deslocamento ( forma usual em terra armada)

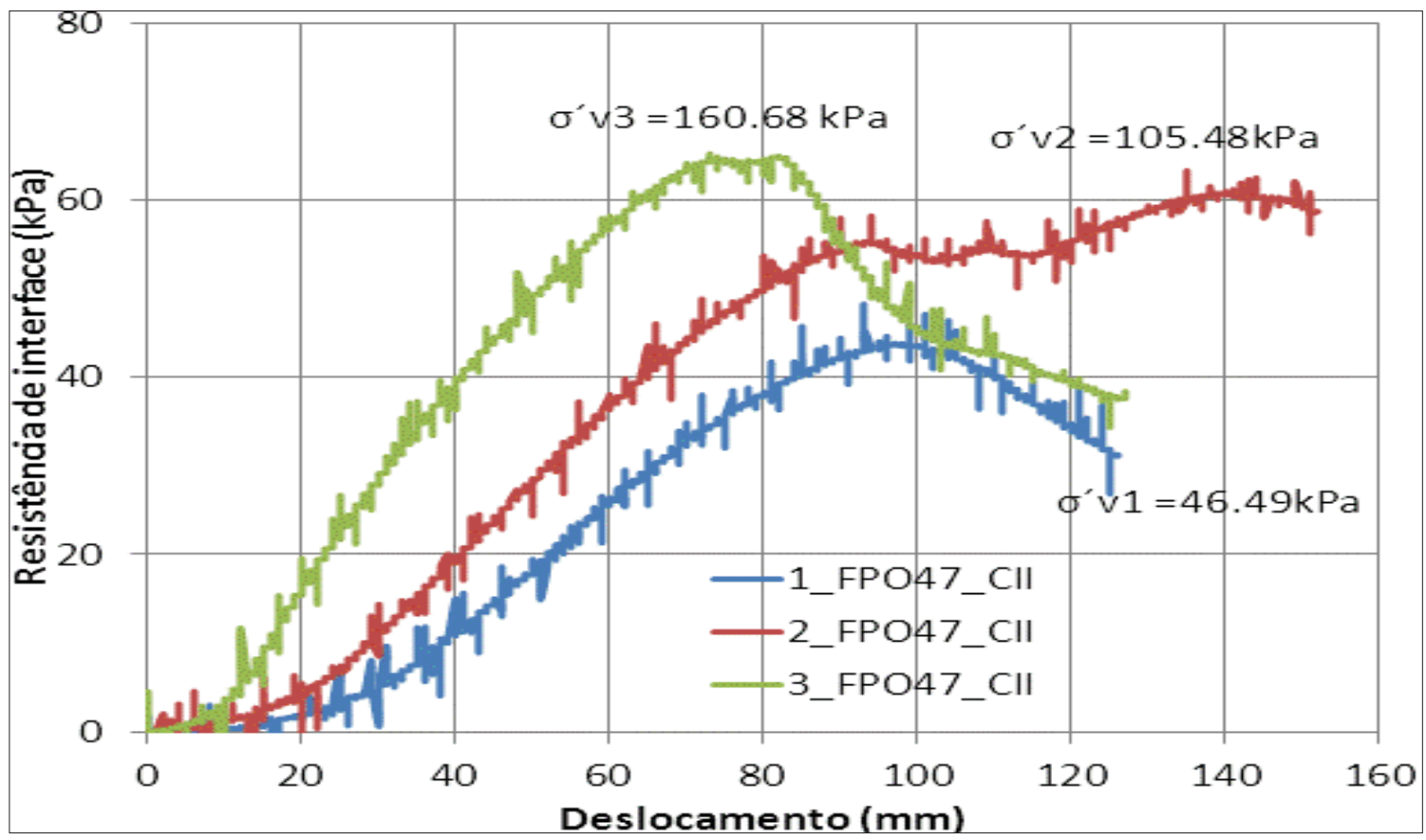

Figura 5.40- Resistência da interface em função do comprimento arrancado X deslocamento

Assim, usando a equação 1, obtêm-se resultados apresentados na Tabela 5.25. 
Tabela 5.25 - Resultados práticos sem considerar a coesão do solo

\begin{tabular}{|c|c|c|c|c|c|c|c|c|}
\hline Ensaio & $\tau_{\max }(\mathrm{kPa})$ & $\mathrm{F}_{\mathrm{ar}}(\mathrm{KN})$ & $\Delta \sigma_{v}{ }^{\prime}(\mathrm{kPa})$ & $\sigma_{\mathrm{v}^{\prime} \text { tatal }}(\mathrm{KPa})$ & $L(m)$ & $B(m)$ & $\mathrm{H}_{\mathrm{eq}}(\mathrm{m})$ & $f^{*}{ }_{a d}$ \\
\hline 1-FPO 47 Cll & 44.01 & 5.792 & 41.470 & 46.492 & 1.400 & 0.047 & 2.50 & 0.947 \\
\hline 2-FPO 47 CII & 57.91 & 7.621 & 100.460 & 105.482 & 1.400 & 0.047 & 5.67 & 0.549 \\
\hline 3-FPO 47 Cll & 64.01 & 8.423 & 155.660 & 160.682 & 1.400 & 0.047 & 8.64 & 0.398 \\
\hline 1-FPO50_ClI & 66.66 & 9.332 & 120.000 & 125.022 & 1.400 & 0.050 & 6.72 & 0.533 \\
\hline 2-FPO50_ClI & 66.88 & 9.363 & 150.201 & 155.223 & 1.400 & 0.050 & 8.35 & 0.431 \\
\hline $3-\mathrm{FPO}_{50} \mathrm{Cll}$ & 70.66 & 9.892 & 160.003 & 165.025 & 1.400 & 0.050 & 8.87 & 0.428 \\
\hline
\end{tabular}

Levando em consideração a norma e adoptando ${f^{*}}_{0}=1,5$; fez-se os cálculos que levaram aos resultados apresentados na Tabela 5.26.

Tabela 5.26 -Resultados obtidos considerando a teoria, na norma 9286/86.

\begin{tabular}{|c|c|c|c|c|c|c|c|}
\hline Ensaio & $\sigma^{\prime}(\mathrm{kPa})$ & $f^{*}$ & $\mathrm{H}_{\mathrm{eq}}(\mathrm{m})$ & $\Phi\left(^{\circ}\right)$ & $\mathrm{Z}_{0}(\mathrm{~m})$ & $\mathrm{T}_{\max }(\mathrm{kPa})$ & $f^{*}{ }_{0}$ \\
\hline 1-FPO ${ }_{47}$ CII & 46.492 & 1.132 & 2.50 & 31.7 & 6 & 52.64 & 1.500 \\
\hline 2-FPO47_Cll & 105.482 & 0.629 & 5.92 & 31.7 & 6 & 66.39 & 1.500 \\
\hline 3-FPO ${ }_{47}$ CII & 160.682 & 0.618 & 8.69 & 31.7 & 6 & 99.24 & 1.500 \\
\hline 1-FPO50_Cll & 125.022 & 0.974 & 3.58 & 31.7 & 6 & 121.71 & 1.500 \\
\hline 2-FPO50_Cll & 155.223 & 0.618 & 6.95 & 31.7 & 6 & 95.87 & 1.500 \\
\hline 3-FPO50_Cll & 165.025 & 0.618 & 8.87 & 31.7 & 6 & 101.92 & 1.500 \\
\hline
\end{tabular}

Também foi considerado o efeito da coesão através equação 37, uma vez se tratando de um solo coesivo e os resultados obtidos são apresentados na Tabela 5.27.

Tabela 5.27 - Resultados do ensaio considerando o efeito da coesão do solo

\begin{tabular}{ccccccccc}
\hline Ensaio & $\sigma^{\prime}{ }^{\prime}$ tatal $(\mathrm{KPa})$ & $\mathrm{F}_{\text {arr }}(\mathrm{KN})$ & $\mathrm{H}_{\mathrm{eq}}(\mathrm{m})$ & $\mathrm{Ca}(\mathrm{kPa})$ & $\tau_{\max }(\mathrm{kPa})$ & $\mathrm{f}^{\prime}$ & $\mathrm{L}(\mathrm{m})$ & $\mathrm{B}(\mathrm{m})$ \\
\hline 1-FPO47-CII & 46.492 & 5.792 & 2.50 & 37.23 & 44.01 & 0.146 & 1.400 & 0.047 \\
2-FPO47-CII & 105.482 & 7.621 & 5.67 & 37.23 & 57.91 & 0.196 & 1.400 & 0.047 \\
3-FPO47-CII & 160.682 & 8.423 & 8.64 & 37.23 & 64.01 & 0.167 & 1.400 & 0.047 \\
1-FPO50-CII & 125.022 & 9.332 & 6.72 & 37.23 & 66.66 & 0.235 & 1.400 & 0.050 \\
2-FPO50-CII & 155.223 & 9.363 & 8.35 & 37.23 & 66.88 & 0.191 & 1.400 & 0.050 \\
3-FPO50-CII & 165.025 & 9.892 & 8.87 & 37.23 & 70.66 & 0.203 & 1.400 & 0.050 \\
\hline
\end{tabular}




\subsubsection{Ensaios de arrancamento de fitas poliméricas em solo granular proveniente da mineradora}

Nos ensaios de arrancamento realizados com areia e fitas poliméricas, foi igualmente aplicada uma pré-carga para cada ensaio com o mesmo objetivo de assegurar que no contato com a garra não houvesse interferências.

Vale lembrar que se trata de uma areia muito mal graduada, como já foi referido anteriormente. A Tabela 5.28 apresenta as forças de arrancamento e as pré-cargas registadas durante a execução de ensaios de arrancamento das fitas poliméricas em areia.

Tabela 5.28 - Os valores das forças de arrancamento e as pré-cargas registadas em ensaios

\begin{tabular}{ccccccc}
\hline Ensaio & $\Delta \sigma_{\mathrm{v}}{ }^{\prime}(\mathrm{kPa})$ & $\sigma_{\mathrm{v}}{ }^{\prime}$ tatal \\
\hline 1_FPa) & Pré-carga $(\mathrm{KN})$ & $\mathrm{F}_{\text {ar }}(\mathrm{KN})$ & $\mathrm{F}_{\text {ar-Tota }}(\mathrm{KN})$ & $\mathrm{CR}(\%)_{\text {médio }}$ \\
2_FPO & 80.465 & 85.065 & 0.304 & 5.334 & 5.638 & 99 \\
3_FPO & 46.790 & 51.380 & 0.274 & 4.531 & 4.805 & 99 \\
\hline
\end{tabular}

Nos ensaios de arrancamento para a avaliação da interação solo granular-fita polimérica, foram consideradas as relações consideradas para areia-fitas metálicas e os resultados encontram-se nas tabelas e em forma de gráficos apresentadas nas Figura 5.41 a Figura 5.43. 


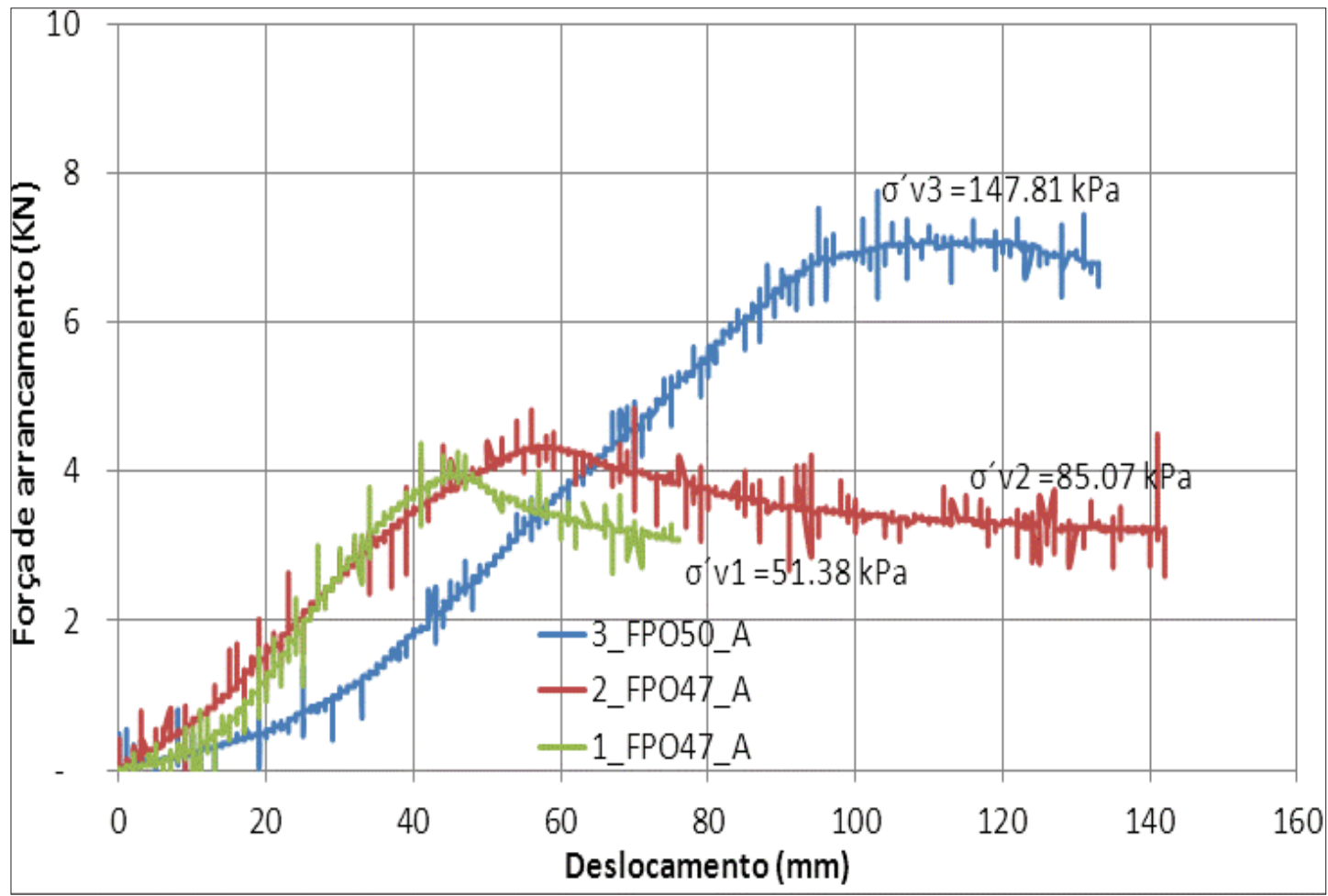

Figura 5.41 - Força de arrancamento $\mathrm{x}$ deslocamento

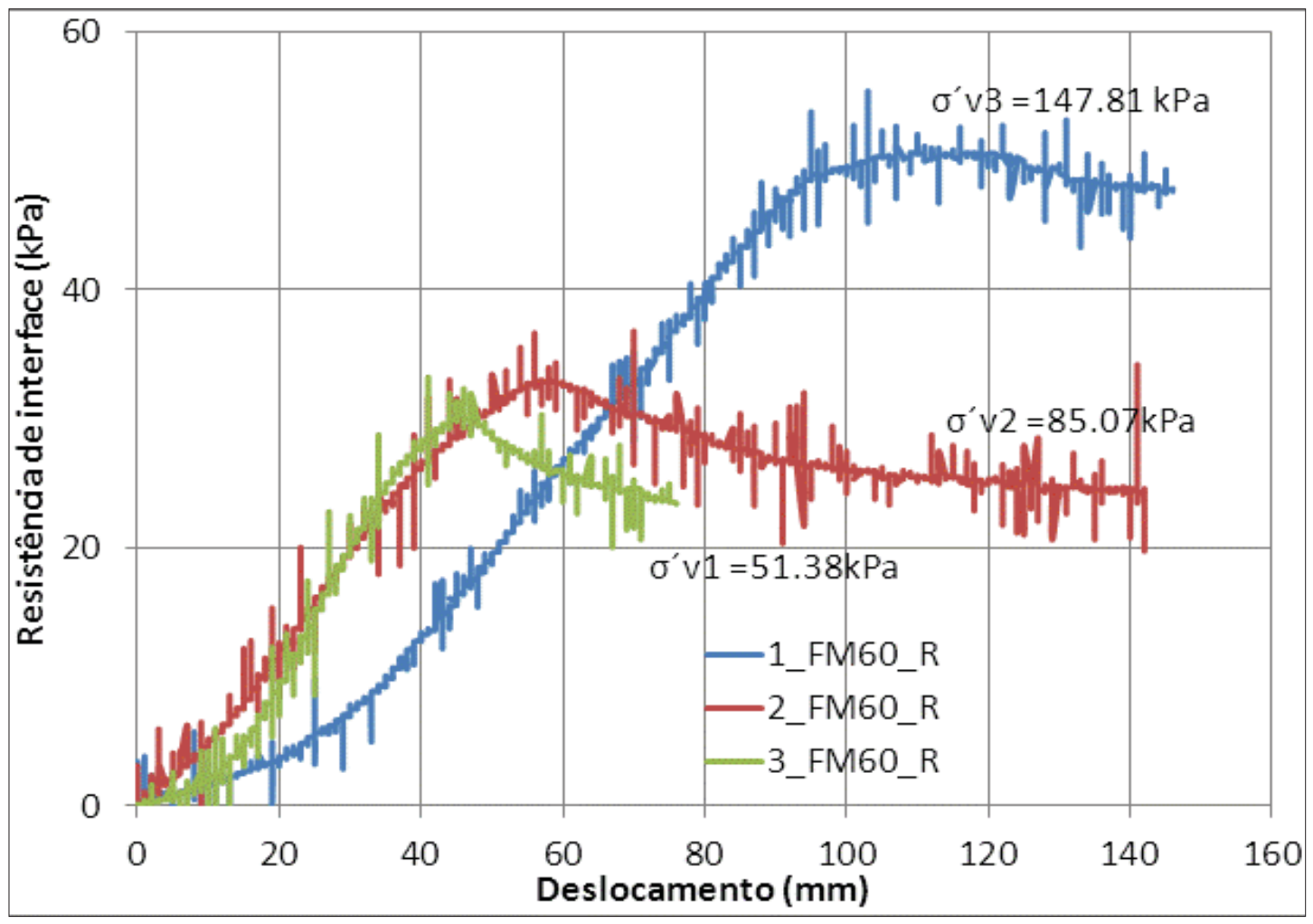

Figura 5.42- Resistência da interface X deslocamento ( forma usual em terra armada) 


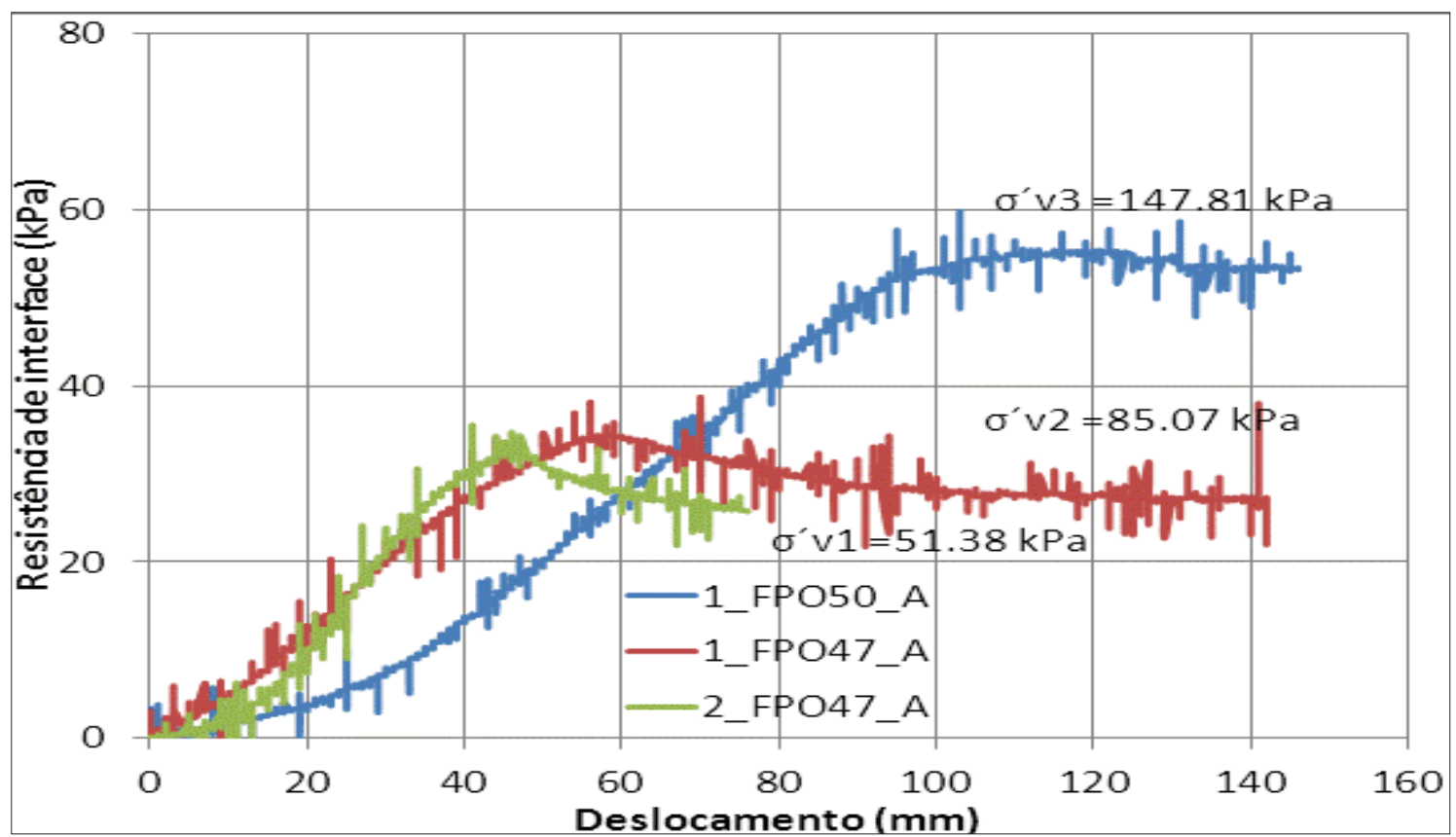

Figura 5.43 - Resistência da interface em função do comprimento arrancado X deslocamento

Nos ensaios de arrancamento de fitas poliméricas em areia, também foram considerados resultados práticos e teóricos. Os resultados práticos são apresentados na Tabela 5.29.

Tabela 5.29 - Resultados práticos do ensaio

\begin{tabular}{|c|c|c|c|c|c|c|c|c|}
\hline Ensaio & $\tau_{\text {max }}(\mathrm{KPa})$ & $\mathrm{F}_{\mathrm{ar}}(\mathrm{NK})$ & $\Delta \sigma_{\mathrm{v}}{ }^{\prime}(\mathrm{kPa})$ & $\sigma_{\mathrm{v}}{ }^{\prime}$ tatal $(\mathrm{KPa})$ & $\mathrm{L}(\mathrm{m})$ & $\mathrm{B}(\mathrm{m})$ & $\mathrm{H}_{\mathrm{eq}}(\mathrm{m})$ & $f^{*}{ }_{a d}$ \\
\hline 1_FPO $\mathrm{FP}_{47} \mathrm{~A}$ & 42.84 & 5.638 & 80.465 & 85.055 & 1.400 & 0.047 & 5.00 & 0.504 \\
\hline 2_FPO $\mathrm{FP}_{47} \mathrm{~A}$ & 36.52 & 4.805 & 46.790 & 51.380 & 1.400 & 0.047 & 3.02 & 0.711 \\
\hline 3_FPO $\mathrm{FPO}_{50} \mathrm{~A}$ & 66.27 & 9.278 & 43.224 & 147.814 & 1.400 & 0.050 & 8.69 & 0.448 \\
\hline
\end{tabular}

Os resultados teóricos determinados a partir das equações 2 e 3, são apresentados na Tabela 5.30.

Tabela 5.30 - Resultado teórico, considerando a norma NBR 9286/86

\begin{tabular}{|c|c|c|c|c|c|c|c|c|c|c|}
\hline Ensaio & $\sigma v^{\prime}(\mathrm{kPa})$ & $f^{*}$ & $\mathrm{H}_{\mathrm{eq}}(\mathrm{m})$ & $\Phi\left({ }^{\circ}\right)$ & $\mathrm{Cu}$ & $\mathrm{D}_{60}(\mathrm{~mm})$ & $\mathrm{D}_{10}(\mathrm{~mm})$ & $\mathrm{Z}_{0}(\mathrm{~m})$ & $\mathrm{T}_{\max }(\mathrm{kPa})$ & $f^{*}{ }_{0}$ \\
\hline 1_FPO 47 _A & 85.055 & 0.782 & 5.00 & 37.5 & 1.71 & 0.68 & 0.35 & 6 & 66.48 & 1.433 \\
\hline 2_FPO $\mathrm{FP}_{47} \mathrm{~A}$ & 51.380 & 1.040 & 3.02 & 37.5 & 1.71 & 0.68 & 0.35 & 6 & 53.41 & 1.433 \\
\hline 3_FPO50_A & 147.814 & 0.767 & 8.69 & 37.5 & 1.71 & 0.68 & 0.35 & 6 & 113.42 & 1.433 \\
\hline
\end{tabular}


Em relação às areias, que constituem grupos de solos recomendados para aterros em terra armada vê-se que os solos nãos convencionais acima são de permeabilidade muito baixa podendo de certa maneira, interferir na drenagem das aguas e consequentemente apresentaram dificuldade de dissipação de pressões neutras.

Para o uso dos solos não convencionais aqui estudados em relação ao solo granular da mineradora de Jandú, também estudado nesta pesquisa para comparar os coeficientes de atrito aparente $\mathrm{f}^{*}$, pode se afirmar que mesmo sem ter atingido aos coeficientes de atrito aparentes desejados, mostrou-se comparável a areia da mineradora tendo, porém apresentados uma permeabilidade baixa, o que durante o projeto de uma obra em terra armada deverá se levar em conta.

\subsubsection{Traçado das envoltórias de cada conjunto de materiais.}

Foram traçadas as envoltórias que caracterizaram cada conjunto de material usado nos ensaios (solo e tipo de fita), sem separar as fitas pelas suas larguras. As envoltórias são apresentadas a seguir nas Figura 5.34 a Figura 5.48. 


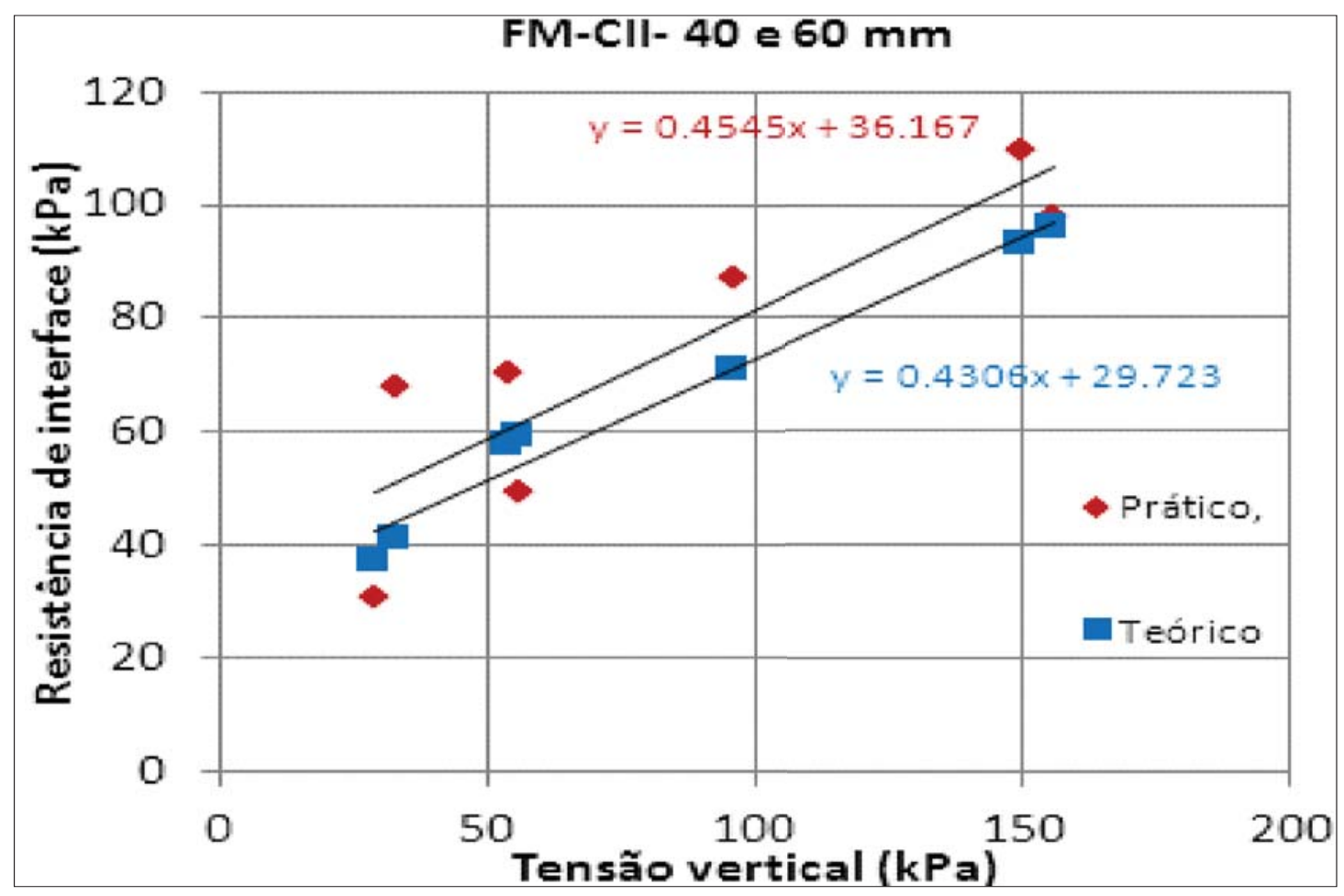

Figura 5.44 - Envoltória do solo não convencional 1 e fitas metálicas

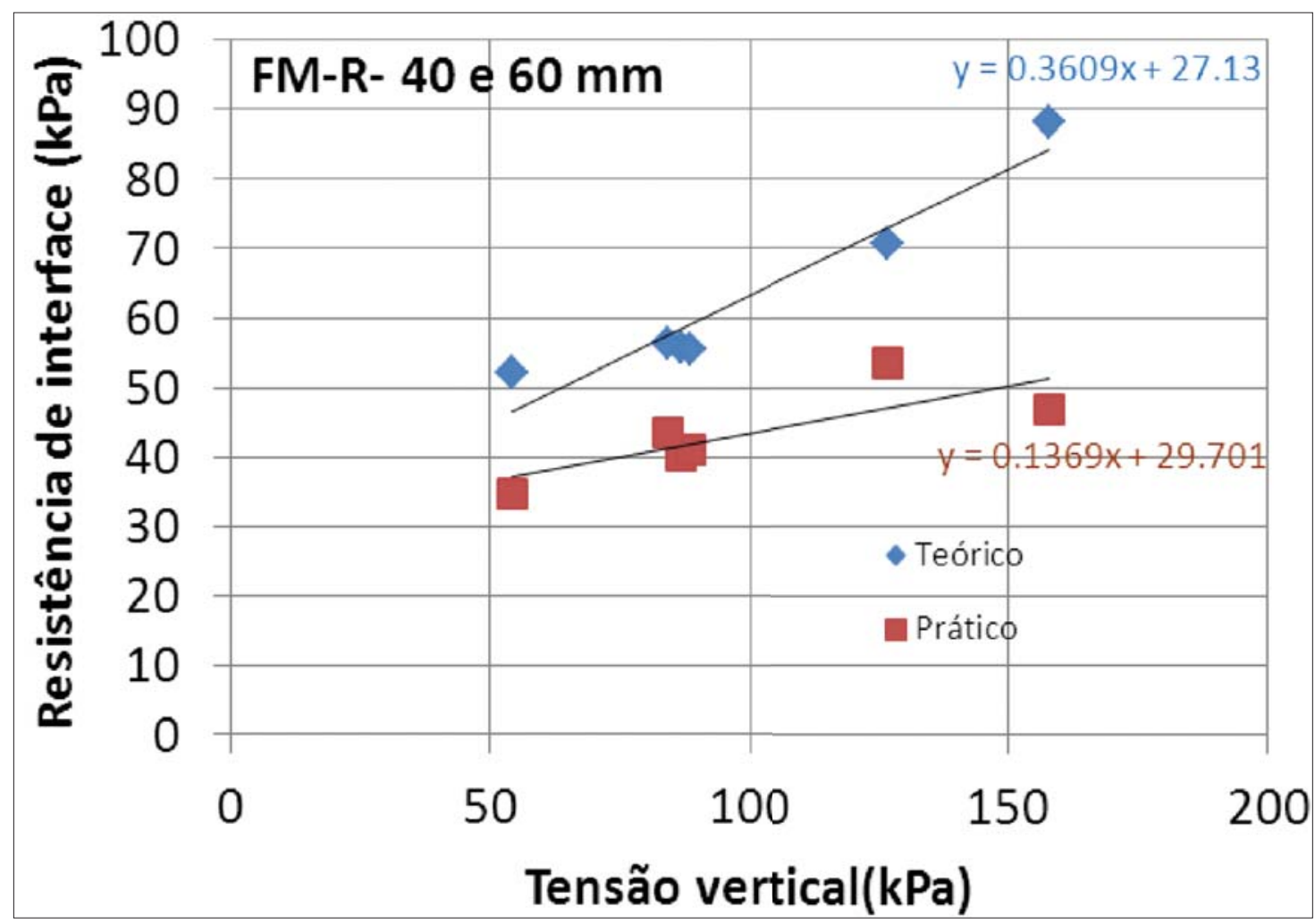

Figura 5.45 - Envoltória do solo não convencional 2 e fitas metálicas 


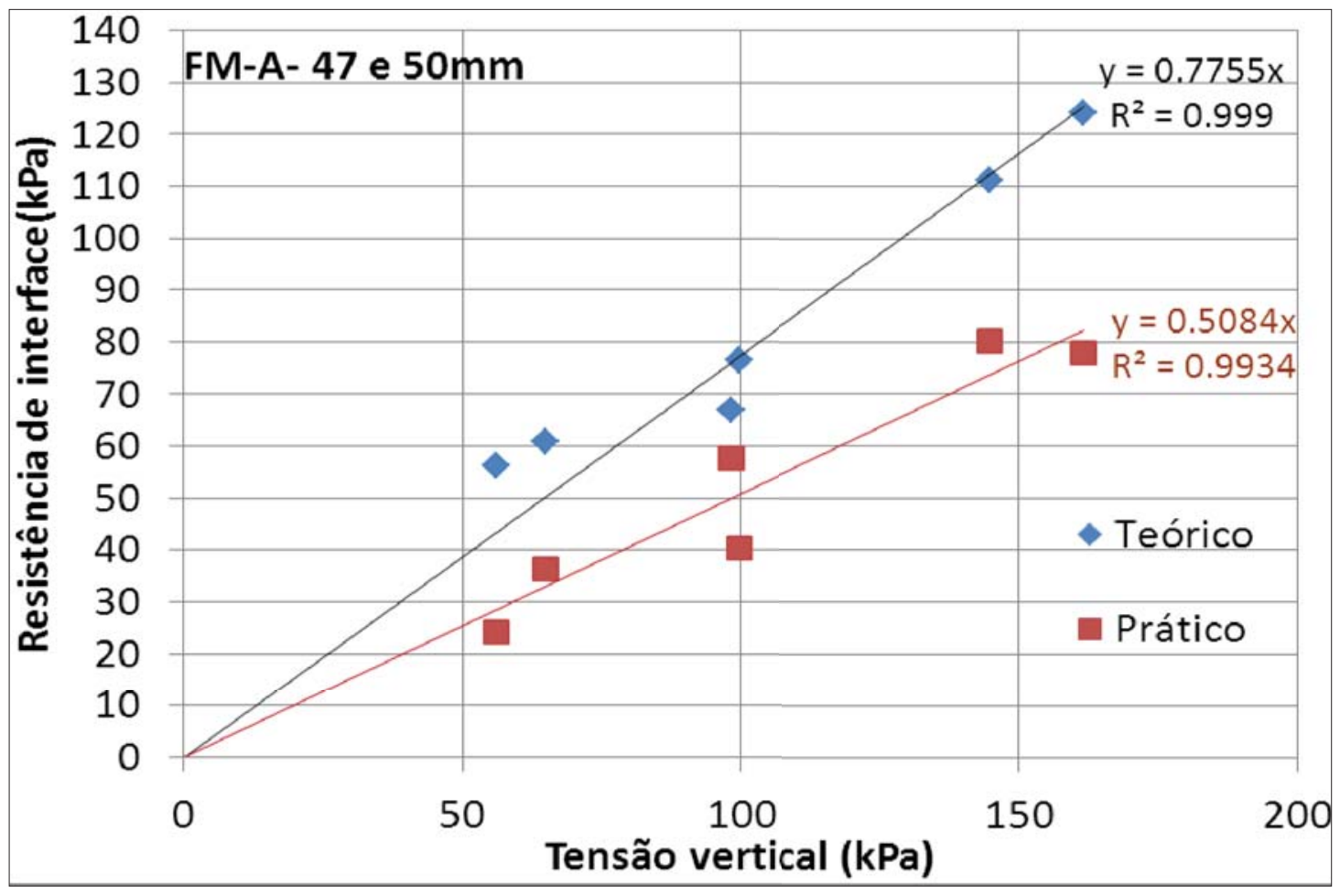

Figura 5.46 - Envoltória da Areia e fitas metálicas

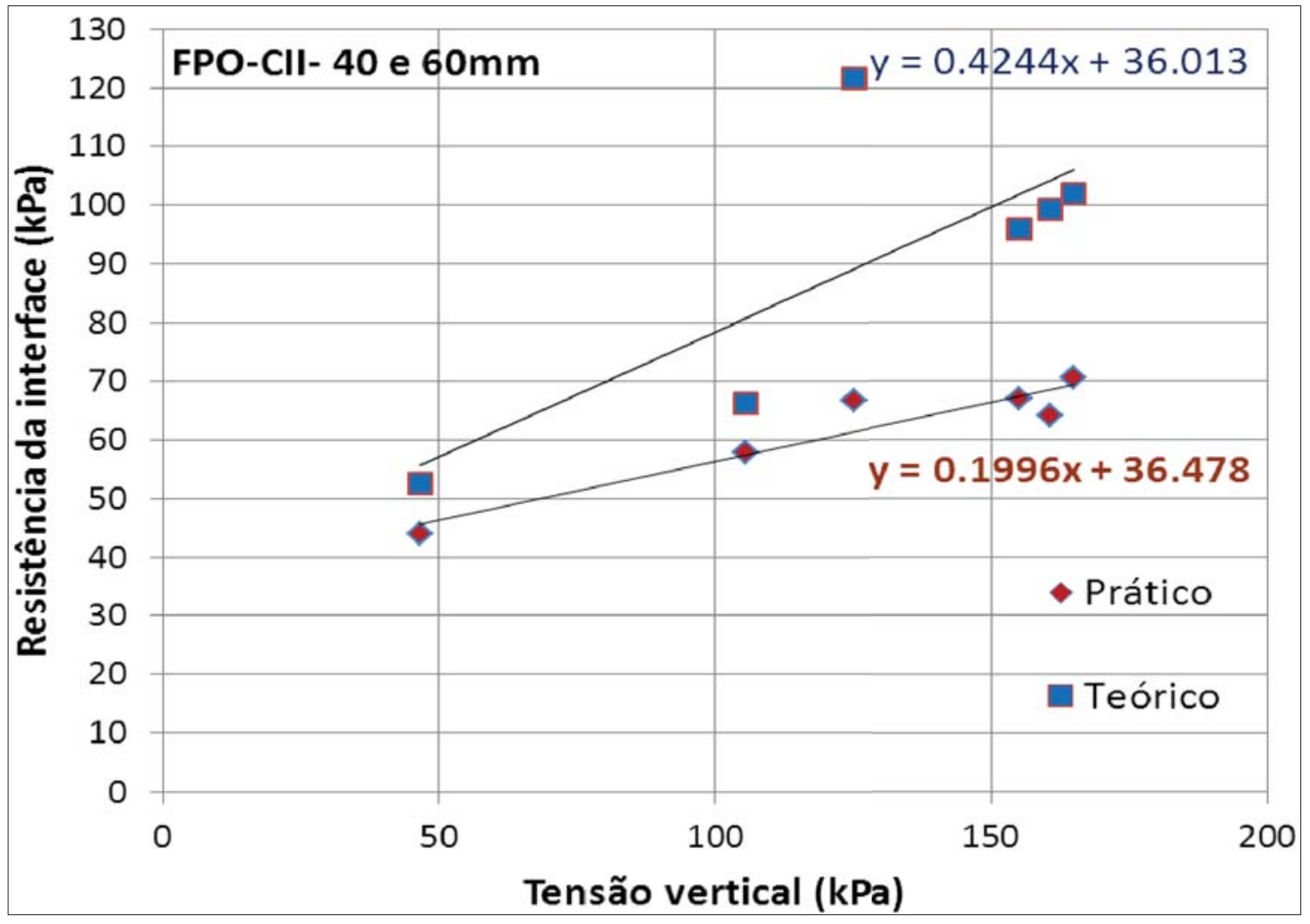

Figura 5.47 - Envoltória do solo não convencional 1 e fitas poliméricas 


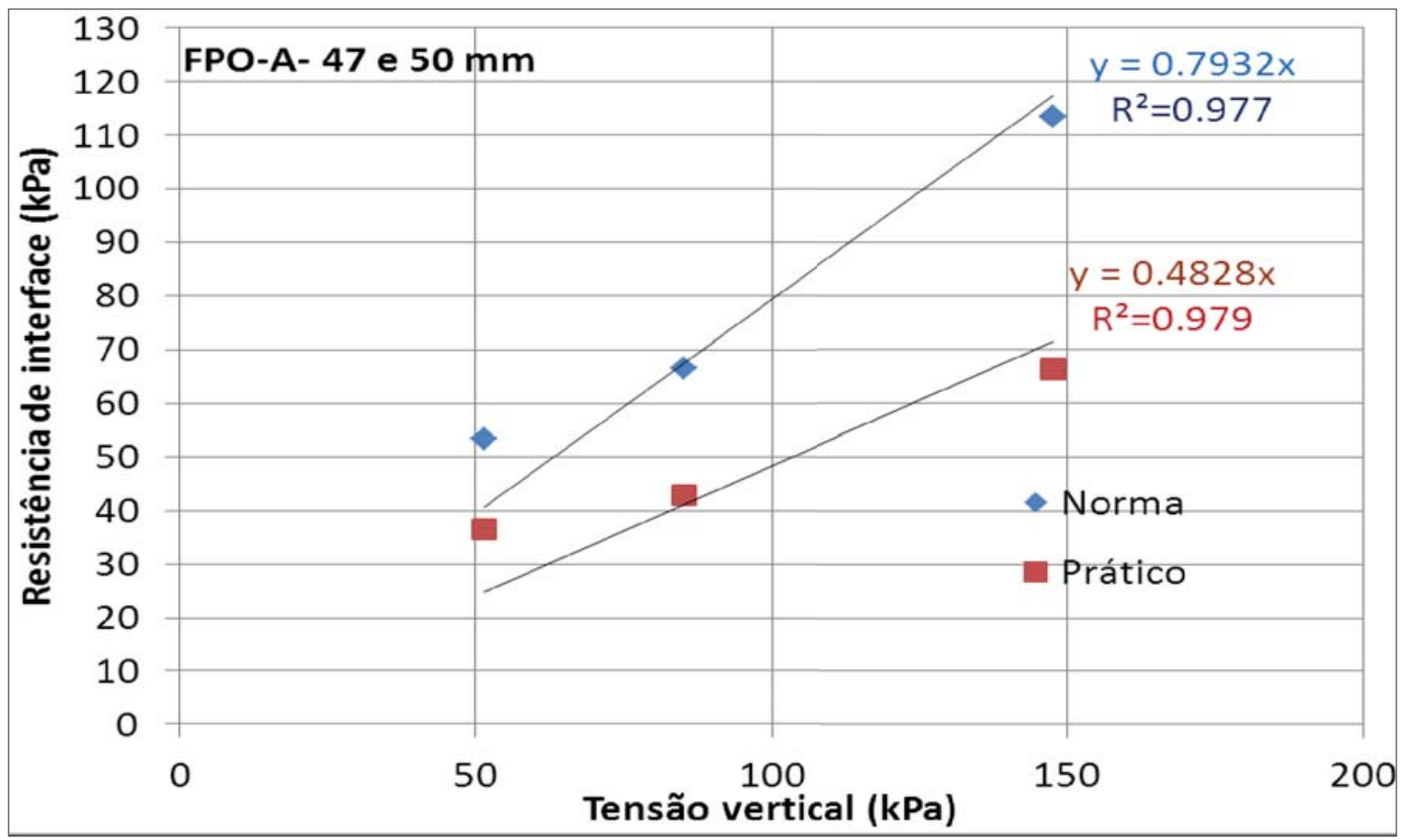

Figura 5.48 - Envoltória da Areia e fitas Poliméricas

5.8.4 Resumo dos resultados dos ensaios considerando os materiais usados, pelas suas envoltórias.

A seguir são apresentadas as tabelas com o resultado dos parâmetros de resistência de interface; ângulos de atrito de interface e a adesão. A Tabela 5.31 apresenta os parâmetros de resistência de interface obtidos a partir de resultados calculados usando a norma NBR 9286/86.

Tabela 5.31 - Para resultados teóricos segundo a norma NBR 9286/86

\begin{tabular}{cccc}
\hline Ensaio & Ângulo de atrito da interface $\delta\left(^{\circ}\right)$ & Adesão $C_{\alpha}(\mathrm{kPa})$ & Equação da envoltória \\
\hline FM_CII & 25,51 & 32,93 & $32,93+\sigma \cdot{\text { tang } 25,51^{\circ}}^{\circ}$ \\
FM_R & 21,16 & 29.09 & $29,09+\sigma \cdot \operatorname{tang} 21,16^{\circ}$ \\
FM_A & 50,85 & 0,00 & $\sigma \cdot \operatorname{tang} 50,87^{\circ}$ \\
FPO_CII & 25,11 & 39.77 & $39,77+\sigma \cdot \operatorname{tang} 25,11^{\circ}$ \\
FPO_A & 52,49 & 0,00 & $\sigma \cdot \operatorname{tang} 52,49^{\circ}$ \\
\hline
\end{tabular}

A Tabela 5.32 apresenta os parâmetros de resistência de interface obtidos a partir de resultados calculados considerando resultados práticos. 
Tabela 5.32 - Para resultados práticos

\begin{tabular}{|c|c|c|c|}
\hline Ensaio & Ângulo de atrito da interface $\delta\left(^{\circ}\right)$ & Adesão $\mathrm{C}_{\alpha}(\mathrm{kPa})$ & Equação da envoltória \\
\hline FM_ClI & 27,03 & 40,60 & $40,60+\sigma$. tang $27,03^{\circ}$ \\
\hline FM_R & 7,87 & 29.98 & $29,98+\sigma . \operatorname{tang} 7,87^{\circ}$ \\
\hline FM_A & 30,57 & 0,00 & $\sigma . \operatorname{tang} 30,57^{\circ}$ \\
\hline FPO_Cll & 11,51 & 37,23 & $37,23+\sigma . \operatorname{tang} 11,51^{\circ}$ \\
\hline FPO_A & 28.87 & 0,00 & $\sigma . \operatorname{tang} 28.87^{\circ}$ \\
\hline
\end{tabular}

\subsection{ANÁLISE COMPARATIVA DOS RESULTADOS.}

\subsubsection{Os ensaios realizados com o mesmo material.}

Nos ensaios de arrancamento das fitas metálicas e poliméricas, quando é considerada a coesão nos cálculos de $\mathrm{f}^{*}$, nota-se que valores de $\mathrm{f}^{*}$ foram sempre menores em relação aos valores teóricos. Sabe-se que a norma não se preocupa muito com a coesão por tratar de solos granulares como sendo os mais apropriados.

Os ensaios realizados com areia seca provinda da mineradora de Jundu, também apresentaram o mesmo comportamento, os valores teóricos de $\mathrm{f}^{*}$ foram maiores do que os práticos; isso se deve ao fato de que a areia usada é de uma faixa granulométrica muito restrita, segundo mostra a sua curva granulométrica e por isso, mal graduada, não tendo um conteúdo de solos que possam preencher aos seus vazios da melhor maneira, e, as recomendações da NHI-00-043, são de que o solo a ser usado como aterro em terra armada para além de ser de boa durabilidade, ter uma boa permeabilidade e boa interação com as inclusões; deve ser um solo granular bem graduado isso para permitir a redução dos vazios.

Os ensaios realizados com as fitas poliméricas de $50 \mathrm{~mm}$ de largura submetidas ao ensaio de arrancamento com o solo não convencional 1 , mostraram que para uma variação da tensão vertical $\sigma^{\prime}{ }_{v}$ de $40,02 \mathrm{kPa}$, registrou um aumento de $0,56 \mathrm{KN}$ na força de arrancamento e consequentemente uma variação insignificante no coeficiente de atrito aparente solo-fita polimérica, como pode ser observado na Tabela 5.27, nos ensaios 1_FPO50_CII, 2_FPO $\mathrm{FP}_{50} \mathrm{CII}$ e 3_FPO ${ }_{50} \mathrm{CII}$. 
No que diz respeito ao solo não convencional 2, os cálculos que respeitam a natureza

Coesiva do solo, mostraram resultados com valores menores ao elevado valor de adesão que o solo apresenta, fazendo com que a sua soma algébrica com a porção da tensão de tração resultasse em uma grande redução. Assim, o solo é deveras inapropriado sob o ponto de vista do parâmetro em análise (f*).

Comparando os ensaios realizados com os mesmos materiais de aterro, porém, com inclusões metálicas e poliméricas; nota-se que para mesmas faixas de tensões verticais as forças de arrancamento foram maiores para ensaios com fitas metálicas do que no caso de fitas poliméricas para o caso de solo não convencional 1 , com a exceção dos ensaios

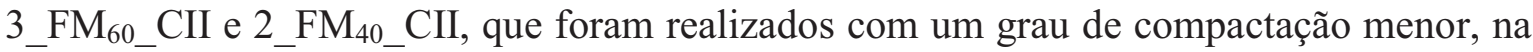
tentativa de evitar a danificação dos strain gages.

Para os ensaios de arrancamento com areia e fitas poliméricas notou-se que os valores de $\mathrm{f}^{*}$, são aproximadamente iguais para ensaios realizados com tensões verticais de valores próximos, isso, para resultados teóricos da norma NBR9286/86. Para os valores práticos, registaram-se maiores valores na mesma faixa com a exceção do ensaio 2_FPO $\mathrm{FP}_{4} \mathrm{~A}$, que registou um valor de f* igual a 0,711 .

Os valores das forças registadas por strain gages durante os ensaios foram de certa maneira, muito dispersos devido a danificação de muitos dos strain gages durante o processo de compactação e para os que resistiram alguns apresentaram leituras errôneas.

As envoltórias correspondentes a cada solo e o tipo de reforço usado, permitiram o conhecimento dos ângulos de atrito da interface e as adesões.

Os resultados dos ensaios comparados com as forças que poderiam criar deformações nas fitas metálicas e poliméricas vê-se que foram insignificantes de tal maneira que não foi possível causar deformações consideráveis. Para as fitas metálicas, a maior força de arrancamento foi de $16.43 \mathrm{KN}$, que resultou da aplicação de uma tensão vertical $\sigma_{\mathrm{v}}$ de $155,49 \mathrm{kPa}$, tendo se provocado uma tração de $97 \mathrm{kPa}$. Estes valores são muito menores se comparados aos dos resultados dos ensaios tração das fitas metálicas que são apresentados na Tabela 5.12, que foram obtidos dos corpos de prova de $6,25 \mathrm{~mm} \times 5,0 \mathrm{~mm}$, fazendo entender que durante o arrancamento a força máxima provocou uma tração correspondente 
a $0,038 \%$ do valor médio da resistência à tração máxima e $0,067 \%$ do valor médio da do escoamento convencional do material; fazendo entender que as fitas metálicas não sofreram deformações que prejudicasse o seu desempenho.

As fitas poliméricas durante a execução dos ensaios de arrancamento apresentaram a força de arrancamento máxima de cerca de 9,90 KN, no ensaio com o solo não convencional 1 (ensaio 3-FPO ${ }_{50}$-CII), quando aplicada uma solicitação de 165,03 kPa. Vêse que o valor da força de arrancamento é menos que a metade da média da que foi usada nos ensaios de tração.

Durante a preparação dos ensaios as fitas foram instrumentadas com strain gages como se tem referido nos capítulos anteriores; esses sensores serviram para facilitar a compreensão do andamento da tração ao longo do comprimento das fitas, tanto metálicas como poliméricas. A

Figura 5.36 mostra o comportamento típico verificado nos ensaios, em que a tendência foi do strain gage mais próximo da aplicação da força de arrancamento estar mais solicitado por tração, e, na medida em que se afasta do ponto de aplicação há uma tendência de redução do valor registado; sendo o strain gage que regista a menor força, o último. As Figura 5.49Figura 5.51 mostram graficamente o registro típico das forças pelos strain gages distribuídos ao longo do comprimento das fitas (Figura 5.10) 


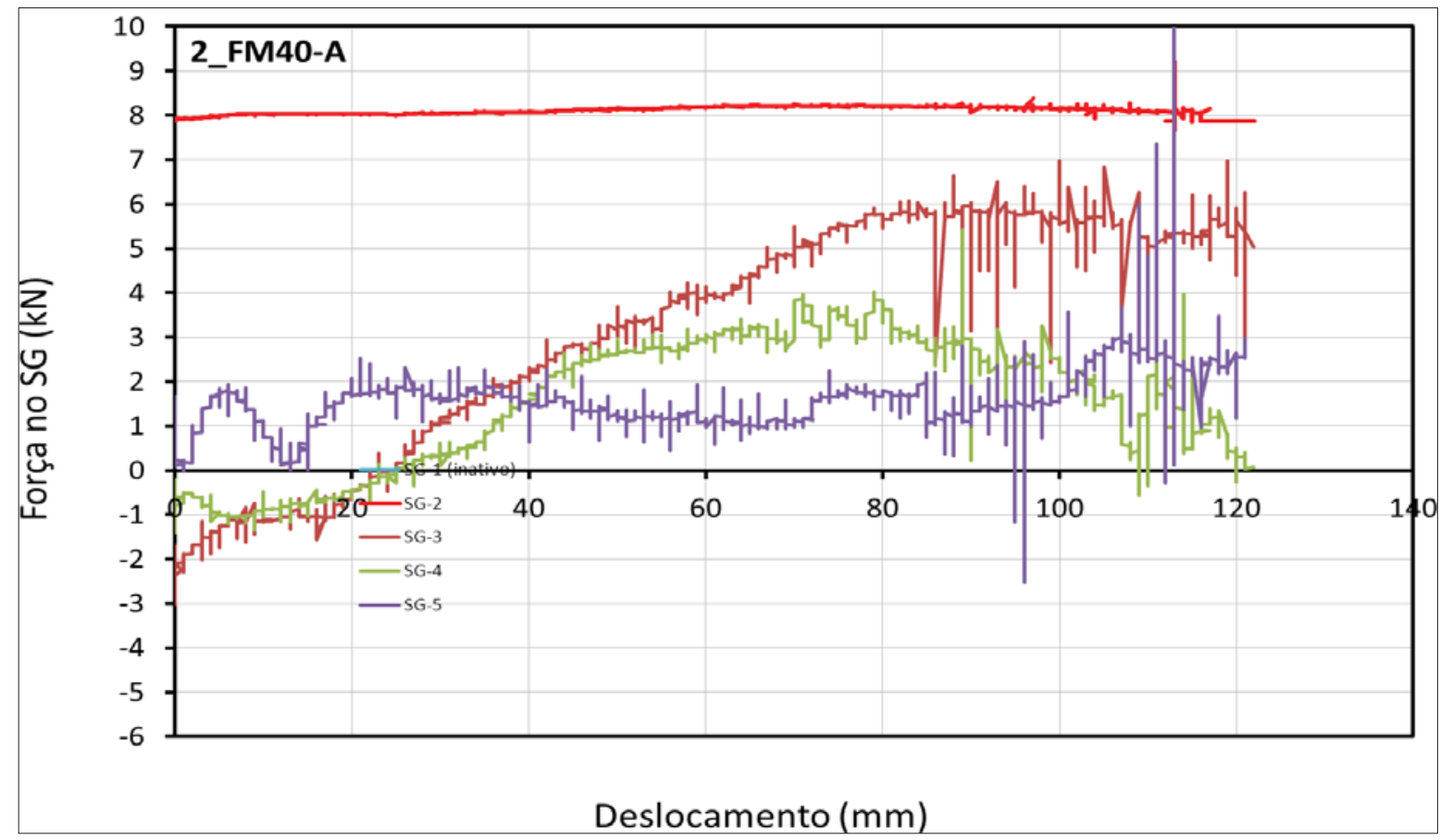

Figura 5.49- Comportamento do andamento das trações ao longo das fitas (Solo granular)

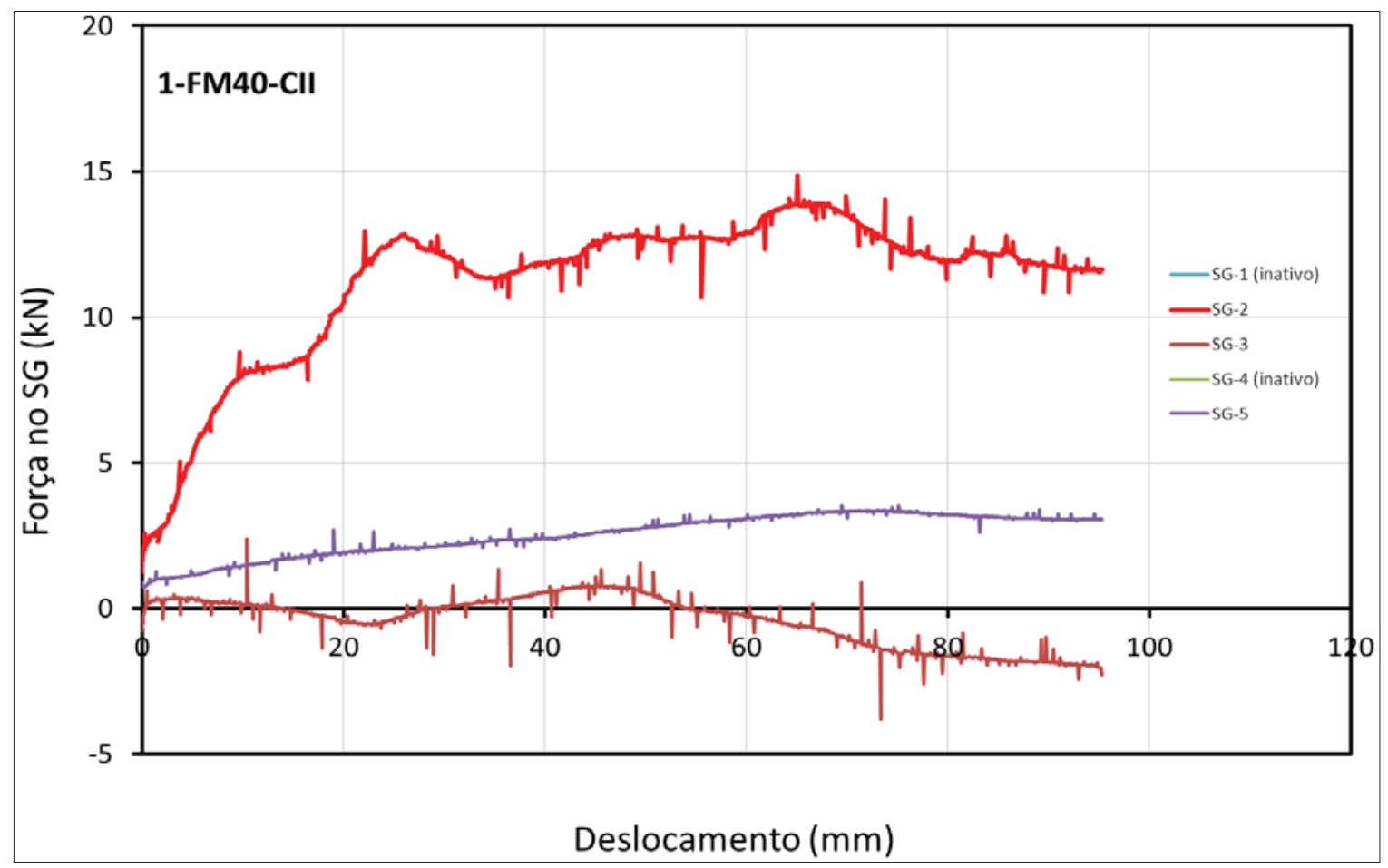

Figura 5.50 - Comportamento do andamento das trações ao longo das fitas (Solo Campus II) 


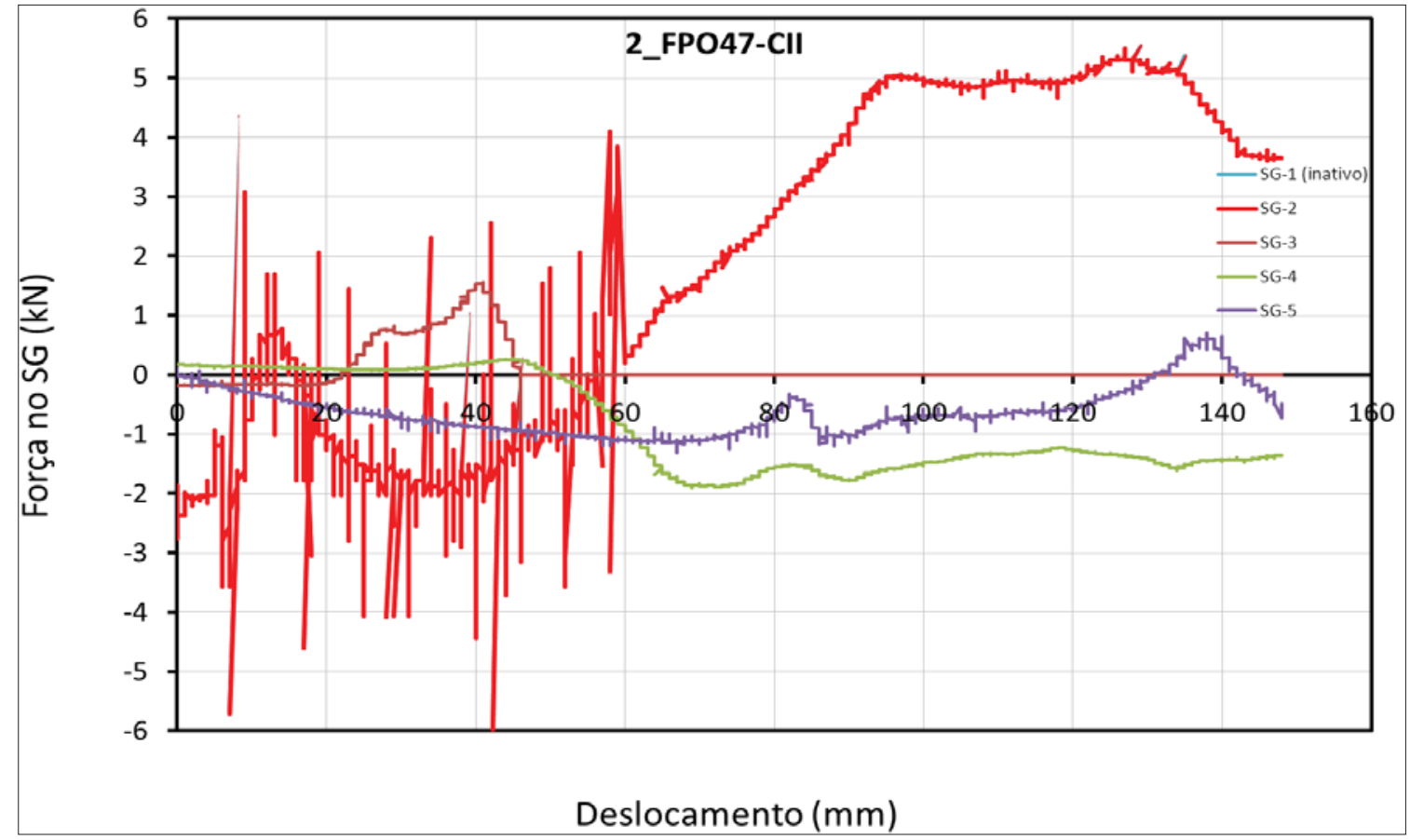

Figura 5.51 - Comportamento do andamento das trações ao longo das fitas poliméricas (Solo Campus II)

Para o uso dos solos não convencionais aqui estudados em relação ao solo granular da mineradora de Jundu, também estudado nesta pesquisa para efeitos de comparação dos coeficientes de atrito aparente $\mathrm{f}^{*}$, pode se afirmar que mesmo sem ter atingido os coeficientes de atrito aparentes desejados, mostrou-se comparável a areia da mineradora tendo, porém apresentado uma permeabilidade baixa, o que durante o projeto de uma obra em terra armada deverá se levar em conta. A areia da mineradora é mal graduada; uma areia muito uniforme.

\subsubsection{Resumo da comparação dos resultados práticos e da norma (NRB 9286/86)}

Para a melhor compreensão da comparação dos resultados dos ensaios em termos de coeficientes de atrito aparente solo-inclusão foi traçada a curva teórica preconizada na norma e depois, na mesma área, lançou-se os resultados dos ensaios; calculados levando em conta a relação teórica, a relação direta sem considerar a coesão e finalmente a relação real para os solos não convencionais, a que considera a coesão através da incorporação da adesão solo-reforço nos cálculos. Para o caso dos ensaios com o solo granular, não coesivo, foram simplesmente usadas duas relações considerando o efeito da coesão igual à zero.

Para além das curvas $\mathrm{f}^{*} v s$ profundidade foram traçadas as envoltórias típicas da interação solo inclusão que permitem calcular os valores típicos da adesão. 
As figuras apresentadas a seguir, serviram para comparação entre a curva teórica e os resultados práticos, considerando o efeito da coesão e desprezado o efeito da coesão. Notase que os resultados obtidos nos ensaios não são coerentes com os teóricos (uso da norma). As comparações são apresentadas nas Figura 5.52 a 54.

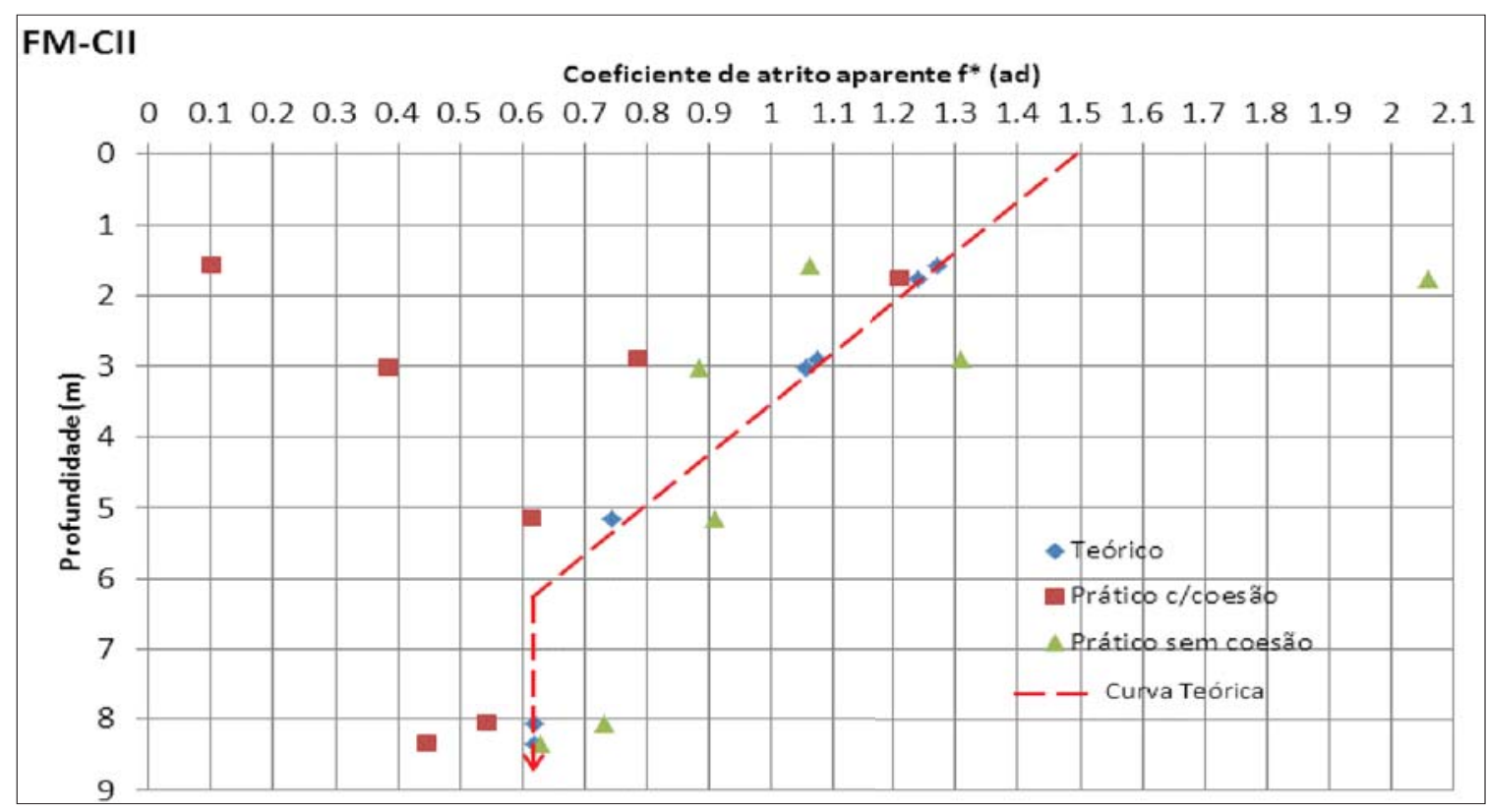

Figura 5.52- Distribuição dos resultados de ensaios em relação à curva da norma NBR9286/86 - solo-fita metálica (campus II)

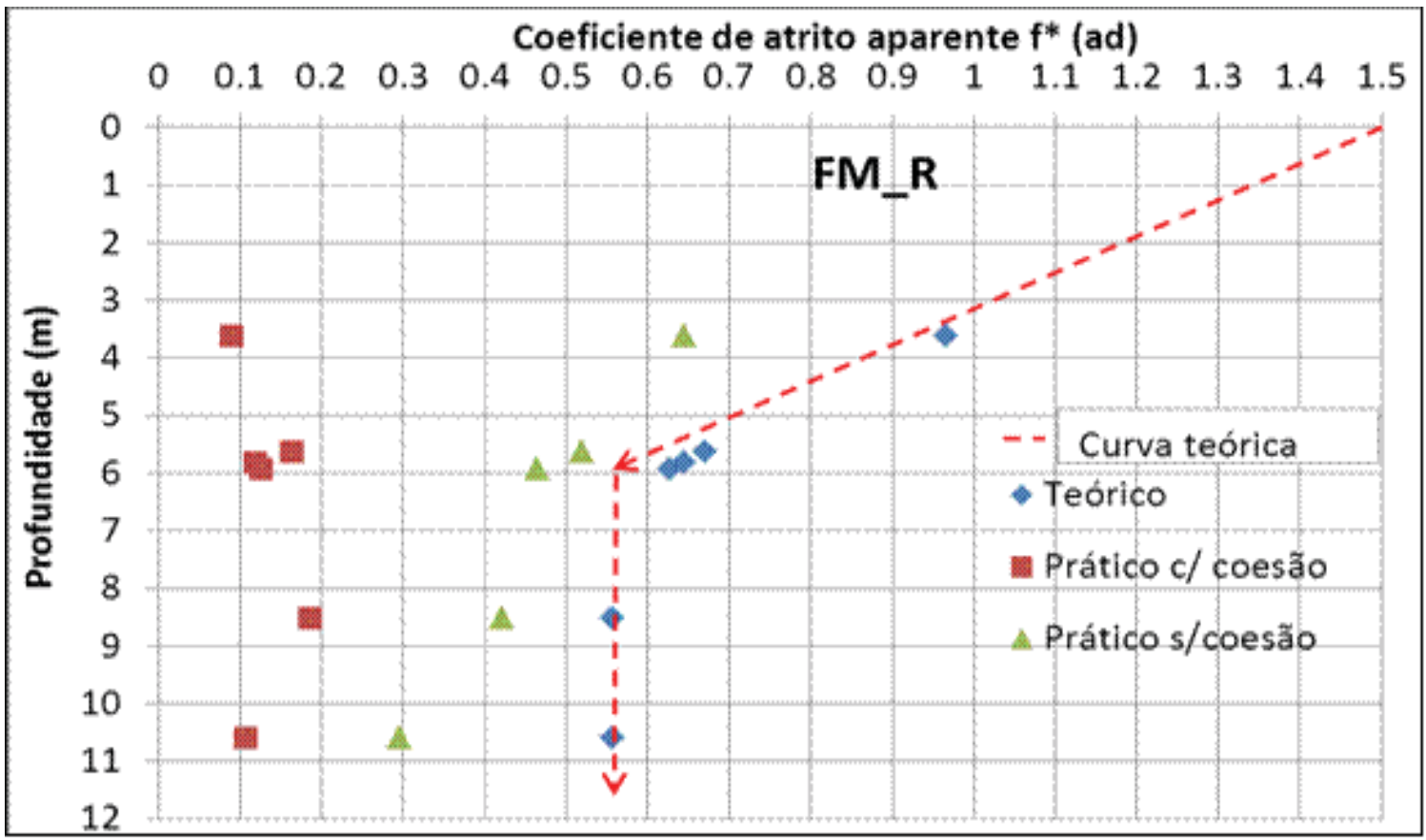

Figura 5.53 - Distribuição dos resultados de ensaios em relação à curva da norma NBR9286/86 - solo-fita metálica (Rodovia SP215) 


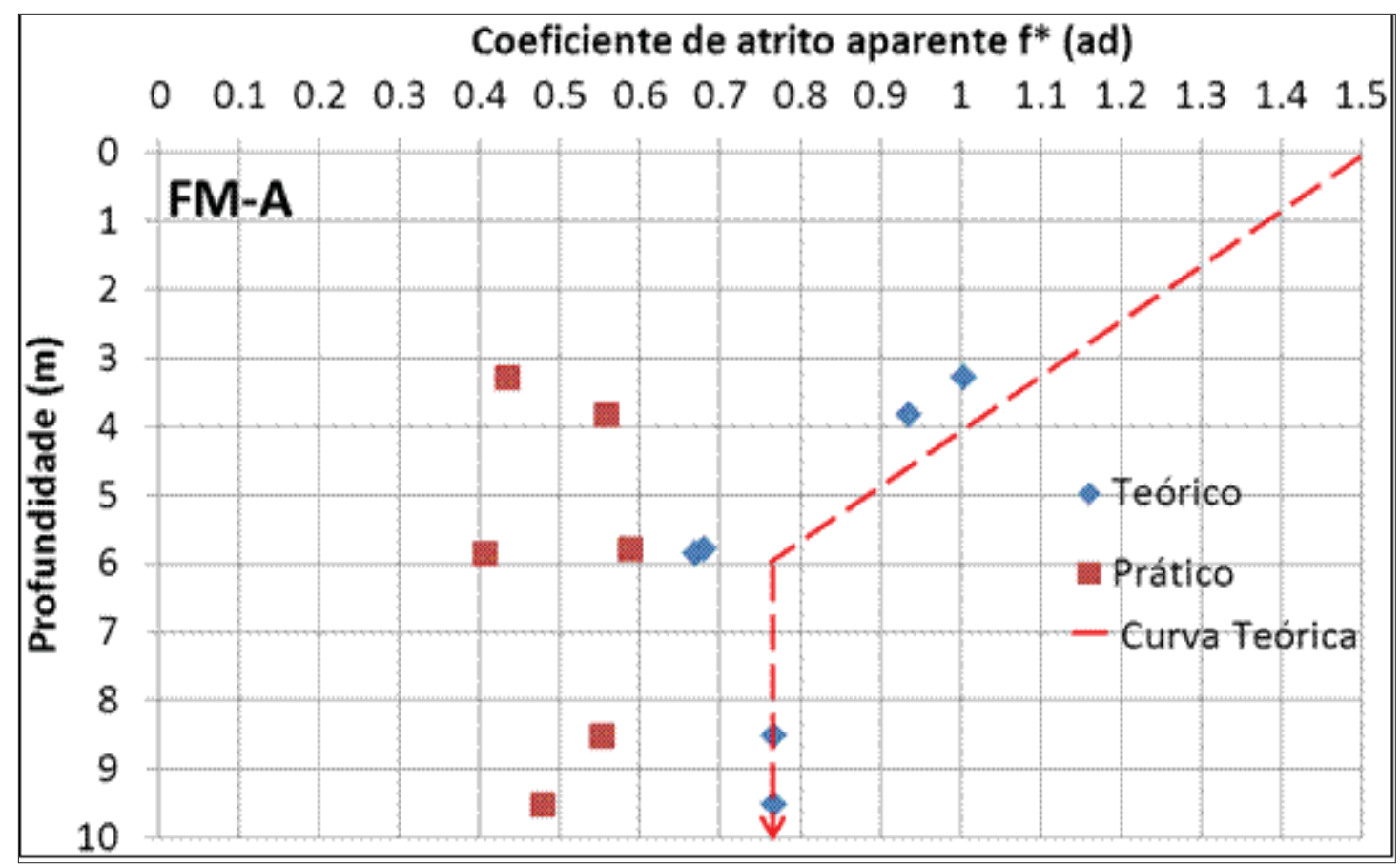

Figura 5.54 - Distribuição dos resultados de ensaios em relação à curva da norma NBR9286/86 solo-fita metálica (Areia) 
Avaliação da Interação Solo-Fitas metálicas e poliméricas para Soluções em Terra Armada em Solos não Convencionais 


\section{CONCLUSÕES}

Foram realizados 28 ensaios de arrancamento de grande escala em laboratório com o objetivo de avaliar a interação solo-fitas metálicas e fitas poliméricas para soluções em terra armada em solos não convencionais e areia. Os objetivos incluíam a comparação com a norma brasileira de terra armada NBR 9286/86 bem como catalogar dados e experiências sobre os solos brasileiros.

Dos resultados dos ensaios concluiu-se que;

1- Quanto maiores foram as profundidades, representadas pelos valores maiores de acréscimos da tensão vertical, o coeficiente de atrito aparente solo-fita tendia a reduzir.

2- Para solos coesivos como foi o caso dos solos não convencionais, os valores do f* são muito menores. A pior situação foi constatada quando se considera a influência da coesão tão elevada dos solos.

3- Quando os cálculos são feitos desprezando o efeito da coesão, o solo convencional 1 apresentam melhores resultados do que os solos não convencional 2 e o granular mal graduado, quando aplicado para contenções de menor altura $(3,00 \mathrm{~m})$.

4- $\mathrm{O}$ andamento das tensões ao longo do comprimento das fitas durante os ensaios de arrancamento, avaliados a partir dos registros de sensores (strain gages), mostraram que as tensões de tração são maiores próximo do ponto de aplicação da força do arrancamento e os seus valores vão reduzindo em direção à zona resistente ou para o interior do maciço (extremidade posterior da fita).

5- O solo não convencional 1 apresentou para pequenas profundidades um coeficiente de atrito aparente muito maior do que o esperado, tendo atingido o valor de 2 , quando desprezada a coesão porém o valor real, considerando o efeito da coesão baixou bastante. 
6- Os resultados dos ensaios mostram que as forças de tração nas fitas são muito menores aos obtidos nos ensaios de tração para a caracterização das mesmas, não havendo assim, perigo de ocorrência de deformações excessivas nas fitas.

7- O comprimento das fitas dentro do maciço é muito menor na caixa de ensaios e não permite tirar a vantagem de maior número de nervuras inseridas no maciço, no caso das fitas metálicas nervuradas, muito menos da superfície rugosa das fitas poliméricas.

8- Os resultados obtidos com fitas poliméricas considerando a norma para o solo não convencional 1; são satisfatórios para profundidades de até 3,6 metros. Para os resultados práticos sem considerar a coesão são satisfatórios até 2,5 metros. Para as areias; usando a norma, são satisfeitas as condições de interação solo-fita polimérica. Para os resultados práticos as condições de interação areia fita polimérica foi satisfeita até a profundidade de 3,0 metros.

9- Os ensaios de permeabilidade realizados com os dois solos não convencionais mostraram que os solos têm permeabilidades médias de $\mathrm{k}$ igual a $3.44 \times 10^{-7} \mathrm{~cm} / \mathrm{s} \mathrm{e}$ $2.62 \times 10^{-7} \mathrm{~cm} / \mathrm{s}$; para os solos não convencional $1 \mathrm{e} 2$, respetivamente. Assim, os solos têm permeabilidades que exigiriam um bom sistema de drenagem de maneiras a não permitirem o carreamento das suas partículas em caso do seu uso em projetos de terra armada. 


\section{REFERÊNCIAS BIBLIOGRÁFICAS}

ABRAMENTO, M.; KOSHIMA, A. \& ZIRLIS, A.C. Reforço do terreno. Fundações Teoria e Prática, São Paulo, 1998, Editora Pini, 2a . edição, pp.641-690.

AFONSO, C; CARDOSO, A. S. Estudo de um muro de terra armada pp45-58, Lisboa 1992- Revista da Sociedade Portuguesa de Geotecnia.

AGUIAR, V Ensaios de Rampa para estudo da resistência de interface soloGeossintéticos-Porto Alegre-Dissertação de Mestrado.

ALIMI, I. et al (1977)-“Étude de I àdherence sol-armature em place em laboratoire” $-9^{\text {th }}$ ICSMFE, Tokyo.

ASSOCIAÇÃO BRASILEIRA DE NORMAS TÉCNICAS. NBR 9286-TERRA ARMADA. RIO DE JANEIRO, 1986.

AZAMUJA, E., STAUSS, M., SILVEIRA, F.G. e NIGUEL, A. Casos de conteções de taludes rodoviários através de solos reforçados com geossintéticos no estado do rio Grande do Sul, Regeo, Porto Alegre, 2003, 12p.

BAKEER, R. M., SAYED, S. M. CATES, P. SUBRAMANIAN, R. Pullout and shear test on geogrid reinforced lightweight aggregate. Geotextiles and geomembranes. V16. 119133. 1998.

BASTICK, M., SCHOLESSER, F., E CANEPA, Y. (1991) "Efforts et déformatins dans une cullée experimentale en terre armeé" - X ECSMF, Firenze.

BUENO, B. S., Geosythetic - Reinforced Soil walls and Slopes: Brazilian Perspectives, Geofrontiers., Austin T., 2005, 14p.

BUENO, b. S., VILAR, O. M. e ZORMBERG, J.G. Use of tropical soil as backfill of reinforced soil structures in Brazil, 8th International Conference on geosynthetics, Yocohama, 2006, pp.1209-1212.

CHANG, D.T., SUN, T.S. E HUNG, F. Pullout mechanism of geogrid under confinement by sand and clayey soils. Transportation research record 1474. New York. pp 64-72.1995.

CINTRA, J. C. A., AOKI, N. Fundações por estacas, projeto geotécnico, São Carlos_SP_Brasil 2010. 
ERLICH, M., DELlE VIANNA, A. J. e FUSARO, F. Comportamento de Um Muro de Solo reforçado. X COBRAMSEG, Foz do Iguaçu. 1994, PP.819-824

FARRAG, K. et al (1993). Pull-Out Resistance of Geogrid Reinforcements. In: Geotextiles and Geomembranes 12.

FELIX, C. M. S. (1991). Comportamento dos Muros de Terra Armada. FEUP-portugal.

MACCAFERRI-Technical data sheet-Paraweb ${ }^{\text {TM }}$ MD (30.01.2007).

MAHMOOD, T. Failure analysis of a mechanically stabilized earth (mse) wall using finite element program PLAXIS, 2009, pp 01-136.

MALLICK, S. B. ELTON, D. J. ANDANUR, S. A new approach in modeling of soilgeotextile interface behavior in pullout tests. $6^{\text {th }}$ International conference on geosynthetics. 729-732, 1998.

MARTINS, A. P. Estudo da influência das interações Físico Químicas no comportamento Mecânico de dois solos tropicais do município de Ouro Preto-MG.

MECHANICALLY STABILIZED EARTH WALLS AND REINFORCED SOIL SLOPES DESIGN \& CONSTRUCTION GUIDELINES No. FHWA-NHI-00-043, NHI Course No. 132042., 2001, PP 20-136.

MENDONÇA, M. B., BRUGGER, PJ.; PEREIRA, G. I. M., MONTEZ, F.T., Recuperação de aterro rodoviário Através de solo Reforçado e blocos intertravados. II Simpósio De prática de Engenharia Geotécnica da Região Sul - GEOSUL 2000, Porto Alegre. V.1.p.95103

MIRANDA, S. B. (2009). Estudo da Resistência ao Cisalhamento de Interfaces em Reforços Unidirecionais.

MUÑOZ, M.A \& ESPINOZA, E. M. Solucion mediante la construccion de muros de tierra armada en terraplenes, 2007, PP 17-55.

NBR 6323- Produtos de aço ou ferro fundido revestido de zinco por imersão a quente. Rio de Janeiro, 1990.

PATIAS, J. Avaliação de Uso de Solos não Convencionais em Estruturas de Solos Reforçados. Dissertação, EESC, USP, 129p.

PAUL, D. P (2000). Mechanically Stabilized Earth Wall Inspector's Handbook.

RECCIUS, G. Muros de Contenção de Solo Reforçado com Geogrelhas e Paramentos de Blocos Pré-fabricados. Geossintéticos, 99, Rio de janeiro, 1999, PP. 421-428. 
SERAPHIN E MELO 2003-PUC- Rio- certificação Digital nº 0321277/CA

TATSUOKO, F. et Al (1990) Reinforced steeps clay slopes with a none woven geotestile. IN INTERNATIONALNAIL REINFORCED SOIL CONFERENCE, 9 1990, gLASGOW.

SIEIRA, A. C. C. F., CASTRO, D. C. Metodologia para a determinação de parâmetros de interação solo-geogrelha. Solos e Rochas: Revista latino americano de geotecnia. V.25, $\mathrm{n}^{\mathrm{o}}$ 3.2002 
Avaliação da Interação Solo-Fitas metálicas e poliméricas para Soluções em Terra Armada em Solos não Convencionais 


\section{APÊNDICE A - Caracterização do solo não convencional 1}

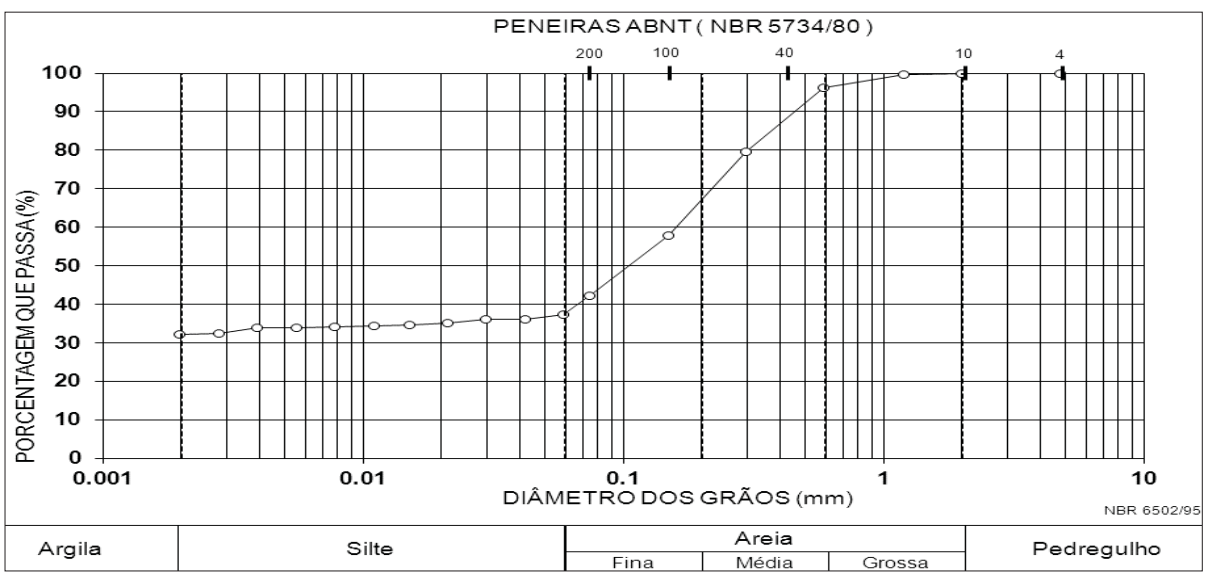

Curva granulométrica do solo não convencional 1

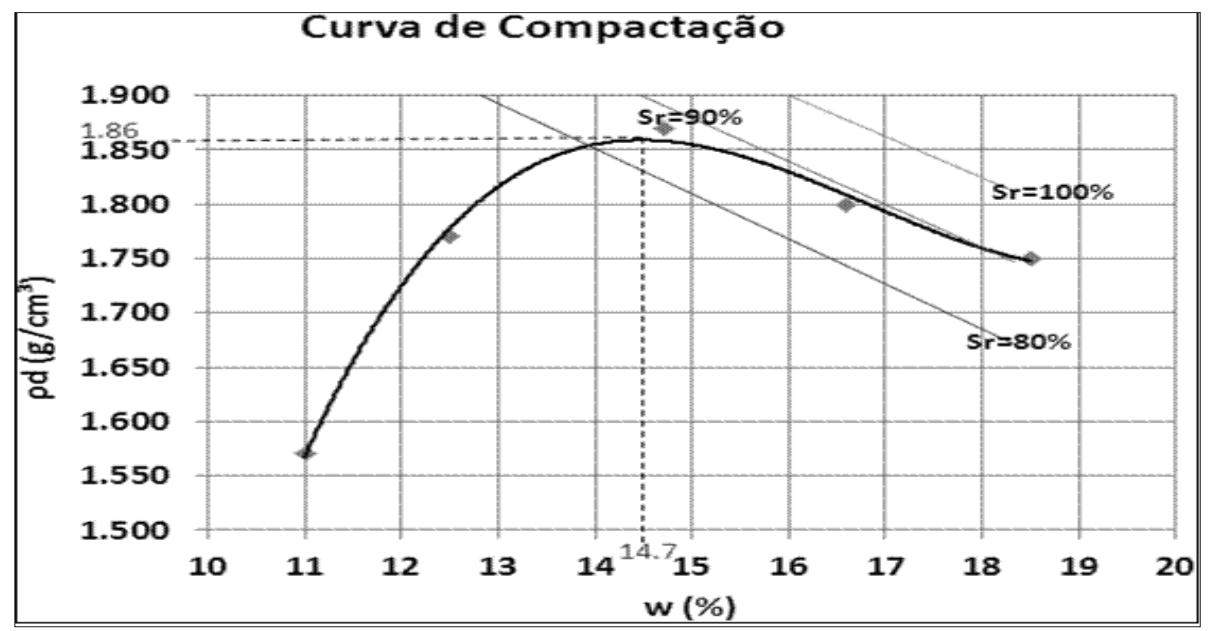

Teor de umidade do solo não convencional 1

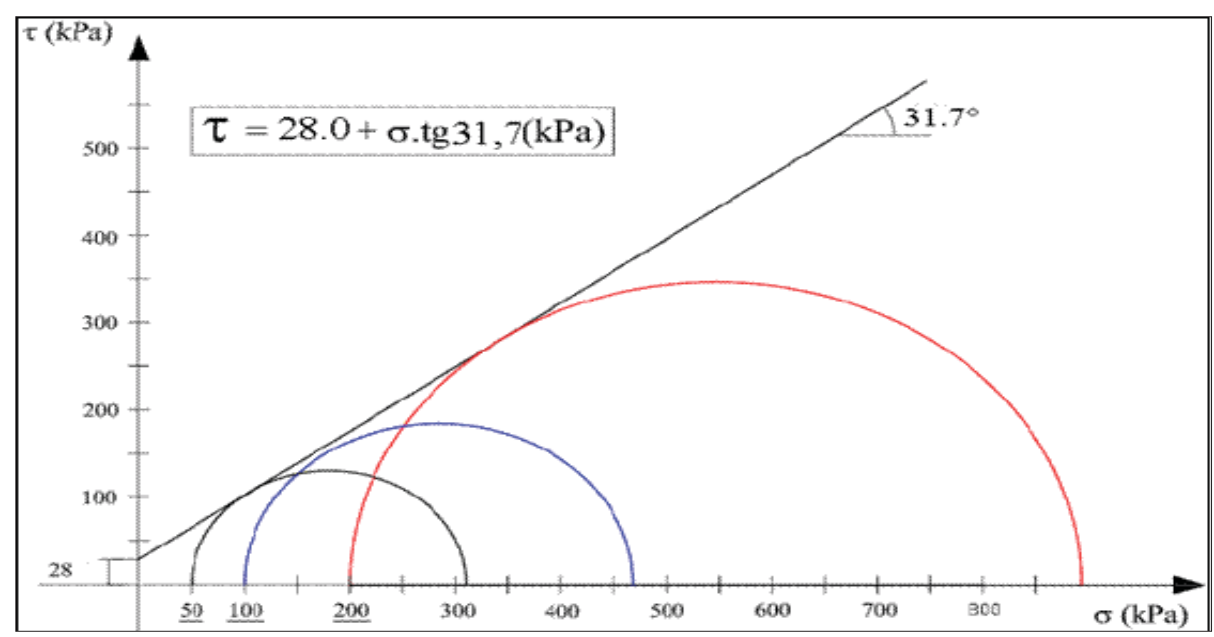

Envoltória do solo não convencional 1 


\section{APÊNDICE B - Caracterização do Solo não convencional 2 - Rodovia SP 215}

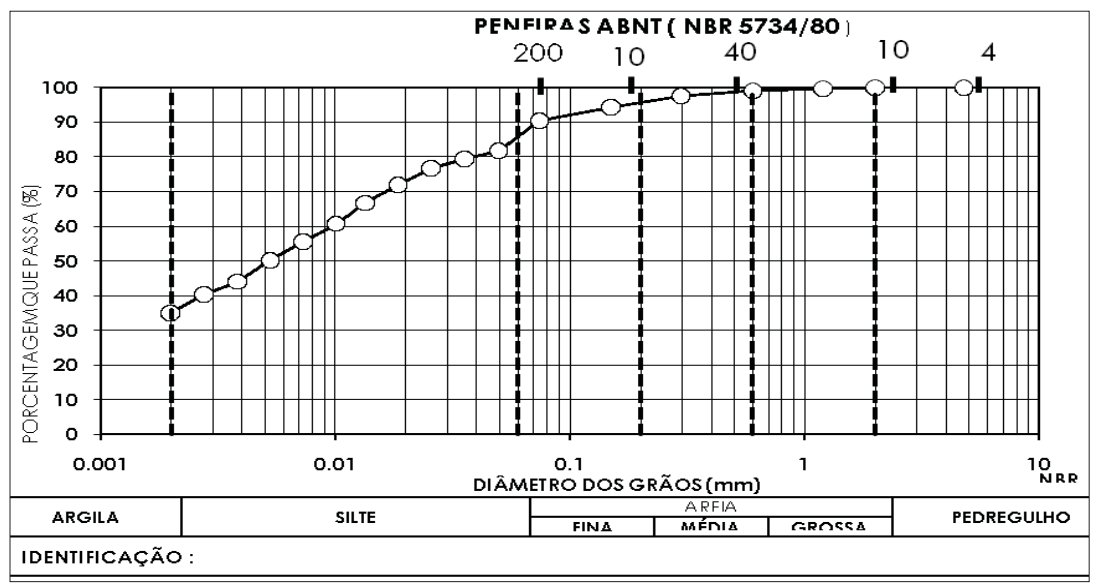

Curva granulométrica do solo não convencional 2

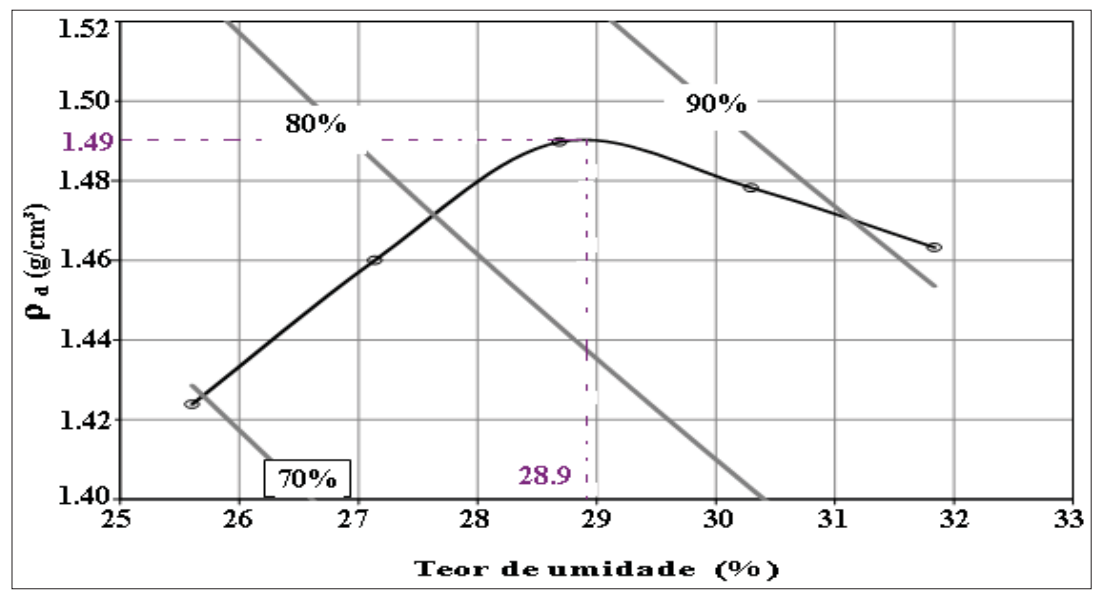

Teor de umidade

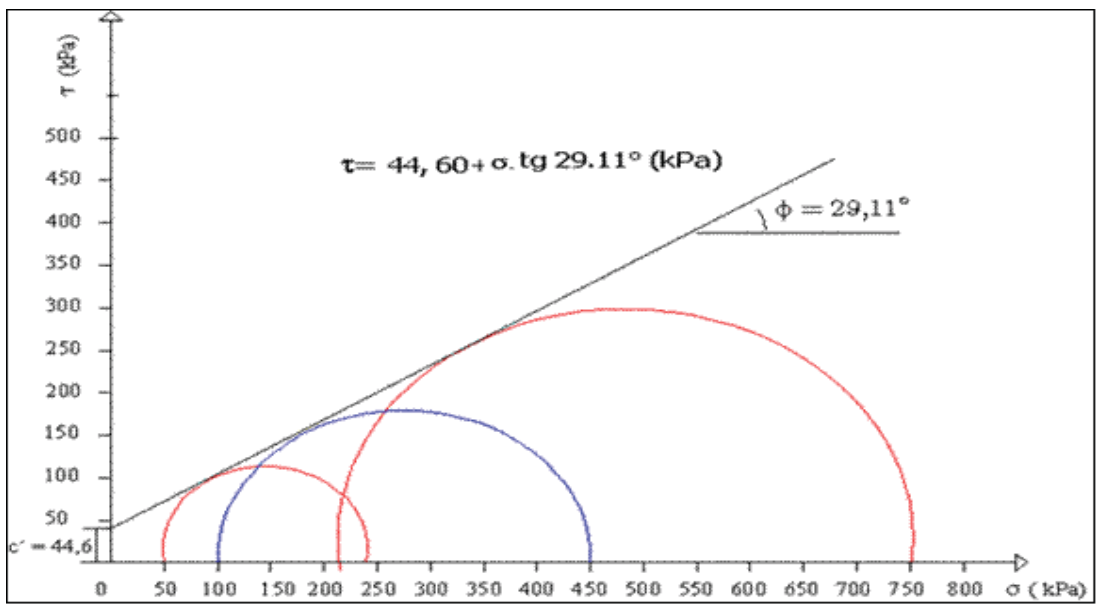

Envoltória do solo não convencional 2_Rodovia SP 215 


\section{APÊNDICE C - Caracterização da Areia - Jundu-Descalvado}

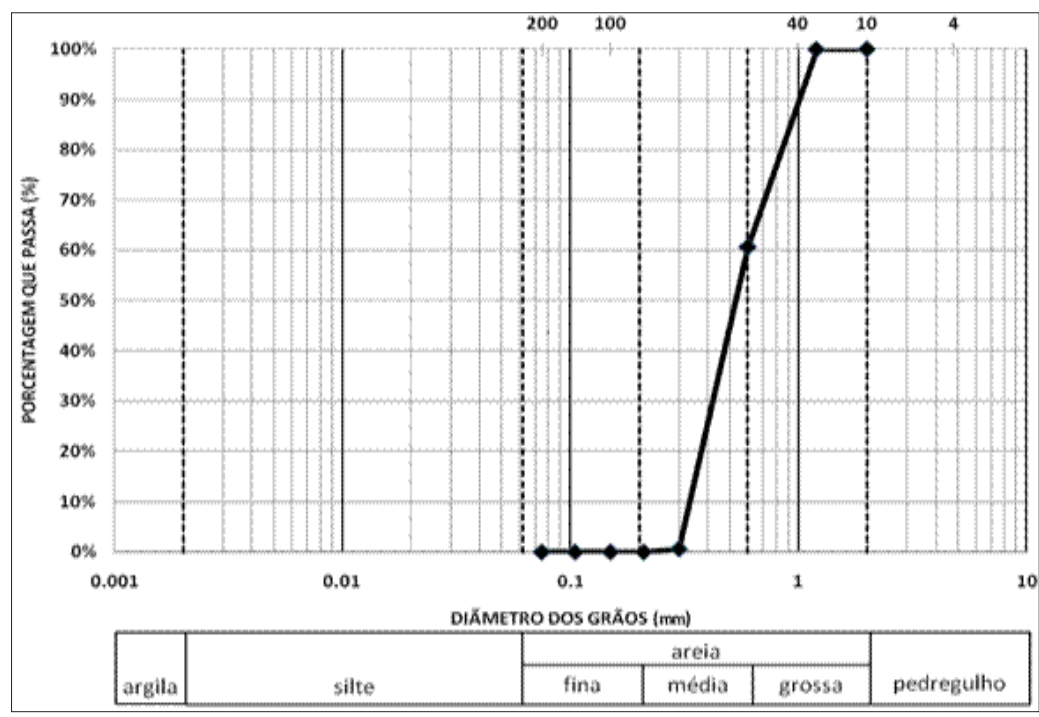

Curva granulométrica da areia

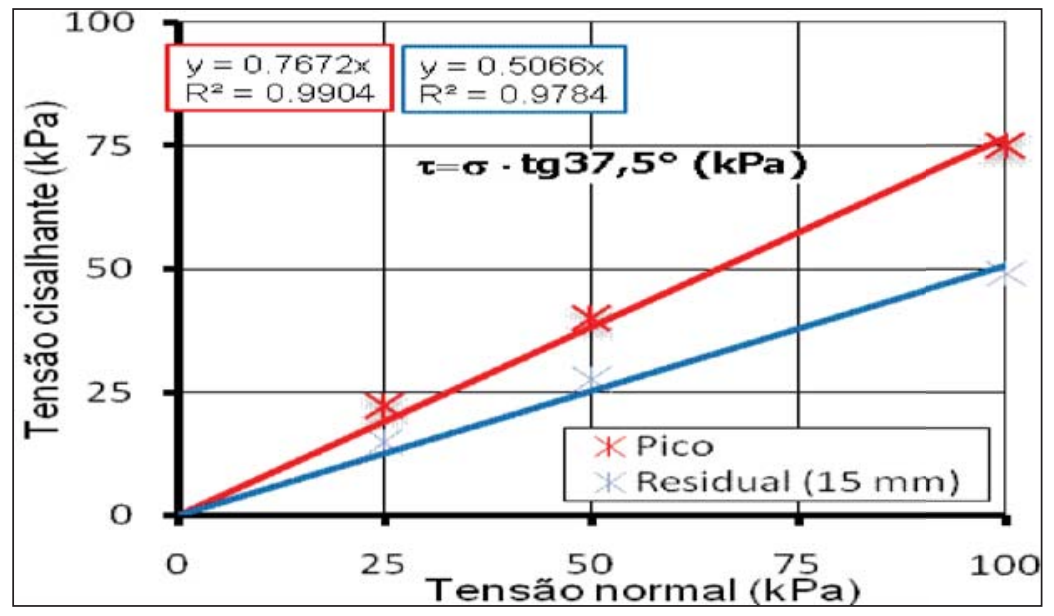

Envoltória da areia da mineradora de Jundu (FAGNER FRANÇA 2009) 

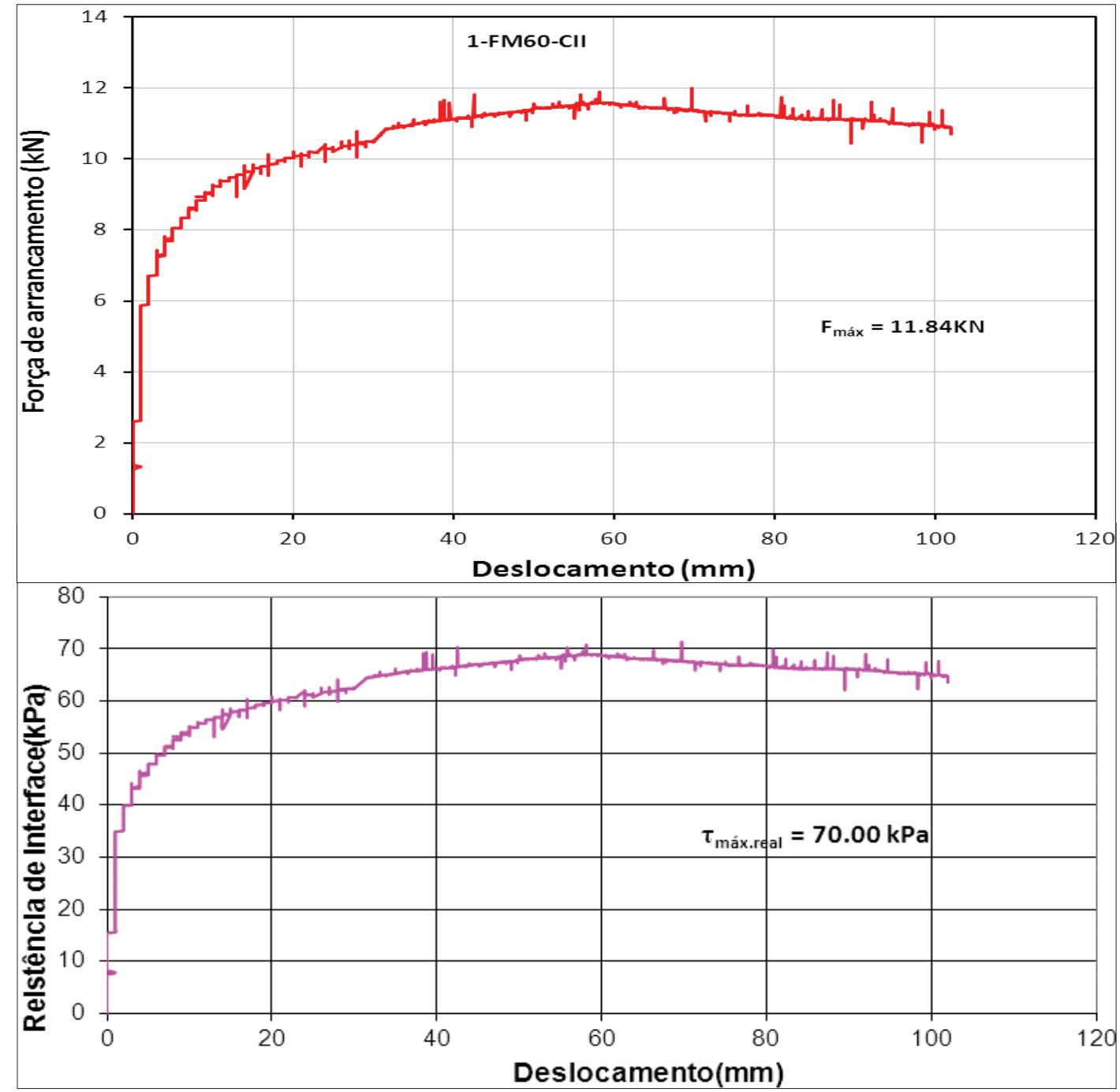

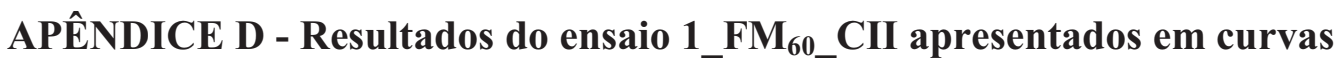

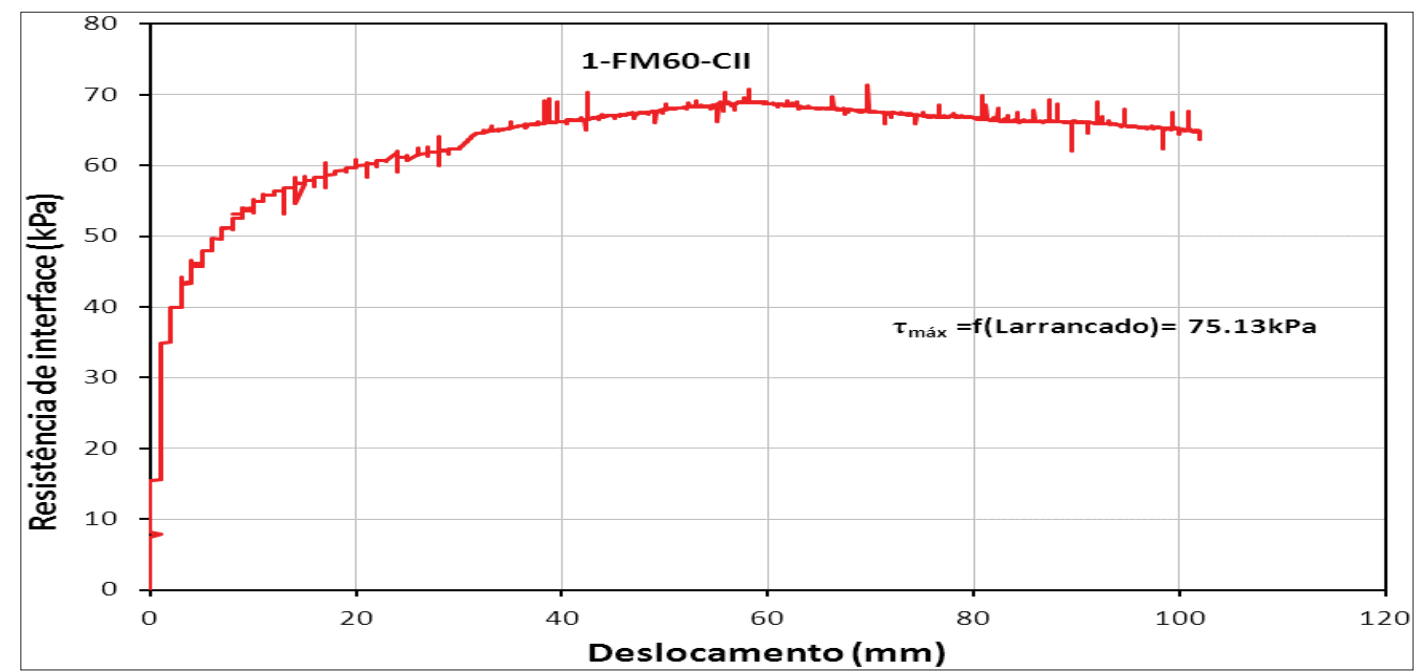




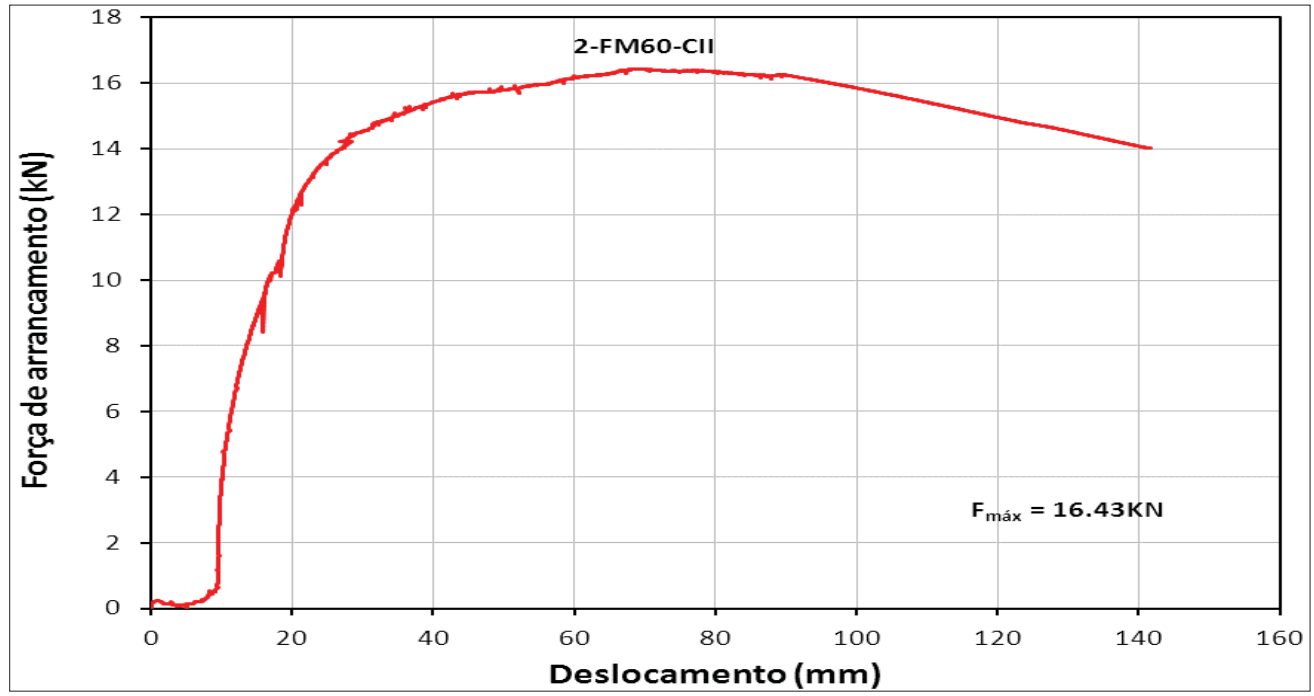

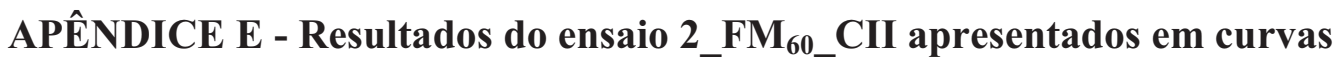

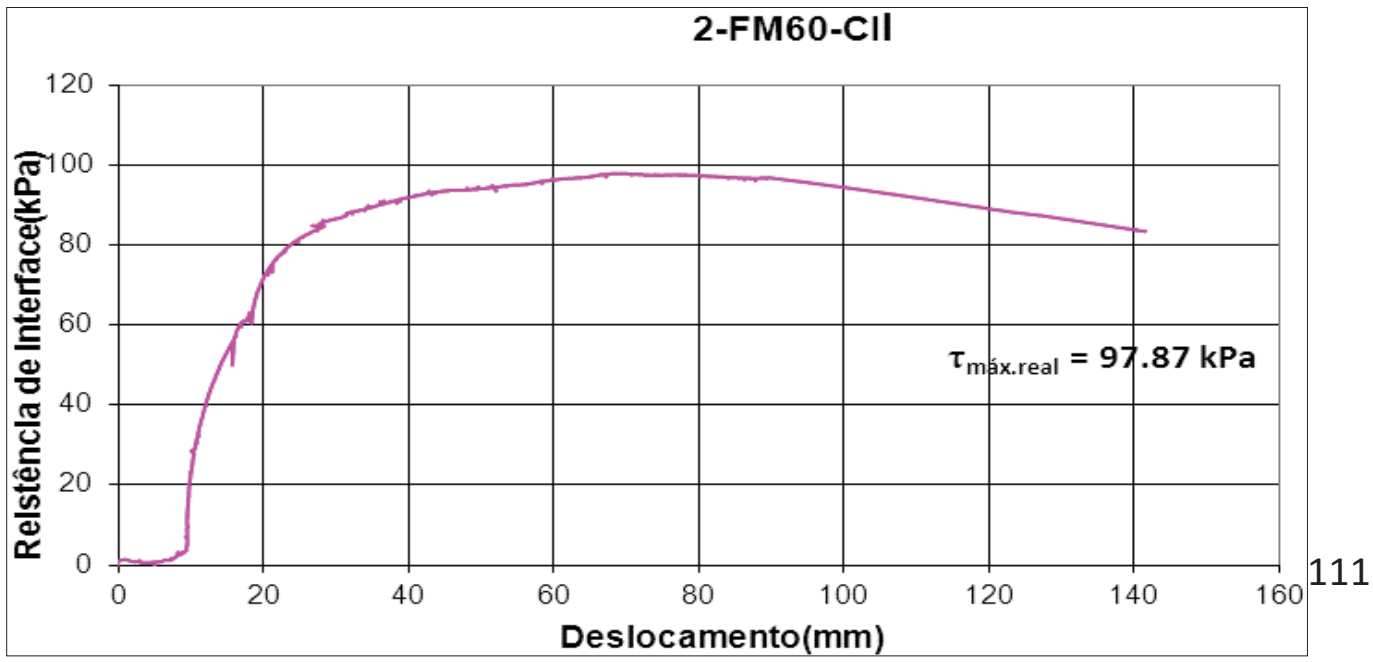




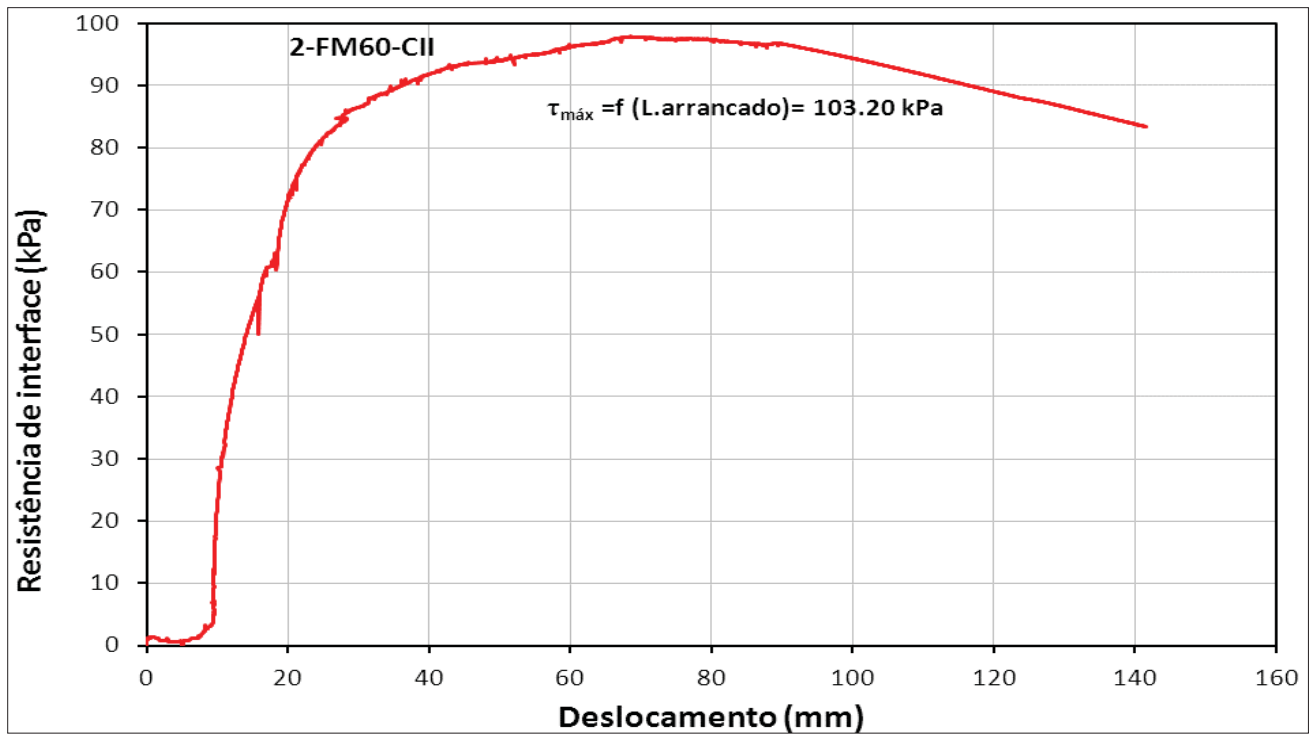

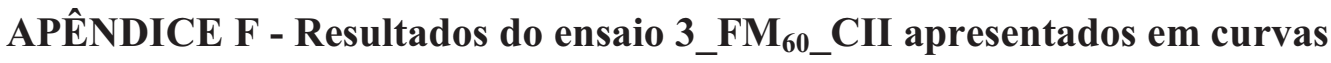




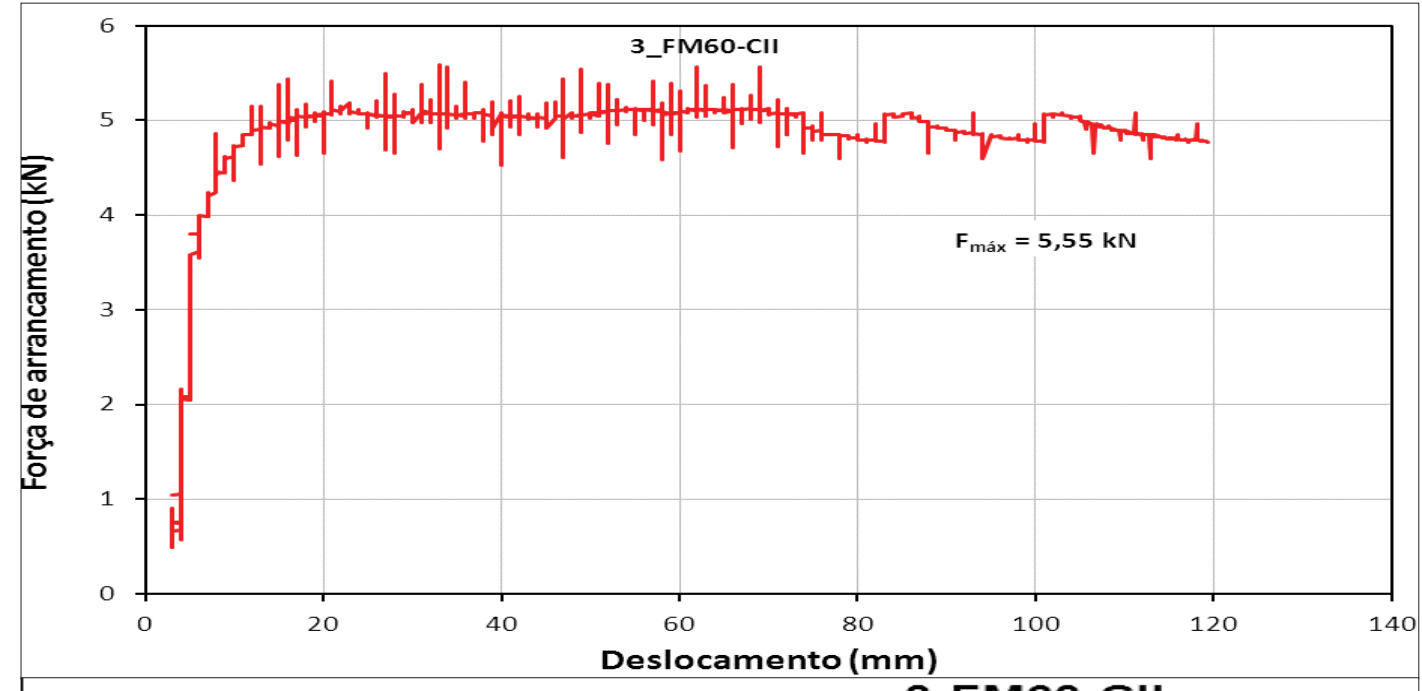

3-FM60-CII
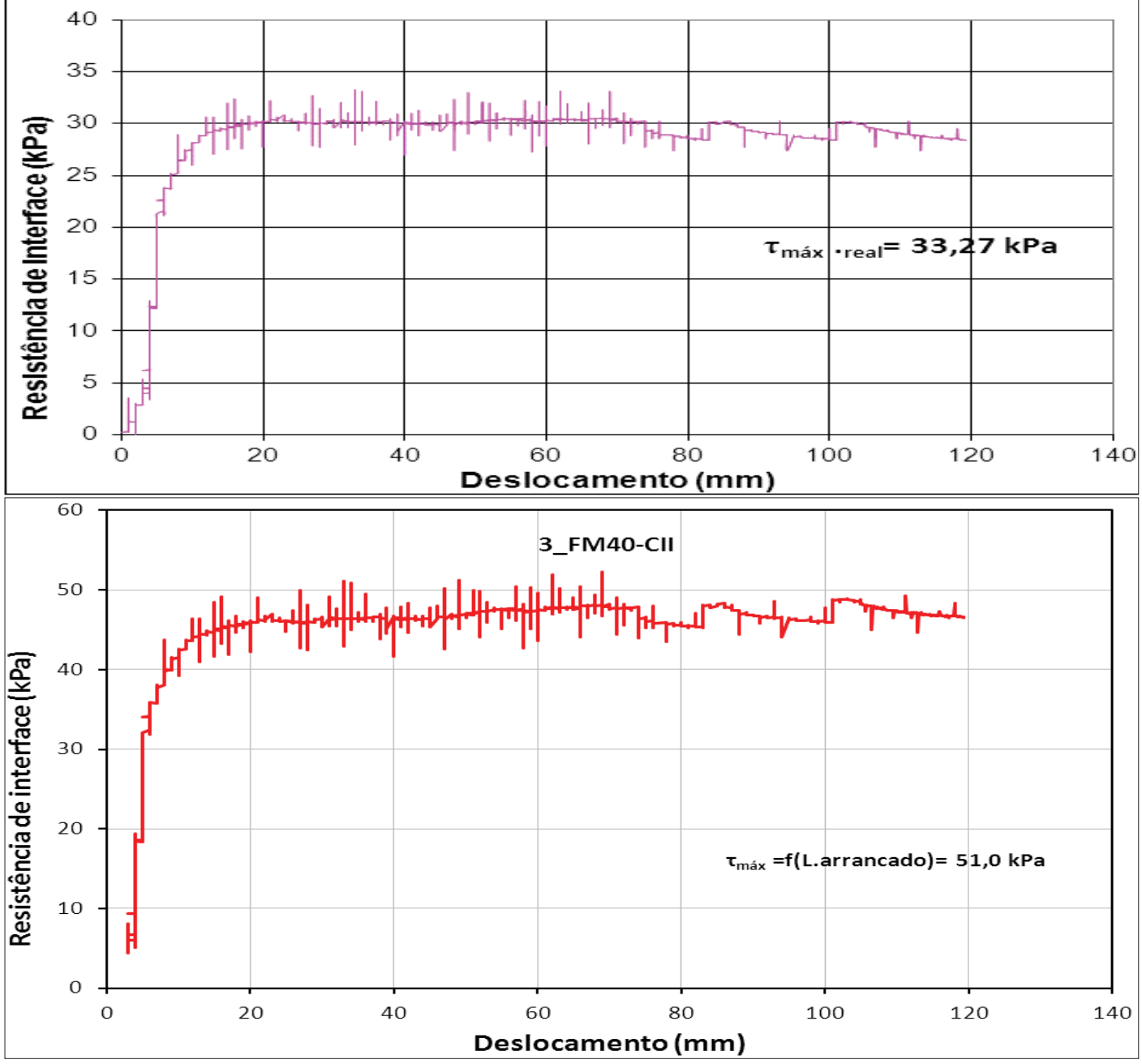


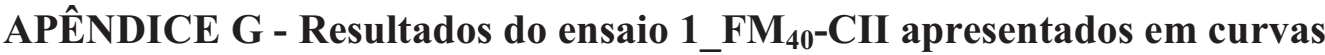
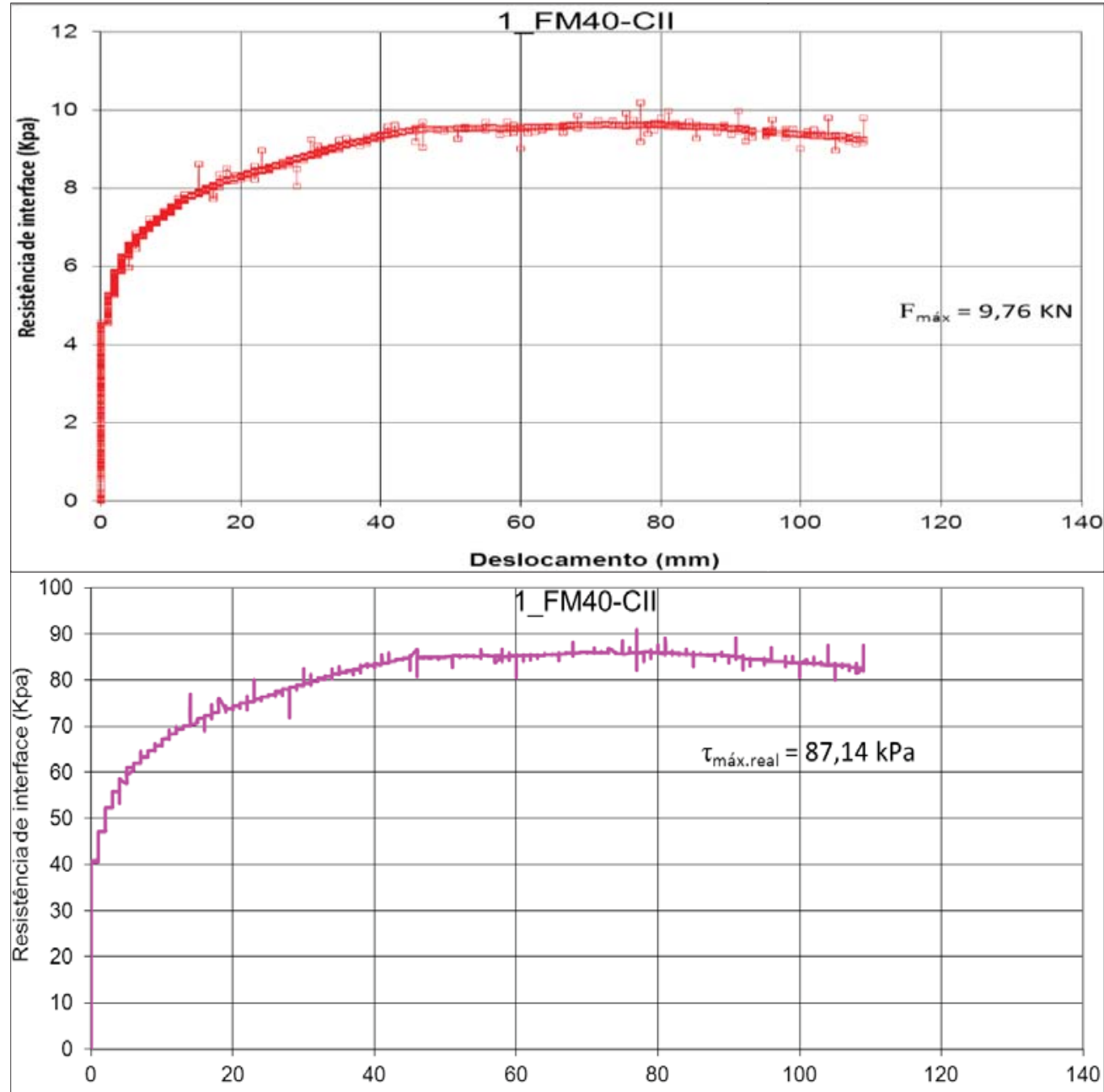

Deslocamento $(\mathrm{mm})$

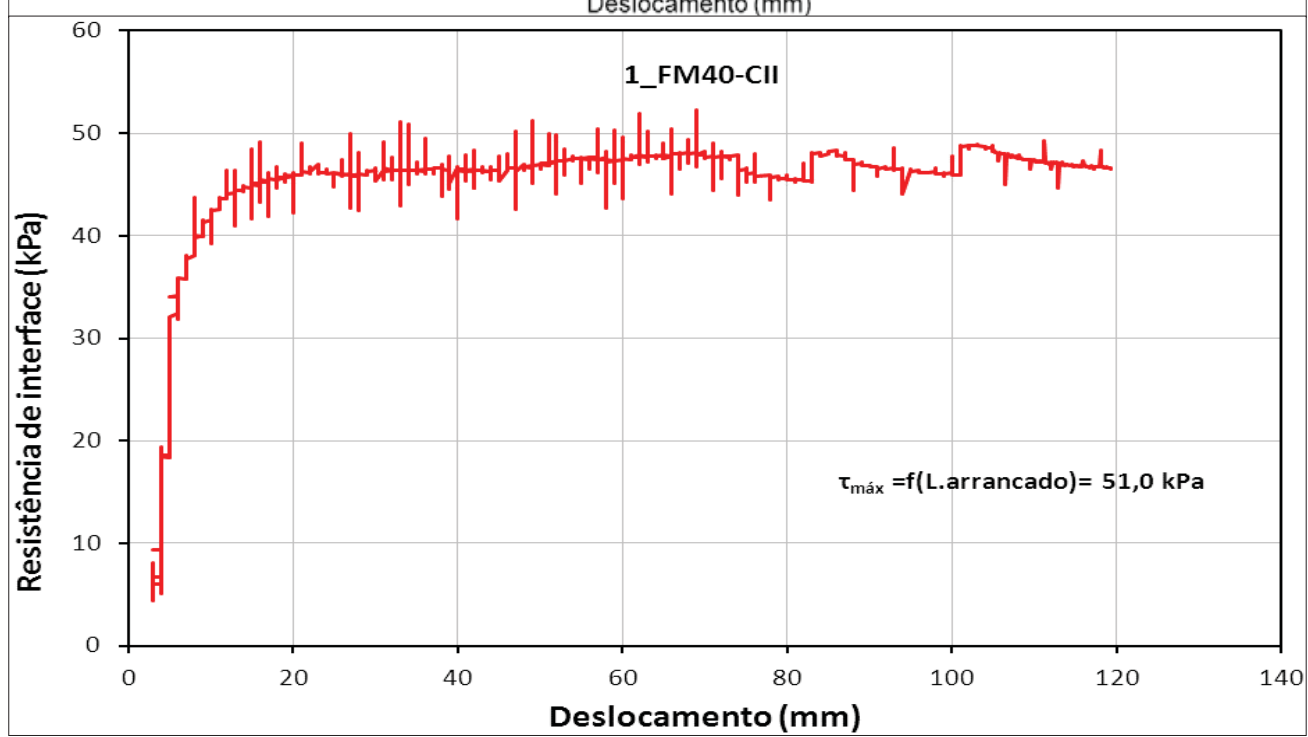


APENDICE H - Resultados do ensaio 2_FM40_CII apresentados em curvas
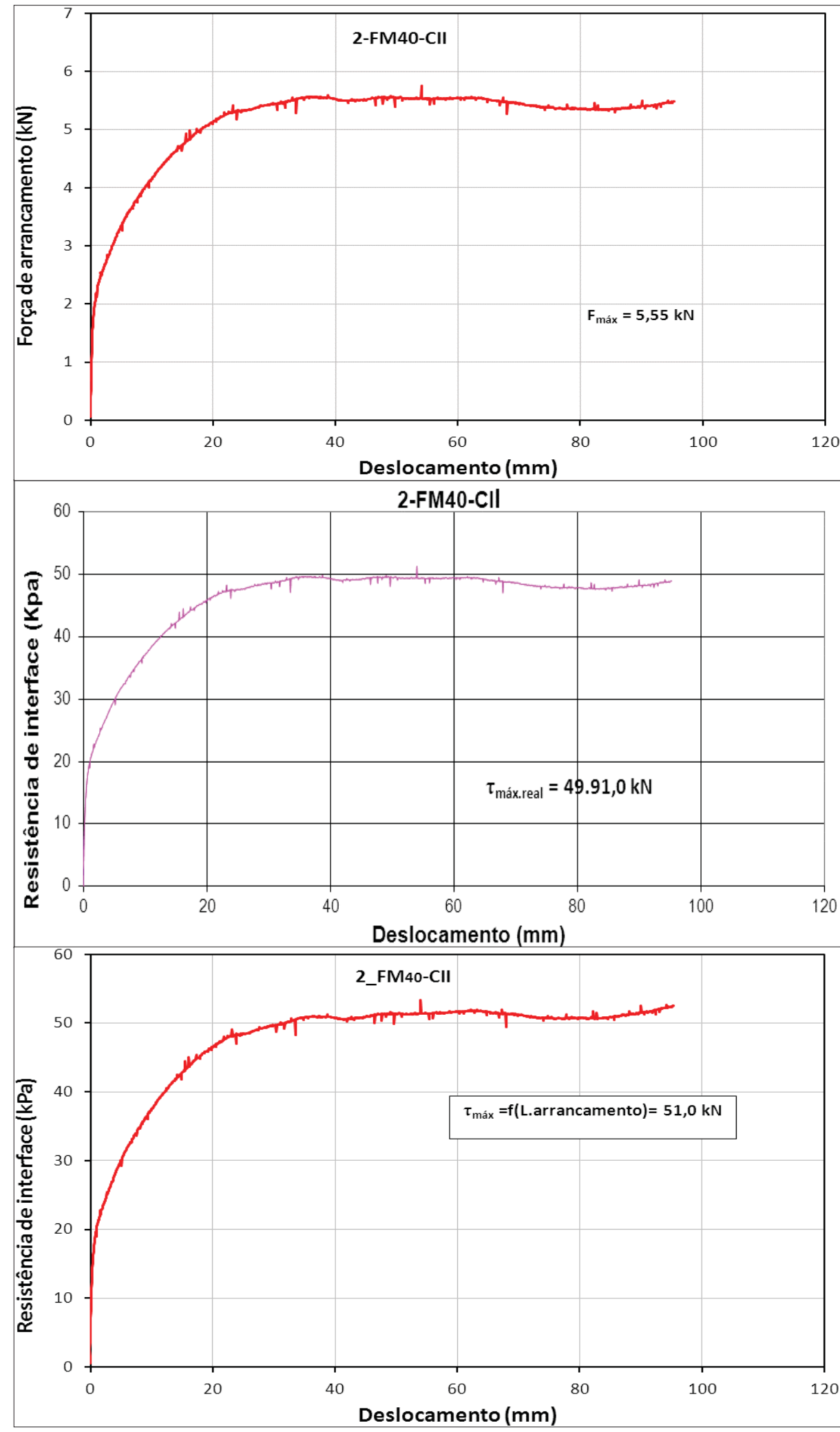
APÊNDICE I - Resultados do ensaio 3_FM F0 $^{-C I I}$ apresentados em curvas
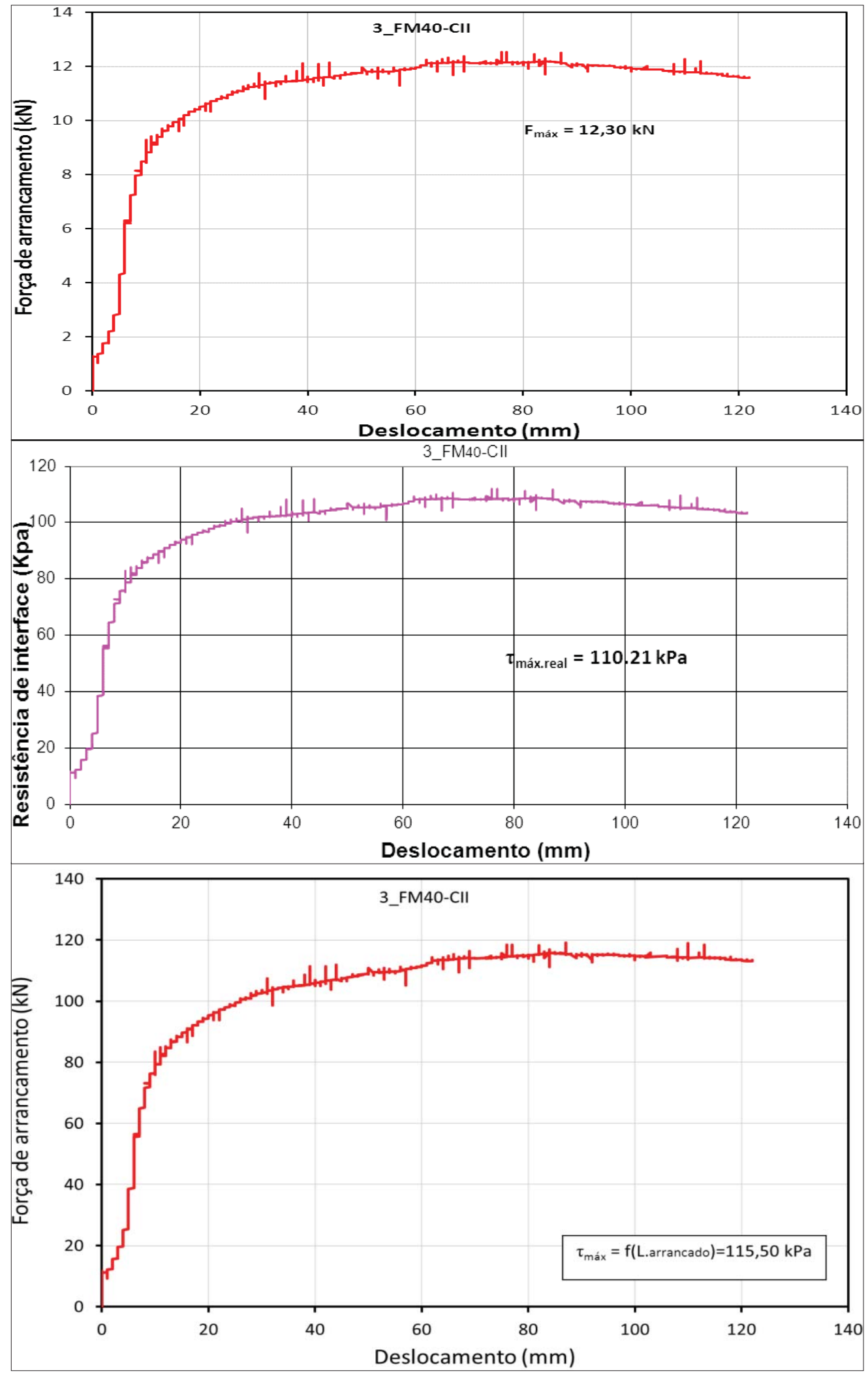
APÊNDICE J - Resultados do ensaio 1- FM $_{60}$ R apresentados em curvas
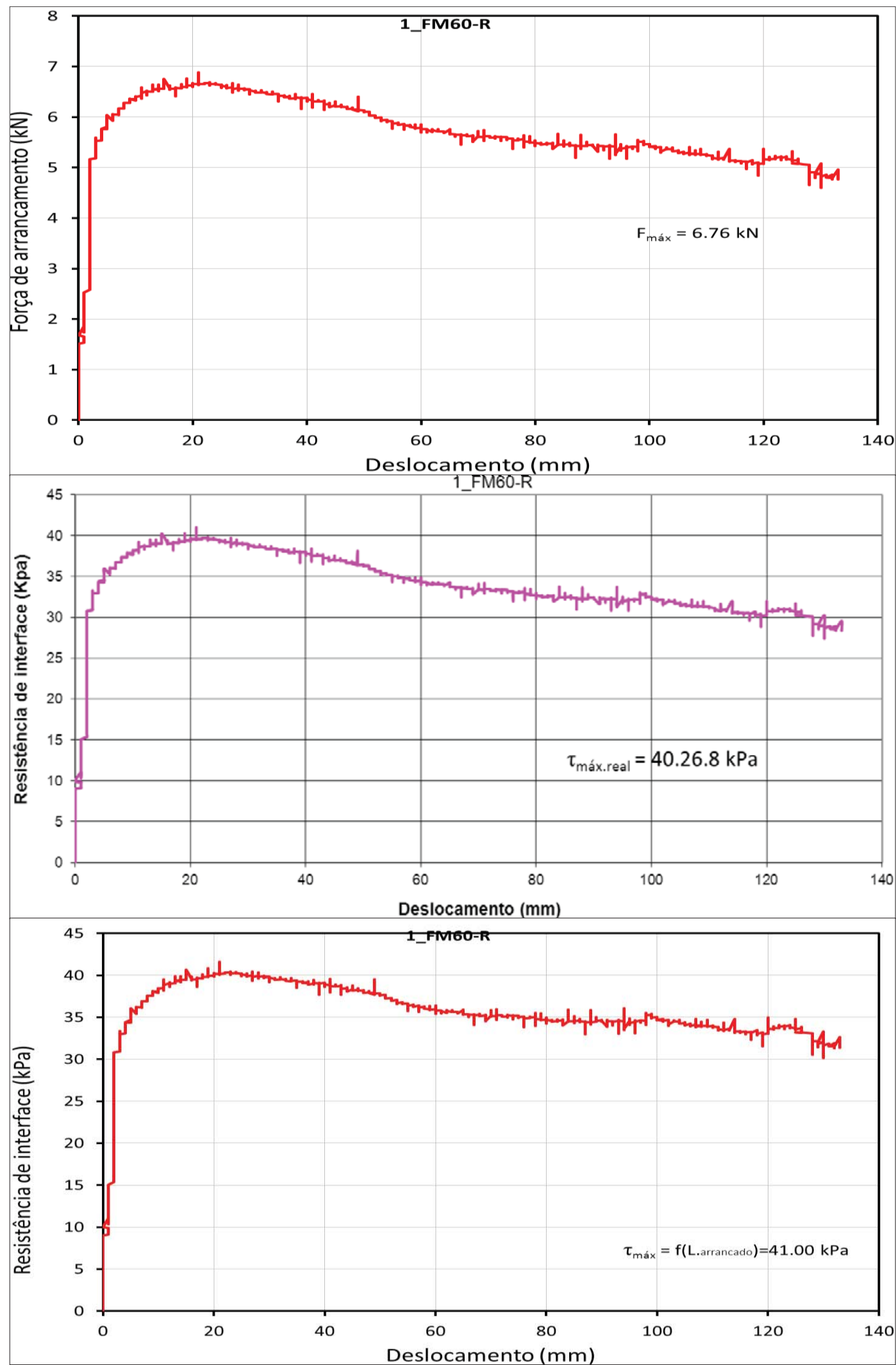
APÊNDICE K - Resultados do ensaio 2_FM F0_R $_{6}$ apresentados em curvas
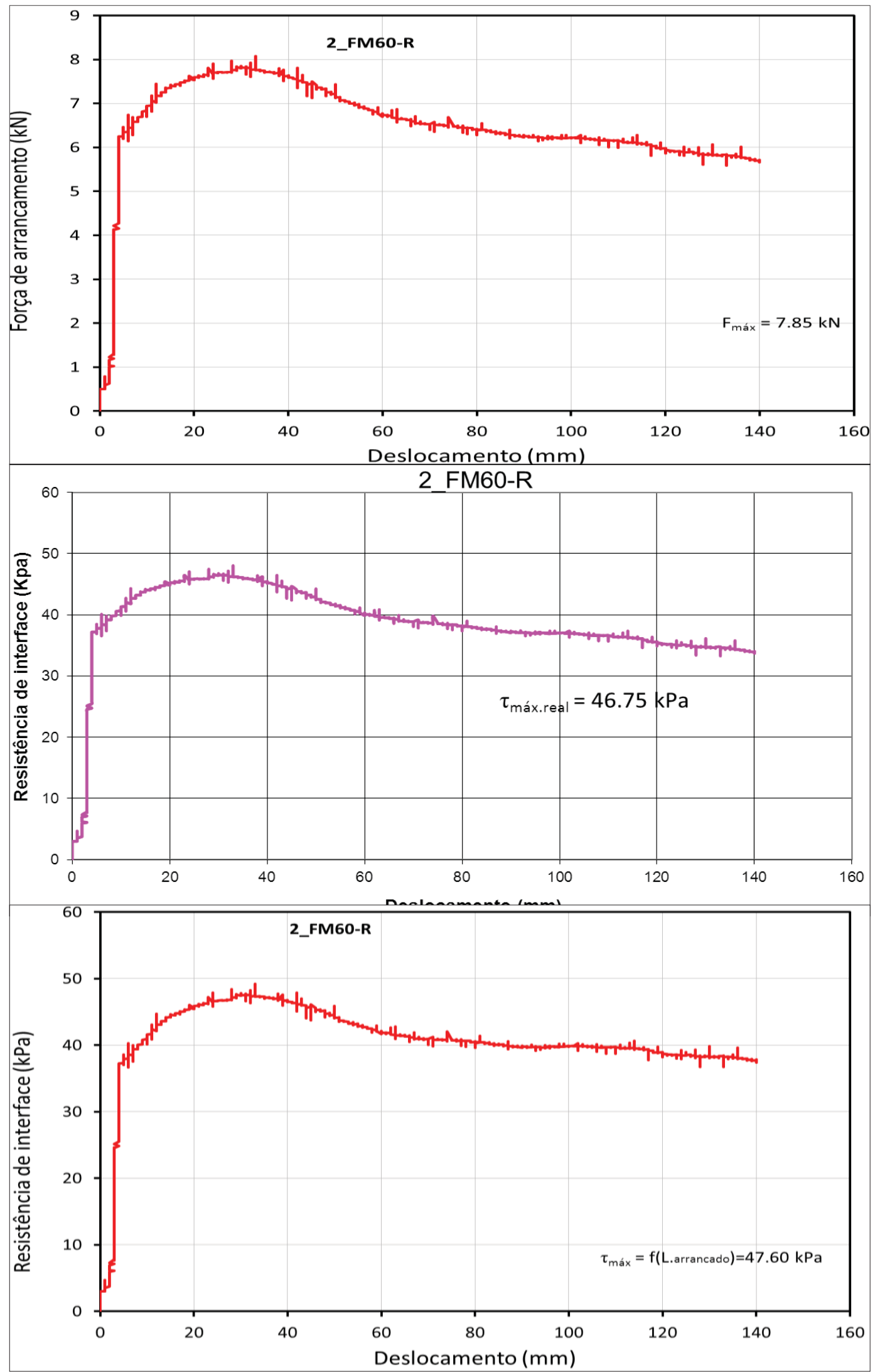
APÊNDICE L - Resultados do ensaio 3_FM F0_R $_{\text {apresentados em curvas }}$
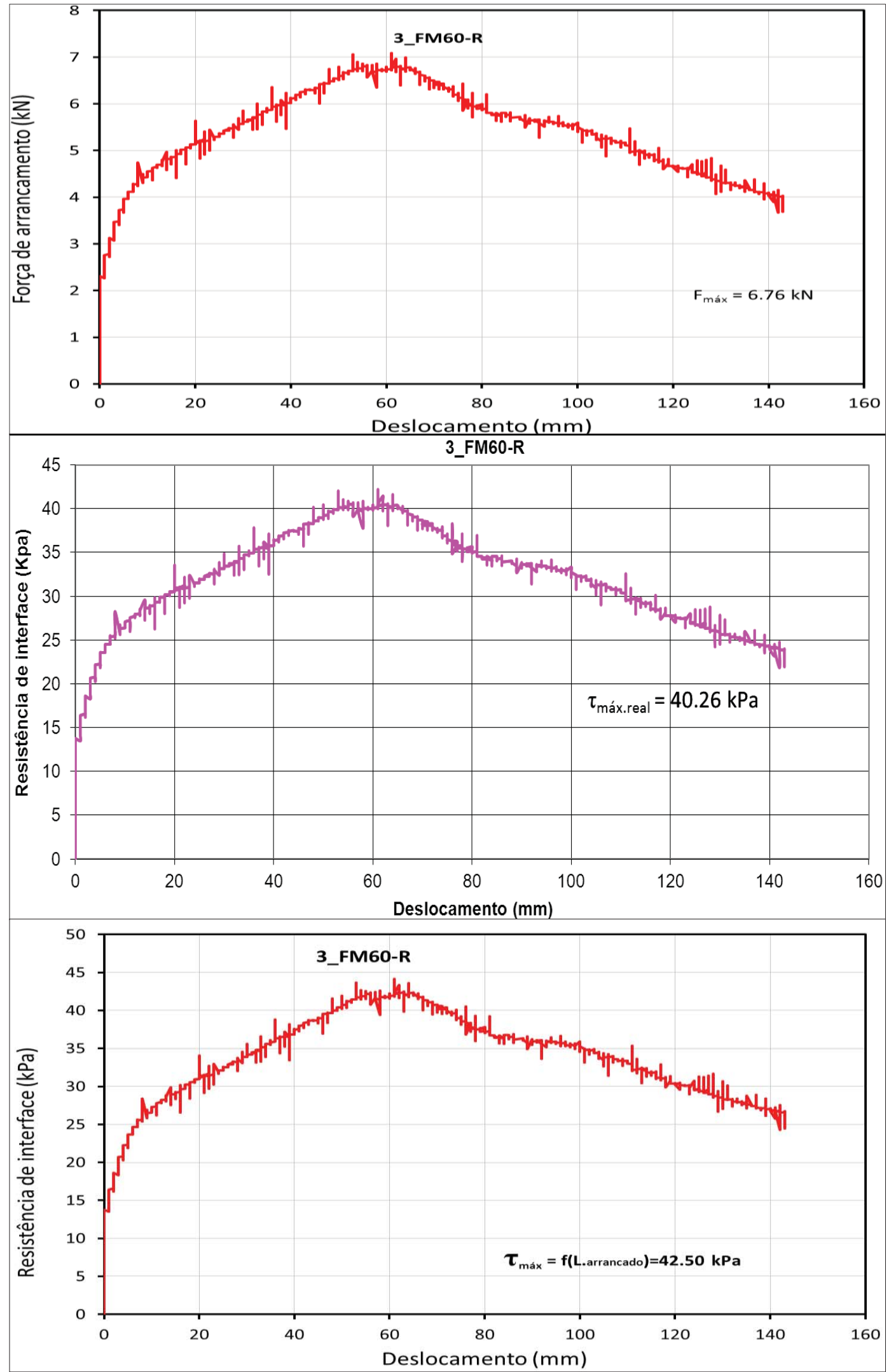
APÊNDICE M - Resultados do ensaio 1_FM40_R apresentados em curvas
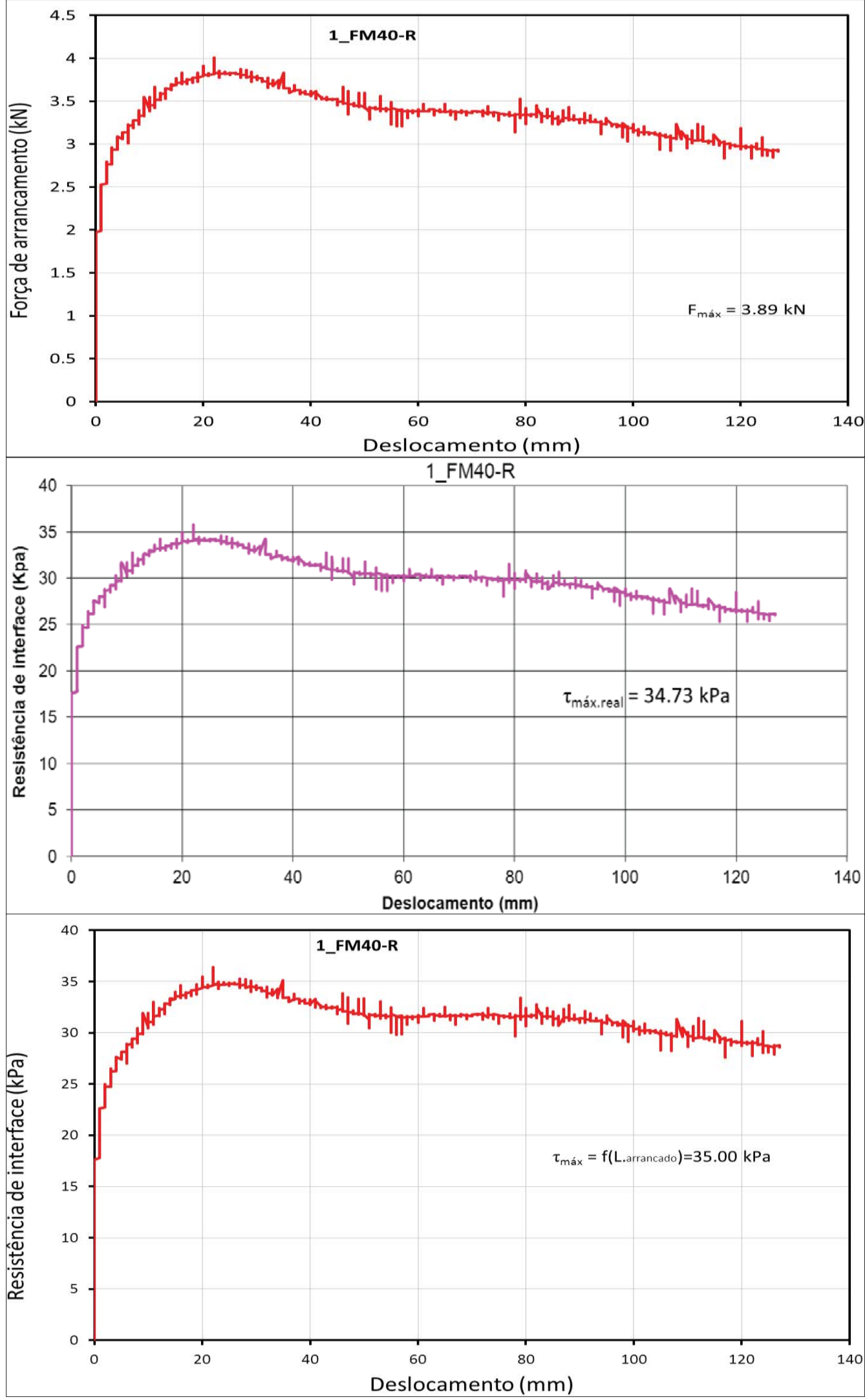
APÊNDICE N - Resultados do ensaio 2_FM FM_R $_{4}$ apresentados em curvas

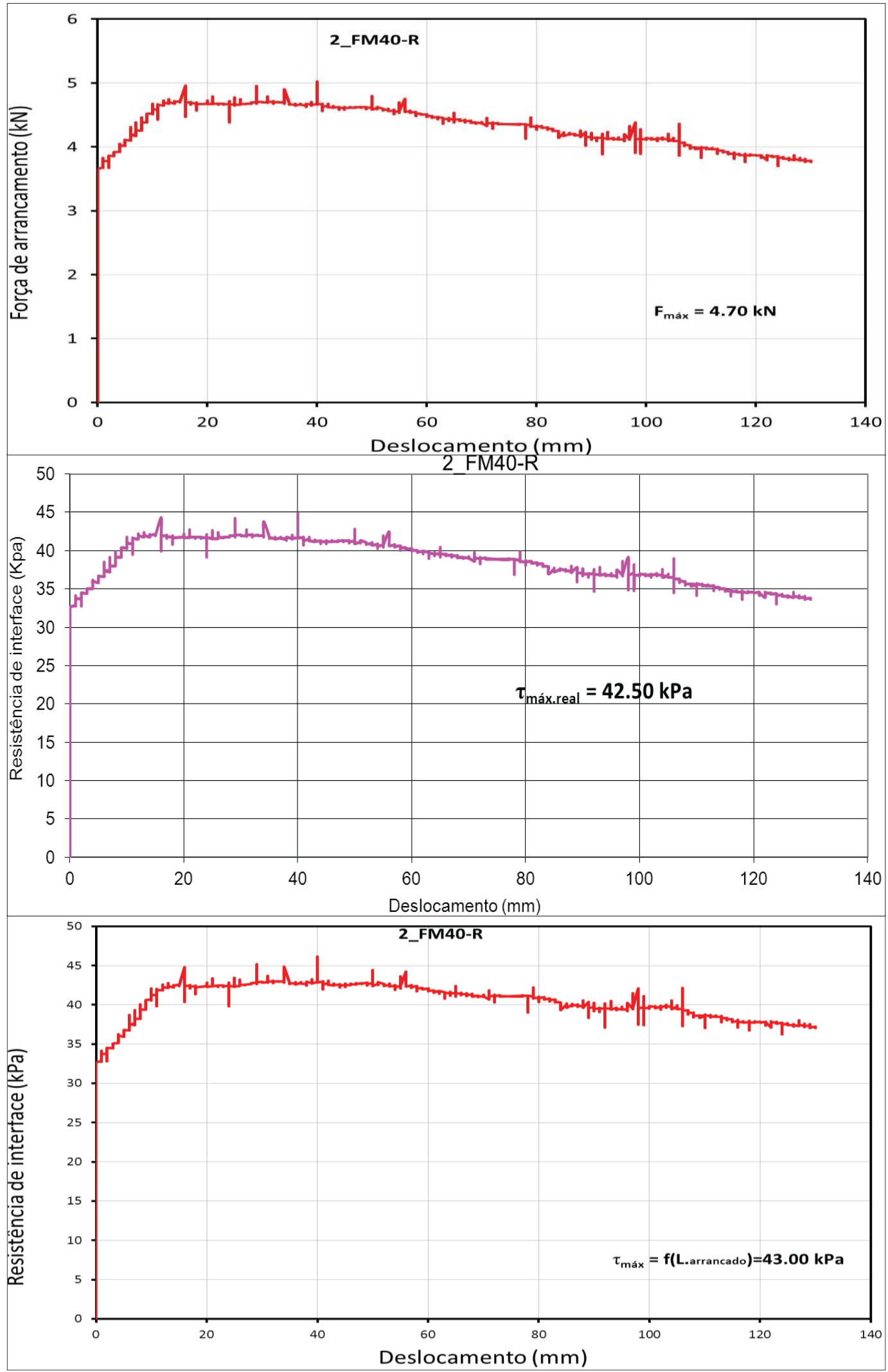




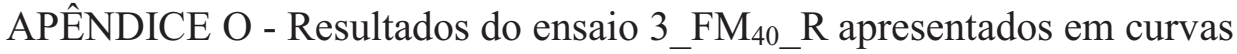
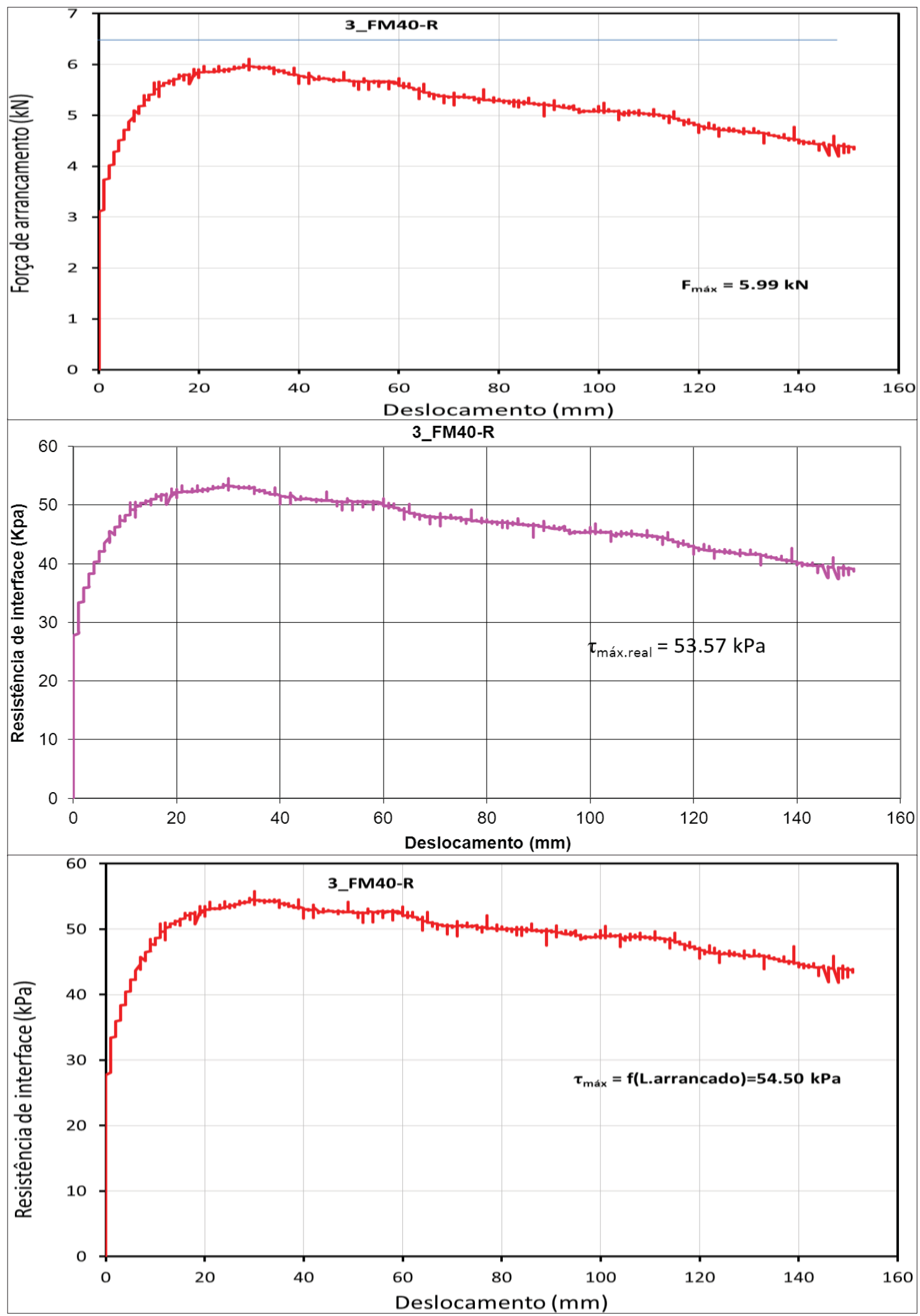
APÊNDICE P - Resultados do ensaio 1_FM $60 \_$A apresentados em curvas

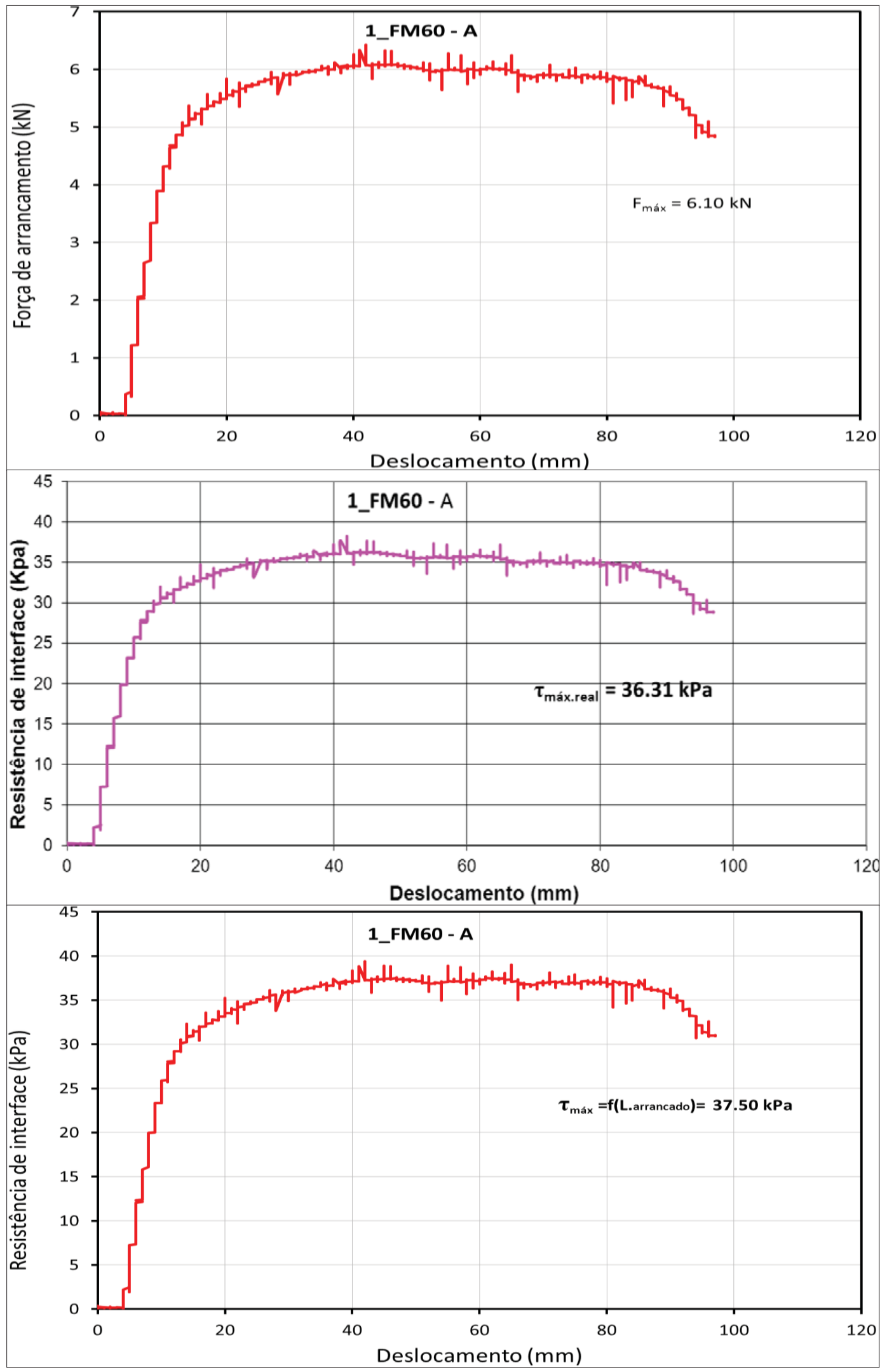


APÊNDICE Q - Resultados do ensaio 2_FM $60 \_$A apresentados em curvas

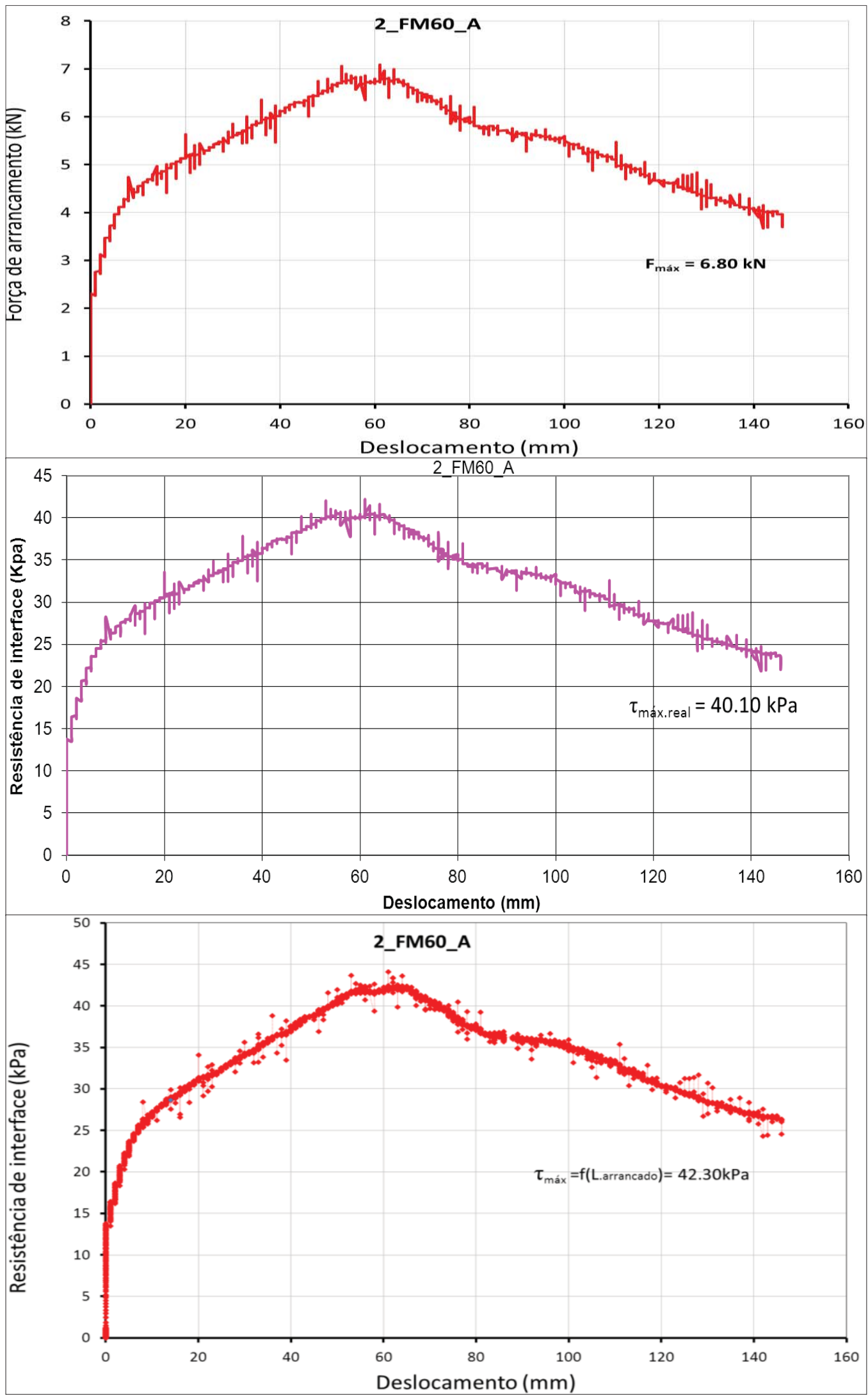


APÊNDICE R - Resultados do ensaio 3_FM $60 \_$A apresentados em curvas
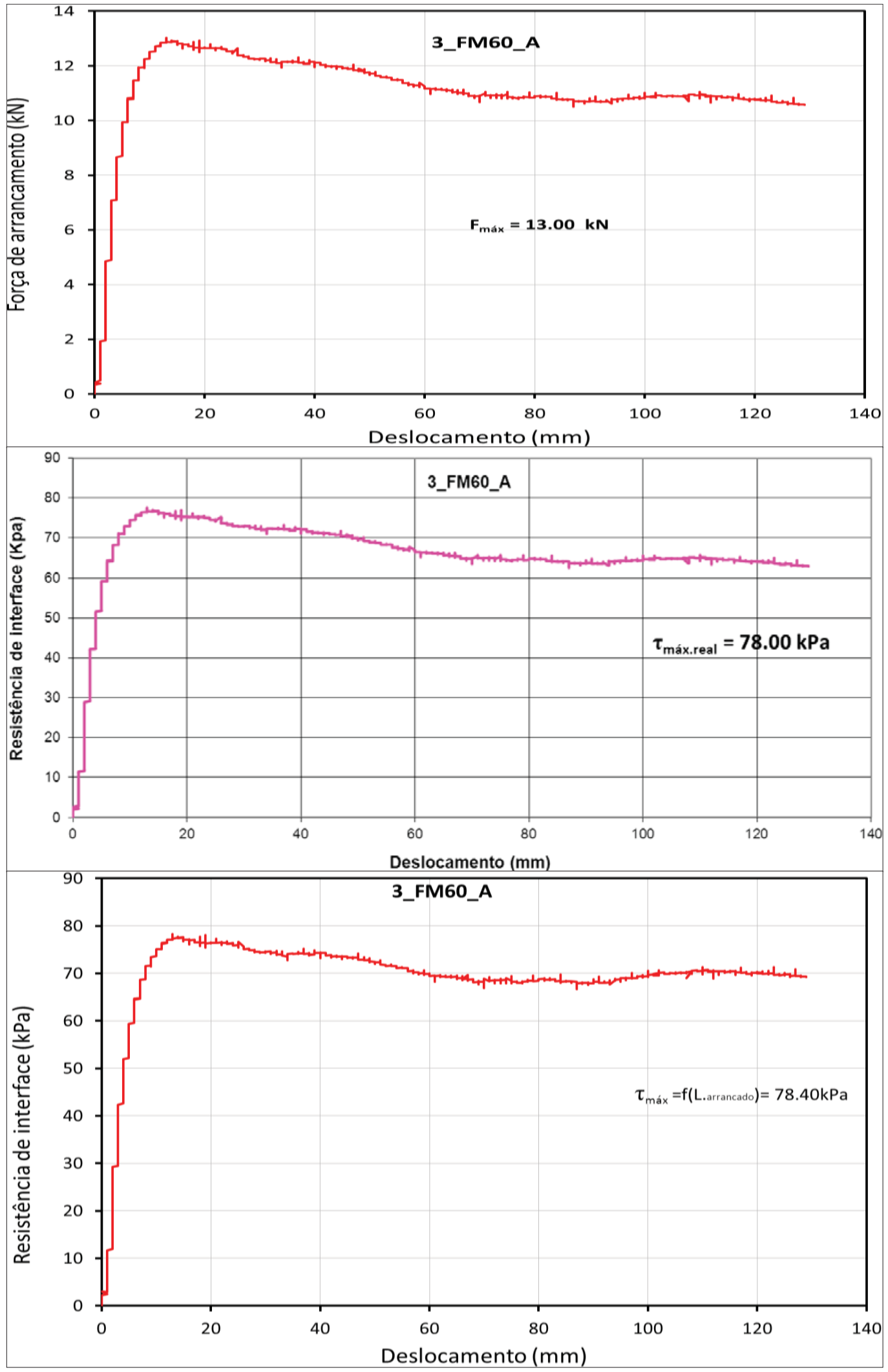
APÊNDICE S - Resultados do ensaio 1_FM40_A apresentados em curvas

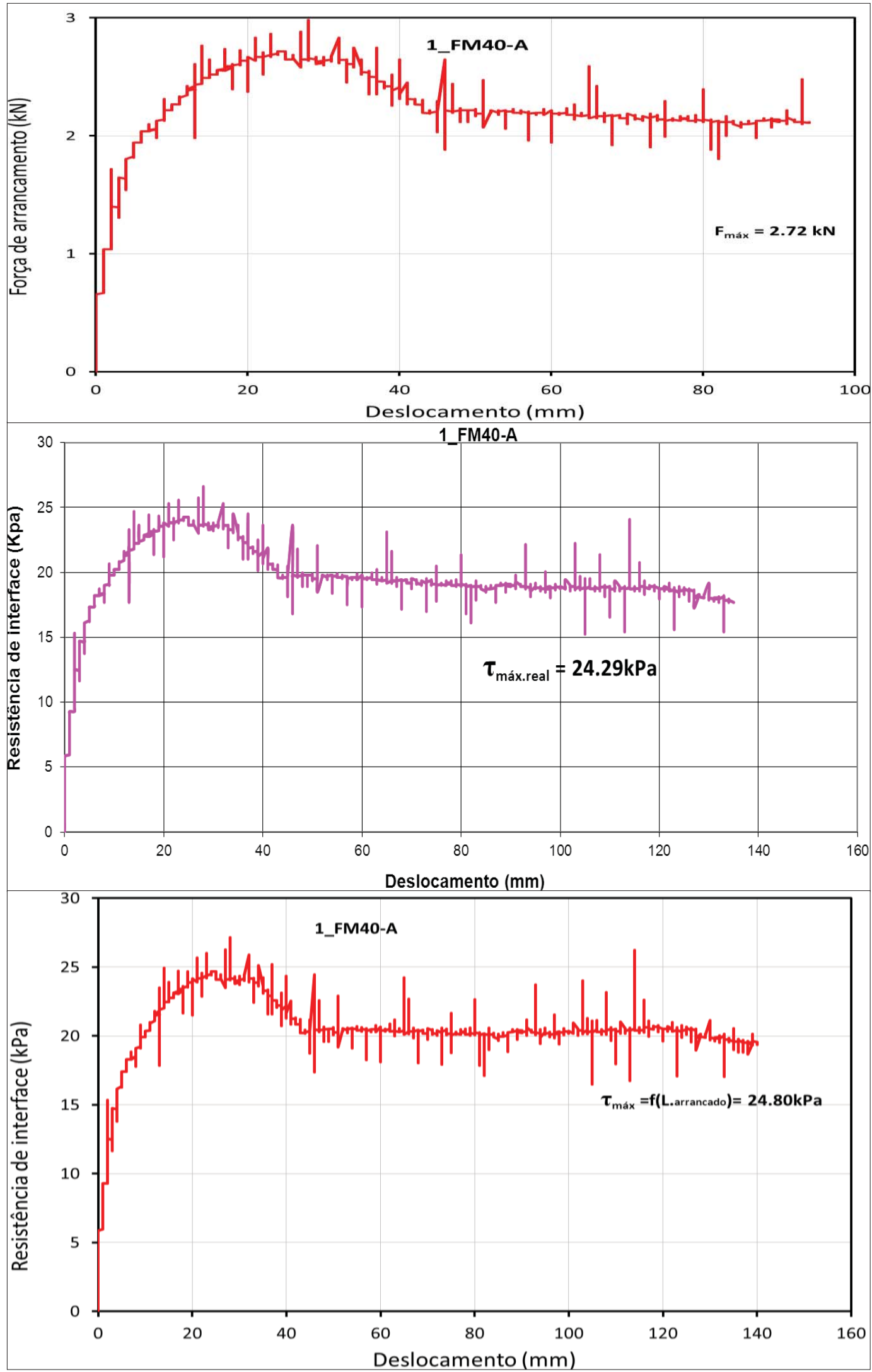


APÊNDICE T - Resultados do ensaio 2_FM40_A apresentados em curvas
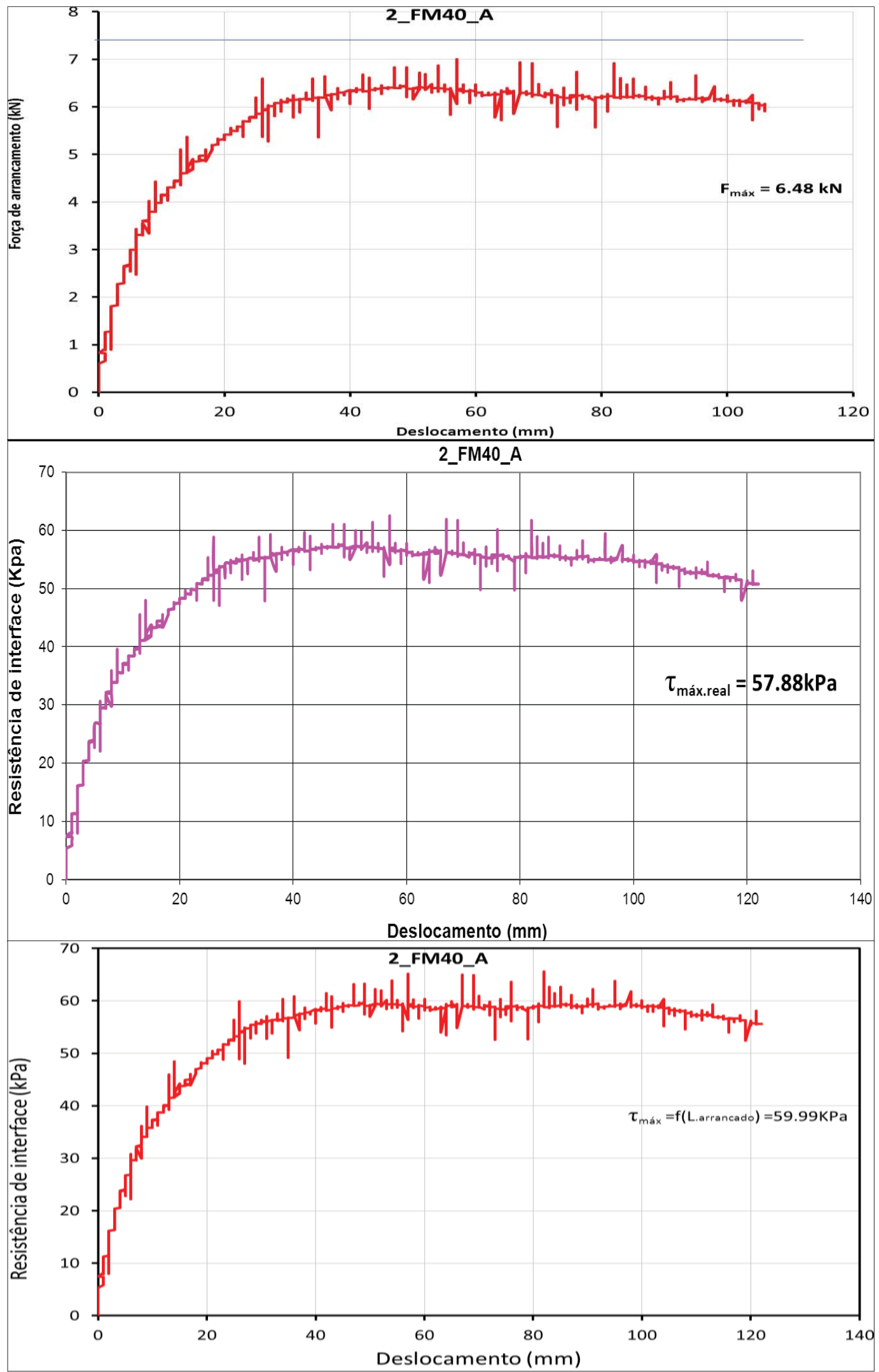
APÊNDICE U - Resultados do ensaio 3_FM40_A apresentados em curvas
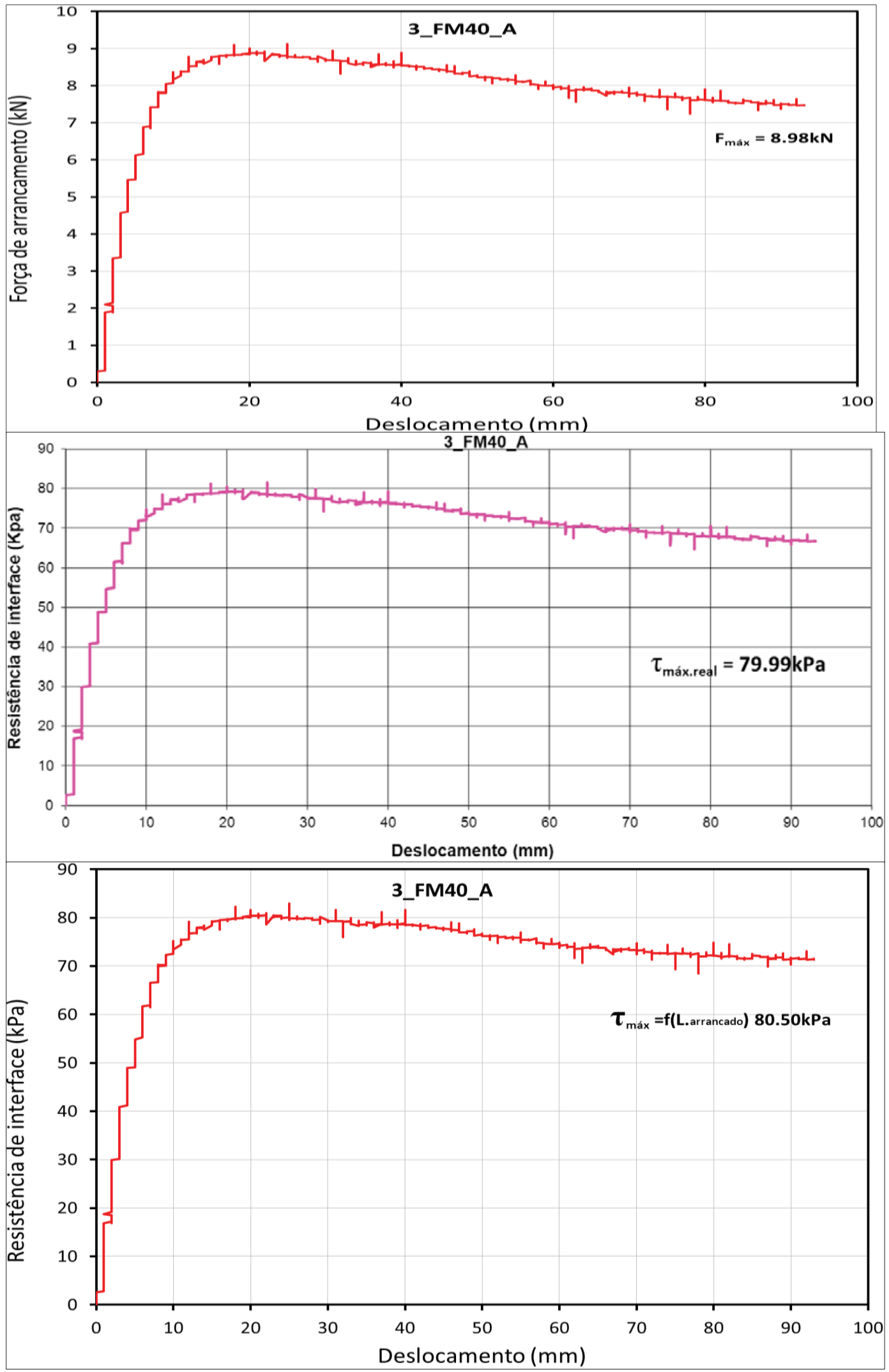
APÊNDICE V - Resultados do ensaio 1_FPO ${ }_{50}$ CII apresentados em curvas
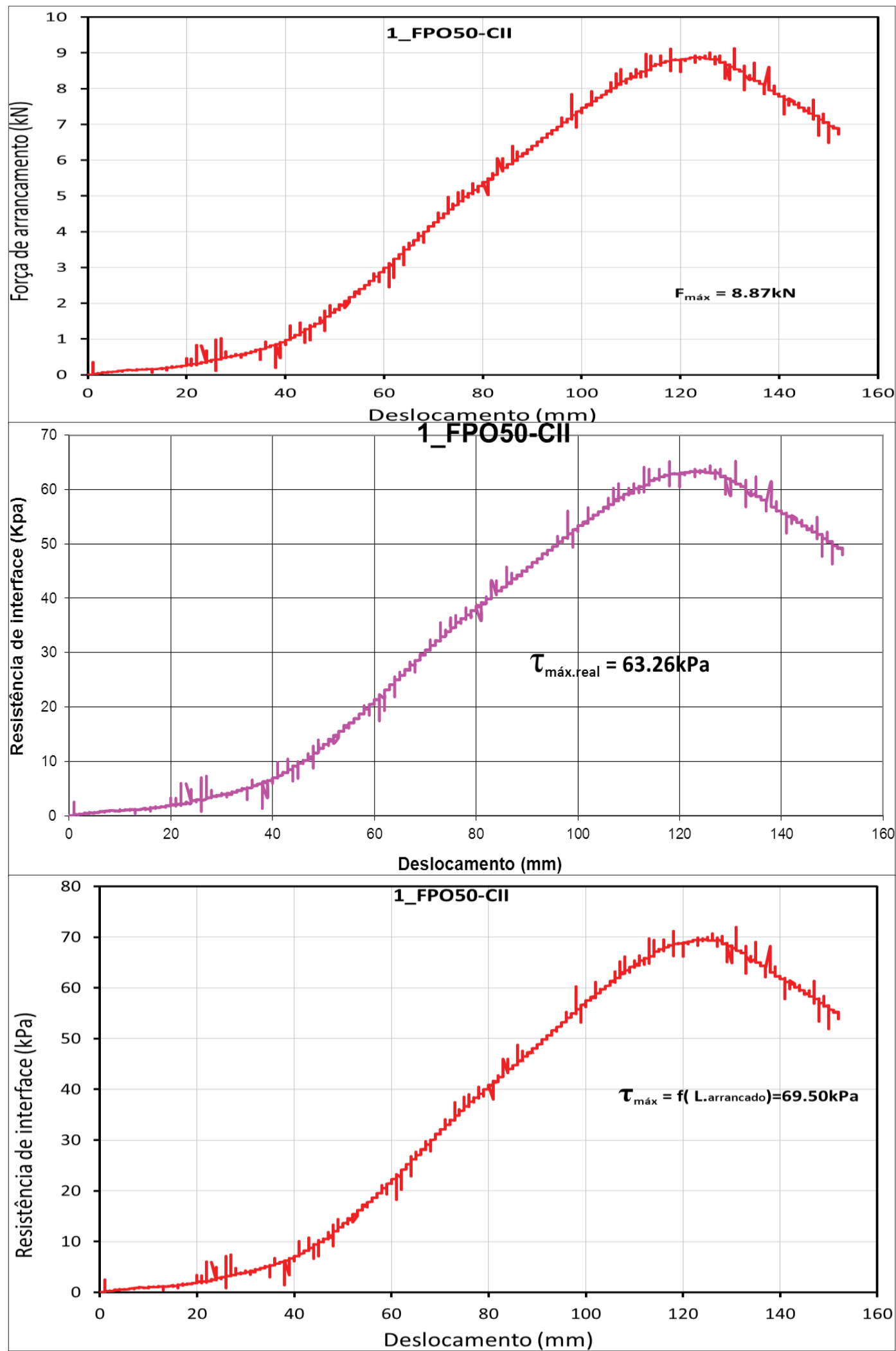
APÊNDICE W - Resultados do ensaio 2_FPO50_CII apresentados em curvas
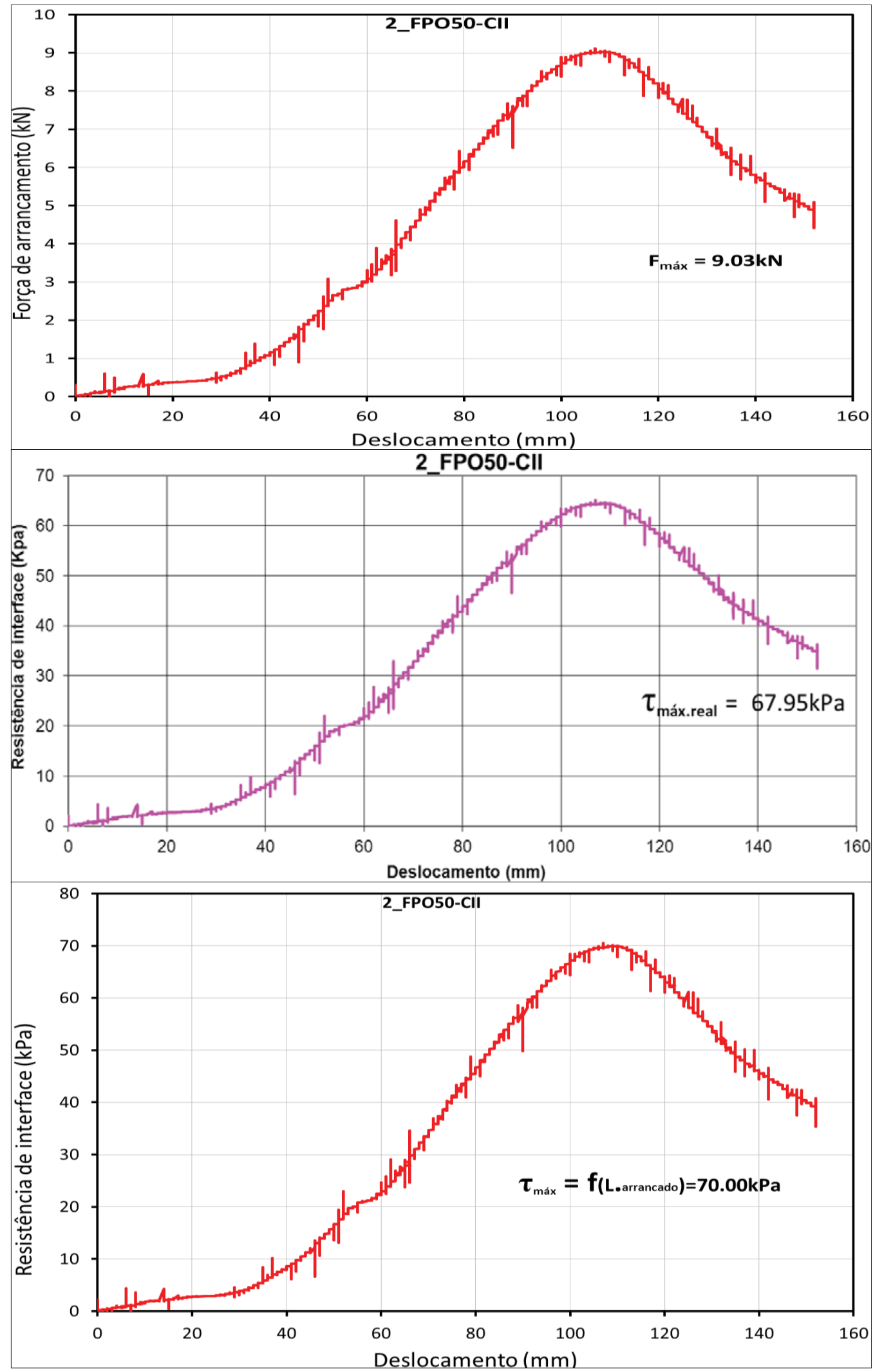
APÊNDICE X - Resultados do ensaio 3_FPO ${ }_{50}$ CII apresentados em curvas
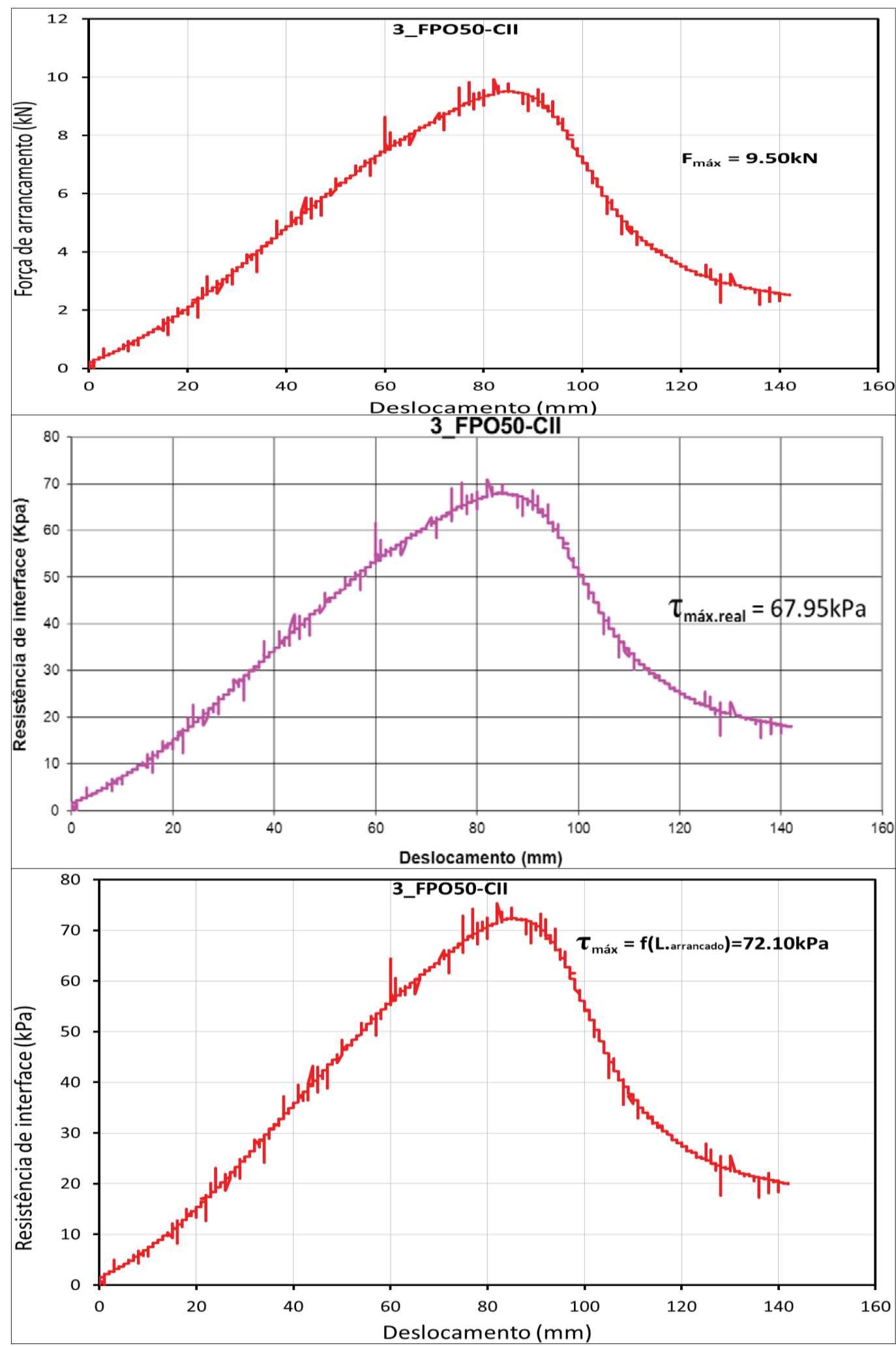
APENNDICE Y - Resultados do ensaio 1_FPO $\mathrm{FP}_{47} \mathrm{CII}$ apresentados em curvas
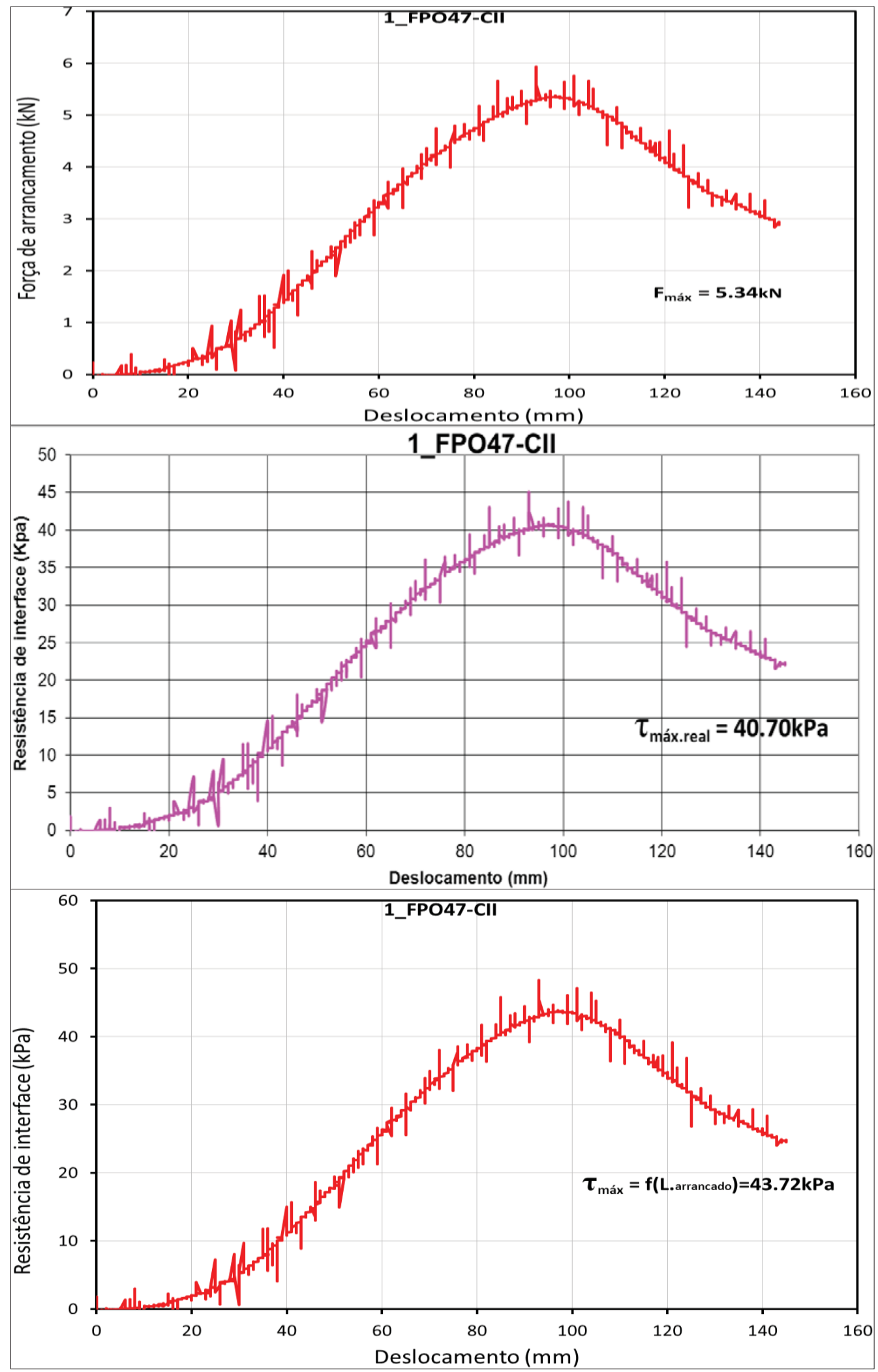
APÊNDICE Z - Resultados do ensaio 2_FPO ${ }_{47}$ CII apresentados em curvas
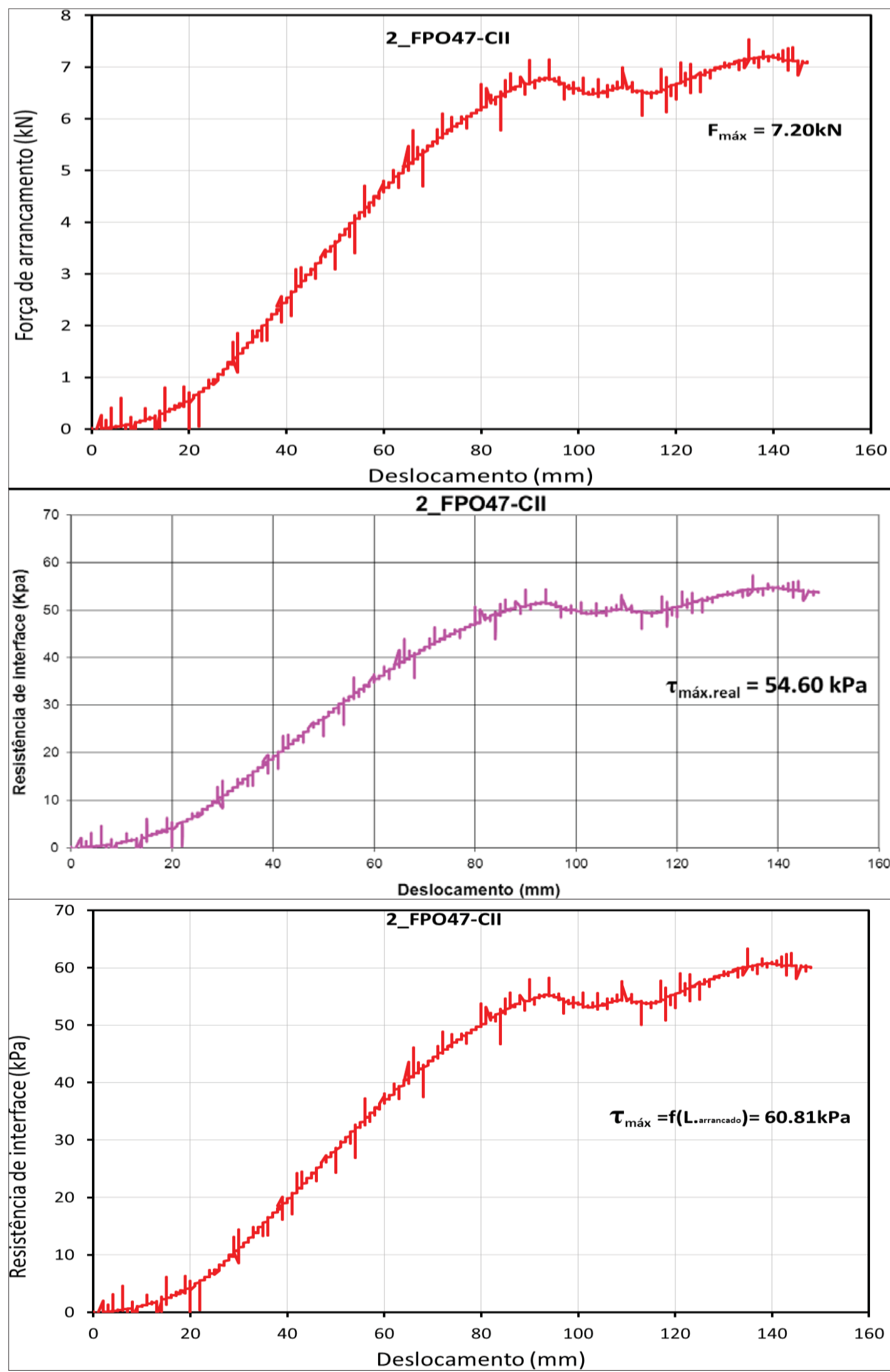


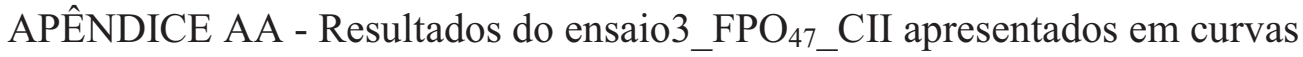
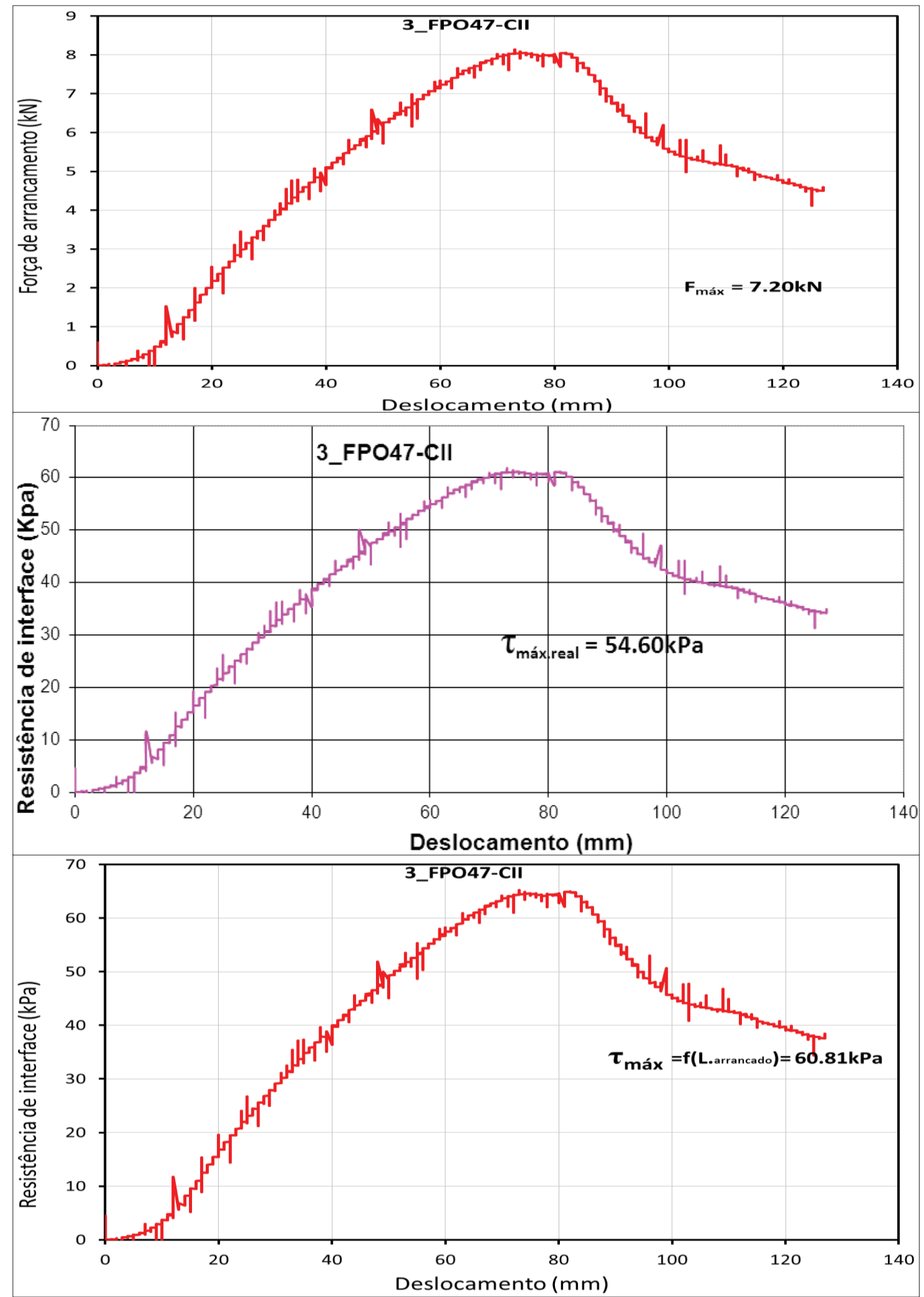


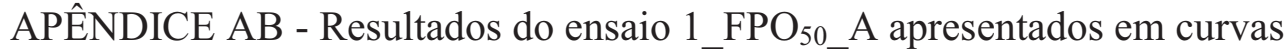
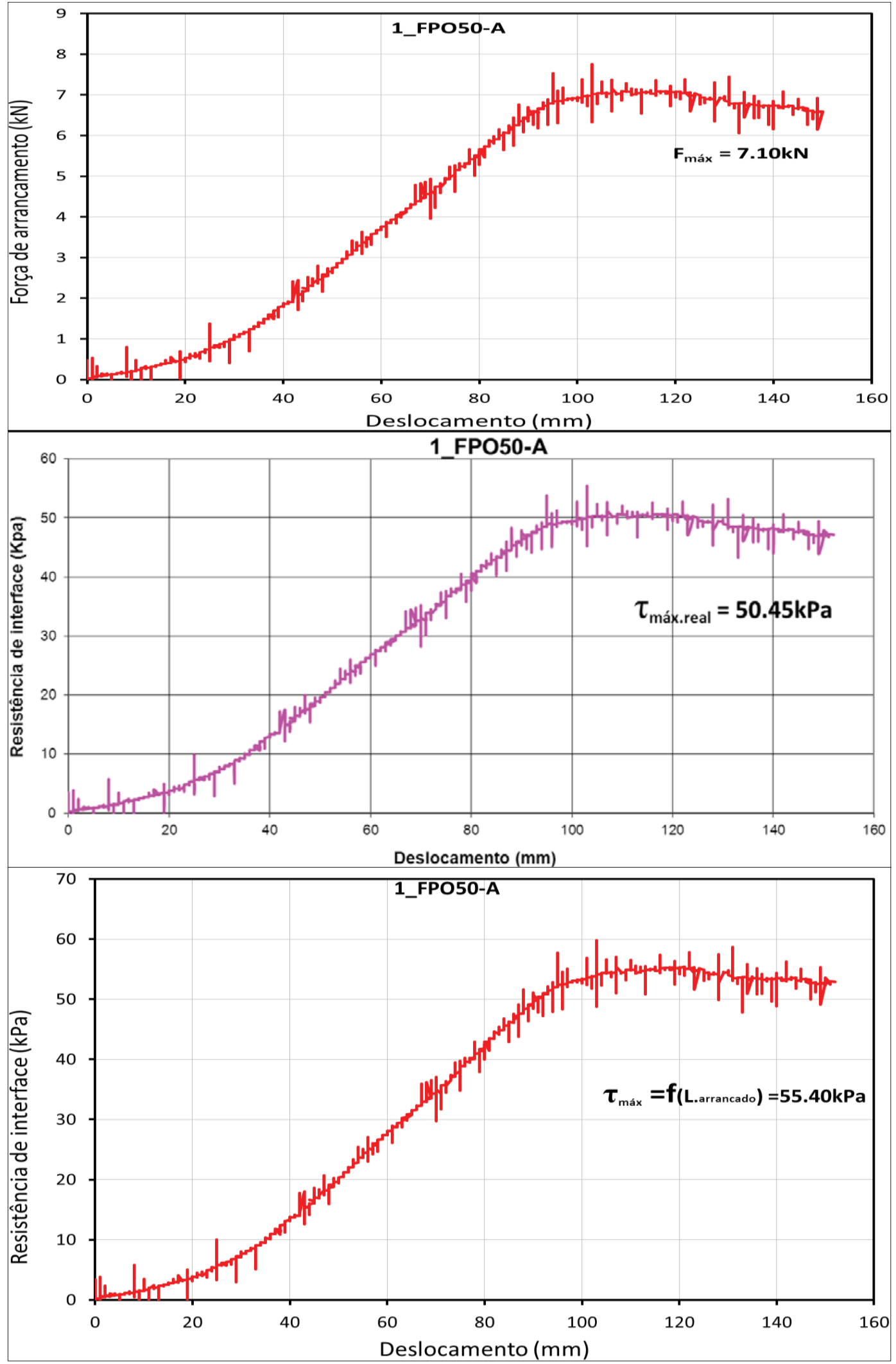
APÊNDICE AC - Resultados do ensaio 1_FPO ${ }_{47}$ A apresentados em curvas
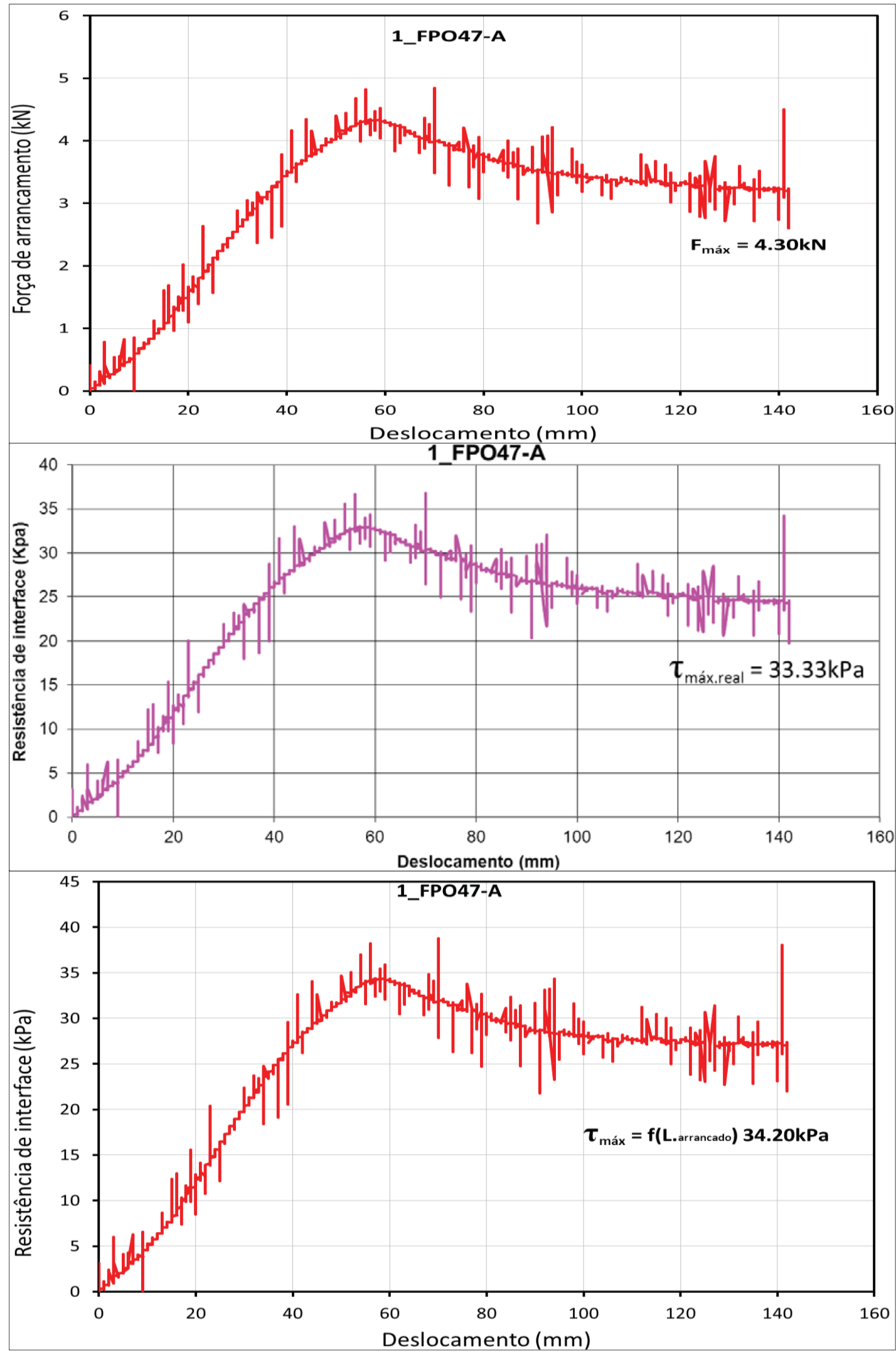
APÊNDICE AD - Resultados do ensaio 2_FPO $\mathrm{FP}_{47} \mathrm{~A}$ apresentados em curvas
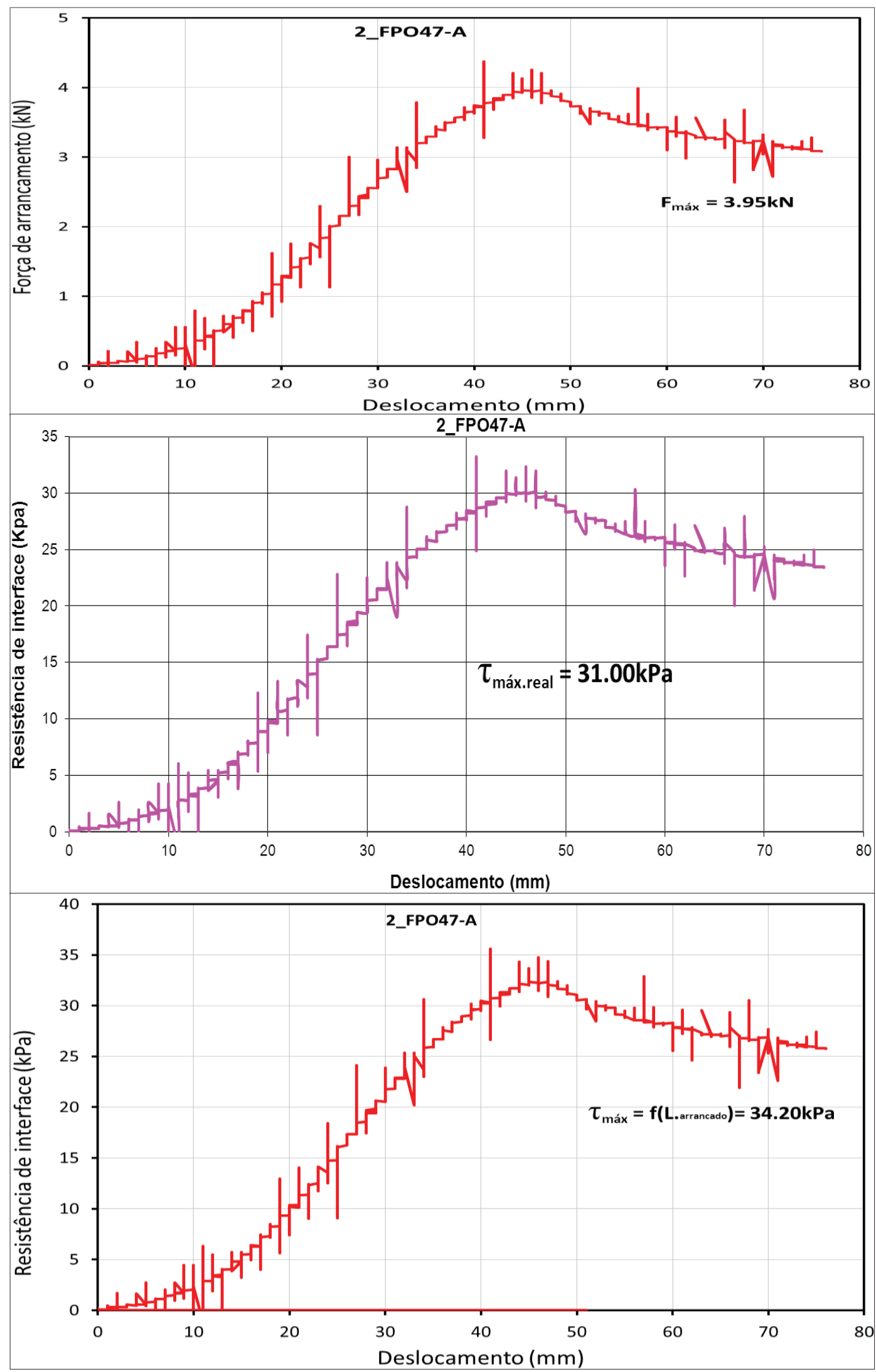